\title{
MULTIFUNCTIONAL WEAK POLYELECTROLYTE MULTILAYERS FOR MEMBRANE APPLICATIONS
}

SHAZIA ILYAS 
MULTIFUNCTIONAL WEAK POLYELECTROLYTE MULTILAYERS FOR MEMBRANE APPLICATIONS

Shazia Ilyas 
This research was performed in the framework of Erasmus Mundus Doctorate in MembraneEngineering (EUDIME) (http://eudime.unical.it/). The EUDIME is one of the nine selected proposals among 151 applications submitted to EACEA in 2010. The work described in this thesis was performed at the Membranes Science and Technology Group (MTG), MESA+ Institute for Nanotechnology, University of Twentetogetherwith KU Leuven andLGCatUniversité ToulouseIII-PaulSabatier.

\section{Promotion Committee at University of Twente}

Prof. dr. ir. J.W.M. Hilgenkamp (Chairman) University of Twente Prof. dr. ir. H.D.W. Roesink (Promotor) University of Twente Dr. ir. W.M. de Vos (Co-promotor) University of Twente

Prof. dr. ir. I.F.J. Vankelecom KU Leuven

Prof. dr. P. Aimar Université Toulouse III

Dr. J.-F. Lahitte Université Toulouse III

Prof. dr. ir. N.E. Benes University of Twente

Dr. ir. B. Schuur University of Twente Prof. dr. M. Schönhoff University of Münster Prof. dr. J. Martens KU Leuven

Cover design

Shazia Ilyas

Multifunctional weak polyelectrolyte multilayers for membrane applications ISBN: 978-90-365-4281-4 DOI-number: 10.3990/1.9789036542814 https://dx.doi.org/10.3990/1.9789036542814 Doctoraatsproefschrift nr. 3E150055 aan de faculteit Bio-ingenieurswetenschappen van de K.U.Leuven

Printed by Ipskamp Drukkers B.V., Enschede

(C) 2017 Shazia Ilyas, Enschede, The Netherlands 


\title{
MULTIFUNCTIONAL WEAK POLYELECTROLYTE MULTILAYERS FOR MEMBRANE APPLICATIONS
}

\author{
DISSERTATION \\ to obtain \\ the degree of doctor at the University of Twente, \\ on the authority of the rector magnificus, \\ Prof. dr. T.T.M. Palstra \\ on account of the decision of the graduation committee, \\ to be publicly defended \\ on Thursday 16th of February 2017 at 14:45
}

by

\section{Shazia Ilyas}

born on 24th March 1985

in Sheikhupura, Pakistan 
For the University of Twente this thesis has been approved by:

Prof. dr. ir. H.D.W. Roesink (Promotor)

Dr. ir. W.M. de Vos (Co-promotor) 


\title{
MULTIFUNCTIONAL WEAK POLYELECTROLYTE MULTILAYERS FOR MEMBRANE APPLICATIONS
}

\author{
DISSERTATION
}

\author{
prepared in the framework of \\ Erasmus Mundus Doctorate in Membrane Engineering (EUDIME) \\ to obtain multiple Doctorate degrees issued by \\ University of Twente (Faculty of Science and Technology) \\ KU Leuven (Faculty of Bioscience Engineering) \\ Université Toulouse III - Paul Sabatier (Doctoral School of Mechanics, \\ Energetics, Civil and Process Engineering) \\ to be publicly defended \\ on Thursday 16th of February 2017 at 14:45
}

by

\section{Shazia Ilyas}

born on 24th March 1985

in Sheikhupura, Pakistan 


\section{EUDIME Doctorate Board}

Promotors:

Prof. dr. ir. H.D.W. Roesink

University of Twente

Prof. dr. ir. I.F.J. Vankelecom

KU Leuven

Prof. dr. P. Aimar

Université Toulouse III

Dr. ir. W.M. de Vos

University of Twente

Dr. J.-F. Lahitte

Université Toulouse III

Other members:

Prof. dr. ir. N.E. Benes

University of Twente

Dr. ir. B. Schuur

University of Twente

External Reviewers:

Prof. dr. M. Schönhoff

University of Münster

Prof. dr. Prof. dr. M.L. Bruening

Michigan State University

Prof. dr. J. Martens

KU Leuven

Chairman:

Prof. dr. ir. J.W.M. Hilgenkamp

University of Twente

\section{UNIVERSITY OF TWENTE.}

\section{KU LEUVEN}
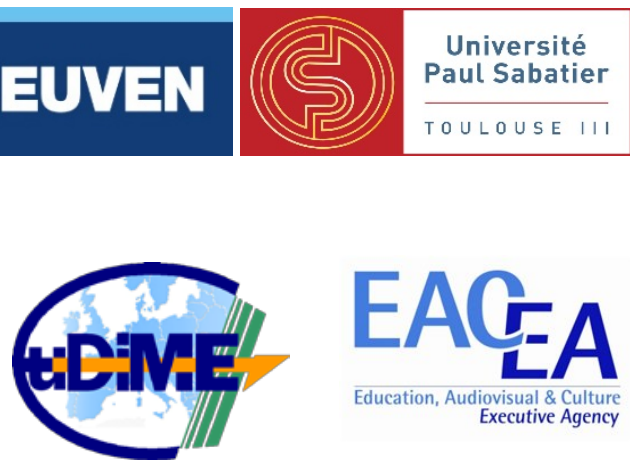


\section{CONTENTS}

\section{Chapter 1}

Introduction

\section{Chapter 2}

Sacrificial polyelectrolyte multilayers for membranes

\section{Chapter 3}

Weak polyelectrolyte multilayers based NF membranes for micro-pollutant removal

\section{Chapter 4}

Weak polyelectrolyte multilayers for solvent resistant nanofiltration membranes

\section{Chapter 5}

Dynamic layer by layer ( $L b L)$ assembly of multifunctional polyelectrolyte multilayers for membranes

\section{Chapter 6}

Conclusions and future perspective 


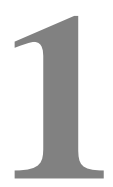

Introduction 


\section{$1.1 \quad$ Coatings}

A Coating is a covering that is applied to the surface of an object for the purpose of functionalization, decoration or both. All living organisms (animals and plants) have some sort of coating around their body. For example, most aerial plant organs (fruits, leaves and young stems) have cuticle, a waxy coating that minimizes water loss and effectively reduces pathogen entry. Insects also have cuticle around their body for the sake of protection. In the human body, the skin protects the body against pathogens and excessive water loss [1, 2], but also includes other functions (insulation, temperature regulation, sensation and synthesis of vitamin D). Inspired by nature, the coating of surfaces has become a fascinating route for the modification of surfaces of a multitude of materials for the sake of different functionalities. Now a days buildings, vehicles, textiles and anything you can think of have some kind of coating around it, either to enhance their aesthetic appearance, give protection, enhance efficiency or life time or to give some other functions (e.g., corrosion resistance, wear resistance, fouling resistance, strength, friction or optical properties). For different materials coating can have different purpose, for example mirrors have thin aluminum coating at the back of the glass to make the surface reflective. Solar cells have an antireflective coating of porous silicon or titanium dioxide at the front surface to reduce reflection and thus enhance their efficiency [4]. All kinds of glasses like spectacles and windows have thin protective coatings. Optical devices have thin polymer coatings to enhance their optical properties [5]. Displays of smartphones and tablets use coatings to enhance their appearance, and life and make these water proof. Now if the coatings are easy to remove, one could easily replace old paint from walls of a house with new to give it new color or look, similarly tear-off plastic sheets on a new mobile phone are there to protect 
the screen against scratches or marks and can easily be torn off to be be replaced with a new sheet.

In today's nanotechnology era, along with a wide range of surface engineering routes available, the manipulation of materials down to the molecular level has paved the way for new functional thin film coatings especially polymer-based thin film coatings. A thin film is a layer of material ranging from fractions of a nanometer (monolayer) to several micrometers in thickness. The controlled synthesis of materials as thin films (a process referred to as deposition) is a fundamental step in many applications. An important functionality of the thin film coatings in daily life can be to protect surfaces from getting dirty (antifouling coatings) or to make cleaning of surfaces easier (sacrificial coatings). For example contact lenses have special hydrophilic/antifouling coatings to avoid accumulation of proteins to the surface of lenses. Hulls of sea ships are coated with antifouling coatings to reduce frictional drag due to fouling otherwise, in ship hulls increased frictional drag due to the fouling not only reduces the speed of the ship up to $10 \%$ but also increases the fuel consumption by $40 \%$ [6]. Surfaces used for biomedical applications are coated with antifouling/antiseptic coatings to avoid adhesion and to kill any adheared bacteria. Membrane separation processes used in water and wastewater treatment, and within the food industry also suffer from fouling, a phenomenon where the membranes get dirty over the time due to adhering foulants. Almost all membrane processes suffer from fouling which ultimately increases the operational cost of the processes by employing additional use of energy, chemical cleaning and sometimes replacement of fouled membrane modules with new ones.

In membrane separation processes especially used for water and wastewater treatment, thin polymer coatings can be utilized to modify the surface of membranes to manage the fouling. But these thin polymer coatings can also 
act as a responsive and/or as a separation layer to give additional functionality to the membranes. Membrane coatings that combine multiple functionalities will be the main topic of this thesis.

\subsection{Polyelectrolyte multilayers (PEMs)}

In this thesis we will focus on a very promising class of coatings. Thin multilayer films composed of polyelectrolytes (PEs) are an interesting class of coating to modify the surface of a variety of materials for giving them certain desired functionalities. Polyelectrolytes are large molecules with repeating units bearing charged or chargeable groups, which can dissociate in aqueous solutions to form a positively, or a negatively charged polymer chain. Based upon their charge PEs can also be classified as cationic $(+)$, anionic (-) and zwitterionic (+ and -). Poly(ethyleneimine) (PEI), poly(allylamine hydrochloride) (PAH), poly(L-lysine) (PLA), etc. belong to cationic PEs; poly(styrenesulfonate) (PSS), poly(vinylsulfonic acid) (PVS), poly(acrylic acid) (PAA), alginic acid (AA) etc. are anionic PEs; and proteins belong to zwitterionic PEs. In this work we will study the combination of two weak polyelectrolytes, for which the degree of dissociation depends on the solution $\mathrm{pH}$, see Fig. 1.1.

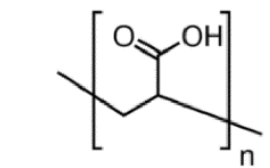

poly(allylamine hydrochloride)

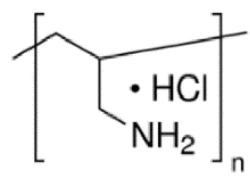

poly(acrylic acid)

Fig. 1.1: Chemical structures of PEs used in this work. 
To prepare layers of PEs in the form of polyelectrolyte multilayers (PEMs), the most attractive technique is the layer-by-layer (LbL) self-assembly approach which was first reported in 1990's by Hong and Decher [7]. Buildup of PEMs using this so called LbL assembly involves alternate exposure of a charged substrate to solutions of polycations and polyanions, in combination with a rinsing step between each deposition step to remove weakly associated polymer chains [7, 8]. A schematic representation of LbL process on a charged substrate is shown in Fig. 1.2. When a negatively charged substrate is exposed to an oppositely charged polycation solution, because the first layer adsorb on the substrate either by electrostatic or hydrophilic attractions so charge overcompensation by the polycation reverses the charge of the substrate. Adsorption of the subsequent polyanion from solution can again overcompensates the charge on the surface again to reverse the substrate's charge, thus allowing consecutive growth of PEMs with controlled thickness [9-11].
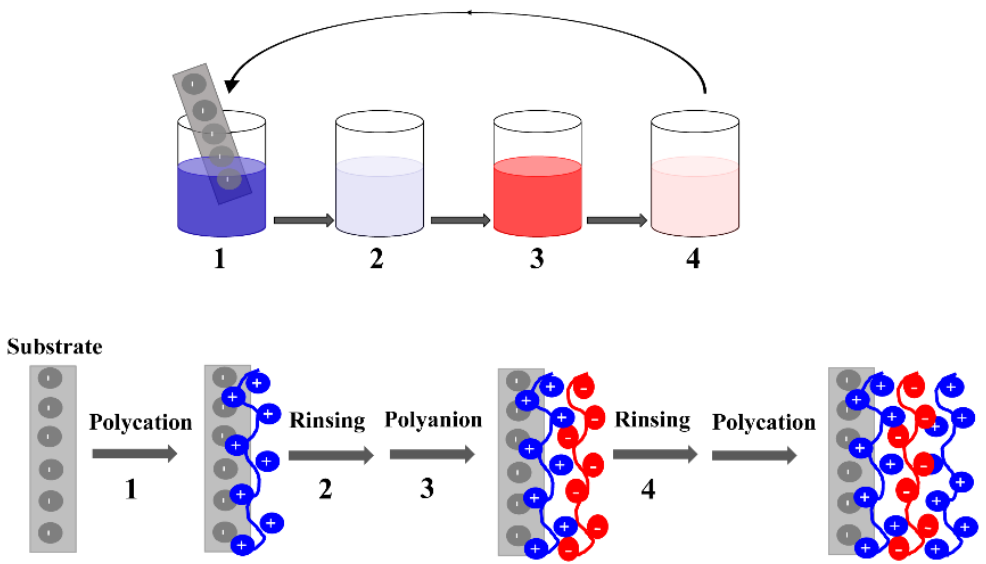

Fig. 1.2: Schematic representation of $L b L$ adsorption of polycation and polyanion on a charged support. 
LbL is suitable for any size and shape of the substrate and has been applied for the fabrication of functional films for use in applications such as biosensing [12-15], catalysis [16-18], separations [19], and optical devices [5], and research into these application has shown explosive growth over the past decade.

The PEM assembly process is performed completely in water and employs a variety of charged and water soluble polymers at low polymer concentrations. Therefore, the technique considered as an economical and environmentally benign technique to prepare coatings with well-defined thickness, composition, and chemical functionalities [3, 20, 21]. It was assumed that individual layers within PEMs are highly interpenetrating and electrically neutralize each other except for the outer most surface layer, which is explained by charge over compensation [22, 23]. But later, it was shown that depending upon the terminal layer, the bulk of the PEMs still can carry charges and may not be overall neutral [24]. Until 1999 it was believed that electrostatic interactions between oppositely charged polymer chains are the sole responsible interactions for the LbL assembly, however now it is well established that actually entropy gain by release of the counterions is the main driving force for the formation of PEMs [25, 26]. The ionic strength of the coating solution can be used to control the magnitude of this entropic gain, while other specific interactions (enthalpy) can also influence the layers.

To describe charge compensation within PEMs, Schlenoff et al., defined two types of charge compensations "intrinsic" and "extrinsic" charge compensation [10, 22, 23]. In intrinsic charge compensation the charges of the polyelectrolyte are balanced by the charges of the oppositely charged PE (PE complexation). In contrast, in extrinsic charge compensation the $\mathrm{PE}$ charges are balanced by counter ions (salt) derived from the coating solution 
(Fig. 1.3). Now the distribution between the intrinsic and extrinsic charge compensation to a large degree is controlled by the ionic strength of the coating solution during LbL assembly process.
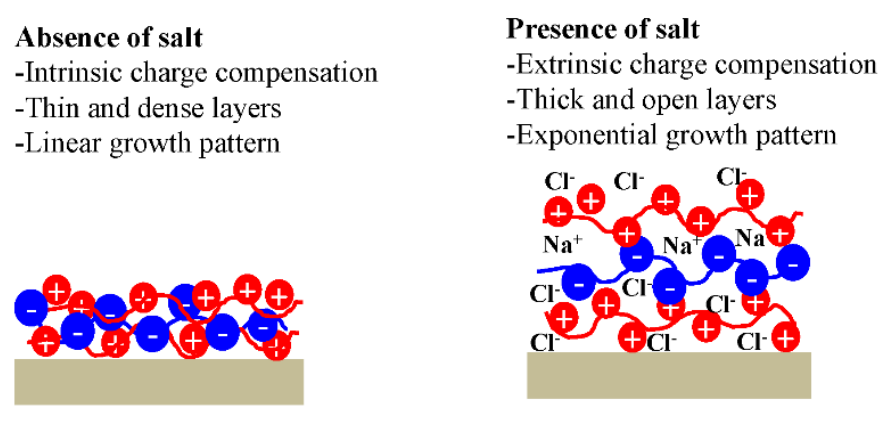

Fig. 1.3: Effect of presence of salt in LbL processes on multilayers structure.

Increasing the ionic strength shifts the equilibrium from intrinsic to extrinsic charge compensation which leads to thicker, more mobile and more swollen layers [10]. Decher et al. showed that PEMs exhibit a somewhat "fuzzy" but layered structure, with significant inter diffusion (penetration) with its neighboring layers $[8,27]$, while the degree of inter diffusion between the layers can be controlled by ionic strength [28]. This property of multilayers is of particular interest especially for membrane separation processes where solute and solvent diffuse through whole of the layer so the whole of the multilayer determines the separation properties. For instance thicker layers on a membrane results in lower permeabilities in membrane, whereas a more open structure of the layers can increase the permeability [29]. As mentioned the structure of the multilayers and their properties are influenced by factors during the coating and/or post treatment such as type of $\mathrm{PEs}, \mathrm{pH}$, ionic strength, temperature etc. [3, 23, 30-35], and could thus be used for optimization towards a specific application. 
Now depending upon the strength of the intermolecular interactions of PEs, PEMs can grow either linearly or exponentially or can have a transition between these two growth types [3, 36-40]. In the linear growth regime the thickness and amount of PE deposited per layer increases is constant, and thin layers are usually formed. In the exponential growth regime, the thickness and amount of deposited PE increases exponentially per deposition step. Linear growth of PEMs is associated with a low mobility of chains in the layer, while exponential growth is due to the presence of much more mobile chains [41].

During PEM growth, the basic structure of PEMs can be subdivided into three zones [42]. Initially the growth occurs in zone I, where the substrate has a strong influence on the multilayers growth, followed by zone III (outer zone) as shown in Fig. 1.4.

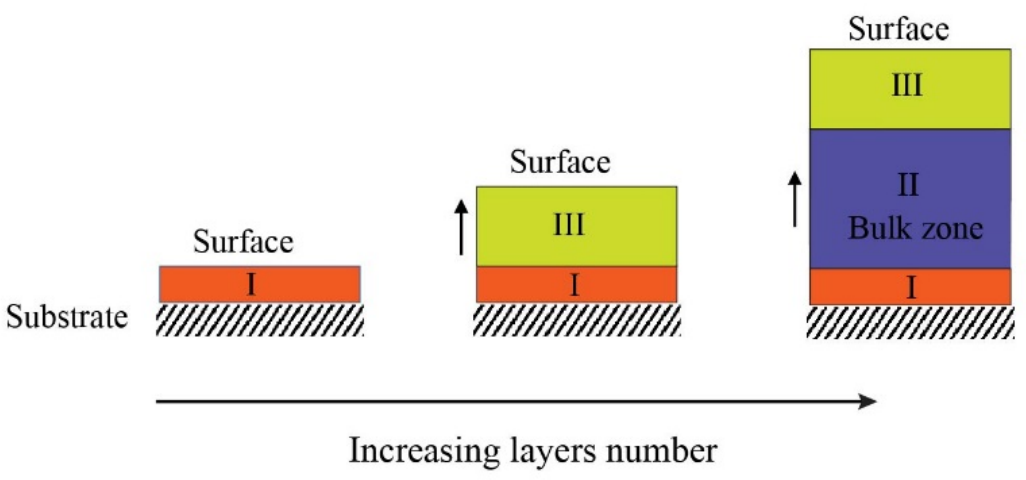

Fig. 1.4: Schematic of zones in multilayers buildup.

Zone II (bulk zone) starts growing at the end when more layers are added, but then zone I and Zone III preserve their respective thickness. Multilayer properties in zone III are determined by outer solution environment. 
Transitions between these three zones are gradual and when the exact regime comes in a multilayer is unclear. Generally the effect of the number of layers is taken into consideration to see the performance of a multilayer system, especially in dense membrane filtration this is paramount when solvent and solute are transported through the whole of the layer.

\section{Weak vs strong PEs}

PEs can be referred to as weak PEs if their charge and charge dissociation is dependent on the $\mathrm{pH}$, while in contrast strong PEs carry permanent charges and thus fully dissociate in water [43]. For strong PEs the addition of salt best controls the thickness of layers. However, the effectiveness of this parameter is often limited to a small range of salt concentrations because of either solubility problems or decomposition of the multilayer films at high ionic strengths $[9,44]$. In contrast, for weak PEs a slight variation of the solution $\mathrm{pH}$ allows a large degree of control over the layer structure and properties (charge density, thickness, charge) of the formed PEMs [3, 33, 45, 46]. The crucial role of solution $\mathrm{pH}$ in the LbL assembly of weak PEs such as PAH and PAA has been explored in detail by the groups of Rubner [3, 33] and Schönhoff [36]. They have shown that a small variation in the coating solution $\mathrm{pH}$ can induce a big change in the layer thickness, the growth behavior, the degree of layer interpenetration and the surface wettability. Rubner et al. [3] developed a complete $\mathrm{pH}$ matrix for PAH/PAA system and found four distinct $\mathrm{pH}$ regimes with different growth behaviors (Fig. 1.5). They identified that the main parameters controlling the layer thickness are the charge density on the adsorbing chain and the surface charge density of the final adsorbed layer. They observed that thin layers are formed close to neutral $\mathrm{pH}$ region (III) when both PEs are fully or equally charged, a behavior that is similar to strong PEs. However when the $\mathrm{pH}$ of the PEs is higher or lower then very thick layers are formed because layers become 
more interpenetrated and because charge compensation requires more material.

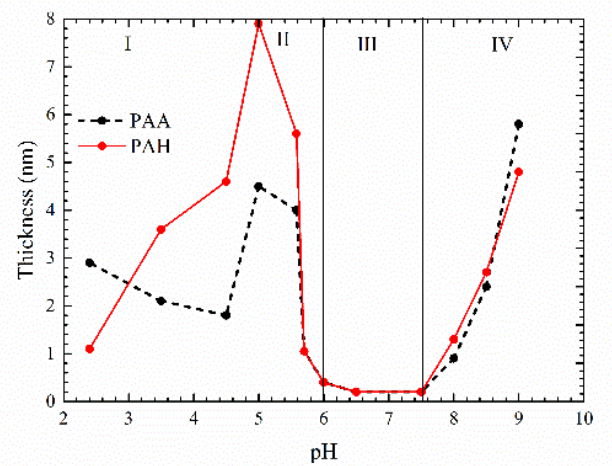

Fig. 1.5: Average incremental thickness contributed by $P A H$ and $P A A$ adsorbed layer as function of solution $\mathrm{pH}$ [3].

\section{PEMs as a new approach to clean the surfaces}

A few years ago, a very different approach named the "sacrificial layer" approach was proposed to clean surfaces [47]. This sacrificial layer approach involved the coating of a surface with a thin polymer film that limits the fouling, however, when it does become fouled, the layer can be desorbed/sacrificed from the surface removing any attached foulants. A schematic representation of the sacrificial layer approach concept is shown in Fig. 1.6.

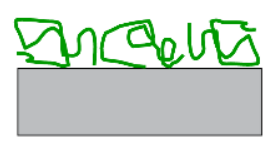

Pre-coating

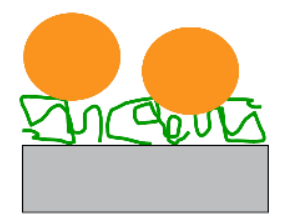

Fouling

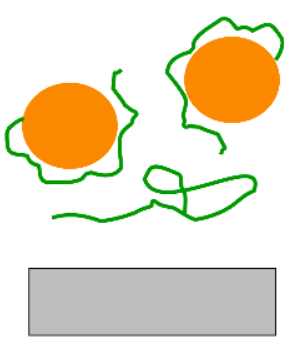

Release/Sacrifice

Fig. 1.6: Schematic representation of sacrificial layer approach concept. 
The removal or sacrificing of the layer is based on a simple trigger i.e. a change in $\mathrm{pH}$, the salt concentration or the addition of a surfactant. The cleaned surface can subsequently be recoated with a new polymer layer to regain its functionality. Additionally when polymers are coated on an interface, it results in a change of the surface properties of the interface. The sacrificial layer coating could thus have additional benefits such as providing antifouling or anti adhesive properties to the surfaces. The sacrificial layer approach can also be based on PEM systems. For this to work it is very important to choose the right combination of PEs which are responsive towards triggers such as $\mathrm{pH}$ and ionic strength. Here the use of weak PEs is advantageous as both the $\mathrm{pH}$ and the ionic strength can be used as a trigger to destabilize these multilayers [48].

\subsection{Membrane processes and fouling}

A membrane is defined as a selective barrier that permits the passage of one or more components of a stream through the membrane while retarding or preventing the passage of one or more other components. The separation of certain species in a fluid by membrane can be described by a combination of sieving and the solution diffusion mechanisms. The application spectrum of membrane processes stretches from the filtration of solids up to separations in the molecular range. Pressure driven membrane separation processes such as microfiltration (MF), ultrafiltration (UF), nanofiltration (NF) and reverse osmosis (RO) used for aqueous (water and wastewater treatment) applications are among the most widely studied and fastest growing membrane processes, and have been industrially established at impressively large scales over the last few decades. The breakthrough discovery of LoebSourirajan's process of non-induced phase inversion [49] to make the first anisotropic, defect free and high flux reverse osmosis (RO) membranes in early 1960's, transformed the membrane separation from laboratory to 
industrial scale processes and improved the quality of life for a great part of the world population relying on sea water as the main water supply.

Membrane processes are used widely for numerous applications such as water and wastewater treatment, desalination, the food and dairy industry, biotechnology and others [50]. However, all of these membrane processes suffer from fouling (Fig. 1.7), which causes flux decline and/or an increase in energy demand [51]. In most applications, periodic hydraulic cleaning limits short-term fouling, whereas more expensive chemical cleaning is needed to remove the hydraulically-irreversible fraction of foulants.

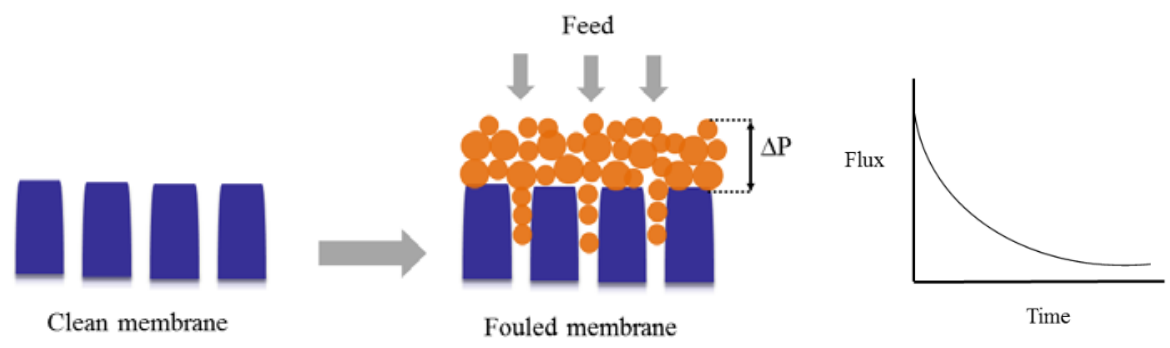

Fig. 1.7: Fouling mechanism in membranes.

Fouling [52] is a general term that describes the deposition of retained substances within the pores or on the surface of membranes. Parameters influencing fouling include the membrane properties, the nature and concentration of the feed solution, and the operating conditions [53]. Regardless of the location of fouling, a foulant layer increases the hydraulic resistance of the system thus reducing the permeability and overall flux at a given applied pressure. Fouling thus represents a major challenge that increases operating costs of membrane based separation processes. For this reason, new cleaning methods and anti-fouling materials have become the focus of research and development centers within the water industry [54]. 
The complex phenomenon of fouling is specific to the feed and process conditions and as such, solutions must be tailor made for the purpose [52].

Fouling is generally caused by a combination of foulants of varying particle sizes. Four main categories of foulants exist: (i) organic materials, (ii) colloids, (iii) inorganic materials and (iv) particulates [53]. Based on the nature of process solutions, major foulants can be colloidal materials and natural dissolved organic matter (NOM). Colloidal and particulate fouling is caused by fine organic, inorganic or biological suspended particles within the nanometre to micrometre range. NOM can be divided into a hydrophobic (humic) and hydrophilic (non-humic) fraction that also includes proteins, polysaccharides and other classes of biopolymers. For simulating fouling, most researchers have used dextran, bovine serum albumin (BSA), humic acid (HA) and silica particles as model foulants [48]. Membrane fouling with organic matter and colloids is influenced by hydrophobic interactions, hydrogen bonding, van der Waals attractions and electrostatic interactions. These properties of both the membrane and the colloids are strongly dependent on the ionic strength, $\mathrm{pH}$, the presence of multivalent ions [55] and temperature. Additionally, surface characteristics such as roughness are important factors that impact the interaction of foulants with the interface. Consequently, strategies for the prevention of these interactions are required to limit fouling.

Currently, as a first step, fouling is controlled in most membrane processes using intermittent backwashes or back flushes. These simple and inexpensive control mechanisms are only effective to remove loosely attached foulants from the membrane surface [56, 57]. Less cooperative foulants, more strongly adsorbed to the surface or lodged in the membrane pores, are then exposed to a chemical wash or a chemical enhanced backwash. The chemical based control is more expensive and generally 
consists of harsh treatments, such as $\mathrm{NaOH}$ for organic foulants, $\mathrm{HCl}$ for inorganic foulants and $\mathrm{H}_{2} \mathrm{O}_{2}$ for bio-fouling, at or above operating temperatures [56]. Even under these cleaning conditions, complete recovery of membrane performance is not guaranteed. Additionally, there exists a high risk of damage to the membrane due to the frequency and severity of the cleaning. As a strategy to control membrane fouling and to improve the longevity of membranes, surface manipulation is an ideal alternative. Existing strategies include altering the surface charge or increasing the hydrophilicity of the surface. One possible solution is the use of polyelectrolyte multilayers on the surface of membranes to induce hydrophilicity therby acting as low fouling layers, while also allowing their desorption/sacrificing to instantly remove all foulants from the membrane surface. The system would then need to be regenerated. This low fouling sacrificial layer approach to membrane fouling control could potentially eliminate the need for frequent chemical cleaning or complete unit overhaul.

\section{$1.4 \quad$ Nanofiltration (NF)}

Nanofiltration (NF) is a pressure driven membrane separation process which covers the filtration spectrum between reverse osmosis (RO) and ultrafiltration (UF) (Table 1). The nominal molecular weight cutoff range for NF is from 200-1000 Da with estimated pore sizes of 0.5-2 nm. NF membranes allow passage of monovalent ions, and reject multivalent ions and low molecular weight organics. Just like RO membranes, NF membranes are also asymmetric; e.g. they consist of a thin active separation layer on a much thicker porous support structure that provides the mechanical strength. The rejection of the solutes by NF membranes is typically described by taking size/steric hindrances, donnan (electrostatic) exclusion, valence, dielectric exclusion, hydrophobic adsorption and dipole moment into account [29, 58-61]. NF has proven its success in many 
applications such as softening of water, micro pollutants removal, viruses and bacteria removal, dyes and color removal, pretreatment step for desalination and heavy metals removal from ground water. Another important application of NF, and one that we will focus on in this thesis, is for the removal of micropollutants from water and wastewater [62-70].

Table 1: Properties of pressure driven membrane processes [71].

\begin{tabular}{|c|c|c|c|c|}
\hline Process & $\begin{array}{c}\text { Pressure } \\
\text { range } \\
\text { (bar) }\end{array}$ & $\begin{array}{c}\text { Permeance } \\
\text { range } \\
\left(\mathbf{l} \cdot \mathbf{m}^{-2} \cdot \mathbf{h}^{-1} \cdot \text { bar }^{-1}\right)\end{array}$ & $\begin{array}{c}\text { Pore size } \\
\text { (nm) }\end{array}$ & Rejected species dimensions \\
\hline \multirow[t]{2}{*}{ Microfiltration } & $0.1-2.0$ & $>50$ & $20-10000$ & Yeasts $(1000-10,000 \mathrm{~nm})$ \\
\hline & & & & Bacteria $(300-10,000$ nm) \\
\hline \multirow[t]{2}{*}{ Ultrafiltration } & $1.0-10$ & $10-50$ & $1-50$ & Viruses (30-300 nm) \\
\hline & & & & Proteins (3-10 nm) \\
\hline Nanofiltration & $5.0-35$ & $1.4-20$ & $<2$ & Smaller molecules (0.6-1.2 nm) \\
\hline Reverse & $10-150$ & $0.05-1.4$ & $<1$ & Ions (0.2-0.4 nm) \\
\hline Osmosis & & & & \\
\hline
\end{tabular}

The occurrence of micropollutants in aquatic environments around the world has become a serious environmental concern over the past few decades, and is posing a new challenge to scientific community. Micropollutants also termed as emerging contaminants (ECs), are low molecular weight compounds ( $M_{w}$ between 100-1000 Da) and encompass a wide range of man-made chemicals (from pesticides, pharmaceuticals, cosmetics, personal and household care products and industrial chemicals among others), which are in use worldwide and are indispensable to modern human society [72] Currently more than a million synthetic chemicals are registered in Europe [73], many of which ultimately will find their way into the environment at some stage in their life cycle. Several studies reported the occurrence of micropollutants in the surface and the ground water in countries around the globe, including the Netherlands, Belgium, France, Germany, Austria, Greece, Spain, Italy, Sweden, Switzerland, Western Balkan Region, UK, 
Korea, US, Canada and China [74-85]. Generally these micropollutants are present in the environment in very low concentrations (ranging from few ng. $l^{-1}$ to several $\left.\mu \mathrm{g} . \mathrm{l}^{-1}\right)$, but their continuous and unregulated addition in environment can affect surface and ground water quality which can potentially impact drinking water supplies, human health and aquatic life [86]. Chronic exposure to these micropollutants (i.e. nonylphenol, sulfamethoxazole, atenolol and atrazine etc.) may cause long term health effects.

Conventional wastewater treatment plants based upon an activated sludge process are considered to be a hot spot for the release of micropollutants into the environment $[87,88]$, as these wastewater treatment facilities were never designed for micropollutant removal. However, applying advanced treatment methods such as oxidation processes ( $\mathrm{UV}-\mathrm{H}_{2} \mathrm{O}_{2}, \mathrm{O}_{3}-\mathrm{H}_{2} \mathrm{O}_{2}$ ), adsorption and membranes processes as a polishing step, before discharging the treated effluent of wastewater plants, could significantly reduce the micropollutant load into the water bodies. Though the capital and operational cost of advanced treatment methods can be high due to increased energy demands or due to the consumption of chemicals, upcoming more stringent regulations are expected to make these techniques much more common place. An additional complication, is that due to their diverse nature (chemical structure, solubility, charge and hydrophobicity/hydrophilicity) a single advanced treatment method might not be suitable for removing all types of micropollutants. However by employing a combination of techniques full removal could be achieved, still for this purpose the advanced techniques need to be flexible, simple and as cheap as possible. Indeed, the use of membrane based treatment methods such as reverse osmosis (RO) and NF are becoming much more common in water treatment facilities [89]. Membrane based processes show a great promising potential for the removal 
of micropollutants with several advantages such as easy scale-up and high product quality, but also some of the disadvantages such as cost and fouling [90]. Among membrane based methods, RO has already proven to be successful for micropollutant's removal, however the high energy demand of $\mathrm{RO}$ and the associated costs are a limiting factor. Moreover, RO treatment not only removes all micropollutants, but also all ions, and these ions need to be added again later in the process to be able to use the water for consumption or irrigation purposes. Due to their low operating pressures, NF membranes are believed to be a more cost-effective alternative of RO membranes for substantial removal of small organic contaminants (micropollutants) from water [91, 92]. In water production, NF is sometimes already applied as a combinatory process for removal of a wide range of inorganic and organic components such as hardness, natural organic matter, dyes, metals, and viruses in a single step [87, 93].

Similar to RO membranes, NF membranes are also asymmetric with a thin selective top layer on a highly permeable support. But membrane geometry is another important aspect for membrane separation processes, especially in terms of fouling. Nearly all commercially available NF membranes are flat sheet with a spacer in a spiral wound module which offers limited hydraulic and chemical cleaning possibilities making these membranes much more prone to fouling. For this reason, an expensive pretreatment step is often needed, before NF treatment. In contrast, hollow fiber based membranes not only have much larger membrane area per unit volume of membrane module compared to a spiral wound geometry, they are also better equipped to withstand fouling. In part this is due to the lack of spacers, and additional fouling interface, but also because these membranes can be cleaned much better by physical cleaning, for example allowing backwashing at higher pressures. By using hollow fibre membranes, one might thus be able to leave 
out the expensive pre-treatment step, but unfortunately most of the currently produced hollow fiber membranes are UF and microfiltration (for removal of bacteria and viruses). So far Pentair X-Flow is the only producer of polymeric NF hollow fiber membranes (HFW 1000) with a molecular weight cutoff (MWCO) of $1000 \mathrm{Da}$, which is not designed to remove micropollutants of small size. It can be clear that there is urgent need to develop hollow fiber NF membranes, with a much lower MWCO.

\section{PEMs for hollow fiber NF}

Polymer coatings in the form of PEMs described earlier can also act separation layer of membranes. In particular, the high surface charge of many PEM films makes them attractive material to be used as separation layer of NF membranes. To produce such membranes with precise control on separation performance one of the easiest way is the surface modification of existing UF membrane support with PEMs. Several studies have already shown that LbL adsorption of oppositely charged polyelectrolytes on porous supports is a suitable method to form NF membranes for the separation or removal of ions [94-106] sugars [107], and dyes [108]. However all of these studies utilized flat sheet membrane supports to prepare PEMs based NF membranes. de Grooth et al. [109] successfully developed hollow fiber NF membranes using PEMs of zwitterions prepared via dip coating for the removal of charged micropollutants from water. To modify the membrane surface using LbL process the traditional procedure is dip coating which involves alternate immersion of charged substrate into solutions of oppositely charged PEs with rinsing steps in between. However use of dynamic coating can give fast and controlled modification of membranes especially for modification of existing modules (UF). Dynamic coating involves running the PE solution through the lumen of the hollow fibers with $[16,110]$ or without [111-113] applied pressure or with a negative pressure 
[114]. In these studies dynamic coating was performed under constant pressure in a dead end mode. Recently Menn et al. [115] have shown dynamic coating under constant flux as effective way to coat the membranes but again in dead end mode and found that by dynamic flux coating in less time deposits more material on the membrane surface as compared to static coating or coating under constant pressure. However, to have precise control over layer deposition and its performance in membranes, it could be also interesting to see effectiveness of applying cross flow through the fibres and variable pressure coating which is discussed in this thesis.

\subsection{Solvent resistant nanofiltration (SRNF)}

The success of NF in the processing of aqueous feeds inspired researchers in 1970's and 1980's to try to expand the use of NF membranes to non-aqueous applications. The first reported membrane application for non-aqueous systems was for the separation of hydrocarbon solvents using a cellulose acetate membrane by Sourirajan in 1964 [116]. Use of NF for non-aqueous (organic) solvents has been referred to as "organic solvent nanofiltration" (OSN) [117] or alternatively as "solvent resistant nanofiltration" (SRNF) or “organophilic nanofiltration” [118]. SRNF is a relatively young technology, with a growing research interest. For example, a total of 335 publications appeared in indexed journals between 2005 and 2016 with keywords using OSN or SRNF but more than two third of these appeared over the last 5 years [119]. With a growing public awareness, and rapidly increasing environmental issues, it has become important to consider processes which are more energy efficient and produce less hazardous waste streams. SRNF offers unique advantages over conventional separation processes (i.e. distillation, extraction, crystallization and chromatography), notably the ability to perform molecular separations in organic solvents at ambient conditions without requiring an energy demanding phase transition. These 
advantages, and the absence of additives, makes this technology attractive for the pharmaceutical and chemical industry [120, 121]. SRNF is interesting, as just like any other membrane separation, it can be combined with existing unit operations into hybrid process such as evaporation, distillation and extraction for solvents recovery and this makes this a strong tool in the bottlenecking processes that would otherwise need a full reconstruction or a parallel unit [118].

SRNF has a great potential to be applied in a wide range of processes in different industries such as food [122-127], petrochemical [121, 128-133], pharmaceutical [125, 134-139] and fine chemical [140-147], to separate desired molecules from solvents and/or to recover solvents and solutes from waste streams. The benefits of implementing SRNF in food industry, especially for edible oil are substantial. Edible oils like sunflower and soy are generally prepared by processing of seeds or by a solvent extraction method. In the preparation of oil, a distillation process applied for solvent recycling is the most energy demanding stage, a stage that could be replaced with SRNF or by a hybrid process to remove the solvents before final distillation. SRNF membranes are also successfully applied in edible oil industry to recover valuable products (carotenoids, tocopherols, sterols) from deodorizer distillates (a by-product of the refining edible oil industry) which have a special interest as a source of bioactive compounds for cosmetics, pharmaceutical and food industry [126, 148, 149]. In the pharmaceutical industry, which utilized high quality solvents in every step of drug synthesis, most of the solvents are discharged as these cannot be reused. To recover solvents from waste streams of pharmaceutical industry, distillation or evaporation is applied which is very expensive and energy intensive, however use of SRNF can limit the energy costs. The petrochemical industry was the first one to recognize the benefits of SRNF, and came up with the 
first industrial scale installation of SRNF in late 1990's by ExxonMobil in Texas to recover dewaxing solvents (methyl ethyl ketone and toluene) from dewaxing lube oil filtrates [150].

Nowadays the majority of SRNF membranes are polymer based because of wide choice of materials, low cost, relatively easy processing (phase inversion or coating) and good reproducibility however the only drawback is their limited chemical and thermal stability; and only very few polymeric membranes are stable because swelling and/or dissolution of the polymeric matrix often results in a loss of membrane selectivity.

\section{Polyelectrolyte multilayers for SRNF}

Thin film composite (TFC) membranes comprised of very thin, top selective layer on a porous UF support are of great value for SRNF. As top selective layer and support are synthesized separately so both can be independently optimized to achieve good membrane performance [151]. One of the recent techniques to prepare TFC membranes for SRNF is LbL assembly, which provides an accurate control over layer thickness in nanometer scale [152]. For industrial application of this technology a material is required which is able to withstand aggressive conditions which involves continuous exposure to organic solvents. Both the support and the selective layer to be used for SRNF should be stable in the organic solvents. Tetrahydrofuran (THF), N,Ndimethylformamide (DMF), dimethyl sulfoxide (DMSO), N-methyl-2pyrrolidone (NMP) and dichloromethane (DCM) are some of the important industrial solvents which are still difficult for most of the currently available SRNF membranes [118]. To broaden the use of polymeric materials for SRNF applications it is essential to enhance interactions among macromolecules in polymeric materials. For PEs which are water-soluble polymers, introducing cross linkable chemical groups or enhancing the 
intertwined and electrostatic attraction among PEs is feasible ways to enhance their stability towards organic solvents.

Some of the commonly used PEs combination to prepare selective separation layer in SRNF membranes are poly(diallyldimethylammonium chloride) (PDDA)/sulfonated poly(ether ether ketone) (SPEEK), PDDA/polyacrylic acid (PAA) PDDA/poly(sodium styrene sulfonate) (PSS) and PDDA/poly(vinyl sulfate) (PVS). In previous studies the combination of strong/strong and strong/weak PE's has been incorporated in the fabrication of PEM based SRNF membranes [153-159]. However the use of two weak PE's are unique in that the charge density is not fixed and depends on the coating $\mathrm{pH}$, and variation in $\mathrm{pH}$ can be used to tailor the membrane performance for specific solutes adding an extra variable as tuning parameter for SNRF performance.

\subsection{Multifunctional polyelectrolyte multilayers for membranes}

In this thesis we will demonstrate that the use of weak polyelectrolytes (PAA/PAH), for which control over the layer thickness and molecular organization of a polyelectrolyte multilayer can be achieved by simple adjustments of the $\mathrm{pH}$ of the dipping solutions, can be used to create multifunctional membrane coatings. For the prepared membranes the PEM coating can not only function as the active separation layer (in NF/SRNF/RO) but can also be used for easy cleaning or as antifouling layers. The sacrificial layer approach discussed before is also ideally suited for membrane applications [48, 101, 160]. Bruening and co-workers [101] have successfully used a PEM as both a sacrificial layer and as the separating layer of an NF membrane. However, to create PEM based NF membranes they chose to use the combination of PSS and PAH, a 
combination of PEs that is known to give extremely stable layers. They could only remove or sacrifice their multilayer by physical means, e.g. backwashing at very high pressure for prolonged periods of time [101]. In the PAH/PAA system (pKa 9.3 and 5.4 respectively), the dissociation of PAH increases under acidic conditions while the dissociation of PAA increases under basic conditions. Both these sensitivities can be used as triggers to induce PEM desorption. In another study from the Bruening group, PEMs of PAH/PAA were destabilized by using a combination of $1 \mathrm{M}$ $\mathrm{HCl}$ followed by $1 \mathrm{M} \mathrm{NaOH}$ and for multilayers where one of the PE was strong were further treated with surfactant triton X-100 [160]. Such a low pH is problematic for many types of membranes and will damage the membrane material with repeated use. However, as we will demonstrate, a combination of a much milder low $\mathrm{pH}(\mathrm{pH} 3)$ and a high salt concentration together can also provide the required sacrificial effect.

\section{Outline of this thesis}

The aim of the work presented in this thesis is to describe how weak PE's can be utilized to fabricate multifunctional PEM based membranes for liquid applications. PEM based membranes were developed utilizing two PEs, where the PEM functions as a selective NF separation layer and as a "sacrificial layer" for easy cleaning of fouled membranes. We investigate PEM's prepared from two weak PEs (PAH/PAA) which are responsive towards $\mathrm{pH}$. We have shown that using this responsive property of PAH/PAA, multilayers of desired characteristics can be prepared for particular membrane application and if required can be sacrificed or erased upon fouling. Moreover strong ionic interactions of these weak PEs lead to stable membranes for non-aqueous applications such as SRNF. Throughout this thesis our main approach will be to combine the characterization results 
of PEMs from model surfaces with PEMs based membrane performance for specific application.

In Chapter 2, a model system of weak PEs (PAH/PAA) is applied using “dipcoating technique” to modify an ultrafiltration membrane support to prepare a PEM based membrane, where the PEM has a dual function: to act as NF separation layer and as a sacrificial layer for easy cleaning of membrane. In order to optimize the conditions for PEM coating and removal, adsorption and desorption of these layers on a model surface (silica) is first studied via optical reflectometry. This allowed us to understand the buildup and removal of the multilayer systems at different conditions, something that cannot be precisely monitored on the membrane itself. Then tight hollow fiber UF membranes were coated with PEMs under identical coating conditions.

In Chapter 3, we investigate in detail the role of the $\mathrm{pH}$ of the coating solution of weak PE's to prepare low pressure hollow fiber NF membranes which allow selective removal of micropollutants while allowing passage of most salt ions. Multilayers properties as determined from reflectometry and contact angle measurements are used to explain the salt ions and micropollutants rejection data.

In Chapter 4, we investigate the use of weak PEMs to prepare NF membranes for organic solvents applications. In this chapter we present a versatile and simple way of using $\mathrm{pH}$ to tune performance of weak PEMs based SRNF-membranes for specific applications.

The next step is the simplification of the LbL procedure for hollow fibre membranes by employing “dynamic coating”. In Chapter 5, dynamic coating by flushing the PE's solutions through the lumen of the hollow fibre membrane is investigated in dead end and cross flow mode. The role of 
different parameters like coating mode, cross flow speed and coating pressure is investigated in detail in order to optimise the coating conditions, that would offer ease in modification of the existing UF hollow fibre membrane modules. Also the fouling and sacrificial study is performed for more common model foulants.

Finally in Chapter 6, a conclusion of this work is presented, followed by an outlook in which recommendations for future work are given. 


\section{References}

[1] K.C. Madison, Barrier Function of the Skin: "La Raison d'Être" of the Epidermis, Journal of Investigative Dermatology, 121 (2003) 231-241.

[2] E. Proksch, J.M. Brandner, J.-M. Jensen, The skin: an indispensable barrier, Experimental Dermatology, 17 (2008) 1063-1072.

[3] S.S. Shiratori, M.F. Rubner, pH-Dependent Thickness Behavior of Sequentially Adsorbed Layers of Weak polyelectrolytes, Macromolecules, 33 (2000) 4213-4219.

[4] M. Cid, N. Stem, C. Brunetti, A.F. Beloto, C.A.S. Ramos, Improvements in antireflection coatings for high-efficiency silicon solar cells, Surface and Coatings Technology, 106 (1998) 117-120.

[5] Y. Lvov, S. Yamada, T. Kunitake, Non-linear optical effects in layer-by-layer alternate films of polycations and an azobenzene-containing polyanion, Thin Solid Films, 300 (1997) 107-112.

[6] J. Telegdi, L. Trif, L. Románszki, 5 - Smart anti-biofouling composite coatings for naval applications A2 - Montemor, M.F, in: Smart Composite Coatings and Membranes, Woodhead Publishing, 2016, pp. 123-155.

[7] G. Decher, J.D. Hong, J. Schmitt, Buildup of ultrathin multilayer films by a selfassembly process: III. Consecutively alternating adsorption of anionic and cationic polyelectrolytes on charged surfaces, Thin Solid Films, 210-211, Part 2 (1992) 831835.

[8] G. Decher, Fuzzy Nanoassemblies: Toward Layered Polymeric Multicomposites, Science, 277 (1997) 1232-1237.

[9] S.T. Dubas, J.B. Schlenoff, Polyelectrolyte Multilayers Containing a Weak Polyacid: Construction and Deconstruction, Macromolecules, 34 (2001) 3736-3740. [10] J.B. Schlenoff, H. Ly, M. Li, Charge and Mass Balance in Polyelectrolyte Multilayers, Journal of the American Chemical Society, 120 (1998) 7626-7634.

[11] J.F. Joanny, Polyelectrolyte adsorption and charge inversion, The European Physical Journal B, 9 (1999) 117-122.

[12] Y. Sun, X. Zhang, C. Sun, B. Wang, J. Shen, Fabrication of ultrathin film containing bienzyme of glucose oxidase and glucoamylase based on electrostatic interaction and its potential application as a maltose sensor, Macromolecular Chemistry and Physics, 197 (1996) 147-153.

[13] C. Amorosi, M. Michel, L. Avérous, V. Toniazzo, D. Ruch, V. Ball, Plasma polymer films as an alternative to (PSS-PAH)n or (PSS-PDADMAC)n films to retain active enzymes in exponentially growing polyelectrolyte multilayers, Colloids and Surfaces B: Biointerfaces, 97 (2012) 124-131.

[14] T. Deng, H. Wang, J.-S. Li, G.-L. Shen, R.-Q. Yu, A novel biosensing interfacial design based on the assembled multilayers of the oppositely charged polyelectrolytes, Analytica Chimica Acta, 532 (2005) 137-144. 
[15] R.M. Iost, F.N. Crespilho, Layer-by-layer self-assembly and electrochemistry: Applications in biosensing and bioelectronics, Biosensors and Bioelectronics, 31 (2012) 1-10.

[16] L. Ouyang, D.M. Dotzauer, S.R. Hogg, J. Macanás, J.-F. Lahitte, M.L. Bruening, Catalytic hollow fiber membranes prepared using layer-by-layer adsorption of polyelectrolytes and metal nanoparticles, Catalysis Today, 156 (2010) 100-106.

[17] S. Kidambi, M.L. Bruening, Multilayered Polyelectrolyte Films Containing Palladium Nanoparticles: Synthesis, Characterization, and Application in Selective Hydrogenation, Chemistry of Materials, 17 (2005) 301-307.

[18] B. Ballarin, M.C. Cassani, D. Tonelli, E. Boanini, S. Albonetti, M. Blosi, M. Gazzano, Gold Nanoparticle-Containing Membranes from in Situ Reduction of a Gold(III)-Aminoethylimidazolium Aurate Salt, The Journal of Physical Chemistry C, 114 (2010) 9693-9701.

[19] G.R. Xu, S.H. Wang, H.L. Zhao, S.B. Wu, J.M. Xu, L. Li, X.Y. Liu, Layer-bylayer (LBL) assembly technology as promising strategy for tailoring pressure-driven desalination membranes, Journal of Membrane Science, 493 (2015) 428-443.

[20] J. Borges, J.F. Mano, Molecular interactions driving the layer-by-layer assembly of multilayers, Chemical Reviews, 114 (2014) 8883-8942.

[21] Y. Li, X. Wang, J. Sun, Layer-by-layer assembly for rapid fabrication of thick polymeric films, Chem. Soc. Rev., 41 (2012) 5998-6009.

[22] J.B. Schlenoff, S.T. Dubas, Mechanism of Polyelectrolyte Multilayer Growth: Charge Overcompensation and Distribution, Macromolecules, 34 (2001) 592-598.

[23] S.T. Dubas, J.B. Schlenoff, Factors Controlling the Growth of Polyelectrolyte Multilayers, Macromolecules, 32 (1999) 8153-8160.

[24] W.M. de Vos, L.L.E. Mears, R.M. Richardson, T. Cosgrove, R. Barker, S.W. Prescott, Nonuniform Hydration and Odd-Even Effects in Polyelectrolyte Multilayers under a Confining Pressure, Macromolecules, 46 (2013) 1027-1034.

[25] D.E. Bergbreiter, K.-S. Liao, Covalent layer-by-layer assembly-an effective, forgiving way to construct functional robust ultrathin films and nanocomposites, Soft Matter, 5 (2009) 23-28.

[26] K. Ariga, J.P. Hill, Q. Ji, Layer-by-layer assembly as a versatile bottom-up nanofabrication technique for exploratory research and realistic application, Physical Chemistry Chemical Physics, 9 (2007) 2319-2340.

[27] M. Lösche, J. Schmitt, G. Decher, W.G. Bouwman, K. Kjaer, Detailed Structure of Molecularly Thin Polyelectrolyte Multilayer Films on Solid Substrates as Revealed by Neutron Reflectometry, Macromolecules, 31 (1998) 8893-8906.

[28] E. Kharlampieva, V. Kozlovskaya, J. Chan, J.F. Ankner, V.V. Tsukruk, SpinAssisted Layer-by-Layer Assembly: Variation of Stratification as Studied with Neutron Reflectivity, Langmuir : the ACS journal of surfaces and colloids, 25 (2009) 14017-14024. 
[29] J. de Grooth, R. Oborný, J. Potreck, K. Nijmeijer, W.M. de Vos, The role of ionic strength and odd-even effects on the properties of polyelectrolyte multilayer nanofiltration membranes, Journal of Membrane Science, 475 (2015) 311-319.

[30] E. Tjipto, J.F. Quinn, F. Caruso, Assembly of Multilayer Films from Polyelectrolytes Containing Weak and Strong Acid Moieties, Langmuir : the ACS journal of surfaces and colloids, 21 (2005) 8785-8792.

[31] K. Büscher, K. Graf, H. Ahrens, C.A. Helm, Influence of Adsorption Conditions on the Structure of Polyelectrolyte Multilayers, Langmuir : the ACS journal of surfaces and colloids, 18 (2002) 3585-3591.

[32] M. Salomäki, I.A. Vinokurov, J. Kankare, Effect of Temperature on the Buildup of Polyelectrolyte Multilayers, Langmuir : the ACS journal of surfaces and colloids, 21 (2005) 11232-11240.

[33] D. Yoo, S.S. Shiratori, M.F. Rubner, Controlling Bilayer Composition and Surface Wettability of Sequentially Adsorbed Multilayers of Weak Polyelectrolytes, Macromolecules, 31 (1998) 4309-4318.

[34] X. Gong, Controlling surface properties of polyelectrolyte multilayers by assembly pH, Physical Chemistry Chemical Physics, 15 (2013) 10459-10465.

[35] M.F. Rubner, pH-Controlled Fabrication of Polyelectrolyte Multilayers: Assembly and Applications, in: Multilayer Thin Films, Wiley-VCH Verlag GmbH \& Co. KGaA, 2003, pp. 133-154.

[36] P. Bieker, M. Schönhoff, Linear and Exponential Growth Regimes of Multilayers of Weak Polyelectrolytes in Dependence on $\mathrm{pH}$, Macromolecules, 43 (2010) 5052-5059.

[37] X. Jiang, Z. Chen, D. Lv, Q. Wu, X. Lin, Basic Law Controlling the Growth Regime of Layer-by-Layer Assembled Polyelectrolyte Multilayers, Macromolecular Chemistry and Physics, 209 (2008) 175-183.

[38] C. Porcel, P. Lavalle, V. Ball, G. Decher, B. Senger, J.-C. Voegel, P. Schaaf, From Exponential to Linear Growth in Polyelectrolyte Multilayers, Langmuir : the ACS journal of surfaces and colloids, 22 (2006) 4376-4383.

[39] A.S. Vikulina, Y.G. Anissimov, P. Singh, V.Z. Prokopović, K. Uhlig, M.S. Jaeger, R. Von Klitzing, C. Duschl, D. Volodkin, Temperature effect on the build-up of exponentially growing polyelectrolyte multilayers. An exponential-to-linear transition point, Physical Chemistry Chemical Physics, 18 (2016) 7866-7874.

[40] L. Xu, D. Pristinski, A. Zhuk, C. Stoddart, J.F. Ankner, S.A. Sukhishvili, Linear versus Exponential Growth of Weak Polyelectrolyte Multilayers: Correlation with Polyelectrolyte Complexes, Macromolecules, 45 (2012) 3892-3901.

[41] R. v. Klitzing, Internal structure of polyelectrolyte multilayer assemblies, Physical Chemistry Chemical Physics, 8 (2006) 5012-5033.

[42] G. Ladam, P. Schaad, J.C. Voegel, P. Schaaf, G. Decher, F. Cuisinier, In Situ Determination of the Structural Properties of Initially Deposited Polyelectrolyte 
Multilayers, Langmuir : the ACS journal of surfaces and colloids, 16 (2000) 12491255.

[43] A. Ciferri Ionic Mixed Interactions in Macromolecules, Chemistry - A European Journal, 16 (2010) 10930-10945.

[44] D. Kovacevic, S. van der Burgh, A. de Keizer, M.A. Cohen Stuart, Kinetics of Formation and Dissolution of Weak Polyelectrolyte Multilayers: Role of Salt and Free Polyions, Langmuir : the ACS journal of surfaces and colloids, 18 (2002) 56075612.

[45] V. Izumrudov, E. Kharlampieva, S.A. Sukhishvili, Salt-Induced Multilayer Growth: Correlation with Phase Separation in Solution, Macromolecules, 37 (2004) 8400-8406.

[46] V. Izumrudov, S.A. Sukhishvili, Ionization-Controlled Stability of Polyelectrolyte Multilayers in Salt Solutions, Langmuir : the ACS journal of surfaces and colloids, 19 (2003) 5188-5191.

[47] W.M. de Vos, A. de Keizer, M.A.C. Stuart, J.M. Kleijn, Thin polymer films as sacrificial layers for easier cleaning, Colloids and Surfaces A: Physicochemical and Engineering Aspects, 358 (2010) 6-12.

[48] S. Ilyas, J. de Grooth, K. Nijmeijer, W.M. de Vos, Multifunctional polyelectrolyte multilayers as nanofiltration membranes and as sacrificial layers for easy membrane cleaning, Journal of Colloid and Interface Science, 446 (2015) 386393.

[49] S. Loeb, S. Sourirajan, Sea Water Demineralization by Means of an Osmotic Membrane, in: Saline Water Conversion-II, AMERICAN CHEMICAL SOCIETY, 1963, pp. 117-132.

[50] R.W. Baker, Membrane Technology and Applications, John Wiley \& Sons Ltd, West Sussex, (2004).

[51] C. Zhao, J. Xue, F. Ran, S. Sun, Modification of polyethersulfone membranes A review of methods, Progress in Materials Science, 58 (2013) 76-150.

[52] V. Kochkodan, D.J. Johnson, N. Hilal, Polymeric membranes: Surface modification for minimizing (bio)colloidal fouling, Advances in Colloid and Interface Science, 206 (2014) 116-140.

[53] K.-V. Peinemann, S.P. Nunes, Membrane Technology, Volume 4: Membranes for Water Treatment, John Wiley \& Sons, 2010.

[54] P. Ahmadiannamini, M.L. Bruening, V.V. Tarabara, Sacrificial polyelectrolyte multilayer coatings as an approach to membrane fouling control: Disassembly and regeneration mechanisms, Journal of Membrane Science, (2015).

[55] A. Schäfer, N. Andritsos, A.J. Karabelas, E. Hoek, R. Schneider, M. Nyström, Fouling in nanofiltration, (2004).

[56] G. Pearce, Introduction to membranes: Fouling control, Filtration \& Separation, 44 (2007) 30-32. 
[57] A.I. Schäfer, A.G. Fane, T.D. Waite, Nanofiltration: principles and applications, Elsevier, 2005.

[58] A.I. Schäfer, A.G. Fane, T.D. Waite, Nanofiltration : principles and applications, Elsevier, Oxford, 2005.

[59] A. Szymczyk, P. Fievet, Investigating transport properties of nanofiltration membranes by means of a steric, electric and dielectric exclusion model, Journal of Membrane Science, 252 (2005) 77-88.

[60] A.E. Yaroshchuk, Dielectric exclusion of ions from membranes, Advances in Colloid and Interface Science, 85 (2000) 193-230.

[61] B. Van der Bruggen, J. Schaep, W. Maes, D. Wilms, C. Vandecasteele, Nanofiltration as a treatment method for the removal of pesticides from ground waters, Desalination, 117 (1998) 139-147.

[62] Y. Zhang, B. Van der Bruggen, G.X. Chen, L. Braeken, C. Vandecasteele, Removal of pesticides by nanofiltration: effect of the water matrix, Separation and Purification Technology, 38 (2004) 163-172.

[63] Y. Zhang, C. Causserand, P. Aimar, J.P. Cravedi, Removal of bisphenol A by a nanofiltration membrane in view of drinking water production, Water research, 40 (2006) 3793-3799.

[64] R. Boussahel, S. Bouland, K.M. Moussaoui, A. Montiel, Removal of pesticide residues in water using the nanofiltration process, Desalination, 132 (2000) 205-209. [65] J. Geens, B. Van der Bruggen, C. Vandecasteele, Transport model for solvent permeation through nanofiltration membranes, Separation and Purification Technology, 48 (2006) 255-263.

[66] K. Košutić, L. Furač, L. Sipos, B. Kunst, Removal of arsenic and pesticides from drinking water by nanofiltration membranes, Separation and Purification Technology, 42 (2005) 137-144.

[67] K.V. Plakas, A.J. Karabelas, Removal of pesticides from water by NF and RO membranes - A review, Desalination, 287 (2012) 255-265.

[68] J.-H. Tay, J. Liu, D. Delai Sun, Effect of solution physico-chemistry on the charge property of nanofiltration membranes, Water research, 36 (2002) 585-598.

[69] B. Van der Bruggen, J. Schaep, W. Maes, D. Wilms, C. Vandecasteele, Nanofiltration as a treatment method for the removal of pesticides from ground waters, Desalination, 117 (1998) 139-147.

[70] B. Van der Bruggen, J. Schaep, D. Wilms, C. Vandecasteele, Influence of molecular size, polarity and charge on the retention of organic molecules by nanofiltration, Journal of Membrane Science, 156 (1999) 29-41.

[71] M.H.V. Mulder, Basic principles of membrane technology, Kluwer Academic Publisher, The Netherlands, 2nd edition (1996).

[72] N.S. Thomaidis, A.G. Asimakopoulos, A.A. Bletsou, Emerging contaminants: A tutorial mini-review, Global Nest J., 14 (2012) 72-79. 
[73] UNEP, Global Chemical Outlook; Towards Sound Management of Chemicals, United Nations Environment Programme, (2012).

[74] M. Kuzmanovic', A. Ginebreda, M. Petrovic', D. Barcelo', Risk assessment based prioritization of 200 organic micropollutants in 4 Iberian rivers, Science of the Total Environment, (2014).

[75] Y. Luo, W. Guo, H.H. Ngo, L.D. Nghiem, F.I. Hai, J. Zhang, S. Liang, X.C. Wang, A review on the occurrence of micropollutants in the aquatic environment and their fate and removal during wastewater treatment, Science of the Total Environment, 473-474 (2014) 619-641.

[76] E.D. N.G.F.M. van der Aa, L. Bijlsma, E. Emke, B.M. van de Ven, A.L.N. van Nuijs, P. de Voogt Drugs of Abuse and Tranquilizers in Dutch Surface Waters, Drinking Water and Wastewater - Results of Screening Monitoring 2009, National Institute for Public Health and the Environment, The Netherlands, (2010).

[77] E. Cho, J. Khim, S. Chung, D. Seo, Y. Son, Occurrence of micropollutants in four major rivers in Korea, Science of the Total Environment, 491-492 (2014) 138147.

[78] K.K. Barnes, D.W. Kolpin, E.T. Furlong, S.D. Zaugg, M.T. Meyer, L.B. Barber, A national reconnaissance of pharmaceuticals and other organic wastewater contaminants in the United States - I) Groundwater, Science of The Total Environment, 402 (2008) 192-200.

[79] Q. Sui, J. Huang, S. Deng, G. Yu, Q. Fan, Occurrence and removal of pharmaceuticals, caffeine and DEET in wastewater treatment plants of Beijing, China, Water research, 44 (2010) 417-426.

[80] D. Rozman, Z. Hrkal, P. Eckhardt, E. Novotná, Z. Boukalová, Pharmaceuticals in groundwaters: a case study of the psychiatric hospital at Horní Beřkovice, Czech Republic, Environ. Earth Sci., (2014).

[81] L. Pasquini, J.F. Munoz, M.N. Pons, J. Yvon, X. Dauchy, X. France, N.D. Le, C. France-Lanord, T. Görner, Occurrence of eight household micropollutants in urban wastewater and their fate in a wastewater treatment plant. Statistical evaluation, Science of the Total Environment, 481 (2014) 459-448.

[82] C.J. Houtman, J. Kroesbergen, K. Lekkerkerker-Teunissen, J.P. van der Hoek, Human health risk assessment of the mixture of pharmaceuticals in Dutch drinking water and its sources based on frequent monitoring data, Science of The Total Environment, 496 (2014) 54-62.

[83] T. Heberer, Occurrence, fate, and removal of pharmaceutical residues in the aquatic environment: a review of recent research data, Toxicology Letters, 131 (2002) 5-17.

[84] S. Kleywegt, V. Pileggi, P. Yang, C. Hao, X. Zhao, C. Rocks, S. Thach, P. Cheung, B. Whitehead, Pharmaceuticals, hormones and bisphenol A in untreated source and finished drinking water in Ontario, Canada - Occurrence and treatment efficiency, Science of The Total Environment, 409 (2011) 1481-1488. 
[85] A. Verliefde, E. Cornelissen, G. Amy, B. Van der Bruggen, H. van Dijk, Priority organic micropollutants in water sources in Flanders and the Netherlands and assessment of removal possibilities with nanofiltration, Environmental Pollution, 146 (2007) 281-289.

[86] J. Rivera-Utrilla, M. Sánchez-Polo, M.Á. Ferro-García, G. Prados-Joya, R. Ocampo-Pérez, Pharmaceuticals as emerging contaminants and their removal from water. A review, Chemosphere, 93 (2013) 1268-1287.

[87] I. Michael, L. Rizzo, C.S. McArdell, C.M. Manaia, C. Merlin, T. Schwartz, C. Dagot, D. Fatta-Kassinos, Urban wastewater treatment plants as hotspots for the release of antibiotics in the environment: A review, Water research, 47 (2013) 957995.

[88] R.I.L. Eggen, J. Hollender, A. Joss, M. Schärer, C. Stamm, Reducing the discharge of micropollutants in the aquatic environment: The benefits of upgrading wastewater treatment plants, Environ. Sci. Technol., 48 (2014) 7683-7689.

[89] J.H. Al-Rifai, H. Khabbaz, A.I. Schäfer, Removal of pharmaceuticals and endocrine disrupting compounds in a water recycling process using reverse osmosis systems, Separation and Purification Technology, 77 (2011) 60-67.

[90] J.L. Acero, F.J. Benitez, F.J. Real, F. Teva, Micropollutants removal from retentates generated in ultrafiltration and nanofiltration treatments of municipal secondary effluents by means of coagulation, oxidation, and adsorption processes, Chem. Eng. J., 289 (2016) 48-58.

[91] C. Bellona, D. Heil, C. Yu, P. Fu, J.E. Drewes, The pros and cons of using nanofiltration in lieu of reverse osmosis for indirect potable reuse applications, Separation and Purification Technology, 85 (2012) 69-76.

[92] V. Yangali-Quintanilla, S.K. Maeng, T. Fujioka, M. Kennedy, G. Amy, Proposing nanofiltration as acceptable barrier for organic contaminants in water reuse, Journal of Membrane Science, 362 (2010) 334-345.

[93] W.R. Bowen, J.S. Welfoot, Modelling the performance of membrane nanofiltration-critical assessment and model development, Chemical Engineering Science, 57 (2002) 1121-1137.

[94] M.L. Bruening, D.M. Sullivan, Enhancing the Ion-Transport Selectivity of Multilayer Polyelectrolyte Membranes, Chemistry - A European Journal, 8 (2002) 3832-3837.

[95] J.J. Harris, J.L. Stair, M.L. Bruening, Layered Polyelectrolyte Films as Selective, Ultrathin Barriers for Anion Transport, Chemistry of Materials, 12 (2000) 1941-1946.

[96] S.U. Hong, R. Malaisamy, M.L. Bruening, Optimization of flux and selectivity in $\mathrm{Cl}-/ \mathrm{SO} 42-$ separations with multilayer polyelectrolyte membranes, Journal of Membrane Science, 283 (2006) 366-372.

[97] G. Liu, D.M. Dotzauer, M.L. Bruening, Ion-Exchange Membranes Prepared Using Layer-by-Layer Polyelectrolyte Deposition, J Memb Sci, 354 (2010) 198-205. 
[98] R. Malaisamy, M.L. Bruening, High-Flux Nanofiltration Membranes Prepared by Adsorption of Multilayer Polyelectrolyte Membranes on Polymeric Supports, Langmuir : the ACS journal of surfaces and colloids, 21 (2005) 10587-10592.

[99] M.D. Miller, M.L. Bruening, Controlling the Nanofiltration Properties of Multilayer Polyelectrolyte Membranes through Variation of Film Composition, Langmuir : the ACS journal of surfaces and colloids, 20 (2004) 11545-11551.

[100] L. Ouyang, R. Malaisamy, M.L. Bruening, Multilayer polyelectrolyte films as nanofiltration membranes for separating monovalent and divalent cations, Journal of Membrane Science, 310 (2008) 76-84.

[101] W. Shan, P. Bacchin, P. Aimar, M.L. Bruening, V.V. Tarabara, Polyelectrolyte multilayer films as backflushable nanofiltration membranes with tunable hydrophilicity and surface charge, Journal of Membrane Science, 349 (2010) 268-278.

[102] J.L. Stair, J.J. Harris, M.L. Bruening, Enhancement of the Ion-Transport Selectivity of Layered Polyelectrolyte Membranes through Cross-Linking and Hybridization, Chemistry of Materials, 13 (2001) 2641-2648.

[103] B.W. Stanton, J.J. Harris, M.D. Miller, M.L. Bruening, Ultrathin, Multilayered Polyelectrolyte Films as Nanofiltration Membranes, Langmuir : the ACS journal of surfaces and colloids, 19 (2003) 7038-7042.

[104] K. Hoffmann, T. Friedrich, B. Tieke, Layer-by-layer assembled polyelectrolyte blend membranes and their use for ion separation and rejection, Polymer Engineering \& Science, 51 (2011) 1497-1506.

[105] W. Jin, A. Toutianoush, B. Tieke, Use of Polyelectrolyte Layer-by-Layer Assemblies as Nanofiltration and Reverse Osmosis Membranes, Langmuir : the ACS journal of surfaces and colloids, 19 (2003) 2550-2553.

[106] A. Toutianoush, W. Jin, H. Deligöz, B. Tieke, Polyelectrolyte multilayer membranes for desalination of aqueous salt solutions and seawater under reverse osmosis conditions, Applied Surface Science, 246 (2005) 437-443.

[107] X. Liu, M.L. Bruening, Size-Selective Transport of Uncharged Solutes through Multilayer Polyelectrolyte Membranes, Chemistry of Materials, 16 (2003) 351-357.

[108] S.U. Hong, M.D. Miller, M.L. Bruening, Removal of Dyes, Sugars, and Amino Acids from NaCl Solutions Using Multilayer Polyelectrolyte Nanofiltration Membranes, Industrial \& Engineering Chemistry Research, 45 (2006) 6284-6288.

[109] J. de Grooth, D.M. Reurink, J. Ploegmakers, W.M. de Vos, K. Nijmeijer, Charged Micropollutant Removal With Hollow Fiber Nanofiltration Membranes Based On Polycation/Polyzwitterion/Polyanion Multilayers, ACS applied materials \& interfaces, 6 (2014) 17009-17017.

[110] B. Su, T. Wang, Z. Wang, X. Gao, C. Gao, Preparation and performance of dynamic layer-by-layer PDADMAC/PSS nanofiltration membrane, Journal of Membrane Science, 423-424 (2012) 324-331. 
[111] G. Liu, D.M. Dotzauer, M.L. Bruening, Ion-Exchange Membranes Prepared Using Layer-by-Layer Polyelectrolyte Deposition, Journal of membrane science, 354 (2010) 198-205.

[112] C. Liu, L. Shi, R. Wang, Enhanced hollow fiber membrane performance via semi-dynamic layer-by-layer polyelectrolyte inner surface deposition for nanofiltration and forward osmosis applications, Reactive and Functional Polymers, 86 (2015) 154-160.

[113] C. Liu, L. Shi, R. Wang, Crosslinked layer-by-layer polyelectrolyte nanofiltration hollow fiber membrane for low-pressure water softening with the presence of SO42- in feed water, Journal of Membrane Science, 486 (2015) 169176.

[114] G. Zhang, X. Song, S. Ji, N. Wang, Z. Liu, Self-assembly of inner skin hollow fiber polyelectrolyte multilayer membranes by a dynamic negative pressure layerby-layer technique, Journal of Membrane Science, 325 (2008) 109-116.

[115] D. Menne, J. Kamp, J. Erik Wong, M. Wessling, Precise tuning of salt retention of backwashable polyelectrolyte multilayer hollow fiber nanofiltration membranes, Journal of Membrane Science, 499 (2016) 396-405.

[116] S. Sourirajan, Separation of Hydrocarbon Liquids by Flow Under Pressure Through Porous Membranes, Nature, 203 (1964) 1348-1349.

[117] L.G. Peeva, S. Malladi, A. G. Livingston, In Comprehensive Membrane Science and Engineering, Drioli, E., Giorno, L., Eds.; Elsevier: Oxford, UK, (2010). [118] P. Vandezande, L.E.M. Gevers, I.F.J. Vankelecom, Solvent resistant nanofiltration: Separating on a molecular level, Chem. Soc. Rev., 37 (2008) 365405.

[119] M. Amirilargani, M. Sadrzadeh, E.J.R. Sudhölter, L.C.P.M. de Smet, Surface modification methods of organic solvent nanofiltration membranes, Chem. Eng. J., 289 (2016) 562-582.

[120] G. Szekely, M.F. Jimenez-Solomon, P. Marchetti, J.F. Kim, A.G. Livingston, Sustainability assessment of organic solvent nanofiltration: from fabrication to application, Green Chem., 16 (2014) 4440-4473.

[121] L.S. White, C.R. Wildemuth, Aromatics Enrichment in Refinery Streams Using Hyperfiltration, Industrial \& Engineering Chemistry Research, 45 (2006) 9136-9143.

[122] W. Cai, Y. Sun, X. Piao, J. Li, S. Zhu, Solvent Recovery from Soybean Oil/Hexane Miscella by PDMS Composite Membrane, Chinese Journal of Chemical Engineering, 19 (2011) 575-580.

[123] L.R. Firman, N.A. Ochoa, J. Marchese, C.L. Pagliero, Deacidification and solvent recovery of soybean oil by nanofiltration membranes, Journal of Membrane Science, 431 (2013) 187-196.

[124] K. Hendrix, S. Vandoorne, G. Koeckelberghs, I.F.J. Vankelecom, SRNF membranes for edible oil purification: Introducing free amines in crosslinked PEEK 
to increase membrane hydrophilicity, Polymer (United Kingdom), 55 (2014) 13071316.

[125] D. Peshev, L.G. Peeva, G. Peev, I.I.R. Baptista, A.T. Boam, Application of organic solvent nanofiltration for concentration of antioxidant extracts of rosemary (Rosmarinus officiallis L.), Chemical Engineering Research and Design, 89 (2011) 318-327.

[126] A.R.S. Teixeira, J.L.C. Santos, J.G. Crespo, Solvent resistant diananofiltration for production of steryl esters enriched extracts, Separation and Purification Technology, 135 (2014) 243-251.

[127] M.V. Tres, H.C. Ferraz, R.M. Dallago, M. Di Luccio, J.V. Oliveira, Characterization of polymeric membranes used in vegetable oil/organic solvents separation, Journal of Membrane Science, 362 (2010) 495-500.

[128] Y. Kong, D. Shi, H. Yu, Y. Wang, J. Yang, Y. Zhang, International Congress on Membranes and Membrane ProcessesSeparation performance of polyimide nanofiltration membranes for solvent recovery from dewaxed lube oil filtrates, Desalination, 191 (2006) 254-261.

[129] M. Namvar-Mahboub, M. Pakizeh, Development of a novel thin film composite membrane by interfacial polymerization on polyetherimide/modified SiO2 support for organic solvent nanofiltration, Separation and Purification Technology, 119 (2013) 35-45.

[130] R. Othman, A.W. Mohammad, M. Ismail, J. Salimon, Application of polymeric solvent resistant nanofiltration membranes for biodiesel production, Journal of Membrane Science, 348 (2010) 287-297.

[131] R. Othman, A.W. Mohammad, M. Ismail, J. Salimon, Selectivity of Polymeric Solvent Resistant Nanofiltration Membranes for Biodiesel Separation, in: Sustainable Membrane Technology for Energy, Water, and Environment, John Wiley and Sons, 2012, pp. 277-287.

[132] M. Takht Ravanchi, T. Kaghazchi, A. Kargari, Application of membrane separation processes in petrochemical industry: a review, Desalination, 235 (2009) 199-244.

[133] L.S. White, A.R. Nitsch, Solvent recovery from lube oil filtrates with a polyimide membrane, Journal of Membrane Science, 179 (2000) 267-274.

[134] R. Abejón, A. Garea, A. Irabien, Analysis and optimization of continuous organic solvent nanofiltration by membrane cascade for pharmaceutical separation, AIChE Journal, 60 (2014) 931-948.

[135] S. Darvishmanesh, L. Firoozpour, J. Vanneste, P. Luis, J. Degrève, B. Van Der Bruggen, Performance of solvent resistant nanofiltration membranes for purification of residual solvent in the pharmaceutical industry: Experiments and simulation, Green Chem., 13 (2011) 3476-3483. 
[136] J.F. Kim, G. Székely, I.B. Valtcheva, A.G. Livingston, Increasing the sustainability of membrane processes through cascade approach and solvent recovery - Pharmaceutical purification case study, Green Chem., 16 (2014) 133-145. [137] L. Peeva, J.D.S. Burgal, I. Valtcheva, A.G. Livingston, Continuous purification of active pharmaceutical ingredients using multistage organic solvent nanofiltration membrane cascade, Chemical Engineering Science, 116 (2014) 183194.

[138] G. Székely, J. Bandarra, W. Heggie, B. Sellergren, F.C. Ferreira, Organic solvent nanofiltration: A platform for removal of genotoxins from active pharmaceutical ingredients, Journal of Membrane Science, 381 (2011) 21-33.

[139] G. Székely, J. Bandarra, W. Heggie, B. Sellergren, F.C. Ferreira, A hybrid approach to reach stringent low genotoxic impurity contents in active pharmaceutical ingredients: Combining molecularly imprinted polymers and organic solvent nanofiltration for removal of 1,3-diisopropylurea, Separation and Purification Technology, 86 (2012) 79-87.

[140] T. Fahrenwaldt, J. Großeheilmann, F. Erben, U. Kragl, Organic solvent nanofiltration as a tool for separation of quinine-based organocatalysts, Org. Process Res. Dev., 17 (2013) 1131-1136.

[141] J. Großeheilmann, H. Büttner, C. Kohrt, U. Kragl, T. Werner, Recycling of phosphorus-based organocatalysts by organic solvent nanofiltration, ACS Sustainable Chemistry and Engineering, 3 (2015) 2817-2822.

[142] J. Großeheilmann, T. Fahrenwaldt, U. Kragl, Organic solvent nanofiltrationsupported purification of organocatalysts, ChemCatChem, 8 (2016) 322-325.

[143] J.F. Kim, G. Szekely, M. Schaepertoens, I.B. Valtcheva, M.F. JimenezSolomon, A.G. Livingston, In situ solvent recovery by organic solvent nanofiltration, ACS Sustainable Chemistry and Engineering, 2 (2014) 2371-2379.

[144] P.G.N. Mertens, F. Cuypers, P. Vandezande, X. Ye, F. Verpoort, I.F.J. Vankelecom, D.E. De Vos, Ag0 and Co0 nanocolloids as recyclable quasihomogeneous metal catalysts for the hydrogenation of $\alpha, \beta$-unsaturated aldehydes to allylic alcohol fragrances, Applied Catalysis A: General, 325 (2007) 130-139.

[145] P.G.N. Mertens, P. Vandezande, X. Ye, H. Poelman, I.F.J. Vankelecom, D.E. De Vos, Recyclable Au0, Ag0 and Au0-Ag0 nanocolloids for the chemoselective hydrogenation of $\alpha, \beta$-unsaturated aldehydes and ketones to allylic alcohols, Applied Catalysis A: General, 355 (2009) 176-183.

[146] R. Valadez-Blanco, F.C. Ferreira, R.F. Jorge, A.G. Livingston, A membrane bioreactor for biotransformations of hydrophobic molecules using organic solvent nanofiltration (OSN) membranes, Journal of Membrane Science, 317 (2008) 50-64. [147] D. Nair, S.S. Luthra, J.T. Scarpello, L.S. White, L.M. Freitas dos Santos, A.G. Livingston, Homogeneous catalyst separation and re-use through nanofiltration of organic solvents, Desalination, 147 (2002) 301-306. 
[148] A.R.S. Teixeira, J.L.C. Santos, J.G. Crespo, Assessment of solvent resistant nanofiltration membranes for valorization of deodorizer distillates, Journal of Membrane Science, 470 (2014) 138-147.

[149] D. Darnoko, M. Cheryan, Carotenoids from red palm methyl esters by nanofiltration, Journal of the American Oil Chemists' Society, 83 (2006) 365-370.

[150] R.M. Gould, L.S. White, C.R. Wildemuth, Membrane separation in solvent lube dewaxing, Environmental Progress, 20 (2001) 12-16.

[151] S. Hermans, H. Mariën, C. Van Goethem, I.F.J. Vankelecom, Recent developments in thin film (nano)composite membranes for solvent resistant nanofiltration, Current Opinion in Chemical Engineering, 8 (2015) 45-54.

[152] N. Joseph, P. Ahmadiannamini, R. Hoogenboom, I.F.J. Vankelecom, Layerby-layer preparation of polyelectrolyte multilayer membranes for separation, Polymer Chemistry, 5 (2014) 1817-1831.

[153] X. Li, S. De Feyter, D. Chen, S. Aldea, P. Vandezande, F.D. Prez, I.F.J. Vankelecom, Solvent-resistant nanofiltration membranes based on multilayered polyelectrolyte complexes, Chemistry of Materials, 20 (2008) 3876-3883.

[154] X. Li, W. Goyens, P. Ahmadiannamini, W. Vanderlinden, S. De Feyter, I. Vankelecom, Morphology and performance of solvent-resistant nanofiltration membranes based on multilayered polyelectrolytes: Study of preparation conditions, Journal of Membrane Science, 358 (2010) 150-157.

[155] P. Ahmadiannamini, X. Li, W. Goyens, B. Meesschaert, I.F.J. Vankelecom, Multilayered PEC nanofiltration membranes based on SPEEK/PDDA for anion separation, Journal of Membrane Science, 360 (2010) 250-258.

[156] P. Ahmadiannamini, X. Li, W. Goyens, N. Joseph, B. Meesschaert, I.F.J. Vankelecom, Multilayered polyelectrolyte complex based solvent resistant nanofiltration membranes prepared from weak polyacids, Journal of Membrane Science, 394-395 (2012) 98-106.

[157] P. Ahmadiannamini, X. Li, W. Goyens, B. Meesschaert, W. Vanderlinden, S. De Feyter, I.F.J. Vankelecom, Influence of polyanion type and cationic counter ion on the SRNF performance of polyelectrolyte membranes, Journal of Membrane Science, 403-404 (2012) 216-226.

[158] D. Chen, Solvent-resistant nanofiltration membranes based on multilayered polyelectrolytes deposited on silicon composite, Journal of Applied Polymer Science, 129 (2013) 3156-3161.

[159] N. Joseph, P. Ahmadiannamini, P.S. Jishna, A. Volodin, I.F.J. Vankelecom, 'Up-scaling' potential for polyelectrolyte multilayer membranes, Journal of Membrane Science, 492 (2015) 271-280.

[160] P. Ahmadiannamini, M.L. Bruening, V.V. Tarabara, Sacrificial polyelectrolyte multilayer coatings as an approach to membrane fouling control: Disassembly and regeneration mechanisms, Journal of Membrane Science. 


\section{Sacrificial polyelectrolyte multilayers for membranes}

This chapter has been published as:

Shazia Ilyas, Joris de Grooth, Kitty Nijmeijer and Wiebe M. de Vos, Multifunctional polyelectrolyte multilayers as nanofiltration membranes and as sacrificial layers for easy membrane cleaning, Journal of colloid and interface science, 446 (2015) 386-393.

DOI: $\underline{10.1016 / j . j c i s .2014 .12 .019 .}$ 


\section{Abstract}

This chapter investigates the modification of an ultra-filtration (UF) membrane support with polyelectrolyte multilayers (PEMs) consisting of the weak polyelectrolytes poly(allyl amine) hydrochloride (PAH) and poly(acrylic acid) (PAA). These prepared polyelectrolyte multilayer membranes have a dual function: They act as nanofiltration (NF) membranes and as sacrificial layers to allow easy cleaning of the membranes. In order to optimize the conditions for PEM coating and removal, adsorption and desorption of these layers on a model surface (silica) was first studied via optical reflectometry. Subsequently, a charged UF membrane support was coated with a PEM and after each deposited layer, a clear increase in membrane resistance against pure water permeation and a switch of the zeta potential were observed. Moreover these polyelectrolyte multilayer membranes, exhibited rejection of solutes in a range typical for $\mathrm{NF}$ membranes. Monovalent ions $(\mathrm{NaCl})$ were hardly rejected $(<24 \%)$, while rejections of $>60 \%$ were observed for a neutral organic molecule sulfamethoxazole (SMX) and for the divalent ion $\mathrm{SO}_{4}{ }^{2-}$. The rejection mechanism of these membranes seems to be dominated by size-exclusion. To investigate the role of these PEMs as sacrificial layers for the cleaning of fouled membranes, the prepared polyelectrolyte multilayers were fouled with silica nano particles. Subsequent removal of the coating using a rinse and a low pressure backwash with $\mathrm{pH} 3,3 \mathrm{M} \mathrm{NaNO}_{3}$ allowed for a drop in membrane resistance from $1.7 \times 10^{14} \mathrm{~m}^{-1}$ (fouled membrane) to $9.9 \times 10^{12} \mathrm{~m}^{-1}$ (clean membrane), which is nearly equal to that of the pristine membrane $\left(9.7 \times 10^{12} \mathrm{~m}^{-1}\right)$. Recoating of the support membrane with the same PEMs resulted in a resistance equal to the resistance of the original polyelectrolyte multilayer membrane. Interestingly, less layers were needed to obtain complete foulant removal from the membrane surface, than was the case for the model surface. The possibility for backwashing allows for an even more 
successful use of the sacrificial layer approach in membrane technology than on model surfaces. Moreover, these PEMs can be used to provide a dual function, as NF membranes and as a Sacrificial coating to allow easy membrane cleaning. 


\subsection{Introduction}

Fouling of surfaces and interfaces is a well-known and often studied problem in colloid and interface science. Irrespective of the anti-fouling strategies employed, all surfaces will eventually become fouled under adverse conditions [1]. Fouling is an especially crucial issue in membrane technology [2]. Separation processes such as microfiltration (MF), ultrafiltration (UF), nanofiltration (NF) and reverse osmosis (RO) are used widely for numerous commercial applications in various fields such as water and wastewater treatment, desalination, the food industry, biotechnology and others [3]. However, fouling is an inherent problem for all of these membrane processes, causing fluxes to decline and thus leading to a decrease in productivity and/or an increase in energy demand. While the removal of foulants can be performed using various cleaning techniques, cleaning is often found to be incomplete (irreversible fouling) and cleaning can damage the membrane itself. In both cases, the membrane will need to be replaced, which increases the operational cost of the process. Over the years much research has been devoted to develop methods to make the cleaning easier, such as the use of surfactants [4], super hydrophobic coatings with self-cleaning properties [5], nanobubbles [1] and antifouling layers such as polymer brushes [6]. A very different approach to cleaning was proposed a few years ago and was denoted as the "sacrificial layer" approach $[7,8]$. This sacrificial layer approach involves the precoating of a surface with a nanometer thick polymer layer that upon fouling can be desorbed/sacrificed from the surface along with any attached foulants. Sacrificing the layer is based on a simple trigger i.e. a change in $\mathrm{pH}$, salt concentration or by the addition of a surfactant. The cleaned surface can subsequently be recoated with a new polymer layer to use it again. As this polymer layer inhibits the contact between foulant and the interface, the 
success of the approach should be independent of the type of foulant. Additionally when polymers are coated on an interface, it results in a change in the surface properties of the interface. The sacrificial layer coating could thus have additional benefits such as antifouling or anti adhesive properties. We strongly believe that the sacrificial layer approach is also ideally suited for membrane applications. Especially as for membranes, the sacrificial layer coating could not only be used for easy cleaning, but could even function as the active separation layer as we discussed in Chapter 1. A schematic representation of this concept on membranes is illustrated in Fig. 2.1.

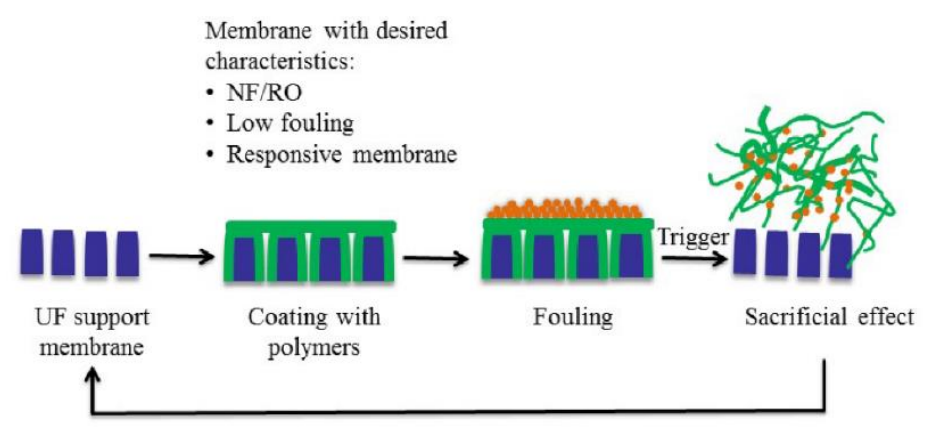

Fig. 2.1: Schematic representation of the application of a thin polymer film onto a UF support membrane and its subsequent use as a "sacrificial layer" to remove fouling. For membranes the sacrificial layer could act double as the effective separating layer to create $N F, R O$ membranes, and/or to create low-fouling and responsive membranes.

To modify the surface of the materials to provide them with the desired properties, a simple and versatile approach is the use of polyelectrolyte layer-by-layer assembly (LbL) $[9,10]$. This approach involves alternatingly dipping of a substrate in a polycation solution and a polyanion solution, typically with an intermediate rinsing step with solvent to remove loosely bound electrolytes from the surface. This LbL approach allows to prepare polyelectrolyte multilayers (PEMs) of just a few nanometers in thickness on 
an interface. The possibility to use a wide range of water soluble polyelectrolytes, its easy application, and the ability to apply it on surfaces of any shape and size are the key strengths of this technique. Since its discovery [10], this technique has been proposed for many applications, including drug delivery, solar sensors, lenses, cell engineering, fuel cells, and membrane processes [11]. For membrane processes the PEMs are always coated onto a membrane support, and have been employed for the preparation of both gas [12] and liquid separating membranes [13]. The key strength of the PEM membranes is the large variety of membrane properties that can be achieved by building in a LbL fashion. As such PEM membranes with a wide variety of properties have been produced for use as reverse osmosis membranes [14], nanofiltration membranes [14-18], solvent resistant nanofiltration (SRNF) membranes [19], forward osmosis membranes [20], low fouling membranes [21-26], antiseptic/antibacterial membranes [22, 26-28], stimuli responsive membranes [8, 29-32] and ion selective membranes [33-36]. Selection of the right combination of polyelectrolytes can also make the membrane sensitive to a certain trigger (such as a change in $\mathrm{pH}$ or salt concentration) that leads to a controlled destruction of these PEMs when required [7, 37-39]. The above shows that PEMs hold much promise for membrane technology, especially in combination with its use as sacrificial layers. For the polymers to be used as sacrificial layers we need to tune the interaction between the polymers.

The use of one or more polymers bearing weak acid/base functionality affords the possibility of controlling the average charge per repeat unit and thus the extent of interaction between charged polymers [38]. Bruening and co-workers [8] have successfully used a PEMs as both a sacrificial layer and as the separating layer of an NF membrane. However, they chose to use the combination of poly(styrene sulfonate) (PSS) and PAH to create their PEM 
based NF membranes, a combination of polyelectrolytes that is known to give extremely stable layers. They could only remove or sacrifice their multilayer by physical means, e.g. backwashing at high pressure. To make the sacrificial layer concept work it is key to have a system that is easy to apply, but also easy to remove. For our sacrificial layer approach, we propose to use a system of weak poly electrolytes of which the charge can be easily controlled by the $\mathrm{pH}$ [7]. For this study a model system of weak polyelectrolytes PAH and PAA was selected (Fig. 2.2). In the PAH/PAA system ( $\mathrm{pK}_{\mathrm{a}} 9.3$ and 5.4 respectively), the dissociation of PAH increases under acidic conditions while the dissociation of PAA increases under basic conditions. Both these sensitivities could be used as triggers to induce PEM desorption.

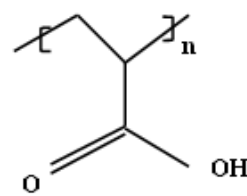

PAA

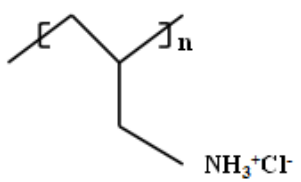

PAH

Fig. 2.2: Polyelectrolytes used for this study PAA poly(acrylic acid) and PAH poly(allyl amine) hydrochloride.

In this chapter, we prepare a PEM membrane, where the PEM functions as a selective NF separation layer and as a sacrificial layer for easy membrane cleaning. Initially the growth of PAA/PAH multilayers on model surfaces is studied by optical fixed angle reflectometry under various amounts of added poly electrolyte to determine the optimal growth conditions for the PEMs. Subsequently different triggers were applied to sacrifice these layers, with and without foulants. This allowed us to understand the buildup and removal of the multilayer systems at different conditions, something that cannot be 
precisely monitored on the membrane itself. Then tight hollow fiber UF membranes were coated with PEMs under identical coating conditions. The membranes were characterized after deposition of each subsequent layer in terms of membrane resistance to pure water permeation and change in zeta potential of membranes. Furthermore, rejection of different solutes was studied to investigate the performance of the layer as a nanofiltration membrane. Then membranes ware subjected to foul with Ludox and when the membranes became fouled, membranes were cleaned with a trigger to release the sacrificial layer, indeed leading to full removal of all foulants. The membrane could then be recoated in a simple manner.

\section{$2.2 \quad$ Experimental}

\subsubsection{Materials}

Polyelectrolytes used in this study were poly(allyl amine) hydrochloride $\left(\mathrm{PAH} ; \mathrm{Mw}=15,000 \mathrm{~g} \cdot \mathrm{mol}^{-1}\right)$ and poly(acrylic acid) $(\mathrm{PAA} ; \mathrm{Mw}=15,000$ $\left.\mathrm{g} \cdot \mathrm{mol}^{-1}\right)$. Silica particles (Ludox SM, radius approximately $9 \mathrm{~nm}$ ) were used as a model fouling agent. Sodium nitrate $\left(\mathrm{NaNO}_{3}\right)$ was used as a background electrolyte in all solutions. All chemicals were obtained from Sigma-Aldrich (The Netherlands) and were used as received without any further purification. Polyelectrolyte solutions always contained $0.1 \mathrm{~g} \cdot \mathrm{l}^{-1}$ of polymer at a $\mathrm{pH}$ of 6 , but with various amounts of background electrolyte $(5 \mathrm{mM}, 50$ $\mathrm{mM}$ or $500 \mathrm{mM} \mathrm{NaNO}$ ). Deionized water (Milli Q, $18.2 \mathrm{M} \Omega \cdot \mathrm{cm}$ ) was used to rinse the membranes and to prepare polyelectrolyte and feed solutions. All solutions were used within eight days after preparation.

\subsubsection{Reflectometry studies of PEMs}

The adsorption and desorption of PEMs and model foulants (silica particles) onto a silica surface was monitored with fixed-angle optical reflectometry. In reflectometry, measurements are performed under well-defined hydrodynamic conditions using a stagnation point flow cell [40]. It is a 
sensitive tool to study the alternating adsorption of different polyelectrolytes on flat, reflective surfaces [41]. The reflectometer is equipped with a $\mathrm{He}-\mathrm{Ne}$ laser (monochromatic light, $\lambda=632.8 \mathrm{~nm}$ ) with linearly polarized light. When this monochromatic light hits the wafer around the Brewster angle $\left(71^{\circ}\right)$, it is reflected towards a detector, where the reflected light is split into its parallel $\left(\mathrm{R}_{\mathrm{p}}\right)$ and perpendicular $\left(\mathrm{R}_{\mathrm{s}}\right)$ polarized components. The ratio between these two components $\left(\mathrm{R}_{\mathrm{p}} / \mathrm{R}_{\mathrm{s}}\right)$ is defined as the signal $S(-)$ and the change in this ratio $(\Delta S)$ is directly proportional to the amount of mass adsorbed on the wafer, according to equation 2.1:

$$
\Gamma=\mathrm{Q}\left(\Delta \mathrm{S} / \mathrm{S}_{0}\right)
$$

Where $\Gamma$ is the amount of mass adsorbed on the silicon wafer $\left(\mathrm{mg} \cdot \mathrm{m}^{-2}\right)$, and where $\mathrm{Q}$ is a sensitivity factor, which depends on the angle of incidence of the laser $(\theta)$, the refractive indices (n), the thicknesses (d) of the layers on the silicon wafer in nanometer, and the refractive index increment $(\mathrm{dn} / \mathrm{dc})$ of the adsorbate. To calculate the Q-factor an optical model was used based upon values as used in our previous study [7]. The Q-factor thus obtained to calculate the actual mass adsorption is $30 \mathrm{mg} \cdot \mathrm{m}^{-2}$ for all of our experiments. $\mathrm{S}_{0}$ is the starting output signal of the bare silicon wafer immersed in solvent (-). All experiments were performed on a silicon wafer with a $85 \mathrm{~nm} \mathrm{SiO}_{2}$ top layer. Before the experiment the silicon surface was cleaned by $\mathrm{O}_{2}$ plasma treatment.

\subsubsection{LbL coating of membranes}

Polyelectrolyte layers were deposited on hollow fiber dense ultrafiltration membranes prepared from poly(ether sulfone) with a sulfonated poly(ether sulfone) separation layer. These so-called Hollow Fiber membranes intended 
for colloidal silica removal were kindly supplied by Pentair X-Flow The Netherlands and have a molecular weight cut-off of 10,000 Da. PEMs were coated on membranes via a dip coating method. For this purpose, fibers were cut into specific lengths (to make bundles) and kept in $15 \mathrm{wt} . \%$ ethanol in water overnight to wet the fibers. After wetting, fibers were rinsed with deionized water three times followed by three times rinsing in the chosen background electrolyte solution $\left(5,50\right.$ or $\left.500 \mathrm{mM} \mathrm{NaNO}_{3}\right)$. For coating, the fibers were completely immersed in $0.1 \mathrm{~g} \cdot 1^{-1}$ polycation solution with the same background electrolyte solution, for 30 minutes, followed by rinsing three times with the used background electrolyte solution. The rinsing step removes any loosely bound or excess polyelectrolyte from the membrane surface. In the same fashion, the polyanion (PAA) layer was adsorbed to give a single bilayer of PAH and PAA. The dipping procedure was then repeated to give the desired number of layers. By dipping the membranes in the coating solution, PE deposition is not only limited to the inner surface of the membrane but also whole the porous structure can be coated. In theory this approach of also coating the inner structure could lead to problems when backflushing, as the polymer released from the inner structure would need to be flushed through the membrane top layer. While we did not observe such problems in our experiments, we still believe that for the real application dynamic coating from the inner side of the hollow fiber is the preferred option. After each coating step a membrane sample was taken for analysis. Membranes coated with the desired number of layers were immersed in a glycerol/water (15wt.\%/85wt.\%) solution for at least 4 hours, followed by a drying step under ambient conditions for at least 8 hours. For filtration experiments, PEM coated membrane fibers were potted in a module with a fiber length of approximately $10 \mathrm{~cm}$. 


\subsubsection{Membrane characterization}

For each prepared membrane, the pure water flux was measured at $20{ }^{\circ} \mathrm{C}$ with demineralized water in a dead-end mode at a trans-membrane pressure of 2.5 bar. From the obtained clear water flux the membrane resistance was calculated using equation 2.2:

$$
\mathrm{R}=\frac{\Delta \mathrm{P}}{\mu \times \mathrm{J}}
$$

Where $\mathrm{R}$ is membrane resistance in $\mathrm{m}^{-1}, \mathrm{~J}$ the membrane flux in $\mathrm{m} \cdot \mathrm{s}^{-1}, \mu$ the dynamic viscosity of the feed in $\mathrm{Pa} \cdot \mathrm{s}$ and $\Delta \mathrm{P}$ the trans-membrane pressure in $\mathrm{Pa}$. The membrane resistance was measured for two separate coating conditions ( $5 \mathrm{mM}$ and $50 \mathrm{mM}$ ), each measurement was performed in triplet.

The membrane performance was investigated by performing retention experiments on salts $\left(\mathrm{NaCl}\right.$ and $\left.\mathrm{Na}_{2} \mathrm{SO}_{4}\right)$ and on a small organic pollutant, sulfamethoxazole $(\mathrm{SMX}) \mathrm{Mw}=253.28 \mathrm{~g} \cdot \mathrm{mol}^{-1}$ with neutral charge. These retention experiments were carried out in a cross-flow mode with a cross flow velocity of $4 \mathrm{~m} \cdot \mathrm{s}^{-1}$ in order to limit the effect of concentration polarization. The transmembrane pressure during filtration was 2 bar. This corresponds to a Reynolds number of approximately 3500 , and is well in the turbulent regime. The salt concentration was measured with a WTW cond 3210 conductivity meter, while the concentration of the organic molecule was measured using a Dionex Ultimate 3000 U-HPLC system equipped with a RS variable wavelength detector. For the organic molecule, the permeate sample was collected after a minimum of 24 hours to ensure steady state rejections. The retention was based on the one minus ratio between the permeate and concentrate concentrations.

The zeta potential measurements were performed with an electrokinetic analyzer SurPASS system (Anton Paar, Graz Austria). The zeta potential 
was calculated by measuring the streaming current versus the pressure in a 5 $\mathrm{mM} \mathrm{KCl}$ solution at room temperature using equation 2.3:

$$
\zeta=\frac{d I}{d P} \frac{\eta}{\varepsilon \varepsilon_{o}} \frac{L_{S}}{A_{S}}
$$

where $\zeta$ is the zeta potential $(\mathrm{V}), \mathrm{I}$ is the streaming current $(\mathrm{A}), \mathrm{P}$ is the pressure $(\mathrm{Pa}), \eta$ is the dynamic viscosity of the electrolyte solution $(\mathrm{Pa} \cdot \mathrm{s}), \varepsilon$ is the dielectric constant of the electrolyte, $\varepsilon_{0}$ is the vacuum permittivity $\left(\mathrm{F} \cdot \mathrm{m}^{-1}\right)$, and $\mathrm{A}_{\mathrm{s}}$ is the cross section of the streaming channel $\left(\mathrm{m}^{2}\right)$.

\subsubsection{Membrane fouling, cleaning and regeneration}

To test the suitability of the PEM as a sacrificial layer, the coated membrane

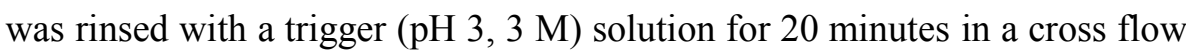
mode with 2 bar pressure. Removal of the coating was investigated by comparing the resistance before and after rinsing. For experiments with a fouled membrane, a feed solution containing Ludox particles (300 mg. $\mathrm{l}^{-1}$ ) was filtered in dead end mode for $20 \mathrm{~h}$ at a pressure of 2.5 bar. Subsequently, the membrane resistance was determined again. After the membrane fouling, the membrane was rinsed with the trigger solution to see if the resistance could be restored to that of the pristine membrane. The rinsing was performed for approximately 20 minutes in a cross flow mode. In a subsequent experiment the membrane was also cleaned with the trigger solution in a back flush mode for about 30 minutes. After these cleaning steps, the PEM coating was regenerated with fresh polyelectrolyte solutions in a cross flow mode. 


\subsection{Results and discussion}

Our results and discussion section is split into three major parts. In the first part, the adsorption and desorption of PAH and PAA multilayers on model surfaces is studied, with and without fouling agents, to determine the optimal coating and cleaning conditions. The second part encompasses the growth of PEM layers on the membrane surface, and describes the performance of the created membranes. In the third and final part we test the PEM as a sacrificial layer for easy membrane cleaning. We stress that the abbreviation PEM refers to Polyelectrolyte Multilayer and not to another common term Polymer Electrolyte Membrane.

\subsubsection{Layer by Layer Coating and layer removal on model surfaces}

\section{Polyelectrolyte multilayer growth}

The preparation of a polyelectrolyte multilayer on a silica surface was measured over time using optical fixed-angle reflectometry. This technique enables the real time continuous monitoring of the adsorbed amount of polymer (in $\mathrm{mg} \cdot \mathrm{m}^{-2}$ ) during exposure to various solutions. Fig. 2.3 (a) shows typical reflectometry data with step by step growth of a PAA and PAH PEMs on a silica surface. The measurement starts by exposure of the silica surface to a solvent solution $(\mathrm{pH} 6,50 \mathrm{mM} \mathrm{NaNO}$ ) and provides the measurement baseline $\left(\mathrm{S}_{0}\right)$. Then switching to a solution containing the weak cationic polymer PAH (denoted with $+, 0.1 \mathrm{~g} \cdot \mathrm{l}^{-1}, \mathrm{pH} 6,50 \mathrm{mM} \mathrm{NaNO}$ ) leads to a small adsorption to the negatively charged silica. Subsequent exposure to the weak negative polymer PAA (denoted with a $-, 0.1 \mathrm{~g} \cdot \mathrm{l}^{-1}, \mathrm{pH}$ $6,50 \mathrm{mM} \mathrm{NaNO}_{3}$ ) leads to an increased adsorbed amount, with the negative PAA adsorbing to the positive PAH. Continued switching between PAH and PAA exposure leads to a stepwise building of the multilayer. In our system, the $\mathrm{pH}$ was kept constant at 6 because at this $\mathrm{pH}$ both polyelectrolytes have a 
similar degree of dissociation and will adsorb in roughly similar amounts $[42]$.

In Fig. 2.3 (b), we show the plateau adsorbed amounts as a function of the adsorbed number of layers. The experiments were done for three different ionic strengths: $5 \mathrm{mM}, 50 \mathrm{mM}$ and $500 \mathrm{mM}$. It is well established that PEM growth and the properties of the resulting layer depend on the ionic strength of the deposition solution and its $\mathrm{pH}[10,42,43]$. In our work, we thus regard the ionic strength as a control parameter to optimize membrane performance and sacrificial layer properties. Indeed, we find large differences in growth behavior for different ionic strengths. At low ionic strength $(5 \mathrm{mM})$, PEMs grow linearly as compared to $50 \mathrm{mM}$ where the layer growth is exponential. Linear growth of PEMs is associated with a low mobility of chains in the layer, while exponential growth is due to the presence of highly mobile chains [44]. However, at the fairly high ionic strength of $500 \mathrm{mM}$ we can see a distinctly different growth feature of these layers. Initially the growth rate is higher than at $5 \mathrm{mM}$ and $50 \mathrm{mM}$ but after a certain number of steps the growth stops. During PAH injection, quite some polymer adsorbs, but this is then followed by desorption with the introduction of the next polymer (PAA). At this high salt concentration, it seems that PAA is able to complex with PAH, but then desorbs as a (quasi) soluble complex. These effects were also observed for other PEM systems [39].

These initial experiments would indicate that the optimal membrane coating conditions would be around $50 \mathrm{mM} \mathrm{NaNO}$. At this ionic strength the growth is exponential, resulting in much thicker films in a smaller number of coating steps than is the case with linearly grown LbL thin films (at $5 \mathrm{mM}$ $\mathrm{NaNO}_{3}$ ). Higher ionic strengths, however, lead to unstable PEMs. Still, the ionic strength could also affect the eventual membrane performance [45] and 
possibly the performance as sacrificial layer. As such both 5 and $50 \mathrm{mM}$ $\mathrm{NaNO}_{3}$ are studied in coming sections.
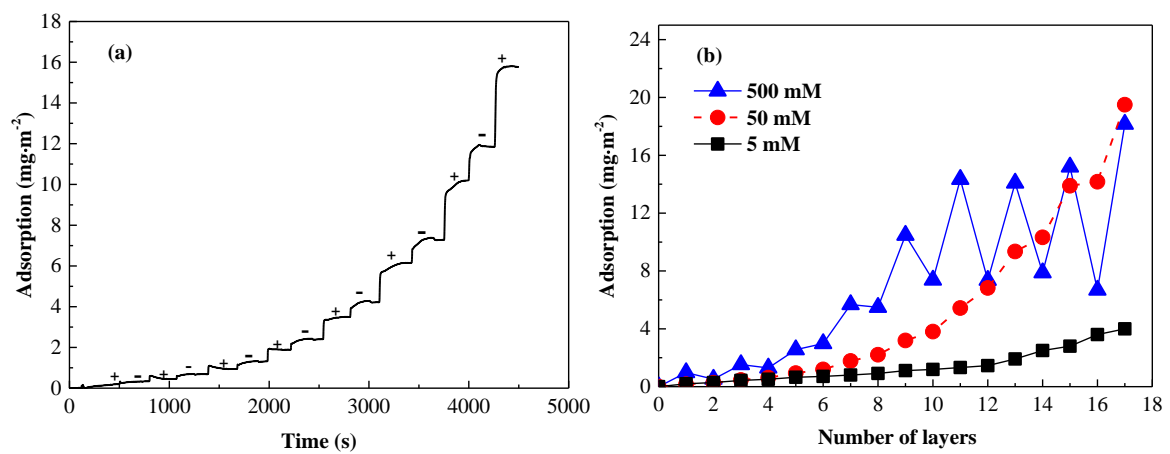

Fig. 2.3: (a) A typical reflectometry graph showing step by step growth of PEMs from PAH (+) and PAA (-) at $0.1 \mathrm{~g} \cdot \mathrm{l}^{-1}$ in $50 \mathrm{mM} \mathrm{NaNO}$ and at $\mathrm{pH}$ 6. (b) Effect of salt concentration on the growth of PEMs monitored with reflectometry; subsequent adsorption of $P A H(+)$ and $P A A$ (-) at $0.1 \mathrm{~g} \cdot l^{-1}$ in $5 \mathrm{mM}, 50 \mathrm{mM}$ and $500 \mathrm{mM} \mathrm{NaNO}$.

\section{Study of triggers for sacrificing PEMs}

For the sacrificial layer approach to be successful, it is key to have a good trigger mechanism to completely desorb the layer. PEMs, depending on the used polyelectrolytes, can be erased by applying external stimuli such as a change in $\mathrm{pH}[7,44,46]$ or an increase in ionic strength [38, 39]. However, the stimuli that will completely remove the fouled PEMs from the membrane surface should not damage the polymeric membrane surface. In previous work [7], PAH/PAA multilayers were desorbed by switching to a $\mathrm{pH}$ of 1 , a trigger unsuitable for membranes. Here we propose to apply, for the first time, the combination of low $\mathrm{pH}$ and high ionic strength to desorb polyelectrolyte multilayers. For this study we did not go below pH 3 because lower $\mathrm{pH}$ might damage the polymer membrane surface. Simultaneously we increased the salt concentration from $0.05 \mathrm{M}$ to $3 \mathrm{M}$, with the results shown in Fig. 2.4. As a reference, we also applied high ionic strength solutions at $\mathrm{pH}$ 6. Only the combination of $\mathrm{pH} 3$ and $3 \mathrm{M}$ of $\mathrm{NaNO}_{3}$ resulted in the 
complete layer removal desired for our application. From these experiments it follows that it is indeed the combination of low $\mathrm{pH}$ and high ionic strength that leads to the complete removal of the layer. At low pH, PAA becomes significantly uncharged, the high ionic strength then further weakens the ionic interactions leading to disintegration of the layer.

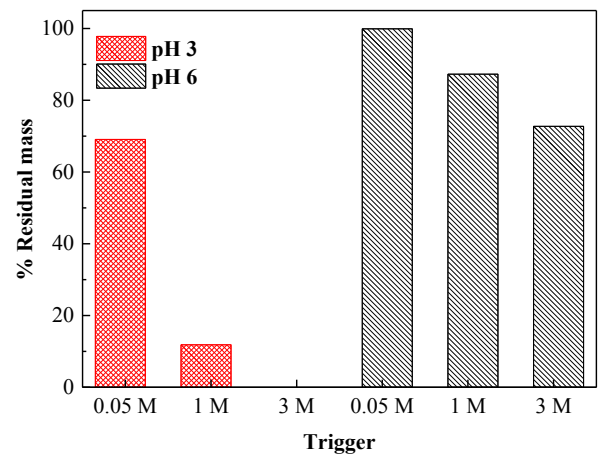

Fig. 2.4: Effect of different triggers on layer mass removal. The investigated layer was $(\mathrm{PAH} / \mathrm{PAA})_{5}$ prepared at $50 \mathrm{mM}, \mathrm{pH} 6$.

\section{Effect of layer mass on the performance as sacrificial layer}

In Fig. 2.5 (a) we show a reflectometry experiment to study PAH/PAA multilayers as a sacrificial layer for easy cleaning. By subsequent adsorption of PAH and PAA we built up the PEMs, ending in this case with a (cationic) PAH layer. Subsequently, we applied a solution containing our model fouling agent, Ludox silica particles $\left(0.1 \mathrm{~g} \cdot 1^{-1}\right.$ Ludox, $\mathrm{pH}$ 6, $\left.50 \mathrm{mM} \mathrm{NaNO}{ }_{3}\right)$, which are spherical silica particles approximately $9 \mathrm{~nm}$ in radius, on top of the PAH layer. As can be seen, these particles lead to a large increase in the adsorbed amount. However, when rinsed with a $\mathrm{pH} 3,3 \mathrm{M}$ solution the adsorbed PEMs, along with the fouling agent, are desorbed from the silicon wafer surface again, demonstrating the potential of these PEMs as a sacrificial coating. We applied this trigger for a different number of layers having fouling agent adsorbed on top and after applying the trigger solution 
we investigated the remaining layer mass. Fig. 2.5 (b) shows the effect of the number of PAH and PAA layers on the residual adsorbed amount, for two different coating conditions, $5 \mathrm{mM} \mathrm{NaNO}$ and $50 \mathrm{mM} \mathrm{NaNO}_{3}$. At both coating conditions the residual adsorption decreases with an increasing number of layers. For polyelectrolyte layers built at low salt concentration, 5.5 bilayers (PAH/PAA) are sufficient to obtain complete desorption.
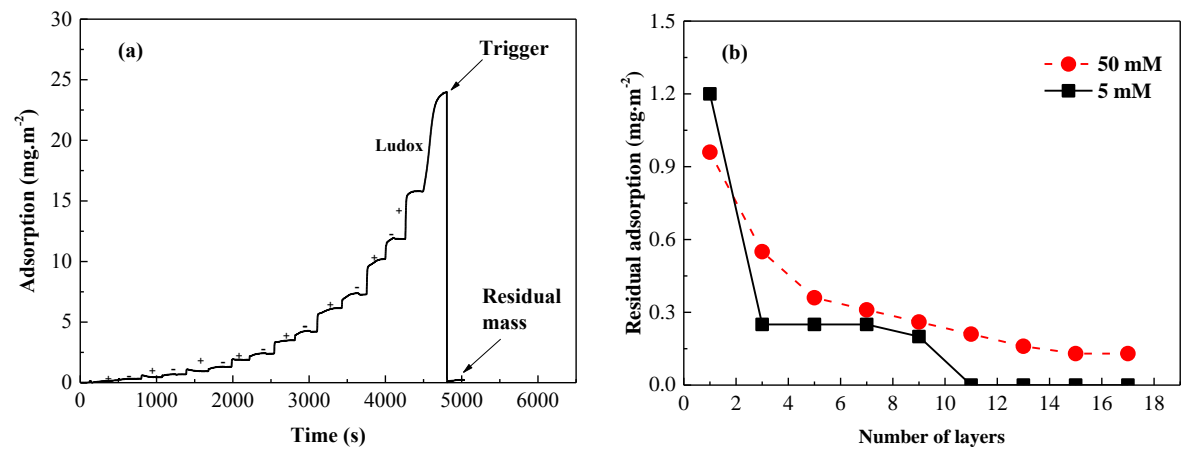

Fig. 2.5: (a) Adsorption and desorption of PAH, PAA and Ludox particles $\left(0.1 \mathrm{~g} \cdot \mathrm{l}^{-1}, \mathrm{pH}\right.$ 6, 5 $m \mathrm{M} \mathrm{NaNO}_{3}$ ) on model surfaces as studied with reflectometry. (b) The residual adsorption of Ludox particles after desorption of the sacrificial PEMs as a function of the number of layers.

Here the role of the number of layers (layer mass) on the performance as a sacrificial layer is important to consider because the polyelectrolytes that are released into the solution upon destruction of the layers are expected to act as so-called anti-redeposition agents. By adsorbing to the released fouling agents they act to prevent possible re-adsorption of the fouling agents on the surface [7].

However other than layer mass, we can also see the role of the layer structure on the sacrificial layer performance. For an ionic strength of 50 $\mathrm{mM}$ the residual adsorbed amount decreases with increasing layer mass but complete desorption is never obtained. A very small amount $\left(0.1 \mathrm{mg} \cdot \mathrm{m}^{-2}\right)$ is left on the surface. We hypothesize that this is because of the high mobility of the polymer chains in this layer, connected to the exponential growth 
regime at this ionic strength. Such mobility would allow some of the highly charged silica particles to penetrate into the layer and to reach the interface. Still, the remaining adsorbed amount is very low. Our results indicate that both the 5 and the $50 \mathrm{mM}$ grown PAA/PAH PEMs have the potential to function as a sacrificial layer coating on membranes.

\subsubsection{Formation and properties of a polyelectrolyte multilayer membrane}

After optimizing the coating and release conditions for PEMs with reflectometry, negatively charged UF membranes were coated with PAH/PAA multilayers via a dip coating method. Change in water permeance $\left(1 \cdot \mathrm{m}^{-2} \cdot \mathrm{h}^{-1} \cdot \mathrm{bar}^{-1}\right)$ through the membrane after deposition of the layer is one of the ways to see if the PEMs are being deposited. Reduction in permeability with every deposited layer (mass) corresponds to an increase in the membrane hydraulic resistance (equation 2.1). To confirm the deposition of PEMs on membranes the hydraulic resistance of the membrane was measured after every deposited layer. In Fig. 2.6 we show the effect of coating the HFS membranes at different ionic strengths on the membrane resistance. Here we can observe increase in resistance with each increment in PEM. Based upon the results of the reflectometry data we coated the membranes under two salt concentrations $5 \mathrm{mM}$ and $50 \mathrm{mM}$. A significant effect of the ionic strength on the membrane resistance can be observed. At higher ionic strength of the coating solution, the membrane resistance per bilayer increases much stronger than the resistance at the lower ionic strength. This is completely in line with the reflectometry data in Fig. 2.3 (b). At higher ionic strengths, thicker layers are formed on the membrane due to increased extrinsic charge compensation within the multilayers. These thicker layers result a higher membrane resistance [45]. Here we also observe a zig-zag behavior which is related to the odd-even effect. Other 
than coating conditions, the properties of the total PEM are also dependent on the terminating-layer. The changes with respect to the different terminating layers are often referred to as odd-even effects. One well established odd-even effect is that the hydration of a PEM depends on the final layer being either the polycation or the polyanion. As shown by de Grooth et al [45] the observed odd-even effect in resistance can give information on the structure of the layer. If the PEM is predominately coated inside of the pores (pore dominated regime), swelling of the PEM layer will narrow the pore and lead to a clear increase in resistance. However, if the PEM forms a dense layer on top of the membrane (layer dominated regime), an increase in hydration (swelling) will actually lead to a more permeable layer and thus a lower resistance.

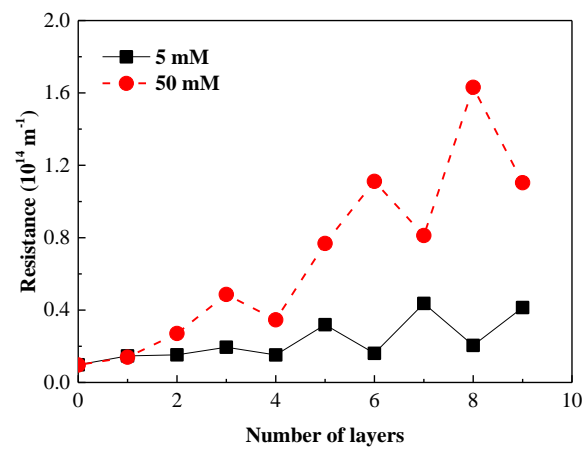

Fig. 2.6: Membrane resistance against pure water permeation for PEMs coated on a UF membrane support as a function of the number of deposited layers. All data are for a polyelectrolyte concentration of $0.1 \mathrm{~g} \cdot \mathrm{l}^{-1}, \mathrm{pH}$, and at a salt concentration of either $5 \mathrm{mM}$ or $50 \mathrm{mM}$; as indicated.

For the membrane formed at $5 \mathrm{mM}$, we always observed an increase in the resistance upon PAH adsorption and a decrease in the resistance upon adsorption of PAA. This would indicate that this membrane is always in the pore dominated regime. However for $50 \mathrm{mM}$, much thicker PEM layers are formed. Here we observed a clear transition (at layer 5) from PAH giving the highest resistance, to PAA giving the highest resistance. This would indicate 
a transition from the pore dominated regime to the layer dominated regime, as also observed by de Grooth et al. [45] for PDADMAC/PSS multilayers. For potential use as a sacrificial layer, it is likely to be beneficial to be in the layer dominated regime, as it would prevent any potential fouling agents from entering the membrane pores. Based on our reflectometry data (Fig. $2.3 \mathrm{a}$ ), we know that we have about $1.7 \mathrm{mg} \cdot \mathrm{m}^{-2}$ of polymer after 5 coating steps. With a typical PEM hydration of 50\%, this would correspond to a layer thickness of roughly $3 \mathrm{~nm}$. For our dense UF membranes, a layer of such a thickness could indeed fully fill its pores, with subsequent coating being only possible on top of the membrane.

To test the stability and compressibility of our PEM membranes, we measured the resistance of a 10 layer PEM (deposited at $50 \mathrm{mM} \mathrm{NaNO}_{3}, \mathrm{pH}$ $6)$ at multiple pressures $(5,10,15,20,25$ and 30 bar). We did not find any significant changes in resistance even at the highest pressures, and from that conclude that the layers are stable and not compressible at this range of pressures.

The zeta potential of the surface of the membranes was investigated after each coating step (Fig. 2.7a). As expected, charge reversal of the negatively charged membrane was observed after coating with a positively charged PAH (layer 1). Subsequently, after each additional layer the charge shifts from positive to negative and back.

These results are exactly what was expected for the formation of a PEM on the membrane and is another clear indication of a successfully applied coating. As we also want to desorb these PEMs made from weak polyelectrolytes by changing the $\mathrm{pH}$, we also investigated the effect of the surrounding $\mathrm{pH}$ after coating on the zeta potential of the $14^{\text {th }}$ layer (Fig. 2.7(b)). As expected, for the set of weak polyelectrolytes, also the zeta 
potential of the layer depends strongly on the solution $\mathrm{pH}$. At a $\mathrm{pH}$ of 2-3 the zeta potential becomes 0 , indicating that the final PAA layer is becoming uncharged.
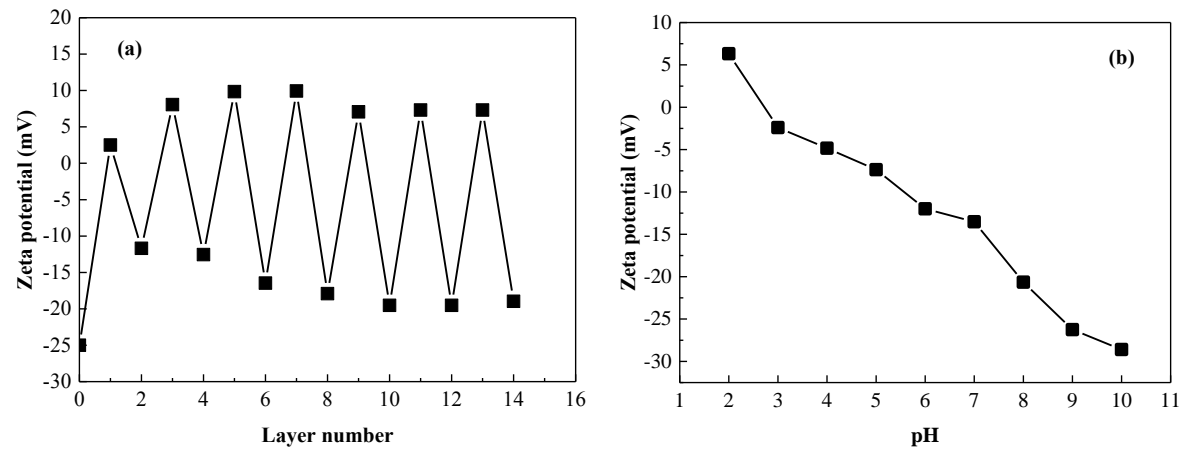

Fig. 2.7: (a) The membrane zeta potential as measured after every deposited layer. The membrane was coated with $0.1 \mathrm{~g}^{-1} \mathrm{PAH}$ and $\mathrm{PAA}$ at $\mathrm{pH}$ 6, $50 \mathrm{mM} \mathrm{NaNO}$, the experiment was performed at $\mathrm{pH} 6,5 \mathrm{mM} \mathrm{KCl}$. (b) Zeta potential as a function of the surrounding $\mathrm{pH}$ for a PEM of $(\mathrm{PAH} / \mathrm{PAA})_{7}$, prepared at $50 \mathrm{mM} \mathrm{NaNO}$, $\mathrm{pH}$ 6, experiment performed at $5 \mathrm{mM}$ $\mathrm{KCl}$.

In Fig. 2.8 we show the rejection performance of $\mathrm{PAA} / \mathrm{PAH}$ polyelectrolyte multilayer membranes prepared under two coating conditions, $5 \mathrm{mM}$ and 50 $\mathrm{mM}$ of $\mathrm{NaNO}_{3}$. The membranes were coated with 9 layers (4.5 bi-layers). The membrane thus has a small positive zeta potential (Fig. 2.7a) as the final layer is the cationic PAH. We investigated the rejection of monovalent ions $(\mathrm{NaCl})$, a divalent ion $\left(\mathrm{Na}_{2} \mathrm{SO}_{4}\right)$ ion and an uncharged small organic molecule, the pharmaceutically active compound $\mathrm{SMX}(\mathrm{Mw}=253.28 \mathrm{Da})$. We observe that monovalent ions can relatively easily pass the prepared membranes, while the divalent ion and SMX show a much higher rejection. The prepared membranes thus perform as typical nanofiltration membranes, allowing the passage of monovalent ions, while rejecting divalent ions and small organics. The rejection performance for the membranes prepared 
under different coating conditions are quite similar. Still, the rejection of the membranes prepared at $5 \mathrm{mM}$ is somewhat higher for all solutes. Polyelectrolyte multilayers prepared at lower ionic strength are known to have lower hydrations [44], leading to thinner and less open layers that can provide better retention behavior [45]. The rejection of the solutes by NF membranes is typically described by taking size, charge, valence and dielectric exclusion into account [47 ]. For a positively charged membrane a lower retention would be expected for $\mathrm{Na}_{2} \mathrm{SO}_{4}$ compared to $\mathrm{NaCl}$ when charge exlusion (Donnan) would be prevalent. As this is not the case here, we believe the rejection mechanism is mostly governed by size exclusion. Still, other separation mechanisms can play a role as well.

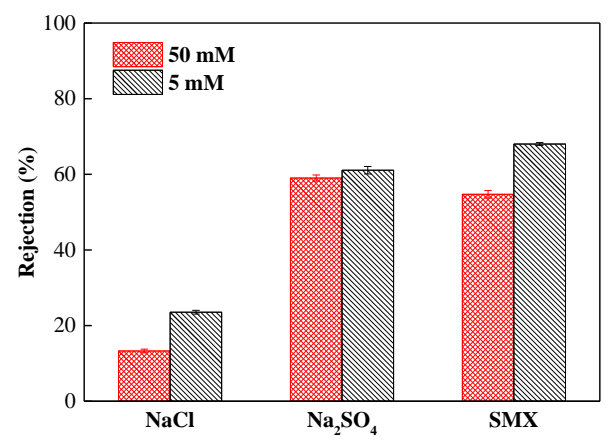

Fig. 2.8: Solute rejection by $(P A H / P A A)_{4} P A H$ polyelectrolyte multilayer membranes prepared under different coating conditions, as indicated.

\subsubsection{The polyelectrolyte multilayer as a sacrificial layer for easy membrane cleaning}

In the previous section, we clearly demonstrated that one can prepare PAH/PAA polyelectrolyte multilayer membranes with the typical characteristics of a NF membrane. Here we will investigate the possibility to use the same PEM coating as a sacrificial layer for easy cleaning of fouled membranes. Initially it was investigated whether the coating was fully 
removable by rinsing a coated membrane $\left((\mathrm{PAH} / \mathrm{PAA})_{3} \mathrm{PAH}\right.$, prepared at 50 $\mathrm{mM} \mathrm{NaNO}_{3}$ ) with the chosen trigger solution ( $\mathrm{pH} 3,3 \mathrm{M} \mathrm{NaNO}$ ) in a cross flow mode at very low pressure ( 2 bar) for a short duration of time (20 minutes). After this rinsing step the membrane resistance reached exactly the level of an uncoated UF membrane confirming the complete removal of the PEM from the membrane surface. We subsequently investigated if the removal of our sacrificial coating could indeed be used to remove foulants from the membrane. In Fig. 2.9 we show the membrane resistance against pure water permeation for several steps, including PEM coating, membrane fouling by silica particles, membrane cleaning by sacrificing the PEM coating and subsequent re-coating. Here we applied the same rinsing step for PEM removal, but only rinsing could not completely remove the fouled PEM and an additional backwashing step with the same cleaning solution was incorporated. Backwashing with the cleaning solution for 30 minutes resulted in a decrease in the membrane resistance up to one that is nearly identical to the resistance of the uncoated membrane.

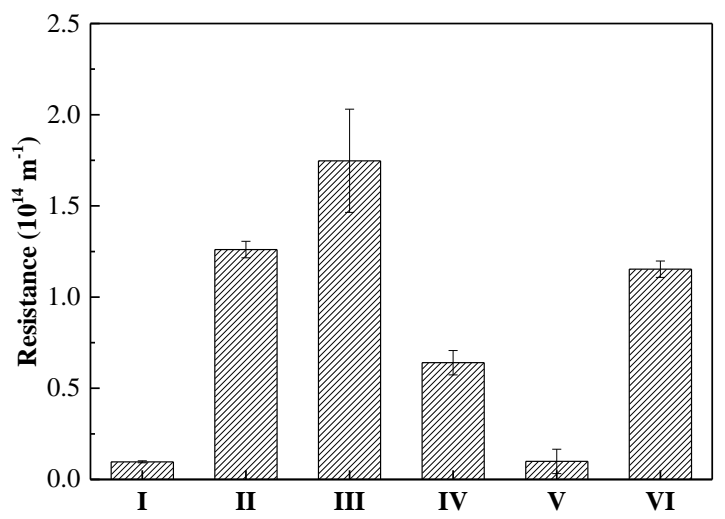

Fig. 2.9: Measured membrane resistance to pure water permeation after the following steps (I) a clean UF support membrane; (II) UF membrane coated with PEMs; (III) PEMs fouling with Ludox particles; (IV) rinsing of fouled PEMs with cleaning solution for 20 minutes; (V) backwashing of fouled PEMs with cleaning solution at 2 bar pressure for 30 minutes; (VI) regeneration of PEMs on cleaned UF membrane support 
If we compare these results with our reflectometry data (Fig. 2.5 (b)), we find that for the same number of coated layers (7), rinsing our model surface with a trigger solution did not result in the complete removal of all foulants. On the membrane, the application of shear forces aid to completely remove the PEM along with any attached foulants. Interestingly, the sacrificial layer approach is thus found to work better on the membrane interface than on the model surfaces due to the added possibility of backwashing. After backwashing a PEM re-coating was performed. As the hollow fibers were already potted in a module, the recoating was performed in a cross flow mode. After coating with the same number of layers the original PEM layer resistance is obtained again.

\subsection{Conclusions}

In this chapter we demonstrate the preparation of a PAA/PAH multilayer that, when coated on a UF membrane support, doubles as a nanofiltration membrane and a sacrificial layer to allow easy cleaning of the membrane. The optimal conditions for layer coating and layer removal were first studied on model surfaces using optical reflectometry. When coating with a background electrolyte concentration of $5 \mathrm{mM} \mathrm{NaNO}_{3}$, a typical linear growth regime is observed for the PAA/PAH multilayers. At a higher ionic strength of $50 \mathrm{mM}$, thicker layers are formed per coating step and a typical exponential growth regime is observed. However, at an even higher ionic strength $(500 \mathrm{mM})$, stable layers could not be coated. Complete desorption of the formed PEM layers could be achieved by combining a high ionic strength $\left(3 \mathrm{M} \mathrm{NaNO}_{3}\right)$, with a low $\mathrm{pH}$ of 3 . However, in combination with model fouling agents (small silica particles) a relatively large amount of polyelectrolyte layers $(>10)$ is needed to obtain complete or near complete fouling removal. 
Upon coating of the PAA/PAH multilayers on a charged UF support membrane, a clear increase in the membrane resistance against pure water permeation is observed. Coating at $50 \mathrm{mM} \mathrm{NaNO}_{3}$ leads to a much stronger increase in resistance compared to coating at $5 \mathrm{mM}$, in line with the reflectometry experiments that showed much thicker layers to form at higher ionic strength. Another proof of successful LbL coating of the membrane support comes from zeta-potential measurements, which demonstrate a clear switching between a positive and a negative zeta-potential after coating of the respective negative and positive polyelectrolytes. The formed polyelectrolyte multilayer membranes, were found to reject solutes in a way typical for nanofiltration membranes: Monovalent ions $(\mathrm{NaCl})$ are hardly rejected, while for a neutral organic molecule such as SMX and for the divalent ion $\mathrm{SO}_{4}{ }^{2-}$ rejections of around $60 \%$ were achieved. The basis for separation is expected to be size exclusion, as the investigated membrane was positively charged and still rejected both the negatively charged $\mathrm{SO}_{4}{ }^{2-}$ and an uncharged small organic molecule.

Finally, the prepared polyelectrolyte multilayer membrane was fouled with silica nanoparticles. Subsequent release of the coating using a rinse and a backwash with $\mathrm{pH} 3,3 \mathrm{M} \mathrm{NaNO}_{3}$ resulted in almost all recovery of the membrane resistance nearly equal to that of the pristine membrane. The support membrane could then easily be recoated to give the resistance typical for the polyelectrolyte multilayer membrane. This is the first clear evidence that in membrane technology a PEMs can be used to provide a double function, as a nanofiltration membrane and as a sacrificial coating to allow easy membrane cleaning. Interestingly, less layers were needed to obtain complete foulant removal from the membrane, than was the case for the model surface. The possibility for backwashing and the resulting shear 
forces allow for an even more successful use of the sacrificial layer approach.

\section{Acknowledgements}

Authors would like to thank the European Commission - Education, Audiovisual and Culture Executive Agency (EACEA) for funding this research under the program named Erasmus Mundus Doctorate in Membrane Engineering $\quad-$ EUDIME $\quad\left(\right.$ FPA $\quad N^{\circ}$ 2011-0014, $\quad 3^{\text {rd }}$ Edition, http://eudime.unical.it/). We also thank Pentair X-Flow, The Netherlands, for kindly supplying the membranes. 


\section{References}

[1] Z. Wu, H. Chen, Y. Dong, H. Mao, J. Sun, S. Chen, V.S.J. Craig, J. Hu, Cleaning using nanobubbles: Defouling by electrochemical generation of bubbles, Journal of Colloid and Interface Science, 328 (2008) 10-14.

[2] C. Zhao, J. Xue, F. Ran, S. Sun, Modification of polyethersulfone membranes A review of methods, Progress in Materials Science, 58 (2013) 76-150.

[3] R.W. Baker, Membrane Technology and Applications, John Wiley \& Sons Ltd, West Sussex, (2004).

[4] K. Holmberg, B. Jonsson, B. Kronberg, B. Lindman, Surfactants and Polymers in Aqueous Solution Wiley, West Sussex, (2002).

[5] E. Celia, T. Darmanin, E. Taffin de Givenchy, S. Amigoni, F. Guittard, Recent advances in designing superhydrophobic surfaces, Journal of Colloid and Interface Science, 402 (2013) 1-18.

[6] O. Azzaroni, Polymer brushes here, there, and everywhere: Recent advances in their practical applications and emerging opportunities in multiple research fields, Journal of Polymer Science Part A: Polymer Chemistry, 50 (2012) 3225-3258.

[7] W.M. de Vos, A. de Keizer, M.A.C. Stuart, J.M. Kleijn, Thin polymer films as sacrificial layers for easier cleaning, Colloids and Surfaces A: Physicochemical and Engineering Aspects, 358 (2010) 6-12.

[8] W. Shan, P. Bacchin, P. Aimar, M.L. Bruening, V.V. Tarabara, Polyelectrolyte multilayer films as backflushable nanofiltration membranes with tunable hydrophilicity and surface charge, Journal of Membrane Science, 349 (2010) 268 278.

[9] G. Decher, M. Eckle, J. Schmitt, B. Struth, Layer-by-layer assembled multicomposite films, Current Opinion in Colloid \& Interface Science, 3 (1998) 32 39.

[10] G. Decher, J.D. Hong, J. Schmitt, Buildup of ultrathin multilayer films by a self-assembly process: III. Consecutively alternating adsorption of anionic and cationic polyelectrolytes on charged surfaces, Thin Solid Films, 210-211, Part 2 (1992) 831-835.

[11] O. Sanyal, I. Lee, Recent Progress in the Applications of Layer-By-Layer Assembly to the Preparation of Nanostructured Ion-Rejecting Water Purification Membranes, Journal of Nanoscience and Nanotechnology, 14 (2014) 2178-2189.

[12] D.M. Sullivan, M.L. Bruening, Ultrathin, Gas-Selective Polyimide Membranes Prepared from Multilayer Polyelectrolyte Films, Chemistry of Materials, 15 (2002) 281-287.

[13] N. Joseph, P. Ahmadiannamini, R. Hoogenboom, I.F.J. Vankelecom, Layer-bylayer preparation of polyelectrolyte multilayer membranes for separation, Polymer Chemistry, 5 (2014) 1817-1831. 
[14] W. Jin, A. Toutianoush, B. Tieke, Use of Polyelectrolyte Layer-by-Layer Assemblies as Nanofiltration and Reverse Osmosis Membranes, Langmuir : the ACS journal of surfaces and colloids, 19 (2003) 2550-2553.

[15] B.W. Stanton, J.J. Harris, M.D. Miller, M.L. Bruening, Ultrathin, Multilayered Polyelectrolyte Films as Nanofiltration Membranes, Langmuir : the ACS journal of surfaces and colloids, 19 (2003) 7038-7042.

[16] M.D. Miller, M.L. Bruening, Controlling the Nanofiltration Properties of Multilayer Polyelectrolyte Membranes through Variation of Film Composition, Langmuir : the ACS journal of surfaces and colloids, 20 (2004) 11545-11551.

[17] S.U. Hong, M.D. Miller, M.L. Bruening, Removal of Dyes, Sugars, and Amino Acids from $\mathrm{NaCl}$ Solutions Using Multilayer Polyelectrolyte Nanofiltration Membranes, Industrial \& Engineering Chemistry Research, 45 (2006) 6284-6288.

[18] B. Su, T. Wang, Z. Wang, X. Gao, C. Gao, Preparation and performance of dynamic layer-by-layer PDADMAC/PSS nanofiltration membrane, Journal of Membrane Science, 423-424 (2012) 324-331.

[19] P. Ahmadiannamini, X. Li, W. Goyens, N. Joseph, B. Meesschaert, I.F.J. Vankelecom, Multilayered polyelectrolyte complex based solvent resistant nanofiltration membranes prepared from weak polyacids, Journal of Membrane Science, 394-395 (2012) 98-106.

[20] C. Qiu, S. Qi, C.Y. Tang, Synthesis of high flux forward osmosis membranes by chemically crosslinked layer-by-layer polyelectrolytes, Journal of Membrane Science, 381 (2011) 74-80.

[21] C. Ba, D.A. Ladner, J. Economy, Using polyelectrolyte coatings to improve fouling resistance of a positively charged nanofiltration membrane, Journal of Membrane Science, 347 (2010) 250-259.

[22] B.P. Tripathi, N.C. Dubey, M. Stamm, Functional polyelectrolyte multilayer membranes for water purification applications, Journal of Hazardous Materials, 252-253 (2013) 401-412.

[23] F. Diagne, R. Malaisamy, V. Boddie, R.D. Holbrook, B. Eribo, K.L. Jones, Polyelectrolyte and Silver Nanoparticle Modification of Microfiltration Membranes To Mitigate Organic and Bacterial Fouling, Environmental Science \& Technology, 46 (2012) 4025-4033.

[24] Y. Kouwonou, R. Malaisamy, K.L. Jones, Modification of PES Membrane: Reduction of Biofouling and Improved Flux Recovery, Separation Science and Technology, 43 (2008) 4099-4112.

[25] L. Tang, W. Gu, P. Yi, J.L. Bitter, J.Y. Hong, D.H. Fairbrother, K.L. Chen, Bacterial anti-adhesive properties of polysulfone membranes modified with polyelectrolyte multilayers, Journal of Membrane Science, 446 (2013) 201-211.

[26] I. Sawada, R. Fachrul, T. Ito, Y. Ohmukai, T. Maruyama, H. Matsuyama, Development of a hydrophilic polymer membrane containing silver nanoparticles 
with both organic antifouling and antibacterial properties, Journal of Membrane Science, 387-388 (2012) 1-6.

[27] M. Ben-Sasson, X. Lu, E. Bar-Zeev, K.R. Zodrow, S. Nejati, G. Qi, E.P. Giannelis, M. Elimelech, In situ formation of silver nanoparticles on thin-film composite reverse osmosis membranes for biofouling mitigation, Water Research, 62 (2014) 260-270.

[28] X. Zan, Z. Su, Polyelectrolyte multilayer films containing silver as antibacterial coatings, Thin Solid Films, 518 (2010) 5478-5482.

[29] N. Wang, G. Zhang, S. Ji, Z. Qin, Z. Liu, The salt-, pH- and oxidant-responsive pervaporation behaviors of weak polyelectrolyte multilayer membranes, Journal of Membrane Science, 354 (2010) 14-22.

[30] Y. Cho, J. Lim, K. Char, Layer-by-layer assembled stimuli-responsive nanoporous membranes, Soft Matter, 8 (2012) 10271.

[31] D. Wandera, S.R. Wickramasinghe, S.M. Husson, Stimuli-responsive membranes, Journal of Membrane Science, 357 (2010) 6-35.

[32] J. de Grooth, M. Dong, W.M. de Vos, K. Nijmeijer, Building PolyzwitterionBased Multilayers for Responsive Membranes, Langmuir : the ACS journal of surfaces and colloids, 30 (2014) 5152-5161.

[33] L. Ouyang, R. Malaisamy, M.L. Bruening, Multilayer polyelectrolyte films as nanofiltration membranes for separating monovalent and divalent cations, Journal of Membrane Science, 310 (2008) 76-84.

[34] S.U. Hong, L. Ouyang, M.L. Bruening, Recovery of phosphate using multilayer polyelectrolyte nanofiltration membranes, Journal of Membrane Science, 327 (2009) $2-5$.

[35] C. Magnenet, F.E. Jurin, S. Lakard, C.C. Buron, B. Lakard, Polyelectrolyte modification of ultrafiltration membrane for removal of copper ions, Colloids and Surfaces A: Physicochemical and Engineering Aspects, 435 (2013) 170-177.

[36] C. Magnenet, S. Lakard, C.C. Buron, B. Lakard, Functionalization of organic membranes by polyelectrolyte multilayer assemblies: Application to the removal of copper ions from aqueous solutions, Journal of Colloid and Interface Science, 376 (2012) 202-208.

[37] D.M. Lynn, Peeling Back the Layers: Controlled Erosion and Triggered Disassembly of Multilayered Polyelectrolyte Thin Films, Advanced Materials, 19 (2007) 4118-4130.

[38] S.T. Dubas, J.B. Schlenoff, Polyelectrolyte Multilayers Containing a Weak Polyacid: Construction and Deconstruction, Macromolecules, 34 (2001) 3736-3740. [39] D. Kovacevic, S. van der Burgh, A. de Keizer, M.A. Cohen Stuart, Kinetics of Formation and Dissolution of Weak Polyelectrolyte Multilayers: Role of Salt and Free Polyions, Langmuir : the ACS journal of surfaces and colloids, 18 (2002) 56075612. 
[40] J.C. Dijt, M.A.C. Stuart, J.E. Hofman, G.J. Fleer, Kinetics of polymer adsorption in stagnation point flow, Colloids and Surfaces, 51 (1990) 141-158.

[41] J.C. Dijt, M.A.C. Stuart, G.J. Fleer, Reflectometry as a tool for adsorption studies, Advances in Colloid and Interface Science, 50 (1994) 79-101.

[42] S.S. Shiratori, M.F. Rubner, pH-Dependent Thickness Behavior of Sequentially Adsorbed Layers of Weak polyelectrolytes, Macromolecules, 33 (2000) 4213-4219.

[43] J.B. Schlenoff, H. Ly, M. Li, Charge and Mass Balance in Polyelectrolyte Multilayers, Journal of the American Chemical Society, 120 (1998) 7626-7634.

[44] R. v. Klitzing, Internal structure of polyelectrolyte multilayer assemblies, Physical Chemistry Chemical Physics, 8 (2006) 5012-5033.

[45] J. de Grooth, R. Oborný, J. Potreck, K. Nijmeijer, W.M. de Vos, The role of ionic strength and odd-even effects on the properties of polyelectrolyte multilayer nanofiltration membranes, Journal of Membrane Science, 475 (2015) 311-319.

[46] S.A. Sukhishvili, S. Granick, Layered, Erasable Polymer Multilayers Formed by Hydrogen-Bonded Sequential Self-Assembly, Macromolecules, 35 (2001) 301310.

[47] J. de Grooth, D.M. Reurink, J. Ploegmakers, W.M. de Vos, K. Nijmeijer, Charged Micropollutant Removal With Hollow Fiber Nanofiltration Membranes Based On Polycation/Polyzwitterion/Polyanion Multilayers, ACS applied materials \& interfaces, 6 (2014) 17009-17017. 


\section{Weak polyelectrolyte multilayers based NF membranes for micro-pollutant removal}

This chapter has been submitted for publication as:

Weak polyelectrolyte multilayers as tunable separation layers for micro-pollutant removal by hollow fiber nanofiltration membranes, authored by Shazia Ilyas, Mehran Abtahi, Namik Akkilic, H.D.W. Roesink and Wiebe M. de Vos. 


\section{Abstract}

The presence of micro-pollutants in wastewater and in drinking water and its sources, is posing both environmental and health concerns. This work describes the development of weak polyelectrolyte multilayer (PEM) based hollow fiber nanofiltration (NF) membranes to remove micro-pollutants from aqueous sources. The charge density of weak polyelectrolytes (PEs) can be controlled by the $\mathrm{pH}$ of the coating solution, providing an additional parameter to tune the performance of the prepared membranes. In this study, PEMs of weak PEs poly(allylamine hydrochloride) (PAH) and poly(acrylic acid) (PAA) were coated in a layer by layer (LbL) fashion on top of an ultrafiltration support to obtain PEM based NF membranes. Before coating the membranes, the role of the $\mathrm{pH}$ during coating on the buildup of multilayers was studied on model surfaces via reflectometry. Detailed investigations were then carried out on the membrane performance, by studying the pure water permeability, salt retention $\left(\mathrm{NaCl}, \mathrm{CaCl}_{2}\right.$ and $\left.\mathrm{Na}_{2} \mathrm{SO}_{4}\right)$ and the retention of micro-pollutants of varying size $\left(\sim 200-400 \mathrm{~g} \cdot \mathrm{mol}^{-1}\right)$, charge and hydrophilicity. Variation of the coating $\mathrm{pH}$ provided a large degree of control over the separation performance of the weak PEM based membranes. The rejection was found to be dominated by size exclusion together with Donnan exclusion. A PEM membrane prepared at $\mathrm{pH} 6$ showed a high micro-pollutant retention (60-80\%) while showing only low ion retentions. Such a membrane would be well suited to reduce the problem of micro-pollutants, without significant alteration of the ionic composition of the feed. 


\subsection{Introduction}

Over the past few decades, the occurrence of micro-pollutants in aquatic environments around the world has become a serious environmental concern, and is posing a new challenge to the scientific community. Micro-pollutants, also termed emerging contaminants (ECs), are low molecular weight compounds (Mw between 100-1000 Da) and cover a broad range of synthetic chemicals (i.e. pesticides, pharmaceuticals, personal and household care products, cosmetics, and industrial chemicals), which are essential to modern human society [1]. Currently more than a million synthetic chemicals are registered in Europe [2], many of which will find their way into the environment at some stage in their life cycle. The presence of micro-pollutants in the surface and the ground water in many countries around the globe has been reported by several studies [3-14]. Generally, these micro-pollutants are only present in very low concentrations (from few $\mathrm{ng} \cdot \mathrm{l}^{-1}$ to several $\mu \mathrm{g} \cdot \mathrm{l}^{-1}$ ), but their continuous and unregulated build-up in the environment do affect surface and ground water quality which can potentially impact aquatic life, but also drinking water supplies and human health [15].

Conventional wastewater treatment plants based upon an activated sludge process are considered to be a hot spot for the release of micro-pollutants into the environment $[16,17]$, as these wastewater treatment facilities were never designed for micro-pollutant removal. However, applying advanced treatment methods such as oxidation ( $\mathrm{UV}-\mathrm{H}_{2} \mathrm{O}_{2}, \mathrm{O}_{3}-\mathrm{H}_{2} \mathrm{O}_{2}$ ), adsorption and membrane processes as a polishing step, just before discharging the treated effluent of wastewater plants, could significantly reduce the micro-pollutant load into the water bodies. Though the capital and operational cost of advanced treatment methods can be high due to increased energy demands or due to the consumption of chemicals, upcoming more stringent regulations are expected to make these techniques much more common place. An additional 
complication, is that due to their diverse nature (chemical structure, solubility, charge and hydrophobicity/hydrophilicity) a single advanced treatment method might not be suitable for removing all types of micro-pollutants. However by employing a combination of these techniques full removal could be achieved, although for this purpose the advanced techniques need to be flexible, simple and as cheap as possible. For these reasons, membrane based treatment methods, especially nanofiltration (NF) and reverse osmosis (RO), are becoming a much more common technology in water-treatment facilities [18]. Membrane based processes show great potential for the removal of micro-pollutants with several advantages such as easy scale-up and high product quality, but also some disadvantages such as cost and fouling [19]. Among membrane based methods, $\mathrm{RO}$ has already proven to be successful for micro-pollutant removal, however the high energy demand of RO and the associated costs are a limiting factor. Moreover, RO treatment not only removes all micro-pollutants, but also all ions, and these ions need to be added again later in the process to be able to use the water for consumption or irrigation purposes.

Due to their low operating pressures, NF membranes are considered as a cheaper and more promising alternative to $\mathrm{RO}$ membranes to remove small organic contaminants (micro-pollutants) from water [20, 21]. Some of the commercially available NF membranes are already reported to achieve partial or near complete removal of micro-pollutants from water and wastewater [2230]. In water production, NF is sometimes already applied as a combinatory process to remove components such as di-valent ions, natural organic matter, dyes, metals, and viruses in just a single step [16, 31].

NF membranes, just like RO membranes, have an asymmetric structure with a thin and dense selective top layer on a very open and permeable membrane support. However, the membrane geometry is another important aspect for 
membrane separation processes, especially in terms of fouling. Nearly all commercially available NF membranes are flat sheet, used together with a spacer in a spiral wound module, which offers limited hydraulic and chemical cleaning possibilities making these membranes much more prone to fouling. For this reason, an expensive pretreatment step is often needed, before NF treatment. In contrast, the hollow fiber (HF) geometry allows for a larger membrane surface area per $\mathrm{m}^{3}$ of membrane module, as compared to a spiral wound geometry. Moreover, hollow fiber membranes are also better equipped to withstand fouling due to the lack of spacers and additional fouling interface, while they can also be cleaned much better by physical cleaning, for example allowing backwashing at higher pressures. By using hollow fiber membranes, one might thus be able to leave out the expensive pre-treatment step needed for spiral wound modules. Unfortunately, most of the commercially available hollow fiber membranes are designed for ultrafiltration (UF) and microfiltration (for removal of bacteria and viruses). So far Pentair X-Flow is the only producer of polymeric NF hollow fiber membranes (HFW 1000) with molecular weight cutoff (MWCO) of $1000 \mathrm{Da}$, a membrane that was never designed to remove micro-pollutants of small size.

A promising and easy way to prepare hollow fiber NF membranes with a lower MWCO is the surface modification of existing UF membranes. Several studies have shown that the assembly of polyelectrolyte multilayers on a porous support is an easy and suitable method to make NF membranes for the separation or removal of ions [32-44] sugars [45], and dyes [46]. Moreover, the used polyelectrolytes (PEs) are water soluble and can increase the hydrophilicity of the resulting membranes, leading to a lower fouling tendency [47]. However, all of these studies utilized flat sheet membrane supports to prepare PEM based NF membranes. Recently, LbL assembly of PEMs on hollow fiber UF membrane supports has been developed in order to 
produce hollow fiber NF membranes [48-50]. Moreover, this versatile method allows one to prepare hollow fiber NF membranes with desired functionalities for some particular applications (Fig. 3.1). De Grooth et al. [51] developed hollow fiber NF membranes using multilayers of zwitterions for the removal of charged (both positive and negative) micro-pollutants from water. In our previous study we developed PEM based NF membranes with a responsive outer layer that can be sacrificed (removed) to quickly and thoroughly clean the membrane surface [52].

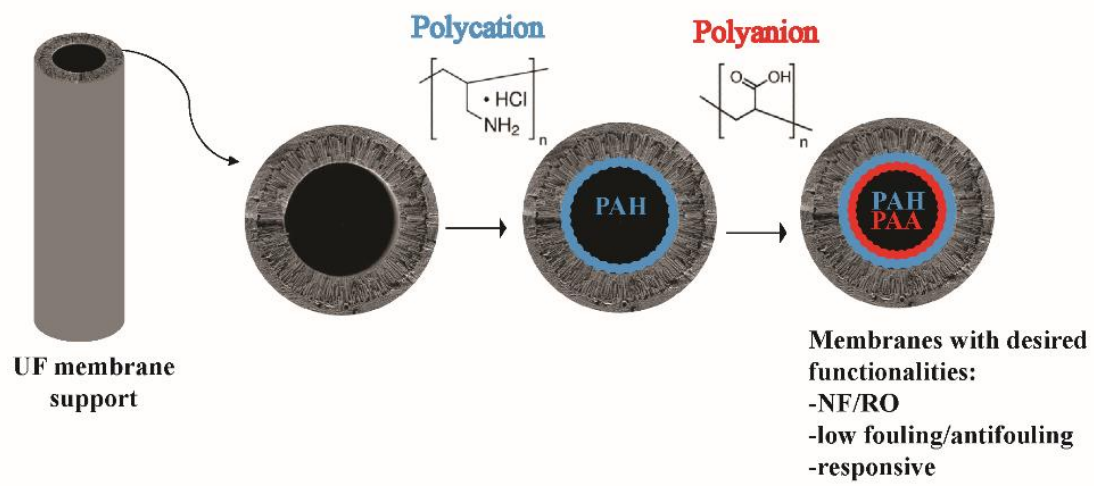

Fig. 3.1: Graphical representation of LbL deposition of PEMs on hollow fiber UF membrane support to make hollow fiber NF membranes with desired functionalities.

PEM membranes are highly versatile, as the layer properties (molecular structure inside and charge on the outside of layers) can be controlled by the choice of polyelectrolyte, the number of deposition steps and the ionic strength of the coating solution [53], which tunes the separation behavior of membranes for different solutes. Compared to strong PEs the use of weak PEs is advantageous, as their ionization degree PEs is determined by the $\mathrm{pH}$ of the coating solution, providing an additional control parameter over the charge density of PEs and the resulting thickness and properties of the deposited PEMs [54-57]. Therefore, two weak PEs (both the polyanion and the polycation) can be useful as the $\mathrm{pH}$ during coating can be used to tune the 
membrane performance [34]. Recently we have shown how the $\mathrm{pH}$ can be used to tune the separation properties of weak PEMs based membranes for solvent resistant nanofiltration (SRNF) [58], truly allowing one to optimize the membrane for specific applications. An additional benefit of weak PEM based membranes is the possibility to easily and thoroughly clean the membranes by utilizing a sacrificial layer approach $[52,59]$.

In this work, we describe the preparation of weak PEM based hollow fiber NF membranes by LbL assembly of poly(allylamine hydrochloride) (PAH) and poly(acrylic acid) (PAA) on an UF membrane support. Three $\mathrm{pH}$ combinations were used to prepare PEM based NF membranes (PAH/PAA: $6.0 / 6.0,6.0 / 3.5,3.5 / 3.5)$. The effect of the coating conditions on the growth and composition of the PEM layers was studied by preparing and characterizing them on model surfaces. Subsequently, the PEMs were coated on an UF membrane support under identical coating conditions to make NF membranes with a hollow fiber geometry. The newly formed multilayered NF membranes were carefully characterized for their water permeability and solute rejection (salt and micro-pollutant) performance. The results on multilayers properties obtained from model surfaces were the basis to explain the observed membrane performance. We show that the retention behavior of weak PEM based membranes towards salts and micro-pollutants can be tailored by varying the coating solution's $\mathrm{pH}$, leading, for example, to a membrane with a high micro-pollutant retention that does not strongly affect the ionic composition of the feed. 


\subsection{Experimental}

\subsubsection{Chemicals}

Polyelectrolytes used for this study were poly(allyl amine) hydrochloride $(\mathrm{PAH}) \mathrm{Mw}=17,500 \mathrm{~g} \cdot \mathrm{mol}^{-1}$ and poly(acrylic acid) $(\mathrm{PAA}) \mathrm{Mw}=15,000$ g. mol $^{-1}$. Sodium nitrate $\left(\mathrm{NaNO}_{3}\right)$ was used as a background electrolyte. Polyelectrolyte solutions always contained $0.1 \mathrm{~g} \cdot \mathrm{l}^{-1}$ of polymer. Polyelectrolyte and feed solutions were prepared using de-ionized (DI) water (Milli Q, 18.2 $\mathrm{M} \Omega \cdot \mathrm{cm}$ ). The $\mathrm{pH}$ was adjusted using hydrochloric acid $(\mathrm{HCl})$ and sodium hydroxide $(\mathrm{NaOH})$. All coating solutions were used within eight days after preparation. $\mathrm{NaCl}, \mathrm{CaCl}_{2}$ and $\mathrm{Na}_{2} \mathrm{SO}_{4}$ were used to study the retention performance of membranes. The molecular structures and properties of micro-pollutants used for the rejection experiments are given in Fig. 3.2. All chemicals were of analytical grade and were supplied by Sigma-Aldrich (The Netherlands). 


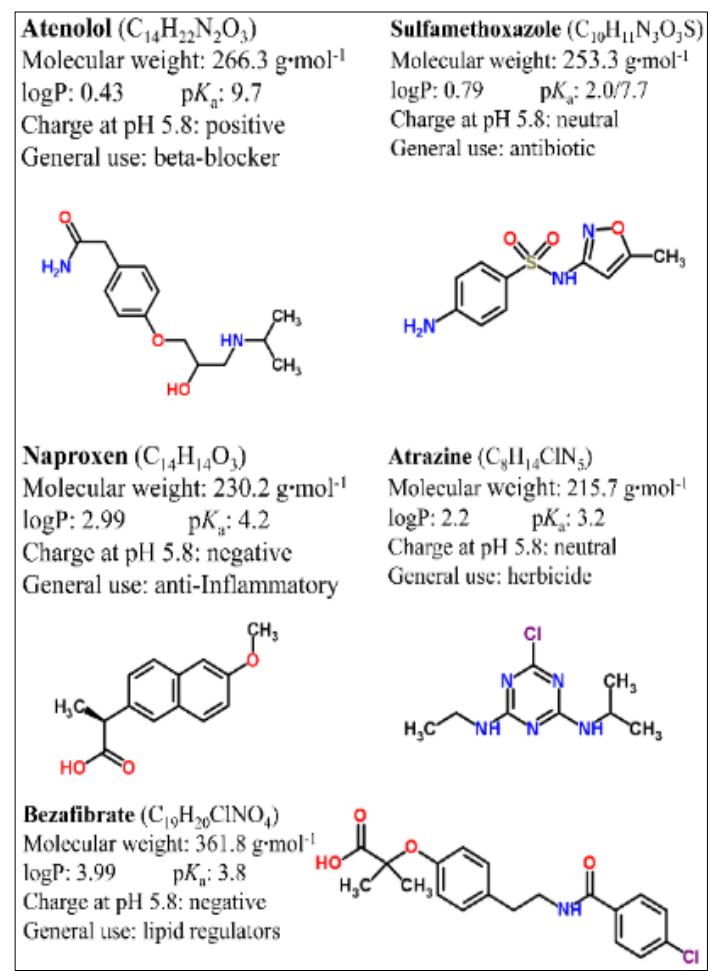

Fig. 3.2: Physico-chemical properties and chemical structures of micro-pollutants used for this work. Chemicalize.org by ChemAxon was used to estimate some properties (http://www.chemicalize.org) [60].

\subsubsection{Reflectometry}

To monitor the alternating adsorption of PEs onto a model surface (a silicon wafer with a silica surface), fixed-angle optical reflectometry equipped with a He-Ne laser (monochromatic light, $\lambda=632.8 \mathrm{~nm}$ ) was used. In reflectometry, using a stagnation point flow cell, the measurements can be performed under well-defined hydrodynamic conditions [61]. When the laser beam strikes the adsorbing substrate in the cell around the Brewster angle $\left(71^{\circ}\right)$, it reflects towards the detector and is split into its perpendicular $\left(R_{s}\right)$ and parallel $\left(R_{p}\right)$ components. The ratio of these two components $\left(\mathrm{R}_{\mathrm{p}} / \mathrm{R}_{\mathrm{s}}\right)$ provides the reflectometric signal $S(-)$. A change in signal $(\Delta S)$ is directly proportional to the quantity of material adsorbed on the substrate, according to equation 3.1: 


$$
\Gamma=\mathrm{Q}\left(\Delta \mathrm{S} / \mathrm{S}_{0}\right)
$$

Here $\Gamma$ is the quantity of material which is adsorbed on the silicon wafer $\left(\mathrm{mg} \cdot \mathrm{m}^{-2}\right) \mathrm{Q}$ is a sensitivity factor, that depends on many factors like the angle of incidence of the laser beam $(\theta)$, the thickness of the silicon layer (d), the refractive indices $(n)$, and the refractive index increment $(\mathrm{dn} / \mathrm{dc})$ of the adsorbing material. All measurements were carried out on a clean silicon wafer surface (with a $70 \mathrm{~nm} \mathrm{SiO}_{2}$ top layer). The Q-factor was calculated using an optical method based on values from our previous work $[52,62]$. The Qfactor value thus obtained is $20 \mathrm{mg} \cdot \mathrm{m}^{-2}$ for PAH and $27 \mathrm{mg} \cdot \mathrm{m}^{-2}$ for PAA and is used to calculate actual adsorbed mass. $\mathrm{S}_{0}$ is the initial output signal of a clean silicon wafer immersed in solvent (-).Before starting the reflectometry measurements the silicon surface was treated for $10 \mathrm{~min}$ by $\mathrm{O}_{2}$ plasma (FemtoDiener electronic plasma cleaner, Germany, at 50\% power). The overall charge of the multilayers was calculated by dividing the adsorbed mass with the monomeric molecular weight of the respective polyelectrolyte, and subsequently subtracting the total negative charges from the positive charges.

\subsubsection{Water contact angle of multilayers}

PEMs deposited on silicon wafers were characterized for their water contact angle using the OCA21 from Dataphysics Instruments GmbH, Germany. The procedure used for the deposition of multilayers is provided below. Before deposition of PEMs, pre-treatment of silicon wafers was carried out for 10 min by $\mathrm{O}_{2}$ plasma (Femto-Diener electronic plasma cleaner, $50 \%$ power, Germany). After the plasma treatment silicon wafers were used within an hour. Before measuring the contact angle, the PEMs deposited under different $\mathrm{pH}$ conditions using the $\mathrm{LbL}$ technique were dried using a nitrogen gas stream. The contact angle of a sessile water drop of $2 \mu \mathrm{L}$ on the PEMs terminated with PAH (+) and PAA (-) was measured using the OCA21 at five different locations for every coating at $20^{\circ} \mathrm{C}$ in a static mode. The contact angle was 
measured $5 \mathrm{~s}$ after placing the water droplet although no substantial effect of time was observed.

\subsubsection{Membrane modification using LbL coating}

A commercially available hollow fiber UF membrane (Hollow Fiber Silica (HFS), with a MWCO of $10 \mathrm{kDa}$ ) was used as a support on which the polyelectrolyte multilayers were coated. This UF support was kindly provided by Pentair X-Flow, The Netherlands. This UF support has a separation skin layer of sulfonated poly(ether sulfone) towards the lumen side and is designed to remove colloidal silica from water. This membrane support was coated with PEMs using dip coating as we reported in chapter 2 of this thesis [52]. To wet the fibers and remove impurities, the hollow fibers were kept overnight in 15 wt. \% ethanol in water. Rinsing of the fibers was performed three times with DI water with the background electrolyte solution $\left(50 \mathrm{mM} \mathrm{NaNO}_{3}\right)$. Next the fibers were dipped in solution of polycation $(\mathrm{PAH})$ with $0.1 \mathrm{~g} \cdot \mathrm{l}^{-1}$ polymer concentration and same background electrolyte concentration for about 30 min, followed by three times rinsing in background electrolyte solution. We used three combinations of $\mathrm{pH}$ for $\mathrm{PAH} / \mathrm{PAA}$ and resulting membranes are [6.0/6.0], [6.0/3.5] and [3.5/3.5]. Here for example [6.0/6.0] represents multilayer membranes coated with $\mathrm{PAH}$ at $\mathrm{pH} 6.0$ and the PAA at $\mathrm{pH}$ 6.0. Rinsing with $50 \mathrm{mM}$ background electrolyte with the same $\mathrm{pH}$ as of the $\mathrm{PE}$ solution between every polyelectrolyte coating is performed to remove any loosely attached or extra PE from the surface of membrane and to avoid formation of complex in the bulk solution. The same coating steps were repeated with other PE to obtain the required number of layers. After each coating step the membranes were immersed in glycerol/water (15 wt. \%/85 wt. \%) solution for at least $4 \mathrm{~h}$, and then dried for at least $8 \mathrm{~h}$ in air. Later the coated fibers were potted in modules. The effective length of the fibers in modules was approximately $10 \mathrm{~cm}$. 


\subsubsection{Characterization of PEM based membranes}

\section{Filtration and rejection}

The prepared membranes were first characterized for their pure water flux at $20{ }^{\circ} \mathrm{C}$ in a dead end mode. The applied trans-membrane pressure (TMP) was 1.8 bar. Normalization of the measured pure water flux gave the water permeability. The performance of prepared membranes was further checked by retention measurements on salt ions $\left(\mathrm{NaCl}, \mathrm{CaCl}_{2}\right.$ and $\left.\mathrm{Na}_{2} \mathrm{SO}_{4}\right)$ and 5 common micro-pollutants (covering medicinal compounds and herbicides). Retention measurements were performed by applying a cross flow velocity of $3.8 \mathrm{~m} \cdot \mathrm{s}^{-1}$ (corresponding to a Reynolds number of approximately 3100 ). The concentration of salts used for these filtration experiments was always $5 \mathrm{mM}$. A conductivity meter WTW cond 3210 was used to measure the salt concentration. Micro-pollutants used for this study included positive, negative and neutral molecules (at a pH of 5.8) and included both hydrophobic and hydrophilic molecules. Properties of these micro-pollutants are given in Fig. 3.2. The micro-pollutant molecular weight range is between 200 and 400 $\mathrm{g} \cdot \mathrm{mol}^{-1}$. Filtration of membranes with solutions containing all five micropollutants (concentration of $10 \mathrm{mg} \cdot \mathrm{l}^{-1}$ ) was performed. Saturation of membranes with solutes and steady state rejection was ensured by taking the permeate samples after 24 hours of filtration.

Equation 3.2 was used to calculate the retention:

$$
R(\%)=1-\frac{C_{p}}{C_{f}} \times 100
$$

where $C_{p}$ is the solute concentration of the permeate and $C_{f}$ is the solute concentration of the feed (concentrate), respectively. All measurements were 
performed for each membrane type in duplicate and the average and standard deviation are reported.

\section{Analysis of micro-pollutants}

The concentration of micro-pollutants in both the concentrate and permeate was determined by a U-HPLC Dionex Ultimate 3000 system equipped with an RS variable wavelength detector. Micro-pollutant separation was done on an Acclaim RSLC C18 $2.2 \mu \mathrm{m}$ column (Thermo Scientific) at $45{ }^{\circ} \mathrm{C}$, while applying a gradient flow from $95 \mathrm{wt} \% \mathrm{H}_{2} \mathrm{O}+5 \mathrm{wt} \%$ acetonitrile at $\mathrm{pH} 2$ to 5 wt $\% \mathrm{H}_{2} \mathrm{O}+95 \mathrm{wt} \%$ acetonitrile at $1 \mathrm{ml} \cdot \mathrm{min}^{-1}$.

\subsection{Results and discussion}

We divided this section in three main parts. The first part entails the characterization of the PEMs on model surfaces via reflectometry and contact angle measurements in order to understand their composition and structure. The second part deals with the characterization of the prepared PEMs based membranes in terms of permeance and salt rejections. In the third part the NF performance of membranes (prepared under different $\mathrm{pH}$ conditions) regarding the retention of five micro-pollutants is given.

\subsubsection{Properties of PEMs}

\section{Growth behavior and total charge on multilayers}

The growth of weak PAH/PAA PEMs under three $\mathrm{pH}$ combinations (6.0/6.0, 6.0/3.5 and 3.5/3.5) was monitored on silicon wafers using optical fixed angle reflectometry (Fig. 3.3). A typical measurement starts when the silicon wafer is exposed to the solvent solution (with identical $\mathrm{pH}$ and salt concentration as the cationic polyelectrolyte) and this gives the baseline signal $\left(\mathrm{S}_{0}\right)$. Adsorption starts when the negatively charged silicon wafer is exposed to a solution containing the positively charged polyelectrolyte (PAH), leading an increase 
in the mass adsorbed. Further exposure to the negatively charged anionic polyelectrolyte PAA leads to another increase in adsorbed amount. Continuous switching between cationic and anionic polyelectrolytes results in stepwise growth of the PEMs as shown in Fig. 3.3.

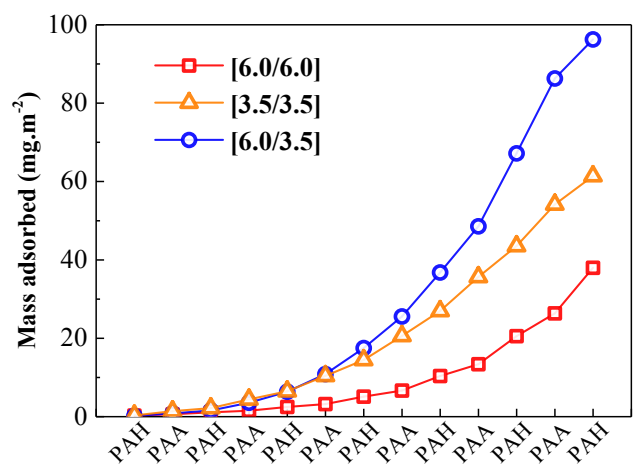

Fig. 3.3: Effect of $p H$ of coating solutions on building of PAH/PAA multilayers on silicon wafer monitored via reflectometry (polyelectrolyte solution contained polymer concentration of $0.1 \mathrm{~g} \cdot \mathrm{l}^{-1}$ with $50 \mathrm{mM} \mathrm{NaNO}$ ). Straight lines are shown to depict the trend.

Every time before switching between polyelectrolyte solutions, the cell was rinsed with a background electrolyte solution for at least $200 \mathrm{~s}$ to remove loosely adsorbed polymer chains. The used salt concentration of $50 \mathrm{mM}$ in the coating solutions was chosen based upon our previous work [52]. Fig. 3.3 shows multilayer growth at three different combinations of $\mathrm{pH}$. The amount of material adsorbed during multilayers formations for the same number of bilayers shows substantial difference for all $\mathrm{pH}$ conditions. In Fig. 3.3, we have initially observed a linear growth then followed by an exponential growth regime of multilayers being formed on the substrate. However, compared to $\mathrm{pH}$ condition [6.0/6.0] the onset of exponential growth regime for $\mathrm{pH}$ conditions [3.5/3.5] and [6.0/3.5] starts quite early (after just 2.5 bilayers). Overall with same number of bilayers the amount of mass adsorbed during multilayer formations is significantly different for the studied $\mathrm{pH}$ conditions (Fig. 3.3). The lowest adsorbed amount is found at $\mathrm{pH}$ [6.0/6.0], at 
the $\mathrm{pH}$ conditions [3.5/3.5] and especially [6.0/3.5] much more material is adsorbed.

Clearly, the growth behavior and in turn the structure of the multilayers is affected by the $\mathrm{pH}$ of the polyelectrolyte solutions. For this pair of weak PEs (PAH/PAA), the composition, the thickness and organization of the PEMs can be tuned by variation in the $\mathrm{pH}$ of each of the $\mathrm{PE}$ solutions $[54,55,63]$. The $\mathrm{pH}$ controls the degree of dissociation of the basic and acidic groups on the polymer chains and thus controls the charge density. $\mathrm{PAH}$ with $\mathrm{pK}_{\mathrm{a}}$ of 8-9 and PAA with $\mathrm{pK}_{\mathrm{a}}$ of 5.4 [63], are mostly charged (with nearly $80-90 \%$ ionised groups) at a $\mathrm{pH}$ combination of [6.0/6.0] and hence form thin layers, with a small quantity of material needed to compensate all charges from the previous deposited layer (most probably with high intrinsic charge compensation within the bulk of the multilayers). Thicker and more swollen multilayers are formed at [3.5/3.5] and [6.0/3.5] when PAA is only partially charged. Here the PE adopts a more coiled conformation while also more extrinsic charge compensation is found [64].

A monomeric excess of a particular polymer during PEM build-up can give an indication on the overall charge in multilayers. To get into insight of the overall charge in prepared multilayers, the excess of particular polymers after each adsorption was also calculated (see Fig. S3.1). We observed a zigzag behavior with the addition of each positive (PAH) or negative (PAA) layer. Here adsorption of PAH leads to a significant excess of cationic monomers, while after PAA addition layers we come to just a very small excess of negative polymer. This effect is strongest for $\mathrm{pH}$ conditions [6.0/3.5] and [3.5/3.5] where thicker layers are formed and weakest for the thin layers of $\mathrm{pH}$ [6.0/6.0] condition (Fig. 3.3). These observations are in line with zeta potential of these multilayers, where switching between the PEs reverses the 
charge of the surface of multilayers which shows that outside of the multilayers represents excess of that particular PE [52]. However, the excess of PAH is so large that it cannot just stem from an excess on the outside of the PEM. The expectation is that also the bulk of the PEM is somewhat positively charged after a PAH adsorption step. A similar effect was found for the cationic PDADMAC and the anionic PSS, with an excess of the cationic charge throughout the PEM layer after PDADMAC deposition. Moreover, individual layers within PEMs are highly interpenetrating and can electrically neutralize each other except for the outer most surface layer $[65,66]$, or depending upon the terminal layer, the bulk (inside) of the PEMs still can carry charges and may not be overall neutral $[67,68]$. The additional cationic charge would then also be expected to lead to stronger swelling after deposition of the cationic polymer.

\section{Contact angle of multilayers}

The wettability of multilayers prepared under the different $\mathrm{pH}$ combinations was investigated for PAH $(+)$ and PAA (-) terminated layers by means of contact angle measurements. These measurements provide insight into the hydrophilicity of the multilayers which can be important for their eventual transport properties. Furthermore, it is common knowledge that membranes with higher a hydrophilicity tend to offer better resistance to fouling [47, 69]. In Fig. 3.4 we present water contact angles measured on the multilayers prepared with the PAH/PAA with three $\mathrm{pH}$ combinations (6.0/6.0, 6.0/3.5 and $3.5 / 3.5)$ at $50 \mathrm{mM} \mathrm{NaNO}$ and $0.1 \mathrm{~g} \cdot 1^{-1}$ polymer. In all cases, results show a change in the layer hydrophilicity for differently terminated layers, with the positively $(\mathrm{PAH})$ terminated layers having a higher contact angle than the negatively (PAA) terminated layers. When comparing three different multilayers, the [6.0/6.0] layers show relatively higher contact angles $\left(37^{\circ}\right.$ and $81^{\circ}$ for PAA and PAH terminated layer respectively), which was expected due 
to the high level of intrinsic charge compensation and dense structure of these layers (few free $-\mathrm{NH}_{2}$ and $-\mathrm{COOH}$ groups) which is comparable to our previous observations [58]. The contact angles measured on [6.0/3.5] and [3.5/3.5] PEMs with a final layer of PAA (-) are $15^{\circ}$ and $24^{\circ}$ respectively, indicating these layers are more hydrophilic compared to multilayers terminated with PAH (+). These results further demonstrate that the segments of the final layer dominates the surface layers.

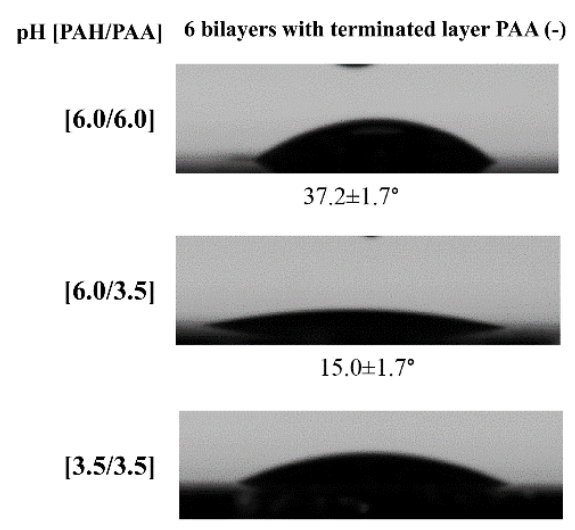

$24.2 \pm 3.8^{\circ}$
6.5 bilayers with terminated layer PAH $(+)$

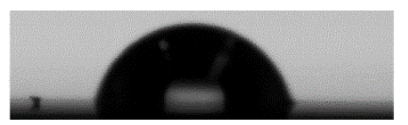

$81.2 \pm 5.3^{\circ}$

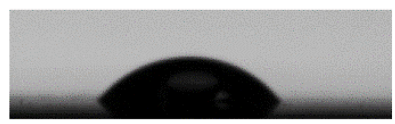

$58.5 \pm 6.4^{\circ}$

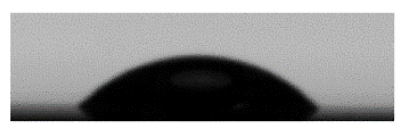

$48.6 \pm 4.9^{\circ}$

Fig. 3.4: Representative contact angle measurements of multilayers with different terminal layers (prepared at [6.0/6.0], [6.0/3.5] and [3.5/3.5] pH combinations with polymer concentration of $0.1 \mathrm{~g} \cdot \mathrm{l}^{-1}$ and $50 \mathrm{mM} \mathrm{NaNO} 3$ ).

\subsubsection{Membrane performance}

\section{Water permeability}

A UF support was coated with PEMs (PAH/PAA) using the same coating conditions as applied for the silicon wafers. After every coating step, the membranes were characterized for their pure water permeability. The effect of coating the UF membrane support at different $\mathrm{pH}$ conditions on the water permeability is given in Fig. 3.5. For all $\mathrm{pH}$ conditions, the membrane permeability decreases with the number of coated layers. This is in agreement with the reflectometry data of multilayer growth and represents that the addition of material on the membrane surface decreases the pore size of 
membranes leading to a decline in the water permeability. We observe a typical zig-zag behavior in the permeability of membranes prepared at $\mathrm{pH}$ condition [6.0/6.0] which is indication of the odd-even effect [48, 52]. Often, the degree of swelling of a whole PEM will depend on the final adsorbed layer. In our reflectometry investigation (Fig. 3.3 and S3.1), we already established a large excess of cationic monomer after PAH adsorption, which would be expected to lead to stronger swelling of the PEM. Initially, after PAH adsorption the permeability is lowest as the additional swelling of that layer closes of the pores. This is most clearly observed between layer 3 and 4 and indicates a pore dominated regime. However, after 5 deposited layers we see a flip in the odd-even effect, with $\mathrm{PAH}$ terminated layers having a higher permeability. With this we have entered the layer dominated regime where a PEM layer has formed on top of the support. A more swollen layer is now also a more open and thus permeable layer. After depositing 6 bilayers PAA is less permeable $\left(1.8 \pm 1.61 \cdot \mathrm{m}^{-2} \cdot \mathrm{h}^{-1} \cdot \mathrm{bar}^{-1}\right)$ because of its dense layer structure, while addition of a layer of PAH makes multilayers swell and more permeable $\left(3.0 \pm 0.51 \cdot \mathrm{m}^{-2} \cdot \mathrm{h}^{-1} \cdot \mathrm{bar}^{-1}\right)$. PAA terminated layers are thus expected to be denser and to show better solute retention behavior. We did not see a clear odd even effect for membranes [6.0/3.5] and [3.5/3.5]. An important observation to make is that the membranes prepared under [6.0/6.0] give the lowest permeability, while we know from reflectometry that these are also the thinnest layers. This must mean that layers prepared under [6.0/6.0] are significantly denser than the layers prepared under other $\mathrm{pH}$ conditions. This effect is most clear after 12 and 13 layers, where the water permeability of membranes coated with similar number of bilayers of PAH/PAA at $\mathrm{pH}$ condition [6.0/3.5] and [3.5/3.5] was almost two times higher than membranes prepared at $\mathrm{pH}$ conditions $[6.0 / 6.0]$ i.e., $11.5 \pm 0.8 \mathrm{l} \cdot \mathrm{m}^{-2} \cdot \mathrm{h}^{-1} \cdot$ bar $^{-1}$ and $7.2 \pm 0.48$ $1 \cdot \mathrm{m}^{-2} \cdot \mathrm{h}^{-1} \cdot \mathrm{bar}^{-1}$ respectively. For LbL membranes solubility and diffusivity of solutes are mainly determined by hydration of layers and the affinity of the 
solute to the membranes [48]. More hydrated layers are swollen and more open with more volume between the polymer chains, allowing easier transport.

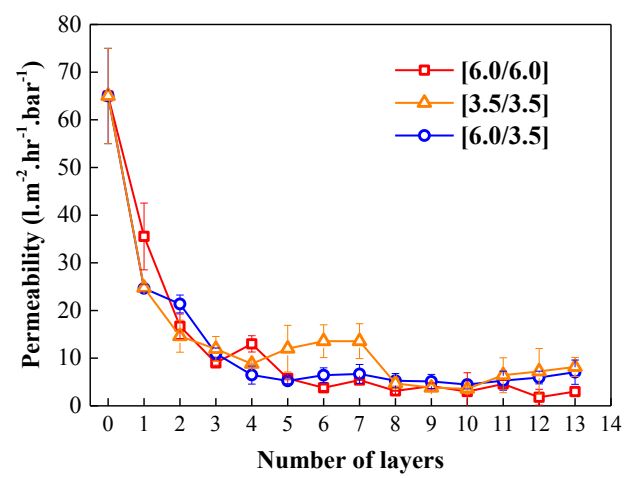

Fig. 3.5: Pure water permeability of membrane support versus the number of coated layers at three $p H$ combinations for PAH/PAA [6.0/6.0], [6.0/3.5] and [3.5/3.5]. All coating solutions contained $0.1 \mathrm{~g} \cdot l^{-1}$ polymer and $50 \mathrm{mM} \mathrm{NaNO}_{3}$.

\section{NF performance}

Various salts $\left(\mathrm{NaCl}, \mathrm{CaCl}_{2}\right.$ and $\left.\mathrm{Na}_{2} \mathrm{SO}_{4}\right)$ were utilized to check the rejection performance of the prepared membranes. The UF support used to prepare these membranes are unable to reject any salt ions, and therefore we are really studying the separation performance of the PEMs. During the filtration of the salt solutions no significant permeability changes were observed compared to the clean water permeabilities, demonstrating a stable performance. Retention of salts is a typical characterization of NF membranes which can also provide proof of successful deposition of PEMs on the support membrane. By studying the retention for a number of salts one can also achieve insight into of the main retention mechanism of the membranes [48]. To describe the solute rejection in NF-membranes usually size/steric hindrances, charge, dielectric exclusion, valence, and adsorption are taken into account [48, 70-73]. 

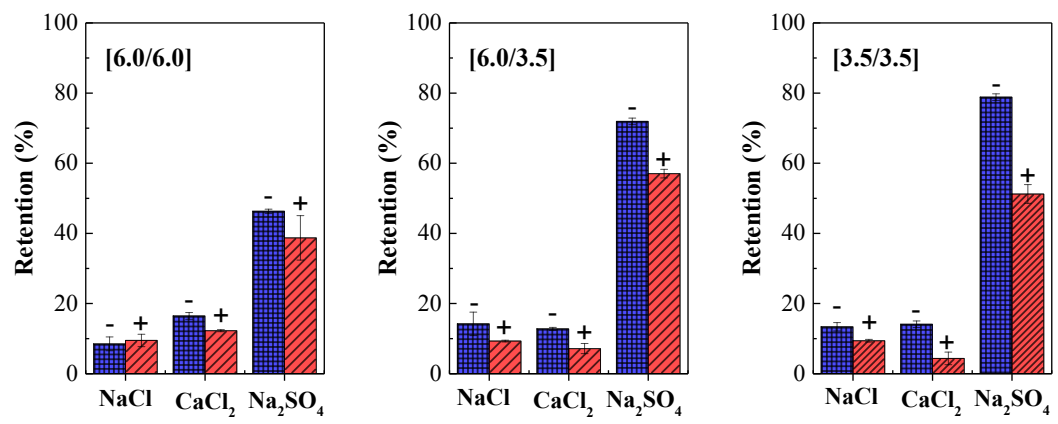

Fig. 3.6: Different ions retention of multilayered membranes with $6(-)$ and 6.5 (+) bilayers of PAH/PAA prepared at [6.0/6.0], [6.0/3.5] and [3.5/3.5] pH combinations with $50 \mathrm{mM}$ $\mathrm{NaNO}_{3}$ and $0.1 \mathrm{~g} \cdot l^{-1}$ polymer.

In Fig. 3.6 the rejection performance of PAA/PAH PEM based membranes for monovalent $(\mathrm{NaCl})$ and divalent ions $\left(\mathrm{Na}_{2} \mathrm{SO}_{4}\right.$ and $\left.\mathrm{CaCl}_{2}\right)$ is shown. The membranes were coated with $6(-)$ and $6.5(+)$ bi-layers under 3 different $\mathrm{pH}$ combinations $(6.0 / 6.0,6.0 / 3.5$ and 3.5/3.5) at an ionic strength of $50 \mathrm{mM}$. We observe that all of the prepared membranes reject a significant amount of the $\mathrm{SO}_{4}{ }^{2-}$, while the membranes hardly retain $\mathrm{Na}^{+}$and $\mathrm{Ca}^{2+}$ ions. The prepared PEMs based membranes thus perform as NF membranes, allowing passage to the monovalent ions, and rejecting bigger divalent ions. Still, the ionic rejection, especially for the PAA/PAH (6.0/6.0) membrane is rather low. This could be seen as competitive advantage to remove organic compounds without significantly affecting the ionic composition of the feed, something that we will come back to. We found membrane performance in terms of rejection quite similar for the different $\mathrm{pH}$ conditions used. For differently terminating layers (PAH or PAA) for [6.0/6.0] membranes show very small differences in terms of retention are observed, which indicates only a very small contribution of the membrane charge towards solute retention. However we do see some role of terminal layer charge for [6.0/3.5] and [3.5/3.5] membranes especially for $\mathrm{SO}_{4}{ }^{2-}$ retention. If the rejection was dominated by Donnon exclusion then 
the order of retention would be $\mathrm{SO}_{4}{ }^{2-}>\mathrm{Na}^{+}>\mathrm{Ca}^{2+}$ for negatively charged membranes and the inverse for positively charged membranes. These trends are clearly absent in our retention data. An alternative would be di-electric exclusion, which is especially powerful in retaining multivalent charged species. However, the low $\mathrm{CaCl}_{2}$ retention for all membranes makes this statement very unlikely. For our dense PAA/PAH layers the retention mechanism seems to be based mainly on the size exclusion. When the ions are dissolved in water, the dynamic hydrated radius of ions is the good representation of their size in water [74], although size differences of the ions used here are not large and their order of size is : $\mathrm{SO}_{4}{ }^{2-}>\mathrm{Ca}^{2+}>\mathrm{Cl}^{-}>\mathrm{Na}^{+}$. Indeed the larger $\mathrm{SO}_{4}{ }^{2-}$ is the most rejected ion, independent of the charge of the membrane, something that we can only really explain on the basis of size exclusion as the dominating separation mechanism for these solutes. Still, other mechanisms are expected to play an additional role.

\section{Micro-pollutant rejection}

To examine the ability of prepared multilayered membranes to reject small organic molecules, the retention of a cocktail of five micro-pollutants was measured with membranes coated under different $\mathrm{pH}$ conditions for PAH/PAA [6.0/6.0, 6.0/3.5 and 3.5/3.5]. Filtration experiments for micropollutants were carried out for $24 \mathrm{~h}$ in order to exclude adsorption as a separation mechanism. It is important to mention that rejection of trace organic compounds by pressure driven membranes is a complex mixture of factors including electrostatic repulsion, steric hindrance, solute/membrane properties and solution effect [75], feed water composition and operating conditions [21]. Bruggen et al. [30] shown that for organic pollutants removal by NF, the key parameters of solute and membrane that can influence the retention are hydrophobicity, molecular size and charge $\left(\mathrm{pK}_{\mathrm{a}}\right)$. 

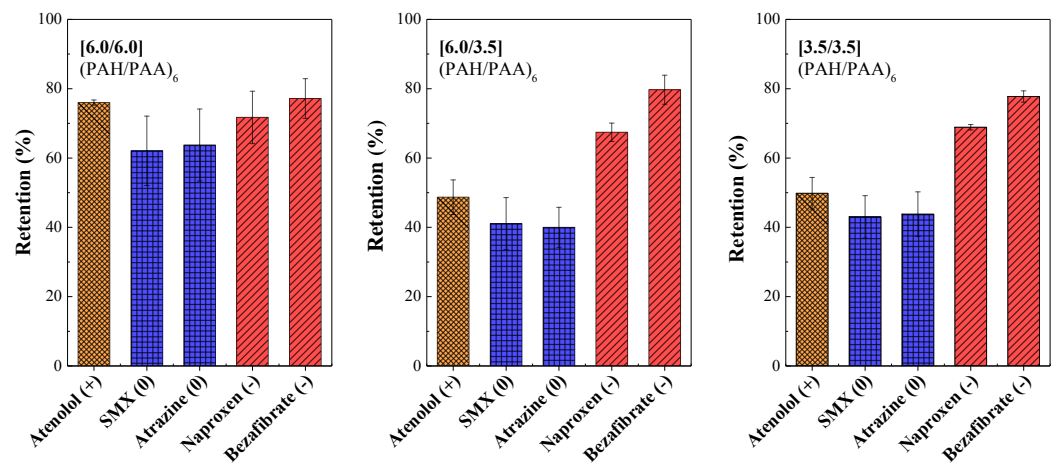

Fig. 3.7: Retention of different micro-pollutants at pH 5.8 by PEM membranes with 6 (-) bilayers of PAH/PAA (prepared with different combinations of $p H$ [6.0/6.0], [6.0/3.5], and [3.5/3.5] and ionic strength of $50 \mathrm{mM}$ with $0.1 \mathrm{~g} \cdot \mathrm{l}^{-1}$ polymer). Conditions for filtration experiments were: $\mathrm{pH} 5.8, \mathrm{Re} \approx 3,100$, and a TMP of $1.8 \mathrm{bar}$.

In Fig. 3.7, the micro-pollutant retention of the multilayered membranes, prepared under different $\mathrm{pH}$ conditions, are given. All of these membranes show between $40 \%$ and $80 \%$ retention for the micro-pollutants, significantly better than the ion retentions given in Fig. 3.6. Interestingly, the membrane with the lowest ion retentions, [6.0/6.0], has a superior micro-pollutant retention compared to the other membranes, [6.0/3.5] and [3.5/3.5], although the negatively charged Naproxen and Bezafibrate have a comparable rejection for all the three membranes. It seems that for [6.0/3.0] and [3.5/3.5] some Donnan exclusion plays a role leading to a preferred rejection of the negative micro-pollutants, while for [6.0/6.0] the high retention of all micro-pollutants, suggests that the retention of these [6.0/6.0] membranes is based mainly on size or steric retention. As mentioned before in discussion of the water permeability, the membranes prepared at [6.0/6.0] are expected to be much denser in nature.

As there is just a relatively small difference in molecular size of the used compounds (range of 200 to $400 \mathrm{~g} \cdot \mathrm{mol}^{-1}$ ) it is difficult to observe a direct 
relation between molecular size (Fig. 3.8) and rejection of molecules, and we expect that other factors such as charge and hydrophobicity will also contribute to the observed retention.
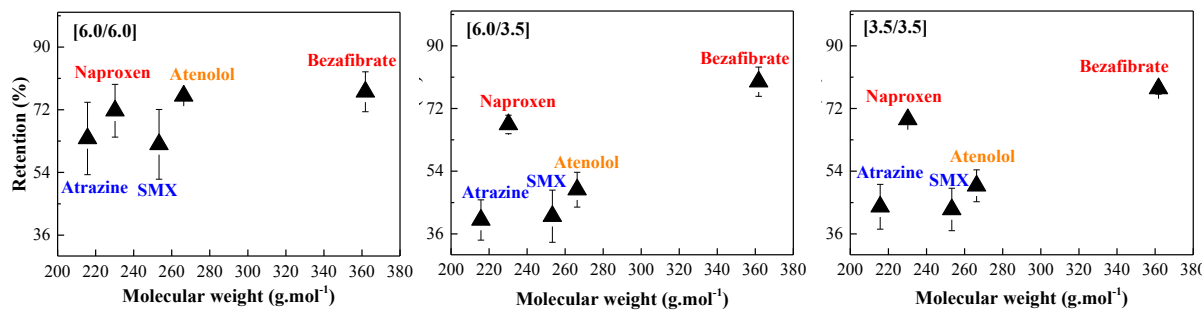

Fig. 3.8: Retention as a function of size of micro-pollutants. Micro-pollutants are color coded based on their charge: orange for positive (+) micro-pollutants, blue for neutral (0) micropollutants, and red (-)for negative micro-pollutants. Membranes are with 6 (-) bilayers $P A H / P A A$ prepared with different combinations of $p H$ [6.0/6.0], [6.0/3.5] and [3.5/3.5] and $50 \mathrm{mM}$ ionic strength with $0.1 \mathrm{~g} \cdot \mathrm{l}^{-1}$ polymer).
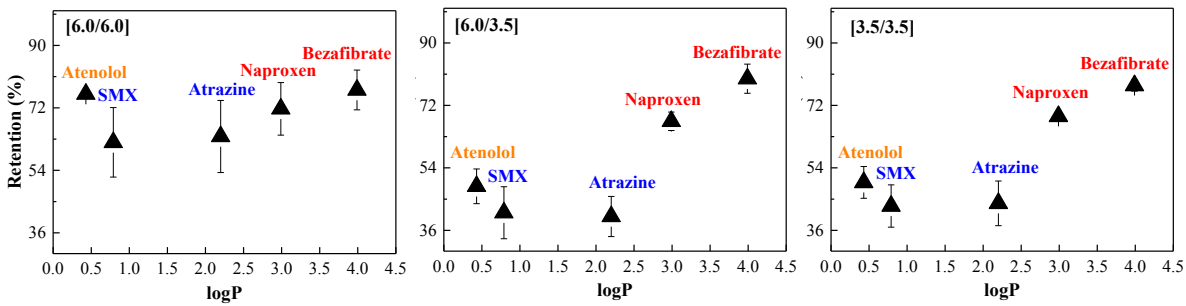

Fig. 3.9: Retention as a function of hydrophilicity of micro-pollutants. Micro-pollutants are color coded based on their charge: orange for positive (+) micro-pollutants, blue for neutral (0) micro-pollutants, and red (-)for negative micro-pollutants. Membranes are with 6 (-) bilayers of PAH/PAA prepared withdifferent combinations of $\mathrm{pH}$ [6.0/6.0], [6.0/3.5] and [3.5/3.5] and $50 \mathrm{mM}$ ionic strength with $0.1 \mathrm{~g} \cdot \mathrm{l}^{-1}$ polymer).

To describe the hydrophobicity of micro-pollutants, an often used indicator is $\log \mathrm{P}$ which is the octanol/water partition coefficient. The $\log \mathrm{P}$ values of micro-pollutants used in this study (Fig. 3.2) range from 0.49 (most hydrophilic) to 4.04 (most hydrophobic). In Fig. 3.9 the rejection is shown as a function of $\log \mathrm{P}$, however there is again no clear trend in rejection of micro- 
pollutant with the degree of hydrophobicity. One thing that is clear from results is that retention of ionic species is better than non-ionic species.

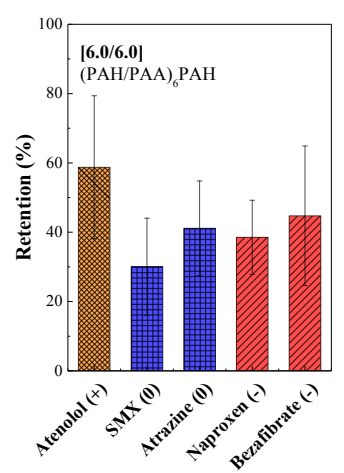

Fig. 3.10: Retention of different micro-pollutants at pH 5.8 PEMs membranes with 6.5 (+) bilayers (PAH/PAA) 6.5 prepared with different combinations of $\mathrm{pH}$ and ionic strength of 50 $m M$ with $0.1 \mathrm{~g} \cdot l^{-1}$ polymer). Conditions for filtration experiments were: $p H 5.8, R e \approx 3,100$, and a TMP of 1.8 bar.

To study the effect of the final layer charge we also performed rejection measurements with membranes terminated with a PAH $(+)$ layer. Our results show a drop in rejection for all investigated micro-pollutants for the membrane [6.0/6.0] (Fig. 3.10). From contact angle measurements this membrane shows more hydrophobicity than all other membranes, so one could expect a different rejection behavior from these membranes. These retention results are in line with reflectometry data (Fig. S3.1) where excess of monomers of PAH in this layer makes the layers swollen and highly permeable. Permeability of this membrane terminated with PAH is $3.0 \pm 0.5$ $1 \cdot \mathrm{m}^{-2} \cdot \mathrm{h}^{-1} \cdot \mathrm{bar}^{-1}$ is higher than a PAA (-) terminated membrane $\left(1.8 \pm 1.61 \cdot \mathrm{m}^{-2} \cdot \mathrm{h}\right.$ ${ }^{1} \cdot$ bar $\left.^{-1}\right)$. A higher permeability, after adding an extra polyelectrolyte layer, would suggest that the multilayer adopts a more open structure leading to a lower degree of size exclusion/steric hindrance and thus a lower rejections. We also studied the final layer effect for other two membranes [6.0/3.5] and [3.5/3.5], the retentions of which are given in Fig. S3.2. Similar to [6.0/6.0], 
the retention of membranes [6/3.5] and [3.5/3.5] was found to be significantly declined. Swelling of the layers after PAH adsorption makes them more permeable.

\subsection{Conclusions}

Growing public awareness about the presence and the health concerns associated with small organic contaminants in water, also increase the demand of membrane based processes in the water industry. Here hollow fiber NF membranes are especially promising as they require much lower operating pressures than for example RO, while their hollow fiber geometry makes them less susceptible to fouling than their spiral wound counterparts. This work investigates the use of weak PEMs for the preparation of low pressure, tunable NF membranes for micro-pollutant removal from water. Hollow fiber based PEM membranes were prepared with the layer-by-layer approach utilizing a combination of two weak PEs (PAH/PAA) at different $\mathrm{pH}$ conditions. Membranes prepared at $\mathrm{pH}[6.0 / 6.0]$ demonstrate a good retention for all the micro-pollutants due to the dense structure, coupled with an acceptable flux due to the thin PEM layer used. Membranes prepared with other $\mathrm{pH}$ combinations [6.0/3.5] and [3.5/3.5] with a more open layer structure demonstrated good retention only for the charged micro-pollutants. Overall the rejection mechanism was found to be dominated by steric hindrance, especially for the membranes prepared at $\mathrm{pH}$ 6. This study demonstrates a simple and versatile method to prepare weak PEM based hollow fiber NF membranes. We show that by varying the $\mathrm{pH}$ during coating one can tune the performance of the membranes towards specific applications. Moreover, the membrane prepared at $\mathrm{pH} 6$, is especially promising as it combines a high MP rejection with low ion rejections. This membrane would be well suited to reduce the problem of micro-pollutants, without significant alteration of the ionic composition of the feed. 


\section{Acknowledgments}

Shazia Ilyas acknowledges the funding provided by the European Commission - Education, Audiovisual and Culture Executive Agency (EACEA), for her PhD project under the program named Erasmus Mundus Doctorate in Membrane Engineering - EUDIME (FPA N² 2011-0014, Edition III, http://eudime.unical.it/). 


\section{References}

[1] N.S. Thomaidis, A.G. Asimakopoulos, A.A. Bletsou, Emerging contaminants: A tutorial mini-review, Global Nest J., 14 (2012) 72-79.

[2] UNEP, Global Chemical Outlook; Towards Sound Management of Chemicals, United Nations Environment Programme, (2012).

[3] M. Kuzmanovic', A. Ginebreda, M. Petrovic', D. Barcelo', Risk assessment based prioritization of 200 organic micro-pollutants in 4 Iberian rivers, Science of the Total Environment, (2014).

[4] Y. Luo, W. Guo, H.H. Ngo, L.D. Nghiem, F.I. Hai, J. Zhang, S. Liang, X.C. Wang, A review on the occurrence of micro-pollutants in the aquatic environment and their fate and removal during wastewater treatment, Science of the Total Environment, 473 474 (2014) 619-641.

[5] E.D. N.G.F.M. van der Aa, L. Bijlsma, E. Emke, B.M. van de Ven, A.L.N. van Nuijs, P. de Voogt Drugs of Abuse and Tranquilizers in Dutch Surface Waters, Drinking Water and Wastewater - Results of Screening Monitoring 2009, National Institute for Public Health and the Environment, The Netherlands, (2010).

[6] E. Cho, J. Khim, S. Chung, D. Seo, Y. Son, Occurrence of micro-pollutants in four major rivers in Korea, Science of the Total Environment, $491-492$ (2014) 138-147.

[7] K.K. Barnes, D.W. Kolpin, E.T. Furlong, S.D. Zaugg, M.T. Meyer, L.B. Barber, A national reconnaissance of pharmaceuticals and other organic wastewater contaminants in the United States - I) Groundwater, Science of The Total Environment, 402 (2008) 192-200.

[8] Q. Sui, J. Huang, S. Deng, G. Yu, Q. Fan, Occurrence and removal of pharmaceuticals, caffeine and DEET in wastewater treatment plants of Beijing, China, Water research, 44 (2010) 417-426.

[9] D. Rozman, Z. Hrkal, P. Eckhardt, E. Novotná, Z. Boukalová, Pharmaceuticals in groundwaters: a case study of the psychiatric hospital at Horní Beřkovice, Czech Republic, Environ. Earth Sci., (2014).

[10] L. Pasquini, J.F. Munoz, M.N. Pons, J. Yvon, X. Dauchy, X. France, N.D. Le, C. France-Lanord, T. Görner, Occurrence of eight household micro-pollutants in urban wastewater and their fate in a wastewater treatment plant. Statistical evaluation, Science of the Total Environment, 481 (2014) 459-448.

[11] C.J. Houtman, J. Kroesbergen, K. Lekkerkerker-Teunissen, J.P. van der Hoek, Human health risk assessment of the mixture of pharmaceuticals in Dutch drinking water and its sources based on frequent monitoring data, Science of The Total Environment, 496 (2014) 54-62.

[12] T. Heberer, Occurrence, fate, and removal of pharmaceutical residues in the aquatic environment: a review of recent research data, Toxicology Letters, 131 (2002) 5-17.

[13] S. Kleywegt, V. Pileggi, P. Yang, C. Hao, X. Zhao, C. Rocks, S. Thach, P. Cheung, B. Whitehead, Pharmaceuticals, hormones and bisphenol A in untreated 
source and finished drinking water in Ontario, Canada - Occurrence and treatment efficiency, Science of The Total Environment, 409 (2011) 1481-1488.

[14] A. Verliefde, E. Cornelissen, G. Amy, B. Van der Bruggen, H. van Dijk, Priority organic micro-pollutants in water sources in Flanders and the Netherlands and assessment of removal possibilities with nanofiltration, Environmental Pollution, 146 (2007) 281-289.

[15] J. Rivera-Utrilla, M. Sánchez-Polo, M.Á. Ferro-García, G. Prados-Joya, R. Ocampo-Pérez, Pharmaceuticals as emerging contaminants and their removal from water. A review, Chemosphere, 93 (2013) 1268-1287.

[16] I. Michael, L. Rizzo, C.S. McArdell, C.M. Manaia, C. Merlin, T. Schwartz, C. Dagot, D. Fatta-Kassinos, Urban wastewater treatment plants as hotspots for the release of antibiotics in the environment: A review, Water research, 47 (2013) 957995.

[17] R.I.L. Eggen, J. Hollender, A. Joss, M. Schärer, C. Stamm, Reducing the discharge of micro-pollutants in the aquatic environment: The benefits of upgrading wastewater treatment plants, Environ. Sci. Technol., 48 (2014) 7683-7689.

[18] J.H. Al-Rifai, H. Khabbaz, A.I. Schäfer, Removal of pharmaceuticals and endocrine disrupting compounds in a water recycling process using reverse osmosis systems, Separation and Purification Technology, 77 (2011) 60-67.

[19] J.L. Acero, F.J. Benitez, F.J. Real, F. Teva, Micro-pollutants removal from retentates generated in ultrafiltration and nanofiltration treatments of municipal secondary effluents by means of coagulation, oxidation, and adsorption processes, Chem. Eng. J., 289 (2016) 48-58.

[20] C. Bellona, D. Heil, C. Yu, P. Fu, J.E. Drewes, The pros and cons of using nanofiltration in lieu of reverse osmosis for indirect potable reuse applications, Separation and Purification Technology, 85 (2012) 69-76.

[21] V. Yangali-Quintanilla, S.K. Maeng, T. Fujioka, M. Kennedy, G. Amy, Proposing nanofiltration as acceptable barrier for organic contaminants in water reuse, Journal of Membrane Science, 362 (2010) 334-345.

[22] Y. Zhang, B. Van der Bruggen, G.X. Chen, L. Braeken, C. Vandecasteele, Removal of pesticides by nanofiltration: effect of the water matrix, Separation and Purification Technology, 38 (2004) 163-172.

[23] Y. Zhang, C. Causserand, P. Aimar, J.P. Cravedi, Removal of bisphenol A by a nanofiltration membrane in view of drinking water production, Water research, 40 (2006) 3793-3799.

[24] R. Boussahel, S. Bouland, K.M. Moussaoui, A. Montiel, Removal of pesticide residues in water using the nanofiltration process, Desalination, 132 (2000) 205-209. [25] J. Geens, B. Van der Bruggen, C. Vandecasteele, Transport model for solvent permeation through nanofiltration membranes, Separation and Purification Technology, 48 (2006) 255-263. 
[26] K. Košutić, L. Furač, L. Sipos, B. Kunst, Removal of arsenic and pesticides from drinking water by nanofiltration membranes, Separation and Purification Technology, 42 (2005) 137-144.

[27] K.V. Plakas, A.J. Karabelas, Removal of pesticides from water by NF and RO membranes - A review, Desalination, 287 (2012) 255-265.

[28] J.-H. Tay, J. Liu, D. Delai Sun, Effect of solution physico-chemistry on the charge property of nanofiltration membranes, Water research, 36 (2002) 585-598.

[29] B. Van der Bruggen, J. Schaep, W. Maes, D. Wilms, C. Vandecasteele, Nanofiltration as a treatment method for the removal of pesticides from ground waters, Desalination, 117 (1998) 139-147.

[30] B. Van der Bruggen, J. Schaep, D. Wilms, C. Vandecasteele, Influence of molecular size, polarity and charge on the retention of organic molecules by nanofiltration, Journal of Membrane Science, 156 (1999) 29-41.

[31] W.R. Bowen, J.S. Welfoot, Modelling the performance of membrane nanofiltration-critical assessment and model development, Chemical Engineering Science, 57 (2002) 1121-1137.

[32] M.L. Bruening, D.M. Sullivan, Enhancing the Ion-Transport Selectivity of Multilayer Polyelectrolyte Membranes, Chemistry - A European Journal, 8 (2002) 3832-3837.

[33] J.J. Harris, J.L. Stair, M.L. Bruening, Layered Polyelectrolyte Films as Selective, Ultrathin Barriers for Anion Transport, Chemistry of Materials, 12 (2000) 1941-1946. [34] S.U. Hong, R. Malaisamy, M.L. Bruening, Optimization of flux and selectivity in $\mathrm{Cl}$-/SO42- separations with multilayer polyelectrolyte membranes, Journal of Membrane Science, 283 (2006) 366-372.

[35] G. Liu, D.M. Dotzauer, M.L. Bruening, Ion-Exchange Membranes Prepared Using Layer-by-Layer Polyelectrolyte Deposition, J Memb Sci, 354 (2010) 198-205. [36] R. Malaisamy, M.L. Bruening, High-Flux Nanofiltration Membranes Prepared by Adsorption of Multilayer Polyelectrolyte Membranes on Polymeric Supports, Langmuir : the ACS journal of surfaces and colloids, 21 (2005) 10587-10592.

[37] M.D. Miller, M.L. Bruening, Controlling the Nanofiltration Properties of Multilayer Polyelectrolyte Membranes through Variation of Film Composition, Langmuir : the ACS journal of surfaces and colloids, 20 (2004) 11545-11551.

[38] L. Ouyang, R. Malaisamy, M.L. Bruening, Multilayer polyelectrolyte films as nanofiltration membranes for separating monovalent and divalent cations, Journal of Membrane Science, 310 (2008) 76-84.

[39] W. Shan, P. Bacchin, P. Aimar, M.L. Bruening, V.V. Tarabara, Polyelectrolyte multilayer films as backflushable nanofiltration membranes with tunable hydrophilicity and surface charge, Journal of Membrane Science, 349 (2010) 268 278. 
[40] J.L. Stair, J.J. Harris, M.L. Bruening, Enhancement of the Ion-Transport Selectivity of Layered Polyelectrolyte Membranes through Cross-Linking and Hybridization, Chemistry of Materials, 13 (2001) 2641-2648.

[41] B.W. Stanton, J.J. Harris, M.D. Miller, M.L. Bruening, Ultrathin, Multilayered Polyelectrolyte Films as Nanofiltration Membranes, Langmuir : the ACS journal of surfaces and colloids, 19 (2003) 7038-7042.

[42] K. Hoffmann, T. Friedrich, B. Tieke, Layer-by-layer assembled polyelectrolyte blend membranes and their use for ion separation and rejection, Polymer Engineering \& Science, 51 (2011) 1497-1506.

[43] W. Jin, A. Toutianoush, B. Tieke, Use of Polyelectrolyte Layer-by-Layer Assemblies as Nanofiltration and Reverse Osmosis Membranes, Langmuir : the ACS journal of surfaces and colloids, 19 (2003) 2550-2553.

[44] A. Toutianoush, W. Jin, H. Deligöz, B. Tieke, Polyelectrolyte multilayer membranes for desalination of aqueous salt solutions and seawater under reverse osmosis conditions, Applied Surface Science, 246 (2005) 437-443.

[45] X. Liu, M.L. Bruening, Size-Selective Transport of Uncharged Solutes through Multilayer Polyelectrolyte Membranes, Chemistry of Materials, 16 (2003) 351-357.

[46] S.U. Hong, M.D. Miller, M.L. Bruening, Removal of Dyes, Sugars, and Amino Acids from $\mathrm{NaCl}$ Solutions Using Multilayer Polyelectrolyte Nanofiltration Membranes, Industrial \& Engineering Chemistry Research, 45 (2006) 6284-6288.

[47] T. Ishigami, K. Amano, A. Fujii, Y. Ohmukai, E. Kamio, T. Maruyama, H. Matsuyama, Fouling reduction of reverse osmosis membrane by surface modification via layer-by-layer assembly, Separation and Purification Technology, 99 (2012) 1-7. [48] J. de Grooth, R. Oborný, J. Potreck, K. Nijmeijer, W.M. de Vos, The role of ionic strength and odd-even effects on the properties of polyelectrolyte multilayer nanofiltration membranes, Journal of Membrane Science, 475 (2015) 311-319.

[49] J. de Grooth, B. Haakmeester, C. Wever, J. Potreck, W.M. de Vos, K. Nijmeijer, Long term physical and chemical stability of polyelectrolyte multilayer membranes, Journal of Membrane Science, 489 (2015) 153-159.

[50] D. Menne, J. Kamp, J. Erik Wong, M. Wessling, Precise tuning of salt retention of backwashable polyelectrolyte multilayer hollow fiber nanofiltration membranes, Journal of Membrane Science, 499 (2016) 396-405.

[51] J. de Grooth, D.M. Reurink, J. Ploegmakers, W.M. de Vos, K. Nijmeijer, Charged Micro-pollutant Removal With Hollow Fiber Nanofiltration Membranes Based On Polycation/Polyzwitterion/Polyanion Multilayers, ACS applied materials \& interfaces, 6 (2014) 17009-17017.

[52] S. Ilyas, J. de Grooth, K. Nijmeijer, W.M. de Vos, Multifunctional polyelectrolyte multilayers as nanofiltration membranes and as sacrificial layers for easy membrane cleaning, Journal of colloid and interface science, 446 (2015) 386393. 
[53] L. Krasemann, B. Tieke, Selective Ion Transport across Self-Assembled Alternating Multilayers of Cationic and Anionic Polyelectrolytes, Langmuir : the ACS journal of surfaces and colloids, 16 (1999) 287-290.

[54] D. Yoo, S.S. Shiratori, M.F. Rubner, Controlling Bilayer Composition and Surface Wettability of Sequentially Adsorbed Multilayers of Weak Polyelectrolytes, Macromolecules, 31 (1998) 4309-4318.

[55] S.S. Shiratori, M.F. Rubner, pH-Dependent Thickness Behavior of Sequentially Adsorbed Layers of Weak polyelectrolytes, Macromolecules, 33 (2000) 4213-4219.

[56] V. Izumrudov, E. Kharlampieva, S.A. Sukhishvili, Salt-Induced Multilayer Growth: Correlation with Phase Separation in Solution, Macromolecules, 37 (2004) 8400-8406.

[57] V. Izumrudov, S.A. Sukhishvili, Ionization-Controlled Stability of Polyelectrolyte Multilayers in Salt Solutions, Langmuir : the ACS journal of surfaces and colloids, 19 (2003) 5188-5191.

[58] S. Ilyas, N. Joseph, A. Szymczyk, A. Volodin, K. Nijmeijer, W.M. de Vos, I.F.J. Vankelecom, Weak polyelectrolyte multilayers as tunable membranes for solvent resistant nanofiltration, Journal of Membrane Science, 514 (2016) 322-331.

[59] P. Ahmadiannamini, M.L. Bruening, V.V. Tarabara, Sacrificial polyelectrolyte multilayer coatings as an approach to membrane fouling control: Disassembly and regeneration mechanisms, Journal of Membrane Science, 491 (2015) 149-158.

[60] http://www.chemicalize.org.

[61] J.C. Dijt, M.A.C. Stuart, J.E. Hofman, G.J. Fleer, Kinetics of polymer adsorption in stagnation point flow, Colloids and Surfaces, 51 (1990) 141-158.

[62] W.M. de Vos, A. de Keizer, M.A.C. Stuart, J.M. Kleijn, Thin polymer films as sacrificial layers for easier cleaning, Colloids and Surfaces A: Physicochemical and Engineering Aspects, 358 (2010) 6-12.

[63] J. Choi, M.F. Rubner, Influence of the Degree of Ionization on Weak Polyelectrolyte Multilayer Assembly, Macromolecules, 38 (2004) 116-124.

[64] J.B. Schlenoff, H. Ly, M. Li, Charge and Mass Balance in Polyelectrolyte Multilayers, Journal of the American Chemical Society, 120 (1998) 7626-7634.

[65] J.B. Schlenoff, S.T. Dubas, Mechanism of Polyelectrolyte Multilayer Growth: Charge Overcompensation and Distribution, Macromolecules, 34 (2001) 592-598.

[66] S.T. Dubas, J.B. Schlenoff, Factors Controlling the Growth of Polyelectrolyte Multilayers, Macromolecules, 32 (1999) 8153-8160.

[67] W.M. de Vos, L.L.E. Mears, R.M. Richardson, T. Cosgrove, R. Barker, S.W. Prescott, Nonuniform Hydration and Odd-Even Effects in Polyelectrolyte Multilayers under a Confining Pressure, Macromolecules, 46 (2013) 1027-1034.

[68] R.A. Ghostine, M.Z. Markarian, J.B. Schlenoff, Asymmetric growth in polyelectrolyte multilayers, Journal of the American Chemical Society, 135 (2013) 7636-7646. 
[69] D. Rana, T. Matsuura, Surface Modifications for Antifouling Membranes, Chemical Reviews, 110 (2010) 2448-2471.

[70] A.I. Schäfer, A.G. Fane, T.D. Waite, Nanofiltration : principles and applications, Elsevier, Oxford, 2005.

[71] A. Szymczyk, P. Fievet, Investigating transport properties of nanofiltration membranes by means of a steric, electric and dielectric exclusion model, Journal of Membrane Science, 252 (2005) 77-88.

[72] A.E. Yaroshchuk, Dielectric exclusion of ions from membranes, Advances in Colloid and Interface Science, 85 (2000) 193-230.

[73] B. Van der Bruggen, J. Schaep, W. Maes, D. Wilms, C. Vandecasteele, Nanofiltration as a treatment method for the removal of pesticides from ground waters, Desalination, 117 (1998) 139-147.

[74] M.Y. Kiriukhin, K.D. Collins, Dynamic hydration numbers for biologically important ions, Biophysical Chemistry, 99 (2002) 155-168.

[75] C. Bellona, J.E. Drewes, P. Xu, G. Amy, Factors affecting the rejection of organic solutes during NF/RO treatment - a literature review, Water research, 38 (2004) 2795-2809. 


\section{Supplementary Information}

\section{Chapter 3}

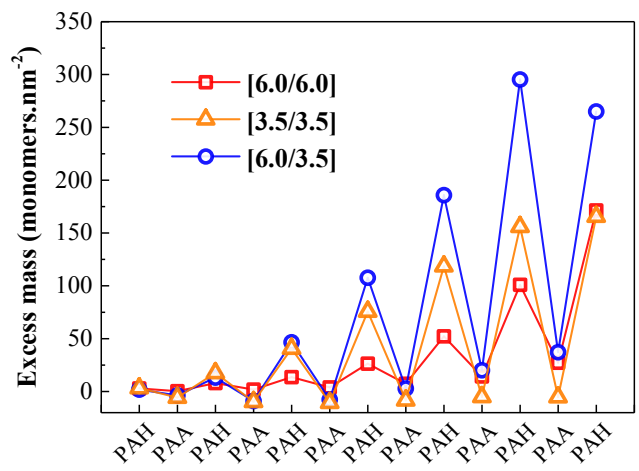

Fig. S3.1: Excess of monomers per adsorption step during LbL assembly of polyelectrolyte multilayers under different $\mathrm{pH}$ conditions. PE $\left(50 \mathrm{mM} \mathrm{NaNO}, 0.1 \mathrm{~g} \cdot \mathrm{l}^{-1}\right)$.
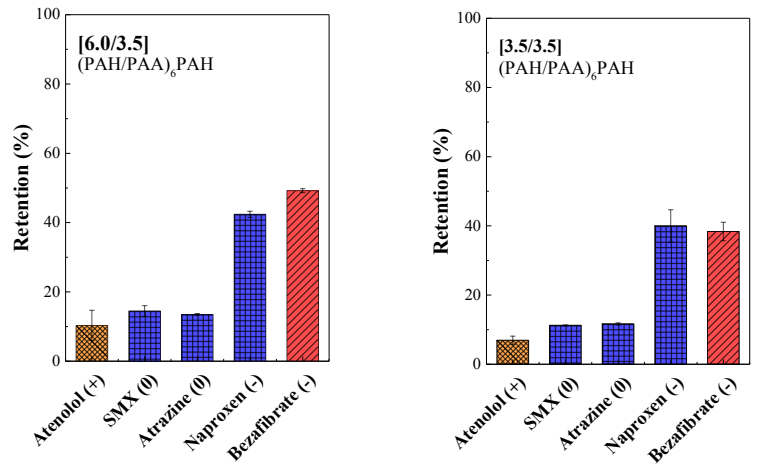

Fig. S3.2: Retention of different micro-pollutants at pH 5.8 by multilayered membranes with 6.5 (+) bilayers of PAH/PAA (prepared at different $\mathrm{pH}$ combinations and ionic strength with $0.1 \mathrm{~g} \cdot l^{-1}$ polymer). Conditions for filtration experiments were: $\mathrm{pH} 5.8, \mathrm{Re} \approx 3,100$, and a transmembrane pressure of 1.8 bar. 


\section{4}

\section{Weak polyelectrolyte multilayers for solvent resistant nanofiltration membranes}

This chapter has been published as:

Shazia Ilyas, Nithya Joseph, Anthony Szymczyk, Alexander Volodin, Kitty Nijmeijer, Wiebe M. Vos, and Ivo F. J Vankelecom, Weak polyelectrolyte multilayers as tunable membranes for solvent resistant nanofiltration, Journal of Membrane Science, 514 (2016) 322-331.

DOI: $10.1016 /$ j.memsci.2016.04.073 


\section{Abstract}

This chapter encompasses the investigation into the solvent resistant nanofiltration (SRNF) performance of multilayer membranes prepared from weak polyelectrolytes. These weak polyelectrolytes are unique in that the charge density is not fixed and depends on the coating $\mathrm{pH}$, adding an extra variable as tuning parameter for SRNF performance. The weak polyelectrolyte based multilayers (PEMs) were prepared on a hydrolyzed PAN support membrane from poly(allylamine hydrochloride) (PAH) as polycation and poly(acrylic acid) (PAA) as polyanion. Detailed investigations on the role of the $\mathrm{pH}$ of the coating solution on the performance of the prepared SRNF-membranes were carried out with organic dyes of different size ( $\sim 300-1000$ Dalton) and charge. Variation in $\mathrm{pH}$ of the coating solutions was found to lead to a large degree of control over the separation performance of the prepared SRNF-membranes for the different dyes. The solvent permeabilities and the dye retentions were measured and correlated to variations in the PEM membrane structures, with more dye adsorption being found for membranes with more free acid and amine groups. The membranes were also found to be stable for long termfiltrations in solvents such as isopropyl alcohol (IPA), acetonitrile (ACN), tetrahydrofuran (THF) and in the challenging polar aprotic solvent, $N, N$ dimethylformamide (DMF). Results of this study clearly demonstrate the potential of using $\mathrm{pH}$ as tuning parameter for weak PEMs to prepare SRNFmembranes optimized for specific applications. 


\subsection{Introduction}

Nanofiltration (NF) is among the pressure-driven membrane processes which have gained a lot of attention recently, with separation characteristics falling in the range between RO and UF membranes. This makes the technology especially promising for separations on a molecular level. One of the key current challenges for NF is to broaden the range of applications from aqueous to organic feeds in the form of solvent-resistant nanofiltration (SRNF) membranes [1]. As SRNF separation does not involve an energy demanding phase transition, it has drawn considerable attention as an alternative separation technique to alleviate the energy costs and related environmental problems caused by conventional separation methods such as distillation [2, 3]. SRNF has potential applications in strategic fields, such as the petrochemical industry, pharmaceutical industry and food industry to separate desired molecules from solvents and/or to recover solvents and solutes from waste streams [4-8]. However, there is lack of membranes that are thermally and chemically stable, that have a high permeability and that provide effective separation of molecules in the range of $200-1000 \mathrm{~g} \cdot \mathrm{mol}^{-1}$ in various organic solvents over long time-scales [1, 3, 9-11]. Polymers are an interesting material for SRNF related applications but very few polymeric membranes are stable: swelling and/or dissolution of the polymeric matrix often results in a loss of membrane selectivity.

In membrane technology, layer by layer (LbL) based self-assembly of charged polyelectrolytes (PEs) on an oppositely charged porous support has recently emerged as one of the simplest, most versatile, and most environmentally benign techniques to fabricate membranes with selective top-layers [12]. Fig. 4.1 shows schematically the LbL process to create membranes with a polyelectrolyte multilayer (PEM) top layer. A key strength of the PEM membranes is their versatility as the layer properties, 
and thus the separation properties, can be controlled via the types of PEs used, the number of deposited layers and the $\mathrm{pH}$ and ionic strength during coating [13]. PEMs have already been used to make different kinds of membranes such as reverse osmosis [14, 15], ion selective [13, 16-19], nanofiltration [14, 20-26] and SRNF membranes [27-32].

Tetrahydrofuran (THF), N,N-dimethylformamide (DMF), acetonitrile (ACN), dimethyl sulfoxide (DMSO), $N$-methyl-2-pyrrolidone (NMP) and dichloromethane (DCM) are some of the important industrial solvents that are still problematic for most of the currently available SRNF membranes [1]. These aprotic solvents demand an extremely high chemical stability from any membrane they come into contact with. Recently, PEM-based SRNF-membranes were reported to have promising and stable performance for some of these solvents [27-31]. Furthermore, PEM-based membranes typically possess a highly charged top layer allowing the possibility for Donnan based exclusion of similarly charged molecules [33]. However, all previous studies utilized at least one strong PE, making their systems relatively insensitive to the $\mathrm{pH}$ at which the layers are formed. With such a combination of PEs, salt addition to the PE dipping solutions best controls the thickness and morphology of the adsorbed layer. With the addition of salt the polymer chains become more coiled due to the screening of the charges along the polyelectrolyte chain. Furthermore, the ionic strength can determine the structure of the formed polyelectrolyte complex. To describe this, Schlenoff et al., [34] defined two types of charge compensations in polyelectrolyte complexation, intrinsic and extrinsic. In the former, a polymeric charge is balanced by an opposite charge of the other polyelectrolyte, while in the later most the polymeric charge is balanced by a counter ion. Increasing the ionic strength shifts the equilibrium from intrinsic to extrinsic charge compensation which leads to thicker, more mobile and 
more swollen layers [34]. Thicker layers on a membrane lead to lower membrane permeabilities, whereas more open layers can increase the permeability [35]. However, the effectiveness of this parameter is often limited to a small range of salt concentrations because of either solubility problems or decomposition of the multilayer films when increasing the ionic strength $[36,37]$.

The use of two weak PEs (both the polycation and the polyanion) can provide the opportunity to use the $\mathrm{pH}$ during coating to allow a large degree of control over membrane performance [38]. Unlike strong PEs, which remains charged over the entire $\mathrm{pH}$ range, the degree of ionization of weak PEs depends greatly on the deposition solution $\mathrm{pH}$. So the resulting charge density of PEs and the thickness of deposited PEMs can be affected by both the $\mathrm{pH}$ and the salt concentration of the PE solutions [39-42]. SRNFmembranes fabricated by the LbL deposition of weak PEs thus have an obvious advantage: the molecular structure inside of the PEM and the charge on the outside of the PEM can be controlled by an additional parameter, the $\mathrm{pH}$. An added advantage of using weak PEs based membranes is that after fouling their cleaning can be made very easy using a sacrificial layer approach as already shown in chapter $2[43,44]$.

In this work, the first example of a PEM-based SRNF-membrane is presented prepared from weak PEs, a system where variation in $\mathrm{pH}$ can be used to tailor the membrane performance for specific solutes. More specifically, poly(acrylic acid) (PAA) and poly(allylamine hydrochloride) (PAH) based PEMs were used, as this system has already shown itself promising in traditional NF-applications $[38,43]$. The $\mathrm{pH}$ of the coating solution was used as a parameter to control the layer thickness and the molecular organization of the multilayers, which in turn leads to different separation behavior for different solutes. PEMs were prepared under three 
$\mathrm{pH}$ combinations (PAH/PAA: 7.5/7.5, 7.5/3.5 and 3.5/3.5) and were characterized on model surfaces in order to understand the effect of coating $\mathrm{pH}$ on their resulting multilayer composition. The PEMs were then prepared on a hydrolyzed PAN support membrane under the same coating conditions and were characterized in terms of surface roughness, contact angle and IPA permeance. The performance of these multilayered membranes was characterized in terms of their ability to retain different organic solutes of varying size and charge from IPA in order to understand the effect of coating $\mathrm{pH}$ on membrane performance. Finally, the multilayered membranes were tested for their stability towards aprotic solvents such as acetonitrile (ACN), dimethylformamide (DMF) and tetrahydrofuran (THF) for long periods of time $(>50 \mathrm{~h})$.

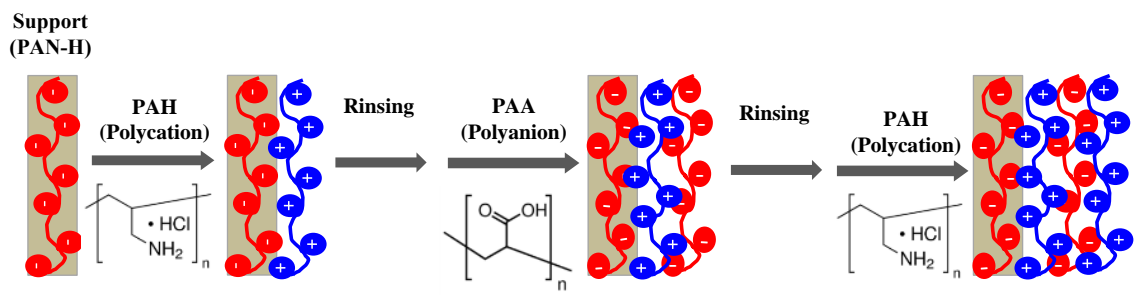

Fig. 4.1: Overview of the LbL assembly of PEMs of PAH/PAA on a charged membrane

\subsection{Experimental}

\subsubsection{Chemicals}

Polyacrylonitrile (PAN, $\left.\mathrm{M}_{\mathrm{W}}=150,000 \mathrm{Da}\right)$ was purchased from Scientific Polymer Products Inc., Ontario, New York. Isopropyl alcohol (IPA), acetonitrile (ACN), tetrahydrofuran (THF), N,N-dimethylformamide (DMF) and dimethyl sulfoxide (DMSO) were obtained from VWR, Leuven, Belgium, and were used as solvents. Rose bengal (RB), acid fuchsin (AF), bromothymol blue (BTB), methylene blue (MB) and methyl orange (MO) were purchased from Sigma-Aldrich and used as solutes (see Table 4.1 for more details). The PEs used in this study were poly(allyl amine) 
hydrochloride $\left(\mathrm{PAH} ; \mathrm{Mw}=15,000 \mathrm{~g} \cdot \mathrm{mol}^{-1}\right)$ and poly(acrylic acid) (PAA; $\left.\mathrm{Mw}=15,000 \mathrm{~g} \cdot \mathrm{mol}^{-1}\right)$. Sodium nitrate $\left(\mathrm{NaNO}_{3}\right)$ was used to adjust the ionic strength in all solutions. Sodium hydroxide $(\mathrm{NaOH})$ and hydrochloric acid $(\mathrm{HCl})$ were used to adjust the $\mathrm{pH}$.

Table 4.1 Properties of solutes used in this study.

\begin{tabular}{|c|c|c|c|}
\hline Solute & $\begin{array}{l}\text { Mol. weight } \\
\text { (Dalton) }\end{array}$ & Charge & $\underset{\left(\mathrm{cm}^{3} \cdot \mathrm{mol}^{-1}\right)}{\text { Molar volume }}$ \\
\hline Rose Bengal (RB) & 1017 & -2 & 273 \\
\hline Methyl Orange (MO) & 327 & -1 & 160 \\
\hline Bromothymol Blue (BTB) & 624 & 0 & 281 \\
\hline Methylene Blue (MB) & 320 & +1 & 242 \\
\hline Acid Fuchsin (AF) & 585 & -2 & 247 \\
\hline
\end{tabular}

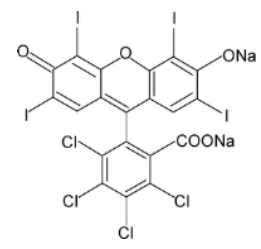

Rose Bengal (RB)

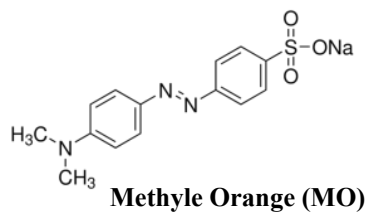

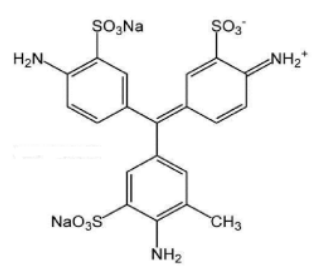

Acid Fuchsin (AF)

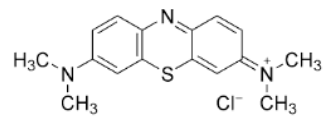

Methylene Blue (MB)

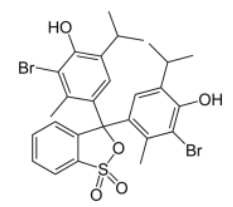

Bromothymol Blue (BTB)

Fig. 4.2: Chemical structures of solutes used for rejection experiments. 
PE solutions always contained $0.1 \mathrm{~g} \cdot \mathrm{l}^{-1}$ of polymer at various $\mathrm{pH}$ conditions and always with $50 \mathrm{mM}$ of background electrolyte. Deionized water (Milli Q, $18.2 \mathrm{M} \Omega \cdot \mathrm{cm}$ ) was used to rinse the membranes and to prepare polyelectrolyte solutions. All solutions were used within eight days after preparation.

\subsubsection{Membrane support preparation and LbL coating}

The charged PAN-H support was prepared using a procedure reported earlier [27], but a short summary is given here. 15 wt.\% PAN in DMSO was cast on a polypropylene/polyethylene support (FO 2471, Viledon) and then immersed in deionized water. The PAN film was subsequently immersed in 10 wt. $\% \mathrm{NaOH}$ at $50{ }^{\circ} \mathrm{C}$ for $45 \mathrm{~min}$ for hydrolysis. The remaining $\mathrm{NaOH}$ was removed by copious rinsing with water. The PEM-based membranes were prepared by means of an automated dip-coater (HTML, Belgium). The dip-coater comprises four separate compartments, two for PE solutions and two for background electrolyte solutions for rinsing. PEs were dissolved in background electrolyte solutions at a concentration of $0.1 \mathrm{~g} \cdot \mathrm{l}^{-1}$. To adsorb the PEs, the PAN-H support was first immersed in the solution of the cationic PE (PAH) for 15 min, followed by rinsing with background electrolyte of same ionic strength and $\mathrm{pH}$ as that of the $\mathrm{PAH}$ solution for $10 \mathrm{~min}$, then immersed in the solution of the anionic PE (PAA) and rinsed with background electrolyte of same ionic strength and $\mathrm{pH}$ as that of the PAA solution. Three different $\mathrm{pH}$ combinations for PAH/PAA were used to coat the membranes and resulting membranes are [7.5/7.5], [7.5/3.5] and [3.5/3.5]. For example, [7.5/3.5] represents membranes with multilayer films (PAH/PAA) alternately assembled with the PAH layers deposited at $\mathrm{pH} 7.5$ and the PAA layers at $\mathrm{pH}$ 3.5. The rinsing step removes any loosely bound or excess polyelectrolyte from the membrane surface and prevents complex formation in bulk solution. The described procedure was repeated to deposit 
the desired number of bilayers. The final membranes were then stored in Milli Q water for further use.

\subsubsection{Preparation of PEMs on glass slides and silicon wafers}

For ellipsometry studies, the PEMs were assembled on silicon wafers using a similar procedure as for the membrane support. For MB adsorption studies, PEMs were assembled on glass slides. Before assembly, the silicon wafers and glass slides were pre-treated with piranha solution (3:1 mixture of 98\% $\mathrm{H}_{2} \mathrm{SO}_{4}$ and $30 \% \mathrm{H}_{2} \mathrm{O}_{2}$; caution: piranha is a strong oxidizer and should not be stored in closed containers) for $2 \mathrm{~h}$ and rinsed in de-ionized water. Wafers and glass slides were used within $1 \mathrm{~h}$ after piranha treatment. PEMs were then deposited on wafers and glass slides [32, 45], and were dried with a nitrogen stream and stored at ambient conditions for characterization.

\subsubsection{Characterization}

\section{Thickness of PEMs by ellipsometry}

The dry thickness of PEMs deposited on polished silicon wafers under different $\mathrm{pH}$ conditions were measured using an ellipsometer (Woolam EC400, M-2000V) at ambient conditions. All samples were dried at room temperature with a nitrogen stream prior to measurements.

\section{Methylene blue adsorption on PEMs}

Methylene blue (MB) staining technique was used to gain information on the charge of the surface layer (terminal layer) of PEMs. PEMs were assembled on glass slides, dried with a nitrogen stream, and subsequently immersed in aqueous $10^{-3} \mathrm{M}$, pH 7.0 $\mathrm{MB}$ aqueous solutions for $10 \mathrm{~min}$. With an immersion time of $15 \mathrm{~min}$ or less the dye can only diffuse into the outer most layers, making the results independent of the layer thickness $[39,40]$. After immersion in the dye solution, the multilayer films were soaked in demiwater for $1 \mathrm{~min}$ to remove unbound dye and dried with a mild air flow. 
$\mathrm{UV} / \mathrm{Vis}$ spectroscopy was used to determine the amount of MB adsorption on multilayer films. Absorbance was measured at a wavelength of $600 \mathrm{~nm}$.

\section{Fourier transform infrared (FTIR) spectroscopy}

FTIR spectra of membranes were acquired using a spectrometer (Varian 670-IR, Varian Inc., USA) in absorbance mode. The samples were dried at room temperature for $24 \mathrm{~h}$ prior to FTIR measurement to minimize the influence of water.

\section{Scanning electron microscopy (SEM)}

SEM (Philips XL FEG30) was used to study the surface structure and cross section of the membranes. Before use, the SEM samples were first gold coated.

\section{Atomic force microscopy (AFM)}

The surface morphology and roughness of dry membranes were measured by AFM (Agilent 5500) operating in tapping mode at ambient conditions (relative humidity $\sim 30 \%$ ). Commercial AFM cantilevers (PPP-NCSTR AFM probes from NanoAndMore GmbH) made of Si with a nominal spring constant of $7.4 \mathrm{~N} \cdot \mathrm{m}^{-1}$ and with a typical tip radius of less than $7 \mathrm{~nm}$ were used. AFM measurements were performed with scan areas of $1 \times 1 \mu \mathrm{m}^{2}$ at 3 different locations for each of the samples. The average roughness $\left(R_{a}\right)$ and the root-mean-square roughness $\left(R_{r m s}\right)$, which is given by the standard deviation of the topography height measurement data ( $Z$ values), were calculated using equation 4.1:

$R_{a}=\frac{1}{N} \sum_{i=1}^{N}|Z i-\bar{Z}| \quad ; \quad R_{r m s}=\sqrt{\frac{1}{N} \sum_{i=1}^{N}|Z i-\bar{Z}|^{2}}$

Where $\bar{Z}$ is the average of the height values within the given area, $Z_{i}$ is the current height, and $N$ is the number of data points taken within the given area. 


\section{Contact angle}

Optical contact angle measurements of a DI water droplet on the membrane surface were performed using a Krüss goniometer (drop shape analysis system DSA $10 \mathrm{Mk} 2$ ). For contact angle measurements, the membranes were dried overnight at room temperature. The contact angle of the sessile drop of $3 \mu \mathrm{L}$ of water on the membrane was measured three times for each membrane at $20{ }^{\circ} \mathrm{C}$ in static mode, and the average value and standard deviation are reported. The contact angles were measured $5 \mathrm{~s}$ after the droplet was placed on the surface.

\subsubsection{Membrane performance}

\section{Filtration and rejection}

Five dyes (Fig. 4.2) were selected for the rejection experiments. The dye molecular weight range was chosen to be between 319 to 1100 Dalton. The selection of dyes was made such that it covers neutral, positive, negative, but also small and large molecular sizes. Filtration of membranes with dye solutions was performed using a stainless steel dead-end high-throughput apparatus (HTML, Belgium) [45] with 8 filtration cells, all with a membrane surface area of $1.77 \mathrm{~cm}^{2}$. The filtration setup was pressurized with nitrogen to 25 bar. To minimize concentration polarization during filtration, the feed solution was constantly stirred at $500 \mathrm{rpm}$. Dye rejections were calculated based on the differences between permeate and concentrate concentrations. The retention values were calculated from concentrations of the permeate and of the original feed solutions according to equation 4.2 :

$$
R(\%)=1-\frac{C_{p}}{C_{f}} \times 100
$$

Where $C_{p}$ and $C_{f}$ are solute concentration in the permeate and the feed, respectively. The permeation was stopped when the retention reached a 
constant value. All measurements were based on at least three samples, and the average values were used. The standard deviation on the measurements was about 5\%. All were used in a $35 \mu \mathrm{M}$ concentration, with most experiments performed in IPA.

\section{Long term filtration studies}

To further demonstrate the chemical stability of these weak PEMmembranes for different solvents and for longer time-scales, ACN, THF and DMF were selected for long-term filtrations. Table 4.2 gives the physicochemical properties of these solvents. Membranes prepared with 5 bilayers [7.5/3.5] were subjected to filtration with RB in IPA, THF, ACN and DMF separately for more than $50 \mathrm{~h}$.

Table 4.2 Physico-chemical properties of solvents used [46].

\begin{tabular}{|c|c|c|c|c|}
\hline Solvent & $\begin{array}{c}\text { Molar volume } \\
\left(\mathrm{cm}^{3} \cdot \mathrm{mol}^{-1}\right)\end{array}$ & $\begin{array}{l}\text { Viscosity } \\
\text { (cP) }\end{array}$ & $\begin{array}{l}\text { Molar volume/viscosity } \\
\left(\mathrm{cm}^{3} \cdot \mathrm{mol}^{-1} \cdot \mathrm{cP}^{-1}\right)\end{array}$ & $\begin{array}{l}\text { Dielectric } \\
\text { constant }\end{array}$ \\
\hline IPA & 76.92 & 2.00 & 38.46 & 18.30 \\
\hline DMF & 77.43 & 0.82 & 94.43 & 36.70 \\
\hline $\mathrm{ACN}$ & 52.86 & 0.38 & 139.10 & 37.50 \\
\hline THF & 81.08 & 0.55 & 147.42 & 7.60 \\
\hline
\end{tabular}

\subsection{Results and discussion}

The results and discussion section is divided into three major parts. The first part deals with the characterization of PEMs by ellipsometry and MB absorption to study their structure and composition. In the second part, the characterization of the support and the prepared multilayered membranes is given. The third part reports on the SRNF-membrane performance, with 
membranes prepared under different $\mathrm{pH}$ conditions, being tested for their retention of different organic molecules.

\subsubsection{Properties of PEMs}

\section{Thickness}

The thickness of multilayer films of PAH/PAA deposited under different $\mathrm{pH}$ combinations (7.5/7.5, 7.5/3.5 and 3.5/3.5 for PAH/PAA) at a polymer concentration of $0.1 \mathrm{~g} \cdot \mathrm{l}^{-1}$ in a $50 \mathrm{mM} \mathrm{NaNO}_{3}$ aqueous solution was determined by ellipsometry. The used salt concentration was selected based on a previous study where optimal growth of these PEMs was achieved at 50 $\mathrm{mM}$ [43]. The measured average thickness for 5 bilayer thick multilayers is reported in Table 4.3. Clearly, the thickness of the layers is influenced by the $\mathrm{pH}$ of the coating solution of the polycation and the polyanion. For weak polyelectrolyte pairs such as PAH/PAA, the thickness, composition and organization of the multilayers can be systematically tuned by varying the $\mathrm{pH}$ of each PE solution [39, 40, 47]. The $\mathrm{pH}$ controls the charge density of the weak PEs by controlling the degree of dissociation of the basic and acidic groups on the polymer chains. PAA with $\mathrm{pK}_{\mathrm{a}}$ of 6.5 and $\mathrm{PAH}$ with $\mathrm{pK}_{\mathrm{a}}$ 8-9 [47], are nearly fully charged (80-90\% charged groups) at a $\mathrm{pH}$ condition of [7.5/7.5] and thus form thin layers upon deposition, requiring just a small amount of material to compensate for all charges from a previously deposited layer, most likely with a high degree of intrinsic charge compensation inside the bulk of the layers. The thickest layers are formed when one of the PEs is only partially charged (PAA at $\mathrm{pH} 3.5$ ) and other is fully or nearly fully charged (PAH at $\mathrm{pH} 3.5$ and 7.5 respectively). The partially charged polymer segments lead to a more coiled conformation and favor diffusion of counter ions of the employed salt into the multilayer, forming more swollen layers with more mobile chains leading to more extrinsic charge compensation of the polymeric charges. 
Table 4.3 Average thickness of PEMs with 5 bilayers of PAH/PAA (prepared at three $\mathrm{pH}$ combinations with $0.1 \mathrm{~g} \cdot \mathrm{l}^{-1}$ polymer and $50 \mathrm{mM}$ salt).

\begin{tabular}{llll}
\hline \multirow{2}{*}{ PEMs } & \multicolumn{2}{l}{$\mathbf{p H}[$ PAH/PAA] } \\
\cline { 2 - 4 } & {$[7.5 / 7.5]$} & {$[7.5 / 3.5]$} & {$[3.5 / 3.5]$} \\
\hline Thickness (nm) & $10 \pm 1$ & $83 \pm 1$ & $61 \pm 2$ \\
\hline
\end{tabular}

\section{Adsorption of the cationic dye methylene blue (MB)}

A dye test was performed on PEMs on glass surfaces to determine the excess of free carboxylic acid groups available as binding sites (for positively charged solutes) on the surface of PEMs. Fig. 4.3 shows the results of the MB test performed with 5 (ending with PAA) and 5.5 (ending with PAH) bilayers of PEMs deposited on glass slides. A higher absorbance of MB indicates the presence of more free carboxylic acid groups. At $\mathrm{pH}$ condition [7.5/7.5] for PAH/PAA, both PEs have a high charge density (fully ionized) producing polycation-polyanion contact pairs and leaving only little free carboxylic acid groups for the adsorption of positive dye. Thus, regardless whether PAH (+) or PAA (-) is the last layer, few free functional sites will be left on the surface with most of the polyions bound with an oppositely charged group. As can be seen from these results, just a small difference in MB absorbance exists for PAH (+) or PAA (-) terminated layers, and these values are always low.

However, at the $\mathrm{pH}$ combinations [7.5/3.5] and [3.5/3.5], an unbalanced ionization state (PAA only partly charged during deposition at $\mathrm{pH} 3.5$ ) results in many free acidic groups. For [7.5/3.5], this result in a very high absorbance for the PAA (-) terminated layer, indicating a highly charged layer. Still for the PAH $(+)$ terminated [7.5/3.5] layer, the absorbance drops strongly, which indicates just a small amount of free unbound acid groups. This is an indication of the normal charge inversion leaving just a small 
amount of free unbound acid groups. For [3.5/3.5], absorbance is always rather high. This is an indication that this layer has many extrinsically compensated ion pairs (free $\mathrm{NH}_{2}$ and $\mathrm{COOH}$ groups).

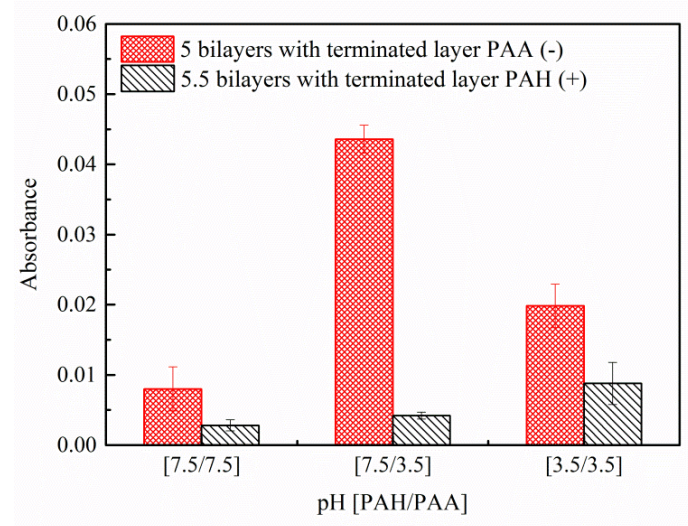

Fig. 4.3: Methylene blue absorbance measured at $600 \mathrm{~nm}$ of 5 and 5.5 bilayers of PAH/PAA prepared at three different $\mathrm{pH}$ combinations with polymer concentration at $0.1 \mathrm{~g} \cdot \mathrm{l}^{-1}$ and 50 mM salt.

The results so far show at the chosen $\mathrm{pH}$ conditions, three entirely different PEMs are created. For [7.5/7.5], a very thin layer with a high degree of intrinsic charge compensation is found. For [7.5/3.5], the thickest layer is created that is especially highly charged when terminated with PAA (-). Finally, for [3.5/3.5] a thick layer is obtained that always has many free acid groups available, likely an indication of very high extrinsic charge compensation and thus presence of free amine and acid groups.

\subsubsection{Characterization of support and PEMs based membranes}

\section{ATR-FTIR}

ATR-FTIR was used to confirm the hydrolysis of the PAN support. Fig. S4.1 presents the ATR-FTIR spectra of a PAN and a hydrolyzed PAN membrane. The peaks at 2243 and $1451 \mathrm{~cm}^{-1}$ are due to stretching vibrations of the $\mathrm{CN}$ 
moiety of the PAN membrane support [48]. For hydrolyzed PAN, most of the $\mathrm{CN}$ groups convert to $\mathrm{COO}^{-}$groups, leading to a peak reduction at 2243 $\mathrm{cm}^{-1}$ and the emergence of a new peak at approximately $1674 \mathrm{~cm}^{-1}$, which corresponds to the $\mathrm{C}=\mathrm{O}$ bond in the $\mathrm{COO}^{-}$groups. FTIR results thus confirm the hydrolyzation of PAN into a negatively charged membrane support.

\section{SEM}

Surface images of the PAN-H support and PEMs based SRNF membranes [7.5/7.5], [7.5/3.5] and [3.5/3.5] showed no significant difference in the surface morphology and are given in Fig. S4.2. A cross section of the PAN$\mathrm{H}$ support shows a very open pore structure with fingerlike pores (Fig. S4.3), while the thickness of the support layer used is in the range of $150 \mathrm{um}$.

\section{Surface morphology and surface roughness}

AFM images presenting the surface morphology of the membrane support and the multilayered membranes are displayed in Fig. 4.4. The surface structure seems to become smooth with the deposition of polyelectrolyte multilayers. These images thus suggest that the applied polyelectrolytes form an even layer on top of the support. In images b and c, some small cracks can be observed but as they are much shallower than the thickness of the PEM films these are not believed to be true defects.

Average surface roughness values of the membranes on $1 \times 1 \mu \mathrm{m}^{2}$ scans in root mean square $\left(\mathrm{R}_{\mathrm{rms}}\right)$ and average roughness $\left(\mathrm{R}_{\mathrm{a}}\right)$ are presented in Table 4.4. When the charge density of both PAH and PAA is high (at $\mathrm{pH} 7.5 / 7.5$ ), smooth layers are formed due to a flattened conformation of the polyelectrolytes. The layers formed seem to be somewhat more rougher when one of the polymers is only partially charged [40] as at $\mathrm{pH} 7 . / 5 / 3.5$ and 3.5/3.5, since these thicker layers will have more coiled polymers. 

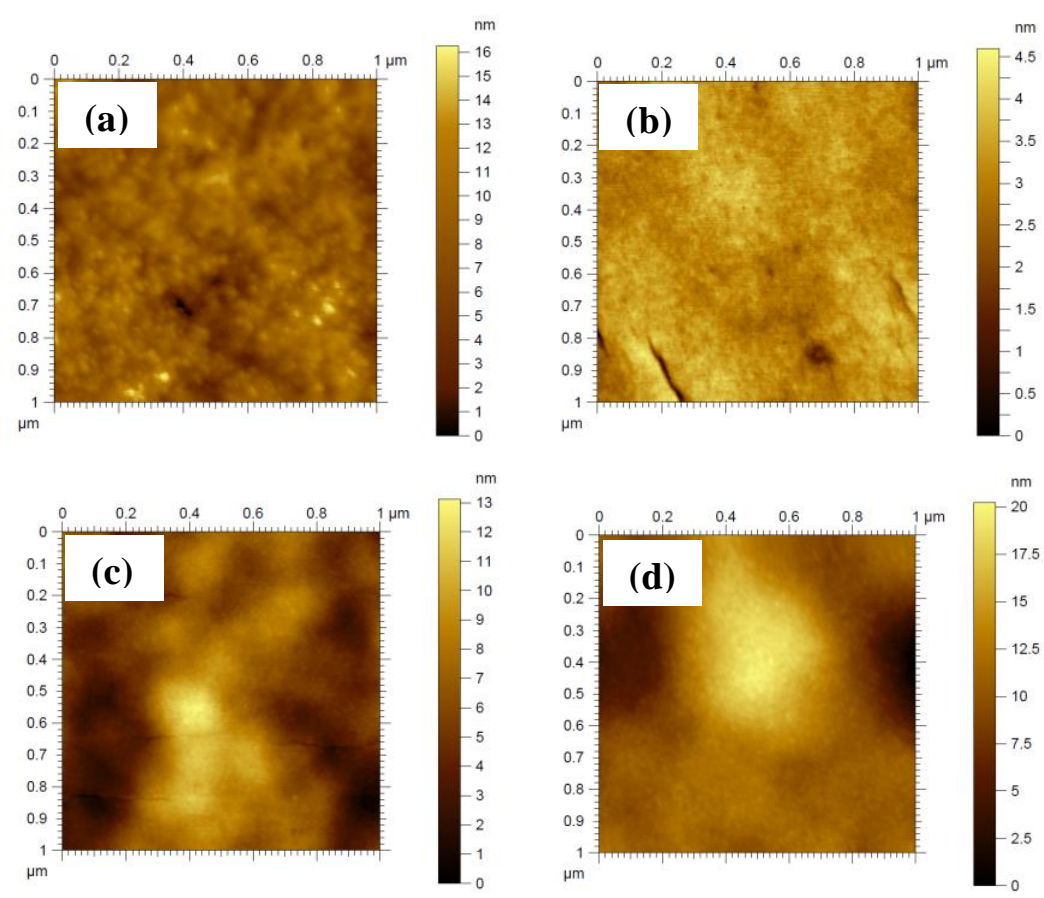

Fig. 4.4: AFM images of (a) support; and multilayered SRNF membranes prepared with PAH/PAA pH of (b) [7.5/7.5] (c) [7.5/3.5] (d) [3.5/3.5] with polymer concentration of 0.1 $\mathrm{g} \cdot \mathrm{t}^{-1}$ and $50 \mathrm{mM}$ salt.

Table 4.4 Calculated surface roughness of membranes with 5 bilayers of PAH/PAA (prepared at three $\mathrm{pH}$ combinations with $0.1 \mathrm{~g} \cdot \mathrm{l}^{-1}$ polymer and $50 \mathrm{mM}$ salt).

\begin{tabular}{lllll}
\hline \multirow{4}{*}{ Roughness } & Support & {$[\mathbf{7 . 5 / 7 . 5}]$} & {$[\mathbf{7 . 5 / 3 . 5}]$} & {$[\mathbf{3 . 5 / 3 . 5}]$} \\
\cline { 3 - 5 } & $2.6 \pm 0.4$ & $0.5 \pm 0.1$ & $2.1 \pm 0.2$ & $3.5 \pm 0.7$ \\
\hline $\mathbf{R}_{\mathbf{r m s}}(\mathbf{n m})$ & $2.4 \pm 0.4$ & $0.4 \pm 0.1$ & $1.4 \pm 0.1$ & $1.5 \pm 0.1$ \\
\hline
\end{tabular}

\section{Contact angle with water}

Determining the contact angle with water is a useful method to observe changes in the hydrophilicity of the membranes. For PAN and PAN-H, contact angles of $47.0 \pm 1.0$ and $15.0 \pm 2.0$ respectively, confirm successful hydrolyzation of the PAN support. Contact angle values measured for all 
three types of membranes with PAH $(+)$ and PAA (-) terminated layers are given in Fig. 4.5. The coating of PEMs on the hydrophilic membrane support in all cases leads to higher contact angles. Little difference in the contact angle value with the type of terminating layer is observed for [7.5/7.5] membranes, while it is substantial for the [7.5/3.5] and [3.5/3.5] membranes. Here, the PAA (-) terminated membrane is more hydrophilic as compared to the $\mathrm{PAH}(+)$ terminated membrane, likely because of the large excess of carboxylic groups. The [7.5/7.5] prepared layer is relatively hydrophobic, as could be expected for a PEM layer with a high degree of intrinsic charge compensation (few free $-\mathrm{NH}_{2}$ and $-\mathrm{COOH}$ groups). On the other hand, the contact angle is considerably lower for [3.5/3.5] and a very high degree of extrinsic charge compensation can be expected. It is good to mention that also roughness influences contact angle measurements, however as the determined rough nesses were found to be very low (table 4.4) this effect could be neglected.

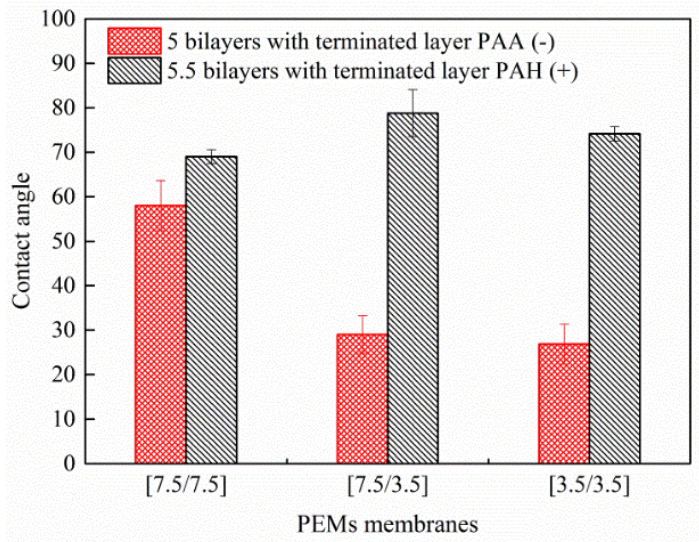

Fig. 4.5: Sessile droplet water contact angle of 5 and 5.5 bilayer membranes [7.5/7.5, 7.5/3.5 and 3.5/3.5] prepared at a polymer concentration $0.1 \mathrm{~g} \cdot \mathrm{t}^{-1}$ and $50 \mathrm{mM}$ salt. In the 5 bilayer membranes the terminating layer is of PAA and in 5.5, PAH is the terminating layer. 


\subsubsection{SRNF performance of PEM based membranes}

\section{Pure solvent permeability}

After coating the support with PEMs, the pure solvent permeability of the support and the prepared membranes was measured. The pure IPA permeance values were: $127.0 \pm 7.01 \cdot \mathrm{m}^{-2} \cdot \mathrm{h}^{-1} \cdot \mathrm{bar}^{-1}$ for the PAN-H support, $7.0 \pm 0.51 \cdot \mathrm{m}^{-2} \cdot \mathrm{h}^{-1} \cdot$ bar $^{-1}$ for $[7.5 / 7.5]$ membranes, $4.0 \pm 1.01 \cdot \mathrm{m}^{-2} \cdot \mathrm{h}^{-1} \cdot \mathrm{bar}^{-1}$ for [7.5/3.5] membranes, and 5.0 $2.01 \cdot \mathrm{m}^{-2} \cdot \mathrm{h}^{-1} \cdot \mathrm{bar}^{-1}$ for [3.5/3.5] membranes. The $[7.5 / 7.5]$ membranes thus have a higher flux. However, when taking into account the thickness, the [7.5/7.5] membranes have much lower permeability as they are 8 times thinner (Table 4.3) than [7.5/3.5] and 6 times thinner than [3.5/3.5] membranes. It seems that not only is this layer quite thin, it is also quite dense, a typical behavior expected for PEM membranes with a high degree of intrinsic charge compensation [35].

\section{Influence of solute size and charge}

Five different dyes with double negative charges (RB, Mw $1017 \mathrm{Da}$ and AF, $\mathrm{Mw} 558 \mathrm{Da}$ ), single negative charge (MO, Mw $327 \mathrm{Da})$, positive charge (MB, Mw $320 \mathrm{Da}$ ) and without charge (BTB, Mw $624 \mathrm{Da}$ ) were selected as solutes (Table 4.1). Filtrations were performed with membranes coated from $50 \mathrm{mM}$ salt solutions and with different $\mathrm{pH}$ combinations for PAH/PAA [7.5/7.5, 7.5/3.5 and 3.5/3.5]. PAN-H support used to prepare PEMs based SRNF membranes has RB retention of $46 \%$ with a $2.21 \cdot \mathrm{m}^{-2} \cdot \mathrm{h}^{-1} \cdot \mathrm{bar}^{-1}$ permeance. It is important to mention that the retention of organic dyes in SRNF is a complex mixture of factors including Donnan exclusion, size exclusion and the mutual affinities between the dye, the solvent and the membrane [1, 49-51]. Furthermore, the dye can potentially foul the SRNFmembrane, either by adsorption on top of the PEM layer, adsorption in the PEM layer or adsorption on the charged membrane support. Such fouling will lead to lower permeance but can substantially increase the initial 
rejection. This is the first investigation of the SRNF performance of multilayered membranes prepared from weak PEs and because of the mentioned complexity, focus is to show the easiness of the approach in combination with its versatility and on comparing the performance of the differently prepared PEM membranes, rather than determining the exact rejection mechanism for all membrane/dye combinations.

In Fig. 4.6, the filtration results of multilayered membranes with 5 bilayers of PAH/PAA, prepared from polymer solutions with different $\mathrm{pH}$ combinations are given. The retention and permeance results are given for negatively charged solutes (RB and AF) in IPA. For all membranes, more than $90 \%$ retention for $\mathrm{RB}$ is observed but with a sharp drop in permeability (Fig. 4.6a). Possibly, a strong solute adsorption in/on the membranes takes place which then densifies (i.e. bivalent dyes can crosslink) the membranes [30]. However, the [7.5/7.5] membrane is more permeable than the others with similar rejection. We hypothesize that the lower amount of free $-\mathrm{NH}_{2}$ and $-\mathrm{COOH}$ groups in this layer, also leaves less adsorption sites available for the dyes. Consequently, [3.5/3.5] has the lowest permeability as compared to pure IPA filtration as it has most free $-\mathrm{COOH}$ and $-\mathrm{NH}_{2}$ groups. $\mathrm{AF}$ is a smaller molecule than $\mathrm{RB}$ and also carries two negative charges. Membranes show slightly less rejection for AF as compared to RB (Fig. $4.6 b)$, probably because of the smaller size. Especially membrane [7.5/7.5] (Fig. 4.6b) shows good rejection while retaining a high operational permeability, in agreement with the RB results. It is surprising that the highly negative layer of the [7.5/3.5] membrane adsorbs so many double negatively charged molecules. It is possible that the molecules do not adsorb at the top of the layer, where the excess of charge is localized, but rather deeper inside the layers. 

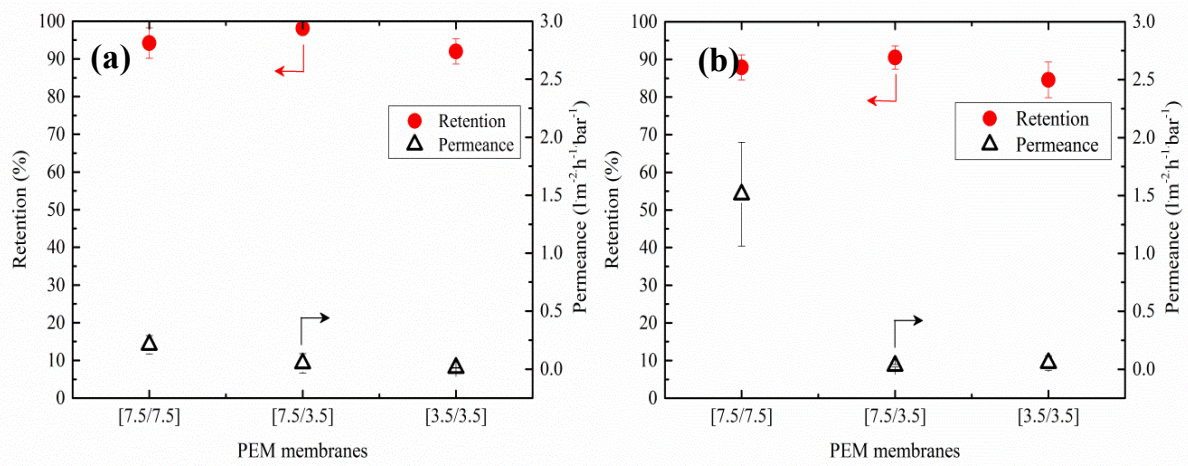

Fig. 4.6: SRNF performance of membranes for large sized charged solutes by 5 bilayers of PAH/PAA (prepared at three $\mathrm{pH}$ combinations with $0.1 \mathrm{~g} \cdot \mathrm{l}^{-1}$ polymer and $50 \mathrm{mM}$ salt) (a) retention and permeance of $R B$ from IPA solution; $(b)$ retention and permeance of $A F$ from IPA solution.

In Table 4.5, the comparison is given of the SRNF performance of membranes from the present work with previously reported PEM membranes prepared from two strong PEs or one strong and one weak PE $[27,31]$. The data are given for 5 bilayer thick PEM membranes for RB retention from IPA. It shows that PEM membranes prepared from both weak PEs have a RB retention comparable to that of membranes prepared from both strong PEs or from one of the weak PEs. Present work even shows the highest observed retention for RB within this comparison.

Table 4.5 Comparison of SRNF performance of PEMs based membranes for RB in IPA.

\begin{tabular}{|c|c|c|c|}
\hline PEMs membrane & $\begin{array}{l}\text { Permeance } \\
\left(\mathbf{l} \cdot \mathbf{m}^{-2} \cdot \mathbf{h}^{-1} \cdot \mathbf{b a r}^{-1}\right)\end{array}$ & $\begin{array}{c}\text { Retention } \\
\text { (\%) }\end{array}$ & References \\
\hline $\begin{array}{l}(\mathrm{PAH} / \mathrm{PAA}, \mathrm{pH} 7.5 / 7.5)_{5} 50 \mathrm{mM} \\
(\mathrm{PAH} \mathrm{pH} 7.5 / \mathrm{PAA} \mathrm{pH} 3.5)_{5} 50 \mathrm{mM}\end{array}$ & $\begin{array}{l}0.21 \pm 0.08 \\
0.05 \pm 0.09\end{array}$ & $\begin{array}{l}95 \pm 4 \\
99 \pm 1\end{array}$ & $\begin{array}{l}\text { Present } \\
\text { work }\end{array}$ \\
\hline $\begin{array}{l}(\mathrm{PDDA} / \mathrm{PAA}, \mathrm{pH} 7 / 4)_{5} 0 \mathrm{mM} \\
(\mathrm{PDDA} / \mathrm{PAA}, \mathrm{pH} 7 / 4)_{5} 100 \mathrm{mM}\end{array}$ & $\begin{array}{l}0.03 \\
0.06\end{array}$ & $\begin{array}{l}97 \pm 2 \\
92 \pm 5\end{array}$ & {$[27]$} \\
\hline $\begin{array}{l}(\mathrm{SPEEK} / \mathrm{PDADMAC})_{5} 0 \mathrm{mM} \\
(\mathrm{SPEEK} / \mathrm{PDADMAC})_{5} 100 \mathrm{mM}\end{array}$ & $\begin{array}{l}0.40 \\
0.08\end{array}$ & $\begin{array}{l}94 \\
98\end{array}$ & {$[31]$} \\
\hline
\end{tabular}


To further explore the performance of these membranes, the retention of the relatively large neutral dye molecule BTB (Mw $624 \mathrm{Da}$ ) was studied. For BTB, membranes [7.5/7.5] show decent performance both in terms of permeance and rejection (See Fig. 4.7). Here, surprisingly, the membrane [3.5/3.5] also shows reasonable performance, but the overall retention of BTB by all these three membranes is lower than for the strongly charged AF and RB. Less dye adsorption would lead to less densified films and a lower retention.

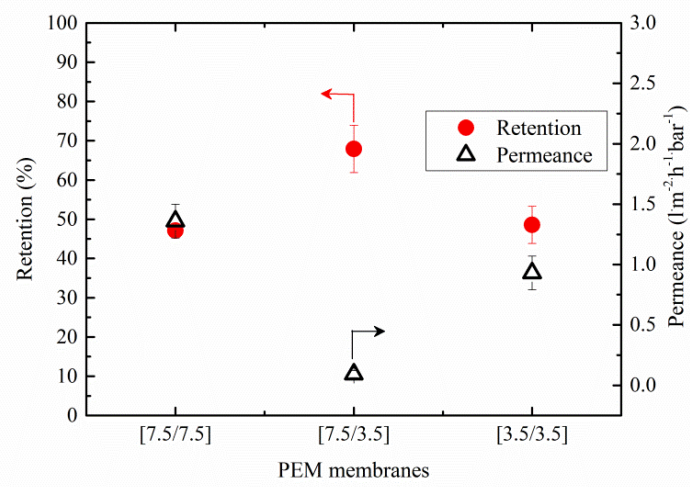

Fig. 4.7: SRNF performance of membranes for BTB from IPA solution with 5 bilayers of PAH/PAA (prepared at three $\mathrm{pH}$ combinations with $0.1 \mathrm{~g} \cdot \mathrm{l}^{-1}$ polymer and $50 \mathrm{mM}$ salt).

Next, MO (with a single negative charge) and MB (with a single positive charge) retentions are given as examples of smaller sized dyes (Fig. 4.8a and b). For MO (-), the membrane [7.5/3.5] shows good rejection and high permeance. This would be expected for such a highly negatively charged layer, having Donnan exclusion as the main separation mechanism. The other less negatively charged layers show much lower retentions, while [3.5/3.5] again suffering from very low permeabilities. For MB (+), none of the membranes show a good combination of retention and permeance. This is expected as the membranes are all negatively charged. Especially for [7.5/3.5] and [3.5/3.5], this leads to very low permeances, likely because of 
adsorption and densification of the layers. So by varying the $\mathrm{pH}$ of coating PEs, PEM membranes can be prepared with very different performances for different dyes in SRNF.
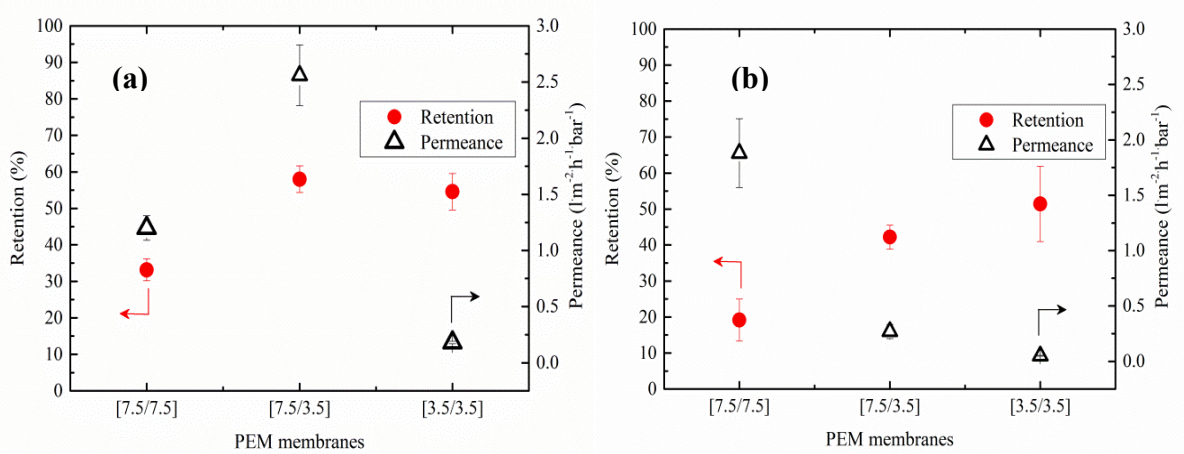

Fig. 4.8. SRNF performance of membranes for small sized charged solutes with 5 bilayers of PAH/PAA (prepared at three $\mathrm{pH}$ combinations with $0.1 \mathrm{~g} \cdot \mathrm{l}^{-1}$ polymer and $50 \mathrm{mM}$ salt) (a) retention and permeance of $M O(-)$ from IPA solution; (b) retention and permeance of $M B(+)$ from IPA solution.

To see the role of the terminating layer charge on retention performance of membranes in terms of electrostatic repulsion, also filtrations were performed with membranes terminated with positive polyelectrolyte $\mathrm{PAH}$ (5.5 bilayers). RB and AF retentions for membranes with 5.5 bilayers of $\mathrm{PAH} / \mathrm{PAA}$ at different $\mathrm{pH}$ combinations with a terminating layer of $\mathrm{PAH}(+)$ are given in Table 4.6. For big dyes, retentions do not significantly change with the type of terminating layer, except for $\mathrm{RB}$ and $\mathrm{AF}$ for [7.5/3.5], where it is slightly less than compared to PAA (-) terminated layers. Strong interactions of negatively charged solutes with the polycation from the membrane layers might densify the membranes [30], and make the membranes less positively charged, which in turn increases the retention and reduces permeance for these layers. The effect of the terminating layer charge is more clear in the retention of small solutes. MO (-) is more rejected 
by the membranes with PAA (-) terminating layer than by the PAH $(+)$ terminating layers and vice versa for $\mathrm{MB}(+)$ retention with membranes prepared at $\mathrm{pH}$ 7.5/3.5 (Table 4.5). For membranes [3.5/3.5], retention of MO (-) is more for a PAH (+) terminating layer than for a PAA (-) terminating layer, but the permeance is also lower, indicating that the higher retention is the result of more adsorption and more densification.

Table 4.6 SRNF performance of PAH (+) terminating multilayered membranes with 5.5 bilayers of PAH/PAA (prepared at three $\mathrm{pH}$ combinations with $0.1 \mathrm{~g} \cdot \mathrm{l}^{-1}$ polymer and $50 \mathrm{mM}$ salt).

\begin{tabular}{ccccccc}
\hline & \multicolumn{3}{c}{ Retention (\%) } & \multicolumn{3}{c}{ Permeance $\mathbf{l}^{-\mathbf{2} \cdot \mathbf{h}^{-1} \cdot \mathbf{b a r}^{-1}}$} \\
\hline $\begin{array}{c}\text { PEM } \\
\text { membranes }\end{array}$ & {$[7.5 / 7.5]$} & {$[7.5 / 3.5]$} & {$[\mathbf{3 . 5 / 3 . 5}]$} & {$[7.5 / 7.5]$} & {$[7.5 / 3.5]$} & {$[\mathbf{3 . 5 / 3 . 5}]$} \\
\hline RB & $93 \pm 2$ & $96 \pm 2$ & $91 \pm 2$ & $0.22 \pm 0.12$ & $0.07 \pm 0.01$ & $0.01 \pm 0.00$ \\
AF & $86 \pm 4$ & $86 \pm 8$ & $96 \pm 2$ & $0.88 \pm 0.22$ & $0.45 \pm 0.30$ & $0.02 \pm 0.00$ \\
MO & $23 \pm 1$ & $31 \pm 4$ & $60 \pm 8$ & $1.00 \pm 0.30$ & $2.00 \pm 0.22$ & $0.10 \pm 0.02$ \\
MB & $28 \pm 5$ & $62 \pm 3$ & $29 \pm 7$ & $0.30 \pm 0.10$ & $0.20 \pm 0.05$ & $0.10 \pm 0.02$ \\
\hline
\end{tabular}

For all dyes, [7.5/7.5] membranes show relatively high permeances coupled with relatively good rejections compared to the other membranes (Fig. 4.6, 4.7 and 4.8). The low degree of extrinsic charge compensation is expected to be responsible for this effect. For MO, membrane [7.5/3.5] gives the best performance, likely due to the high negative charge of this layer. Membrane [3.5/3.5] shows only decent performance for the neutral dye BTB. Ionic dyes thus seem to adsorb strongly to this layer, possibly because of a very high degree of extrinsic charge compensation. The main point however, is that by varying the $\mathrm{pH}$, PEM membranes can be prepared with very different performances for different dyes in SRNF. For this system of multilayers, the $\mathrm{pH}$ can thus be used as a tuning parameter to optimize the performance for a specific application. 


\subsubsection{Influence of solvent type and long term stability}

To evaluate the membrane performance over long time-scales, filtrations were performed with RB in different solvents such as THF, DMF and ACN. The membranes, coated with 5 bilayers of PAH/PAA at $\mathrm{pH}$ [7.5/3.5] were used as they showed the highest RB retention of all tested membranes (Fig. 4.6a). The membranes exhibited very good performance in terms of RB retention ( $>90 \%)$ and permeance for all of these organic solvents (Fig. 4.9).

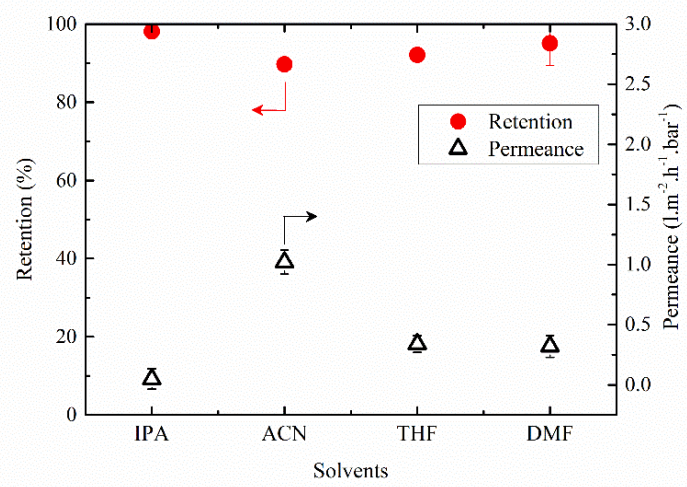

Fig. 4.9. $S R N F$ properties of weak PEM membranes for $R B$ in different organic solvents. Tested membranes are [7.5/3.5] with 5 bilayers of PAH/PAA prepared with $0.1 \mathrm{~g} \cdot \mathrm{l}^{-1}$ polymer and $50 \mathrm{mM}$ salt. (a) Short term $(5 \mathrm{~h})$ SRNF performance for polar aprotic solvents.

The maximum retention of RB is observed in IPA and DMF with a value of 99 and $95 \%$ respectively. The permeability was found to be in the following order of $\mathrm{ACN}>\mathrm{THF}>\mathrm{DMF}>\mathrm{IPA}$. This variation in permeation behavior for different solvents may be attributed to solvent-membrane interactions and the physico-chemical properties of the solvents, like molar volume and viscosity. However, it is also important to consider the effect of interactions between membrane-solute, membrane-solvent, and solute-solvent [4]. A part of the viscosity effect we can see in (Fig. 4.9) where IPA, with the highest viscosity, shows the lowest permeance and $\mathrm{ACN}$, with the lowest viscosity, 
is the highest. The permeability trend observed in the present study is similar to that observed in previously reported SRNF membranes prepared with 20 bilayers of PDDA/PAA [27].
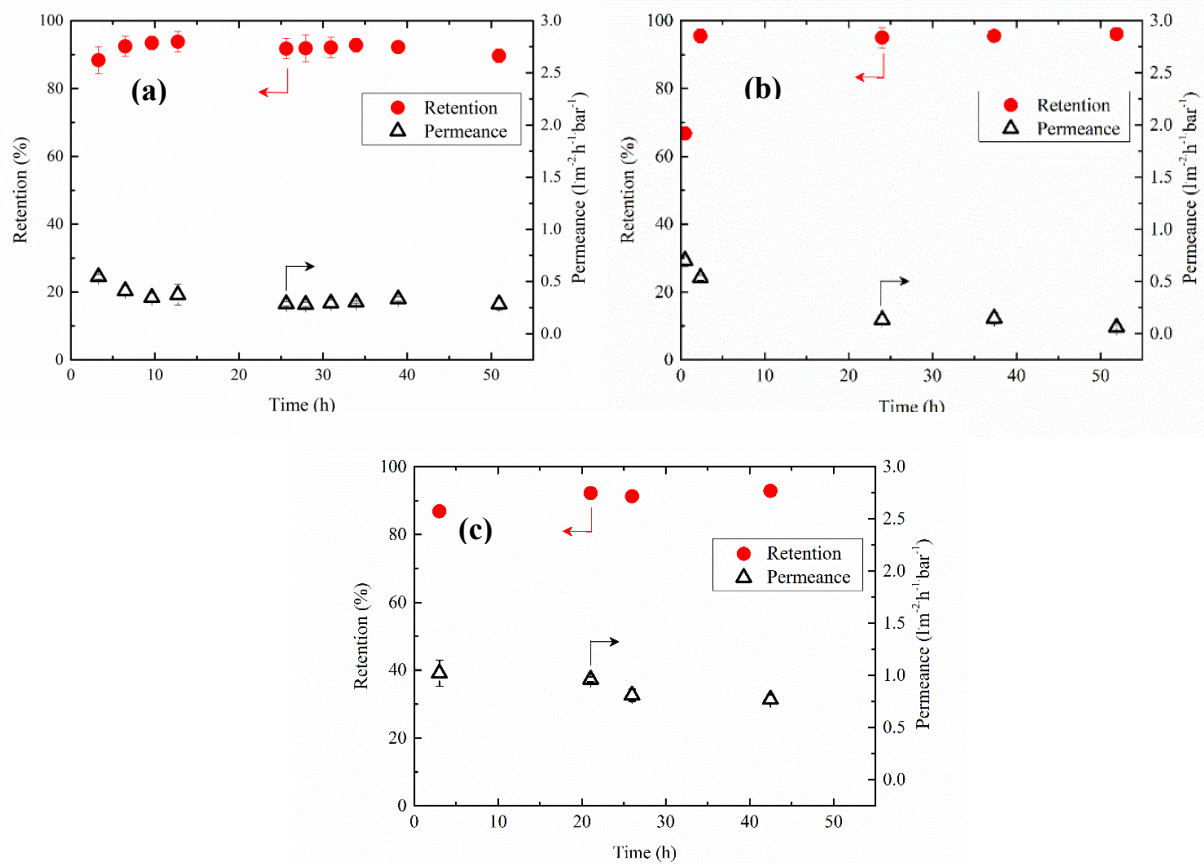

Fig. 4.10: Long term SRNF performance of [7.5/3.5] membranes for (a) THF and (b) DMF and (c) ACN (tested membranes are with 5 bilayers of PAH/PAA prepared with $0.1 \mathrm{~g} \cdot l^{-1}$ polymer and $50 \mathrm{mM}$ salt).

To further evaluate the long term stability of these multilayered membranes, filtrations were performed for extended periods of time (about $50 \mathrm{~h}$ ) with RB in different solvents (Fig. 4.10a, b and c) using the membranes [7.5/3.5] prepared with 5 bilayers of PAH/PAA. The membranes show very stable performance in terms of $\mathrm{RB}$ retention $(>90 \%)$ and permeance as a function of time. In the case of DMF, the permeability decreased significantly in the first hour of filtration indicating strong interactions between DMF and the membrane, or RB and the membrane. The membrane seems to take up RB 
over time, densify and become less permeable, while the rejection shoots up (Fig. 4.10b).

In our investigation we have focused on $\mathrm{pH}$ as a tuning parameter. We stress that the membranes could be further improved by including the ionic strength as a variable. For example, coating at low ionic strength where intrinsic charge compensation between the layers is high and layers are thin $[35,43]$ would lead to less free charges being available for complexation with the dye molecules, and could further reduce fouling of the PEM layers by the dye molecules.

\subsection{Conclusions}

This manuscript encompasses the first investigation into the use of weak polyelectrolyte multilayers for SRNF applications. PEM-based SRNFmembranes of the weak polyelectrolytes PAH and PAA were successfully prepared by the LbL method with varying the $\mathrm{pH}$ of the coating solutions to tune the charge density and structure of PEs, and thus further control the morphology and performance of the resulting membranes for specific dyes from organic media. Membranes [7.5/7.5] have high a permeance coupled with a relatively good retention performance for all the dyes because of a low degree of extrinsic charge compensation combined with a dense structure and a thin layer. Membranes prepared under $\mathrm{pH}$ conditions [7.5/3.5] and [3.5/3.5] have more free acid and amine groups and were found to be much more susceptible to dye adsorption, leading to a pronounced film densification, a low permeance, but in some case excellent dye retentions. Specifically for the negative dye methyl orange, a PAA terminated [7.5/3.5] membrane was found to have good performance in terms of retention and permeance, likely due to the high negative charge of that multilayer film. The resulting membranes also showed long term (more than $50 \mathrm{~h}$ ) stable 
performance for organic solvents, including troublesome aprotic solvents of industrial importance like THF, DMF and ACN. The results of this study provide a versatile and simple way of using $\mathrm{pH}$ to tune performance of weak PEs based multilayered SRNF-membranes for specific applications.

\section{Acknowledgments}

S. Ilyas acknowledges the European Commission - Education, Audiovisual and Culture Executive Agency (EACEA), for her PhD scholarship under the program: Erasmus Mundus Doctorate in Membrane Engineering - EUDIME (FPA N² 2011-0014, Edition III, http://eudime.unical.it/). 


\section{References}

[1] P. Vandezande, L.E.M. Gevers, I.F.J. Vankelecom, Solvent resistant nanofiltration: Separating on a molecular level, Chem. Soc. Rev., 37 (2008) 365 405.

[2] A.V. Volkov, D.F. Stamatialis, V.S. Khotimsky, V.V. Volkov, M. Wessling, N.A. Platé, New membrane material for SRNF applications, Desalination, 199 (2006) 251-252.

[3] P. Marchetti, M.F. Jimenez Solomon, G. Szekely, A.G. Livingston, Molecular Separation with Organic Solvent Nanofiltration: A Critical Review, Chemical Reviews, 114 (2014) 10735-10806.

[4] D. Bhanushali, D. Bhattacharyya, Advances in Solvent-Resistant Nanofiltration Membranes, Annals of the New York Academy of Sciences, 984 (2003) 159-177.

[5] K. Hendrix, S. Vandoorne, G. Koeckelberghs, I.F.J. Vankelecom, SRNF membranes for edible oil purification: Introducing free amines in crosslinked PEEK to increase membrane hydrophilicity, Polymer (United Kingdom), 55 (2014) 13071316.

[6] S. Aerts, A. Buekenhoudt, H. Weyten, L.E.M. Gevers, I.F.J. Vankelecom, P.A. Jacobs, The use of solvent resistant nanofiltration in the recycling of the CoJacobsen catalyst in the hydrolytic kinetic resolution (HKR) of epoxides, Journal of Membrane Science, 280 (2006) 245-252.

[7] L. Peeva, J.d.S. Burgal, I. Valtcheva, A.G. Livingston, Continuous purification of active pharmaceutical ingredients using multistage organic solvent nanofiltration membrane cascade, Chemical Engineering Science, 116 (2014) 183-194.

[8] H.J. Zwijnenberg, S.M. Dutczak, M.E. Boerrigter, M.A. Hempenius, M.W.J. Luiten-Olieman, N.E. Benes, M. Wessling, D. Stamatialis, Important factors influencing molecular weight cut-off determination of membranes in organic solvents, Journal of Membrane Science, 390-391 (2012) 211-217.

[9] A.W. Mohammad, Y.H. Teow, W.L. Ang, Y.T. Chung, D.L. Oatley-Radcliffe, N. Hilal, Nanofiltration membranes review: Recent advances and future prospects, Desalination, 356 (2015) 226-254.

[10] S. Hermans, H. Mariën, C. Van Goethem, I.F.J. Vankelecom, Recent developments in thin film (nano)composite membranes for solvent resistant nanofiltration, Current Opinion in Chemical Engineering, 8 (2015) 45-54.

[11] P. Silva, S. Han, A.G. Livingston, Solvent transport in organic solvent nanofiltration membranes, Journal of Membrane Science, 262 (2005) 49-59.

[12] N. Joseph, P. Ahmadiannamini, R. Hoogenboom, I.F.J. Vankelecom, Layer-bylayer preparation of polyelectrolyte multilayer membranes for separation, Polymer Chemistry, 5 (2014) 1817-1831.

[13] L. Krasemann, B. Tieke, Selective Ion Transport across Self-Assembled Alternating Multilayers of Cationic and Anionic Polyelectrolytes, Langmuir : the ACS journal of surfaces and colloids, 16 (1999) 287-290. 
[14] W. Jin, A. Toutianoush, B. Tieke, Use of Polyelectrolyte Layer-by-Layer Assemblies as Nanofiltration and Reverse Osmosis Membranes, Langmuir : the ACS journal of surfaces and colloids, 19 (2003) 2550-2553.

[15] J. Park, J. Park, S.H. Kim, J. Cho, J. Bang, Desalination membranes from pHcontrolled and thermally-crosslinked layer-by-layer assembled multilayers, Journal of Materials Chemistry, 20 (2010) 2085.

[16] S.U. Hong, L. Ouyang, M.L. Bruening, Recovery of phosphate using multilayer polyelectrolyte nanofiltration membranes, Journal of Membrane Science, 327 (2009) 2-5.

[17] G. Liu, D.M. Dotzauer, M.L. Bruening, Ion-Exchange Membranes Prepared Using Layer-by-Layer Polyelectrolyte Deposition, J Memb Sci, 354 (2010) 198-205. [18] C. Magnenet, S. Lakard, C.C. Buron, B. Lakard, Functionalization of organic membranes by polyelectrolyte multilayer assemblies: application to the removal of copper ions from aqueous solutions, Journal of colloid and interface science, 376 (2012) 202-208.

[19] C. Magnenet, F.E. Jurin, S. Lakard, C.C. Buron, B. Lakard, Polyelectrolyte modification of ultrafiltration membrane for removal of copper ions, Colloids and Surfaces A: Physicochemical and Engineering Aspects, 435 (2013) 170-177.

[20] B.W. Stanton, J.J. Harris, M.D. Miller, M.L. Bruening, Ultrathin, Multilayered Polyelectrolyte Films as Nanofiltration Membranes, Langmuir : the ACS journal of surfaces and colloids, 19 (2003) 7038-7042.

[21] M.D. Miller, M.L. Bruening, Controlling the Nanofiltration Properties of Multilayer Polyelectrolyte Membranes through Variation of Film Composition, Langmuir : the ACS journal of surfaces and colloids, 20 (2004) 11545-11551.

[22] R. Malaisamy, M.L. Bruening, High-Flux Nanofiltration Membranes Prepared by Adsorption of Multilayer Polyelectrolyte Membranes on Polymeric Supports, Langmuir : the ACS journal of surfaces and colloids, 21 (2005) 10587-10592.

[23] X. Liu, M.L. Bruening, Size-Selective Transport of Uncharged Solutes through Multilayer Polyelectrolyte Membranes, Chemistry of Materials, 16 (2003) 351-357.

[24] S.U. Hong, M.D. Miller, M.L. Bruening, Removal of Dyes, Sugars, and Amino Acids from $\mathrm{NaCl}$ Solutions Using Multilayer Polyelectrolyte Nanofiltration Membranes, Industrial \& Engineering Chemistry Research, 45 (2006) 6284-6288.

[25] L. Ouyang, R. Malaisamy, M.L. Bruening, Multilayer polyelectrolyte films as nanofiltration membranes for separating monovalent and divalent cations, Journal of Membrane Science, 310 (2008) 76-84.

[26] L.Y. Ng, A.W. Mohammad, C.Y. Ng, A review on nanofiltration membrane fabrication and modification using polyelectrolytes: Effective ways to develop membrane selective barriers and rejection capability, Advances in Colloid and Interface Science, 197-198 (2013) 85-107.

[27] P. Ahmadiannamini, X. Li, W. Goyens, N. Joseph, B. Meesschaert, I.F.J. Vankelecom, Multilayered polyelectrolyte complex based solvent resistant 
nanofiltration membranes prepared from weak polyacids, Journal of Membrane Science, 394-395 (2012) 98-106.

[28] P. Ahmadiannamini, X. Li, W. Goyens, B. Meesschaert, W. Vanderlinden, S. De Feyter, I.F.J. Vankelecom, Influence of polyanion type and cationic counter ion on the SRNF performance of polyelectrolyte membranes, Journal of Membrane Science, 403-404 (2012) 216-226.

[29] P. Ahmadiannamini, X. Li, W. Goyens, B. Meesschaert, I.F.J. Vankelecom, Multilayered PEC nanofiltration membranes based on SPEEK/PDDA for anion separation, Journal of Membrane Science, 360 (2010) 250-258.

[30] X. Li, S. De Feyter, D. Chen, S. Aldea, P. Vandezande, F.D. Prez, I.F.J. Vankelecom, Solvent-resistant nanofiltration membranes based on multilayered polyelectrolyte complexes, Chemistry of Materials, 20 (2008) 3876-3883.

[31] X. Li, W. Goyens, P. Ahmadiannamini, W. Vanderlinden, S. De Feyter, I. Vankelecom, Morphology and performance of solvent-resistant nanofiltration membranes based on multilayered polyelectrolytes: Study of preparation conditions, Journal of Membrane Science, 358 (2010) 150-157.

[32] N. Joseph, P. Ahmadiannamini, P.S. Jishna, A. Volodin, I.F.J. Vankelecom, 'Up-scaling' potential for polyelectrolyte multilayer membranes, Journal of Membrane Science, 492 (2015) 271-280.

[33] L. Krasemann, B. Tieke, Selective Ion Transport across Self-Assembled Alternating Multilayers of Cationic and Anionic Polyelectrolytes, Langmuir : the ACS journal of surfaces and colloids, 16 (2000) 287-290.

[34] J.B. Schlenoff, H. Ly, M. Li, Charge and Mass Balance in Polyelectrolyte Multilayers, Journal of the American Chemical Society, 120 (1998) 7626-7634.

[35] J. de Grooth, R. Oborný, J. Potreck, K. Nijmeijer, W.M. de Vos, The role of ionic strength and odd-even effects on the properties of polyelectrolyte multilayer nanofiltration membranes, Journal of Membrane Science, 475 (2015) 311-319.

[36] S.T. Dubas, J.B. Schlenoff, Polyelectrolyte Multilayers Containing a Weak Polyacid: Construction and Deconstruction, Macromolecules, 34 (2001) 3736-3740. [37] D. Kovacevic, S. van der Burgh, A. de Keizer, M.A. Cohen Stuart, Kinetics of Formation and Dissolution of Weak Polyelectrolyte Multilayers: Role of Salt and Free Polyions, Langmuir : the ACS journal of surfaces and colloids, 18 (2002) 56075612.

[38] S.U. Hong, R. Malaisamy, M.L. Bruening, Optimization of flux and selectivity in $\mathrm{Cl}$-/SO42- separations with multilayer polyelectrolyte membranes, Journal of Membrane Science, 283 (2006) 366-372.

[39] D. Yoo, S.S. Shiratori, M.F. Rubner, Controlling Bilayer Composition and Surface Wettability of Sequentially Adsorbed Multilayers of Weak Polyelectrolytes, Macromolecules, 31 (1998) 4309-4318.

[40] S.S. Shiratori, M.F. Rubner, pH-Dependent Thickness Behavior of Sequentially Adsorbed Layers of Weak polyelectrolytes, Macromolecules, 33 (2000) 4213-4219. 
[41] V. Izumrudov, E. Kharlampieva, S.A. Sukhishvili, Salt-Induced Multilayer Growth: Correlation with Phase Separation in Solution, Macromolecules, 37 (2004) 8400-8406.

[42] V. Izumrudov, S.A. Sukhishvili, Ionization-Controlled Stability of Polyelectrolyte Multilayers in Salt Solutions, Langmuir : the ACS journal of surfaces and colloids, 19 (2003) 5188-5191.

[43] S. Ilyas, J. de Grooth, K. Nijmeijer, W.M. de Vos, Multifunctional polyelectrolyte multilayers as nanofiltration membranes and as sacrificial layers for easy membrane cleaning, Journal of colloid and interface science, 446 (2015) 386393.

[44] P. Ahmadiannamini, M.L. Bruening, V.V. Tarabara, Sacrificial polyelectrolyte multilayer coatings as an approach to membrane fouling control: Disassembly and regeneration mechanisms, Journal of Membrane Science, 491 (2015) 149-158.

[45] http://www.biw.kuleuven.be/cok/membrane2/.

[46] I.M. Smallwood, in: Handbook of Organic Solvent Properties, ButterworthHeinemann, Oxford, 1996, pp. 73-291.

[47] J. Choi, M.F. Rubner, Influence of the Degree of Ionization on Weak Polyelectrolyte Multilayer Assembly, Macromolecules, 38 (2004) 116-124.

[48] G. Zhang, H. Meng, S. Ji, Hydrolysis differences of polyacrylonitrile support membrane and its influences on polyacrylonitrile-based membrane performance, Desalination, 242 (2009) 313-324.

[49] P. Marchetti, M.F. Jimenez Solomon, G. Szekely, A.G. Livingston, Molecular Separation with Organic Solvent Nanofiltration: A Critical Review, Chemical Reviews, (2014).

[50] D.F. Stamatialis, N. Stafie, K. Buadu, M. Hempenius, M. Wessling, Observations on the permeation performance of solvent resistant nanofiltration membranes, Journal of Membrane Science, 279 (2006) 424-433.

[51] L.E.M. Gevers, G. Meyen, K. De Smet, P. Van De Velde, F. Du Prez, I.F.J. Vankelecom, P.A. Jacobs, Physico-chemical interpretation of the SRNF transport mechanism for solutes through dense silicone membranes, Journal of Membrane Science, 274 (2006) 173-182. 


\section{Supplementary Information}

\section{Chapter 4}

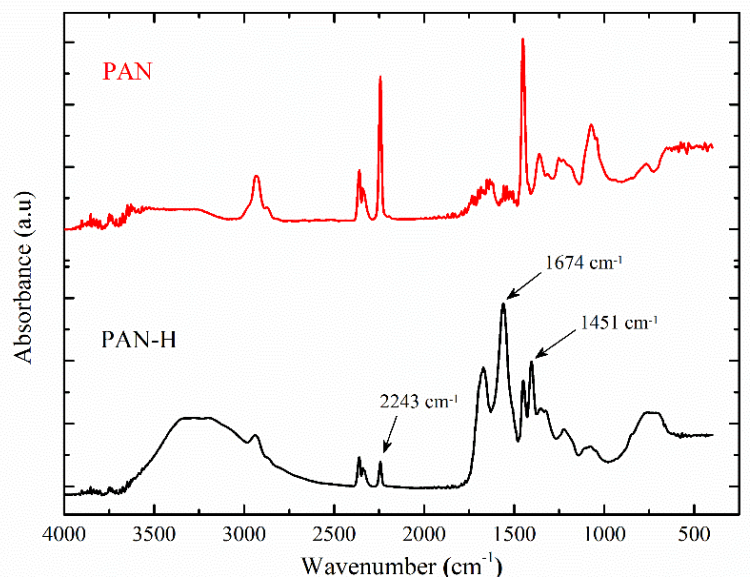

Fig. S4.1: ATR-FTIR spectra of PAN and hydrolyzed PAN membrane support. 

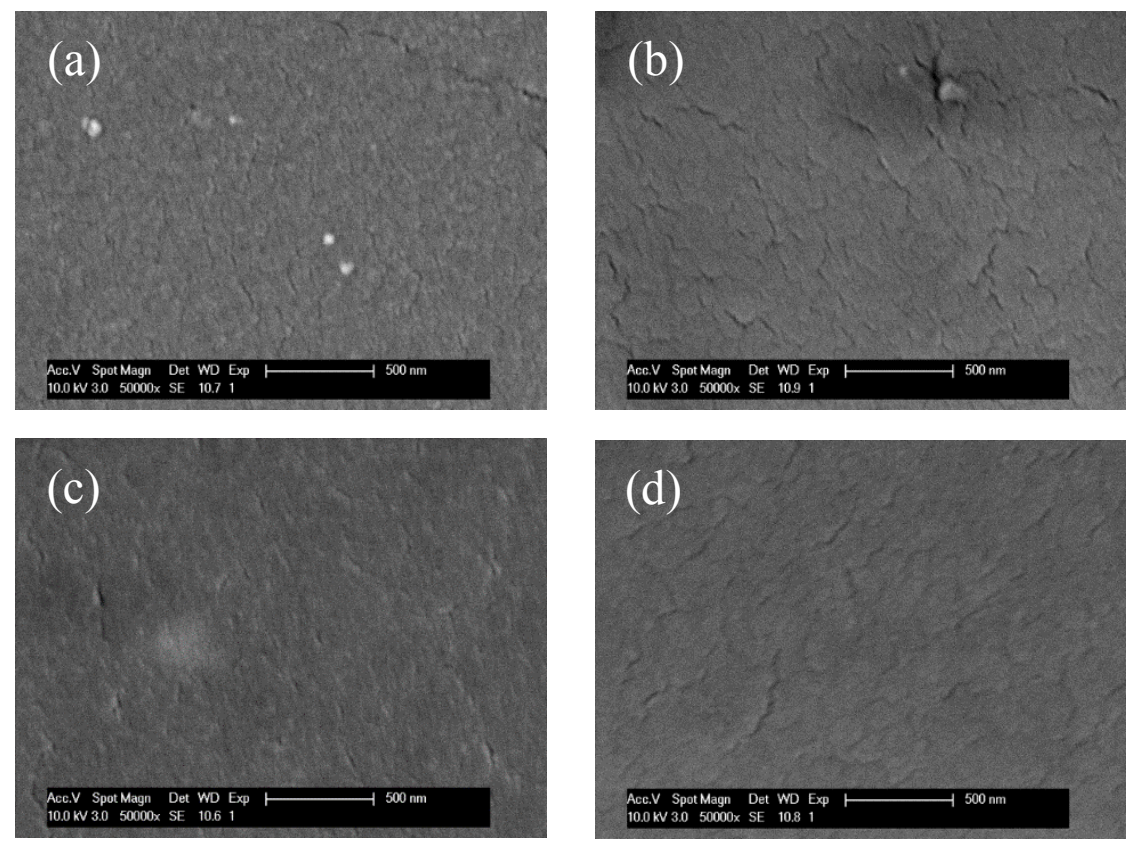

Fig. S4.2: SEM Surface images of (a) PAN-H support; and multilayered SRNF membranes prepared with PAH/PAA pH of (b) [7.5/7.5] (c) [7.5/3.5] (d) [3.5/3.5] with polymer concentration of $0.1 \mathrm{~g} \cdot \mathrm{l}^{-1}$ and $50 \mathrm{mM}$ salt.
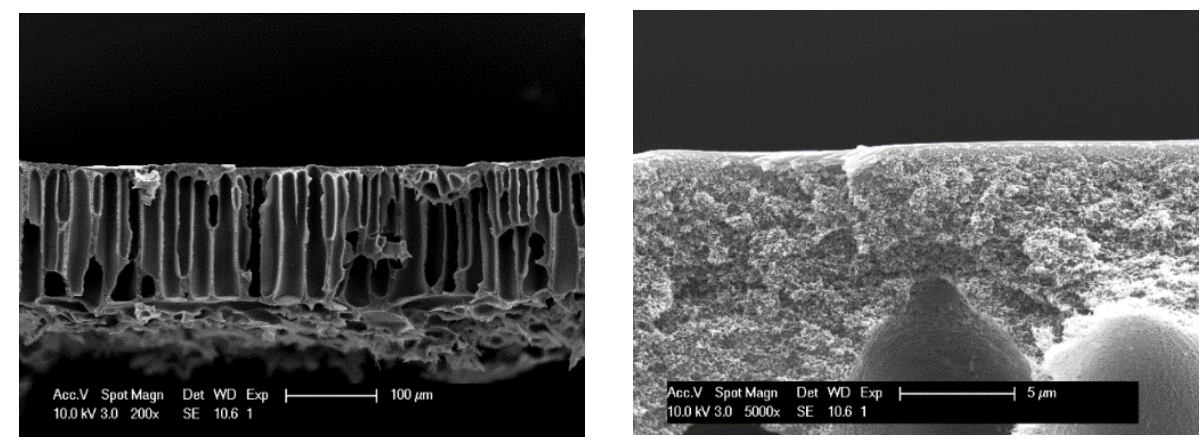

Fig. S4.3: Cross section images of PAN-H support at two different magnifications observed by SEM. 


\section{Dynamic layer by layer ( $L b L)$ assembly of multifunctional polyelectrolyte multilayers}

This chapter is prepared as:

Preparation of multifunctional hollow fiber NF membranes by dynamic LbL assembly of weak polyelectrolyte multilayers, authored by Shazia Ilyas, Renee English, Pierre Aimar, Jean Francois Lahitte and Wiebe M. de Vos. 


\section{Abstract}

In this work, we investigate the effect of preparation conditions for dynamic layer by layer (LbL) assembly to prepare multifunctional hollow fiber nanofiltration (NF) membranes. Dynamic coating was performed at constant pressure and variable cross flow speeds to deposit multilayers of the weak polyelectrolytes poly(acrylic acid) (PAA) and poly(allylamine hydrochloride) (PAH) on a negatively charged polyethersulfone ultrafiltration (UF) support. The resulting membrane performance was investigated and compared to membranes prepared by different methods (dip coating and dead end filtrations), and it was found to be comparable. It was shown that PAH/PAA multilayers can be fabricated reproducibly and homogenously using optimised dynamic LbL deposition conditions on single fibre module (surface area of $6.2 \mathrm{~cm}^{2}$ ) and on a module of 15 fibres (surface area of $67 \mathrm{~cm}^{2}$ ). Moreover the approach of dynamic coating could be easily upscaled to coat existing UF modules. The resulting membrane rejects the solutes on the basis of size exclusion and Donnan exclusion, while retentions of divalent ions and organic solutes (retentions of 50-70\%) are comparable to membranes prepared via dip-coating. Membranes terminated with PAA exhibit a lower fouling tendency than membranes terminated with PAH and than the UF support membrane, demonstrating a low fouling potential. Moreover, if severe membrane fouling would occurs after prolonged use, the PEM coating, including any attached foulants can be removed by rinsing with a solution that combines a low $\mathrm{pH}$ and a high salinity ( $\mathrm{pH} 3,3 \mathrm{M}$ ). The surface of bovine serum albumin (BSA) fouled membranes were successfully regenerated at least twice, after which a new PEM coating could be applied by active coating. 


\subsection{Introduction}

Growing water crises around the globe and more stringent environmental regulations are increasing the interest of the water industry to consider new, more energy efficient, treatment processes. During the last two decades, membrane separation processes in general and NF in particular have attracted enormous attention as an environmental friendly separation technology for water and wastewater treatment and for re-use applications [1]. NF is a pressure driven membrane separation process with properties falling between reverse osmosis (RO) and ultrafiltration (UF), allowing the effective removal of inorganic and organic pollutants at much lower pressures than those required for RO. NF membranes are proposed to be an alternative to RO membranes, because of their lower operating pressures, higher fluxes, and high retention of multivalent salt ions, and their low operation and maintenance costs [2].

However, a major challenge for all membrane processes, including NF, is the loss of membrane productivity over time, due to the accumulation of particles and larger molecules at the membrane interface in the form of a fouling layer. Fouling can lead to lower fluxes and therefore higher operating costs, while frequent physical and chemical cleaning is costly and might shorten the membrane life-time [3, 4]. Fouling is affected by many parameters, including the membrane surface chemistry, feed composition, operational parameters, and hydrodynamic conditions [4-6]. To deal with membrane fouling, new cleaning methods and anti-fouling materials have become the focus of research and development within the water industry [7]. In a typical process, fouling is controlled using intermittent backwashes or backflushes, which is only effective for loosely attached foulants on the membrane surface $[8,9]$. Organic impurities in the water, such as proteins, humics, and polysaccharides, can behave as strong, irreversible foulants 
[10]. For these foulants, which are more strongly adsorbed to the surface or lodged in the membrane pores, chemical cleaning is required. Chemical cleaning is expensive and generally consists of harsh treatments with acids, alkalis, chlorine etc. [5, 8]. Even under these cleaning conditions, complete recovery of membrane performance is not guaranteed. Additionally, there exists a high risk of damage to the membrane due to the frequency and severity of the cleaning. Other strategies to control membrane fouling are mainly focused on surface modification of the membrane to weaken the interactive forces between foulants and membrane, thus inhibiting foulant adsorption. This can be achieved by altering the membrane surface charge, increasing the hydrophilicity or decreasing the surface roughness [11-13].

In the past decade, LbL adsorption of oppositely charged polyelectrolytes (PEs) in the form of polyelectrolyte multilayer (PEM's) onto a charged and porous support has proven to be a promising method for the surface modification of membranes for antifouling purposes [11, 12, 14-18], as well as for the preparation of a separation (skin) layer for NF membranes [19]. Similar to RO membranes, the majority of the NF membranes are asymmetric thin film composite (TFC) membranes, with a thin active skin layer deposited on a thick and highly permeable support. The composition of the active layer determines the separation characteristics of the membrane, while the support provides mechanical strength. Most of the previous studies on PEM based NF membranes, utilized flat sheet membrane supports as reported for example by Bruening et al. [20-25] and Tieke et al. [26, 27]. However, the hollow fiber configuration would offer a higher productivity per unit volume due to the high packing density [28, 29]. Furthermore, the hollow fiber geometry also offers the possibility of backwashing (with or without chemicals) at higher pressures for enhanced foulant removal. To our knowledge only one commercial hollow fiber NF product with the trade 
name HFW 1000 and a molecular weight cutoff (MWCO) of $1000 \mathrm{Da}$ is available in market. So, it would be very beneficial to develop hollow fibre NF membranes at a lower MWCO, and for that the surface modification of a UF support using LbL assembly of PEMs is a very promising method. This approach was shown to successfully produce hollow fiber NF membranes with precise control over separation performance [30-34]. In these studies LbL deposition is performed by dip coating (static coating) by immersing the hollow fibers into the solutions of PEs followed by intermittent rinsing steps. An alternative is the use of dynamic coating or active coating, which involves running the PE solution through the lumen of the hollow fibers while controlling the pressure [35-39] or the flux [40]. This dynamic approach can give fast and controlled convective transport of PEs towards the membrane. Recently Menne et al. [40] studied dynamic coating of the strong PEs poly(diallyl-dimethylammonium chloride) (PDADMAC) and poly(styrene sulfonate) (PSS) in a dead end mode. He found that especially the constant flux approach was an effective way to coat the hollow fiber UF membrane support. Coating in dead end mode quickly increases the filtration resistance due to accumulation of material, while the cross flow mode where liquid stream over the surface of membrane limits the accumulation of PEs, and thus provides more precise control over layer deposition. Apart from the mode of coating, PEs with different sizes, charge densities degrees of swelling and diffusion velocities may have completely different deposition speeds on the membrane. Now depending upon the used PEs, these multilayers can be erasable by some external stimuli such as by changing $\mathrm{pH}$ [41-43] or by increasing ionic strength [44, 45]. For weak PE system such as PAH/PAA where charge density is not fixed and depends on solution $\mathrm{pH}$, a combination of both of these stimuli (low $\mathrm{pH}$ and high ionic strength) can add extra trigger for complete disintegration of PEM along the foulant (ludox particles), as shown previously [34]. This sacrificial approach to 
cleaning is highly promising as a new approach to help alleviate fouling, but it could only really be used in practice if the coating an recoating steps are both simple, and can be applied on module level. In the current work we investigate exactly this, we study the application of PEM based NF separation layers by dynamic coating, to demonstrate that a simple method is available to coat and recoat membranes, while imbuing it with NF separation properties and a low fouling propensity. This weak polyelectrolyte system of $\mathrm{PAH} / \mathrm{PAA}$, holds great promise for membrane applications and this work intends to help to bring this system to maturity.

In this study we have developed hollow fiber NF membranes with sacrificial layers (PAH/PAA) employing dynamic (cross flow and dead end) coating. The effects of coating parameters (deposition time, applied pressure, coating mode and cross flow speed) on membranes in terms of permeability and NF performance have been investigated in detail and compared with those prepared by a static (dip coating) LbL process. Moreover, the applied dynamic coating in cross flow mode is also shown to be applicable for upscaling, to allow coating of longer modules for industrial applications. Fouling studies of PEMs and their cleanability by releasing the PEM coating (the sacrificial layer effect) were also studied, first on model surfaces, and subsequently on membranes.

\subsection{Experimental}

\subsubsection{Materials}

UF hollow fiber membranes with a sulfonated poly(ether sulfone) separation layer were kindly supplied by Pentair X-Flow (The Netherlands). These membranes with a nominal molecular weight cut-off of 10,000 Da are intended for colloidal silica removal from water. The polyelectrolytes used were poly(allylamine) hydrochloride $\left(\mathrm{PAH}, \mathrm{M}_{\mathrm{W}}\right.$ 17,500 $\left.\mathrm{g} \cdot \mathrm{mol}^{-1}\right)$ and 
poly(acrylic acid) (PAA, $\left.\mathrm{M}_{\mathrm{W}} 15,000 \mathrm{~g} \cdot \mathrm{mol}^{-1}\right)$. The $\mathrm{pH}$ of the polyelectrolyte solutions was adjusted with $1 \mathrm{M}$ hydrochloric acid $(\mathrm{HCl})$ or $1 \mathrm{M}$ sodium hydroxide $(\mathrm{NaOH})$. Humic acid (HA) and bovine serum albumin (BSA) were used as model foulants to simulate hydrophilic natural organic matter and the presence of proteins respectively. HA sodium salt was obtained from Sigma Aldrich (The Netherlands) with a reported molecular weight greater than $50,000 \mathrm{Da}$ and a $\mathrm{pH}$ of 5.2 when dissolved in deionized water. Bovine serum albumin (cold alcohol precipitated BSA) was purchased from Sigma Chemical Co. (St. Louis, MO) with a well-defined molecular weight of 67,000 $\mathrm{Da}$ and an isoelectric point of 4.8. At a $1 \mathrm{~g} \cdot \mathrm{l}^{-1}$ concentration, at the used $\mathrm{pH}$ of 7.3 the protein therefore has a net negative charge. It should be noted that the size of both model foulants was larger than the pore size of the PEM membranes. The salts $\mathrm{NaCl}, \mathrm{Na}_{2} \mathrm{SO}_{4}$ and $\mathrm{MgSO}_{4}$, and organic compounds Bezafibrate and Naproxen, were used for NF performance tests and were purchased from Sigma Aldrich (The Netherlands). Deionised (DI) water used in all experiments was purified by a commercial water system (Synergy Water Purification System, Millipore) to a water resistivity of 18.2 $\mathrm{M} \Omega \mathrm{cm}$ or greater. All reagents were of analytical grade and used without further purification.

\subsubsection{Membrane modification using dynamic LbL assembly}

For membrane coating, PE solutions were prepared with a polymer concentration of $0.1 \mathrm{~g} \cdot 1^{-1}$ using a background electrolyte of $50 \mathrm{mM} \mathrm{NaNO}_{3}$ at pH 6 for both PEs based on the results of our previous study [34]. Single membrane fibers were potted in $300 \mathrm{~mm}$ long modules with a total surface area of $6.2 \mathrm{~cm}^{2}$. Prior to coating, the membrane modules were wetted with $15 \mathrm{wt} . \%$ ethanol for $8 \mathrm{~h}$ to remove any impurities and then immersed in deionized water overnight. SEM images of the structure of membrane support used in this work were taken by JEOL JSM-6010LA and are given 
in Fig. S5.1. The coating was performed using a homemade fully automated crossflow system (schematic shown in Fig. S5.2) under different cross flow speeds $\left(0.5,2,4\right.$ and $\left.6 \mathrm{~m} \cdot \mathrm{s}^{-1}\right)$ and pressures $(0.1,0.5$ and 1 bar). The LbL deposition of PEs was performed from lumen to shell, and for that the membrane module was fed with a $0.1 \mathrm{~g} \cdot \mathrm{l}^{-1}$ polycation (PAH) solution. The module was then flushed with background electrolyte solution to remove excess PE, after which the switch was made to a $0.1 \mathrm{~g} \cdot \mathrm{l}^{-1}$ polyanion (PAA) solution. By repeating these steps the membrane was coated the desired number of PAH/PAA bi-layers. The coated membranes were stored in DI water until used.

Dead end coating was performed using a constant pressure setup (Amicon cell) with the feed side of the system pressurized at 1 bar $\mathrm{N}_{2}$ gas as illustrated in Fig. S5.2. Similar to cross-flow coating, dynamic LbL coating in dead end mode includes the following preparation procedure: First, the membrane module was flushed with background electrolyte solution at 1 bar for $15 \mathrm{~min}$. Then, the feed was changed to PAH solution and membrane module was flushed at 1 and 0.5 bar for 15 min followed by flushing with background electrolyte solution for $15 \mathrm{~min}$ as intermediate rinsing step. Again, the feed was changed to PAA solution and module was flushed for 15 min followed by a rinsing step with background electrolyte solution. Thus one bilayer of self-assembly was completed. Additional bilayers were prepared by the same procedure until the target number of bilayers was produced. During the whole preparation procedure, the permeability of the DI water or the polymer solution through the UF support or the LbL membrane was determined simultaneously. To check the effectiveness of dynamic coating at a much larger scale, the same cross flow modification procedure mentioned before was carried out for modules with an effective 
length of approximately $200 \mathrm{~mm}$ housing 15 fibers in one module (surface area of $67 \mathrm{~cm}^{2}$ ).

\subsubsection{TOC analysis}

A total organic carbon (TOC) analyzer (TOC-V $\mathrm{V}_{\mathrm{CSN}}$, SHIMADZU) was used to determine the TOC values of PAH and PAA feed solution and UF permeate in the first filtration run.

\subsubsection{Filtration and NF performance tests}

The pure water permeability of membranes was measured for each coating step. The water permeability (in $1 \cdot \mathrm{m}^{-2} \cdot \mathrm{h}^{-1} \cdot \mathrm{bar}^{-1}$ ) of membrane was obtained by normalizing the pure water flux measured at $20{ }^{\circ} \mathrm{C}$ by the trans membrane pressure. The pure water flux was measured using DI water in dead end mode at a trans-membrane pressure of 1 bar. The membrane permeability was then calculated using equation 5.1:

$$
P\left(l . m^{-2} \cdot h^{-1} \cdot b a r^{-1}\right)=\frac{V}{A \cdot \Delta t \cdot \Delta P}
$$

Where $\mathrm{V}$ is the volume (1), $\mathrm{A}$ is the membrane area $\left(\mathrm{m}^{-2}\right), \mathrm{t}$ is the time (s), $\Delta \mathrm{P}$ is the trans-membrane pressure (bar). The relative permeability was obtained by dividing the final permeability at a specific time with the initial value and is reported as a percentage. Each measurement was performed in duplicates and repeated only if the deviation was significant.

Retention experiments were performed using a laboratory scale crossflow filtration unit (Fig. S5.3) in batch mode with recirculation of the retentate in the feed tank. The inorganic salts used for salt retention measurements were $\mathrm{NaCl}, \mathrm{MgSO}_{4}$ and $\mathrm{Na}_{2} \mathrm{SO}_{4}$. Salt retention of the coated hollow fibers was 
determined by cross flow filtration at 1 bar applied pressure with a crossflow velocity of $4.5 \mathrm{~m} \cdot \mathrm{s}^{-1}$ (Reynolds number of approximately 3600). Concentration changes of the salts in the permeate and concentrate were monitored using conductivity measurements (WTW cond 3210 conductivity meter).

The retention values of solutes were calculated using equation 5.2:

$$
R(\%)=1-\frac{C_{p}}{C_{f}} \times 100
$$

Where $c_{p}$ and $c_{f}$ represent the concentration of the solute in the permeate and feed at the end of the experiment respectively. The experiment was stopped when the retention reached a constant value and the average of a minimum of three measurements was used.

The membrane performance was also investigated by performing retention experiments on the small organic pollutants Bezafibrate $\mathrm{Mw}=361.8 \mathrm{Da}$ and Naproxen $\mathrm{Mw}=230.26 \mathrm{Da}$ both with a negative charge. Dionex Ultimate 3000 U-HPLC system equipped with an RS variable wavelength detector was used to determine the concentration of micro-pollutants in the concentrate and permeate. Micro-pollutant separation was done on an Acclaim RSLC C18 $2.2 \mu \mathrm{m}$ column (Thermo Scientific) at $45{ }^{\circ} \mathrm{C}$, while applying a gradient flow from $95 \mathrm{wt} . \% \mathrm{H}_{2} \mathrm{O}+5 \mathrm{wt} . \%$ acetonitrile at $\mathrm{pH} 2$ to 5 wt. $\% \mathrm{H}_{2} \mathrm{O}+95 \mathrm{wt} . \%$ acetonitrile at $1 \mathrm{ml} \cdot \mathrm{min}^{-1}$.

\subsubsection{Fouling and sacrificial studies}

\section{Reflectometry}

Adsorption and desorption of multilayers and model foulants (BSA and HA) was monitored on silicon wafers using optical reflectometry, a proven 
technique for studying adsorption onto substrates [46]. The fixed-angle optical reflectometry set-up consists of a He-Ne laser $(\lambda=632.8 \mathrm{~nm})$ with linearly polarized light. During adsorption or desorption, the resulting change in polarization is measured by detecting the parallel $\left(\mathrm{R}_{\mathrm{p}}\right)$ and perpendicular $\left(R_{s}\right)$ components of the polarized light. The ratio of the two components is the signal, $\mathrm{S}_{0}(-)$ and the change is the ratio, $\Delta \mathrm{S}(-)$, is directly proportional to the amount of mass adsorbed on the substrate (equation 5.3).

$$
\Gamma=\mathrm{Q}\left(\Delta \mathrm{S} / \mathrm{S}_{0}\right)
$$

Where $\Gamma$ is the amount of mass adsorbed on the substrate $\left(\mathrm{mg} \cdot \mathrm{m}^{-2}\right)$ and $\mathrm{Q}$ is the sensitivity factor $\left(\mathrm{mg} \cdot \mathrm{m}^{-2}\right)$ that depends on the Brewster angle $(\theta)$, refractive indices $(\eta)$, thickness of the layers $(d)$ and the refractive index increment $(d n / d c)$ of the adsorbate. The values used to calculate $\mathrm{Q}$ factor are refractive index of silicon wafer $\mathrm{n}_{\mathrm{Si}}=3.85$, refractive index of silica layer $\mathrm{n}_{\mathrm{SiO} 2}=1.46$, thickness of the silica layer $\mathrm{d}_{\mathrm{SiO} 2}=120 \mathrm{~nm}$, refractive index of solutions $\mathrm{n}_{\mathrm{s}}=1.33 \mathrm{dn} / \mathrm{dc}=0.185 \mathrm{ml} \cdot \mathrm{g}^{-1}$ [41]. The corresponding $\mathrm{Q}$ factor was calculated to be $45 \mathrm{mg} \cdot \mathrm{m}^{-2}$ for all experiments. Prior to adsorption tests, the surface of the treated silicon wafer was cleaned using $\mathrm{O}_{2}$ plasma cleaner with $50 \%$ power (Femto Diener, Germany).

\section{Membrane fouling and cleaning}

Fouling and cleaning experiments on membranes were performed in crossflow mode by applying the minimum cross flow speed $\left(0.5 \mathrm{~m} \cdot \mathrm{s}^{-1}\right)$. These tests included three main steps. The coated and uncoated membranes were first fed with DI water until a stable flux was achieved. The feed was then changed to an aqueous solution containing the model foulant at the appropriate concentration $\left(1 \mathrm{~g} \cdot \mathrm{l}^{-1} \mathrm{BSA}, \mathrm{pH} 7\right)$. The fouling experiments were performed for $2 \mathrm{~h}$ at a transmembrane pressure of $2 \mathrm{bar}$, and over the time 
the change in flux was monitored. Similar experiments were performed for HA fouling ( $1 \mathrm{~g} \cdot \mathrm{l}^{-1} \mathrm{HA}, \mathrm{pH}$ 5.8). From the obtained flux membrane resistance was calculated using equation 5.4:

$$
R=\frac{\Delta P}{\mu \times J}
$$

Here, $\mathrm{R}$ is the membrane resistance $\left(\mathrm{m}^{-1}\right), \mu$ is the dynamic viscosity of the feed $(\mathrm{Pa} \cdot \mathrm{s})$ and $\mathrm{J}$ is the membrane flux $\left(1 \cdot \mathrm{m}^{-2} \cdot \mathrm{h}^{-1}\right)$. Following the fouling experiments, membrane cleaning and surface regeneration was conducted to determine the success of the sacrificial layer concept. The fouled membranes were washed in crossflow mode with a $3 \mathrm{M} \mathrm{NaNO}_{3}$ solution at $\mathrm{pH} 3$ for specified time. The membranes were subsequently cleaned in black flush mode at 1 bar using the same trigger solution. After each cleaning, the membrane was rinsed with DI water and membrane resistance was measured. The extent of cleaning was characterized through comparison of the resistance before and after the cleaning. Following the cleaning steps, the PEM coating was regenerated with fresh PE solutions as outlined in section 2.2. In order to evaluate the success of the cleaning and regeneration, the membrane resistance to pure water at each stage is compared.

\subsection{Results and discussions}

The results and discussion section is divided into two main parts. In the first part we report on the preparation of hollow fiber PEM NF membranes using dynamic coating under different modes and dynamic coating conditions. The second part deals with the fouling and sacrificial cleaning studies of PEM's first on model surfaces and subsequently on dynamically coated hollow fiber NF membranes. 


\subsubsection{Membrane coating and performance}

\section{Effect of cross flow speed, filtration time and pressure on coating}

In order to optimise the deposition of PEMs on membranes by active coating, several parameters were investigated such as adsorption time, applied pressure and cross flow speed. Typically, the adsorption time for PEs is in the order of a few seconds to a few minutes to reach a stable plateau in stagnation point flow [47]. However, this applies to a non-porous model substrate under very well defined flow conditions. Prior to coating the multilayers onto the porous UF support via dynamic assembly, the effect of filtration time and coating speed on the deposition of the first layer of PE was investigated by feeding an uncoated UF support with a PAH (+) solution at constant cross flow speed and a constant pressure of 1 bar. The same experiment was carried out at different crossflow velocities ranging from 0.5 to $6 \mathrm{~m} \cdot \mathrm{s}^{-1}$. Fig. 5.1(a) shows the profiles of the membrane permeability as a function of filtration time. The results are presented in terms of permeability of PE solution relative to the initial pure water permeability. It can be observed that initially, the flux of the UF support decreased rapidly for low cross flow speeds $\left(0.5\right.$ and $\left.2.0 \mathrm{~m} \cdot \mathrm{s}^{-1}\right)$, while remaining quite high for the higher cross-flow velocities ( 4.0 and $\left.6.0 \mathrm{~m} \cdot \mathrm{s}^{-1}\right)$. The onset of a stable flux is approximately within initial 10-12 min of filtration except for very low cross flow $\left(0.5 \mathrm{~m} \cdot \mathrm{s}^{-1}\right)$ condition, where it takes longer (around $60 \mathrm{~min}$ ) for the flux to stabilize. Just as a high cross flow velocity limits the fouling in membranes, a high cross flow applied during coating allows less material to deposit on the membrane resulting in thinner and more permeable layers

Since the size of PAH is approximately $50 \%$ larger than the MWCO of the virgin membrane and the PEs system is fully dissociated at $\mathrm{pH} 6$, the rate of deposition is therefore expected to be primarily controlled by electrostatic interactions with just the top of the membrane support. To verify if PE 
chains are $100 \%$ retained by the membrane pores under pressure coating, the TOC values of the PE during the first coating step for the permeate and the feed were determined. TOC values of feed and the permeate were 47.22 mg. $1^{-1}$ and $1.03 \mathrm{mg}^{-1} \mathrm{l}^{-1}$ respectively, which suggests that $97 \%$ of $\mathrm{PE}$ was retained by the membrane during deposition of the first bilayer and only $3 \%$ PE molecules may pass across the pores of the support membrane, confirming that most of the PE material is deposited inside or on top of the pores during coating.
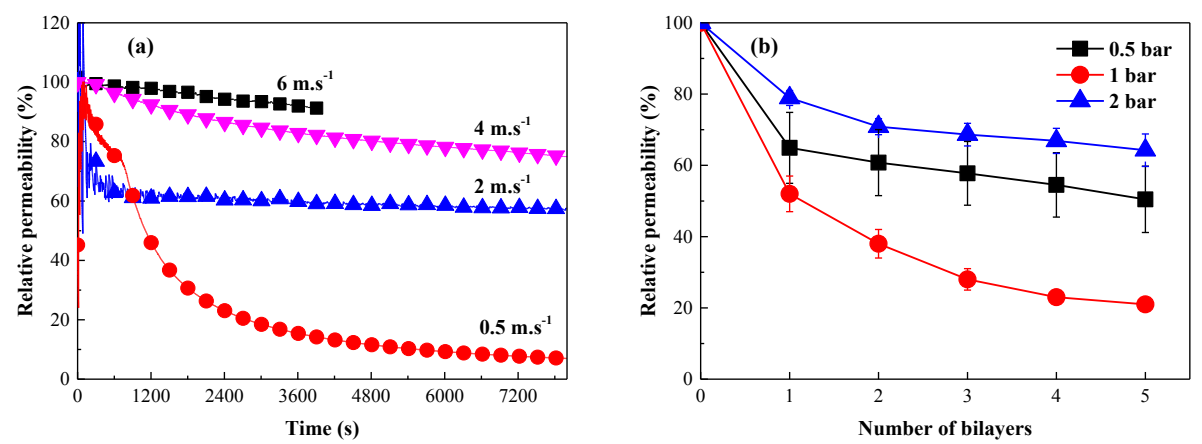

Fig. 5.1: (a) Time dependent variation of permeability with reference to initial water permeability during coating of the first PAH layer under different cross flow speeds; (b) Effect of coating pressure and coating steps on membrane permeability. Measurements performed in triplicates, coating solutions contained PE conc. $0.1 \mathrm{~g} \cdot \mathrm{l}^{-1}$ with $50 \mathrm{mM}$ salt and $\mathrm{pH}$ 6. Permeability of uncoated support was 60-70 l.m- $\mathrm{m}^{-2} \cdot h^{-1} \cdot$ bar $^{-1}$.

We then evaluated the impact of pressure on the membranes coated at a constant crossflow velocity. Fig. 5.1(b) shows the relative permeability as a function of the number of bi-bilayers for membranes coated for $15 \mathrm{~min}$ at varying pressures but at a constant crossflow velocity of $0.5 \mathrm{~m} \cdot \mathrm{s}^{-1}$. At constant cross-flow velocity, an increase in the pressure from 0.5 bar to 1 bar resulted in a decrease in permeability. At a higher pressure more polymers are transported to the membrane surface and are retained there, leading to a 
thicker less permeable layer. Unexpectedly, however, an increase from 1 bar to 2 bar resulted in an increase in the permeability of the membrane. Possibly the higher flux and the resulting higher shear leads to thinner layers at the membrane interface. On the basis of these experiments the condition of 1 bar was chosen as the optimum based on the drop in permeability observed. This will be used in the next sections.

Since preparation conditions (cross flow speed and pressure) greatly influence the efficiency of the formed membranes, the performance of these modified membranes was followed in greater detail using relative permeability measurements. Furthermore, preparation under cross-flow was compared to preparation under dead-end conditions and under static conditions (dip coating). As shown in Fig. 5.2(a), the permeability decreases as the number of bilayers increase. The reduction in permeability with each bilayer confirms that the layers are indeed being deposited, while small error bars confirm that all approaches give very reproducible results. This trend was observed for all investigated dynamic modes. As a basis for comparison, statically coated fibres were also made via dip coating in $0.1 \mathrm{~g} \cdot \mathrm{l}^{-1} \mathrm{PE}$ solutions with an adsorption time of 15 minutes per layer. When comparing dynamic and static LbL coating methods, thinner layers are expected for the former due to the fact that the driving force (pressure) present in dynamic coating results in deeper penetration of the PEs into the pores of the support membrane. However as we are also applying cross flow through the fibres so layers formed could be different. As can be seen in Fig. 5.2 (a) the membranes prepared by dip-coating LbL assembly show sharper decrease in permeability followed by a plateau after 3 bilayers. Between 2 to 3 bilayers a $40 \%$ decrease in permeability of dip coated membranes occurs with the permeability being approximately 20\% lower than dynamic modes. Therefore, dip coated membranes also show an overall lower permeability 
(higher resistance) than dynamically coated membranes. Moreover after a certain number of bilayers dead end coating does not differ much from cross flow coating, possibly also due to the low cross flow speed and low polymer concentrations used in this investigation.
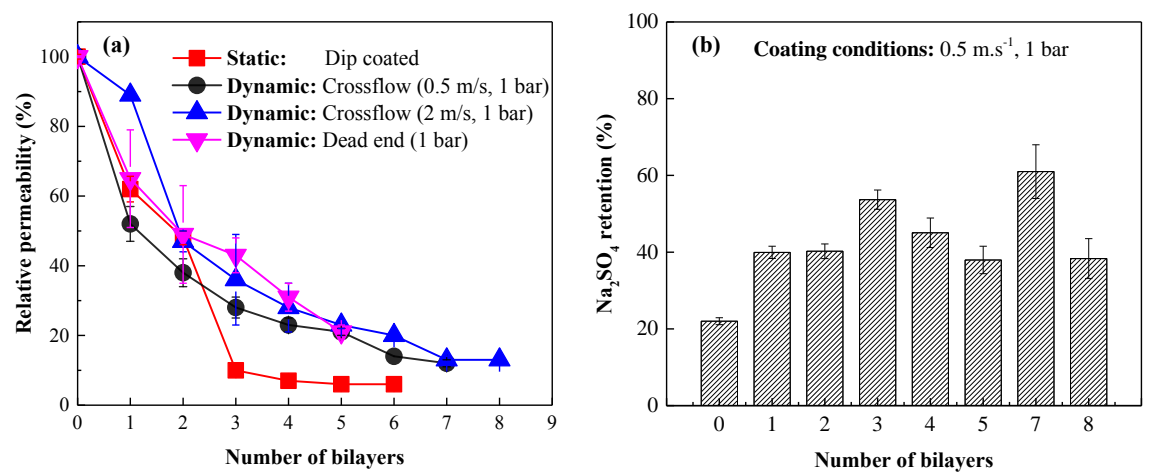

Fig. 5.2: Comparison of different modes of coating on membrane performance; (a) Relative permeability change with increasing bilayers coated under different coating techniques; (b)

Effect of coating steps on membrane performance in terms of $\mathrm{Na}_{2} \mathrm{SO}_{4}$ rejection.

Recently Menne et al. [40] demonstrated that thicker layers are produced from dynamic coatings (constant flux coating in dead end) relative to dip coating. However they used a different support, a combination of strong PEs (PDADMAC/PSS) and higher concentration of PEs $\left(1 \mathrm{~g} \cdot \mathrm{l}^{-1}\right)$. Nevertheless, one clear similarity between the finding of this research and those of Menne et al., is the fact that the quantity of polyelectrolytes, and by extension membrane permeability, is a function of the amount of polyelectrolyte that is transported to the substrate surface via an external driving force. This conclusion could also be drawn from the results of Fig. 5.1, where at higher cross flow less material is deposited. Since $0.5 \mathrm{~m} \cdot \mathrm{s}^{-1}$ proved to have the lowest permeability (better deposition of PEs) of the dynamic techniques used, this cross flow velocity was used for subsequent experiments. In order to test the separation capability of the membranes created using $0.5 \mathrm{~m} \cdot \mathrm{s}^{-1}$ 
cross flow speed and 1 bar pressure, salt rejection experiments were conducted using $\mathrm{Na}_{2} \mathrm{SO}_{4}$. The effect of layer numbers on salt retention was then investigated. All tested membranes are terminated with PAA (-) layer. The pristine (uncoated) membrane showed a 20-22\% retention of $\mathrm{Na}_{2} \mathrm{SO}_{4}$, with increase in rejection performance reaching $60 \%$. The rejection of solutes seems to be mainly based on size exclusion and donnan exclusion, something that will be discussed in more detail later.

\section{Homogeneity of LbL coating}

While the UF support used in this study possesses its own pore size distribution which could lead to different permeation rates at different points on the membrane, the membrane is assumed to be homogenous at the experimental scale. In order to check the homogeneity of the coating, a longer (40 cm long) membrane module was taken and divided into three segments of $10 \mathrm{~cm}$ active length and the permeability and retention of segmented sections were compared. A schematic of the segmented fibre is shown in Fig. 5.3.

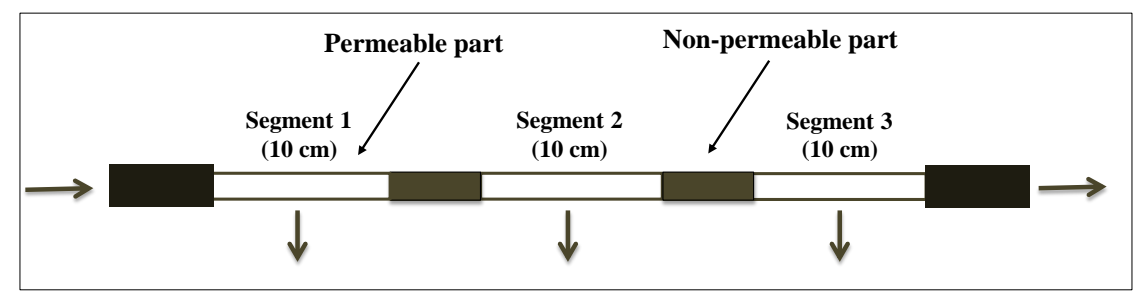

Fig. 5.3: Schematic of segmented module used for homogeneity test of membrane coating.

The segmented module was coated dynamically under 1 bar pressure, while applying $0.5 \mathrm{~m} \cdot \mathrm{s}^{-1}$ cross flow through the fiber. Fig. 5.4(a) shows the relative pure water permeability of each segment with a $2 \%$ deviation indicating that 
the sections are coated evenly. This is important to consider for longer modules where pressure drop inside the fiber can limit the proper coating, but that is not the case under the coating conditions used here. As shown in Fig. 5.4(b) the retention of $\mathrm{Na}_{2} \mathrm{SO}_{4}$ in each segment was comparable and no significant deviation was found. The dynamic coating process may therefore be applied to industrial systems and a uniform performance is expected from the entire module.
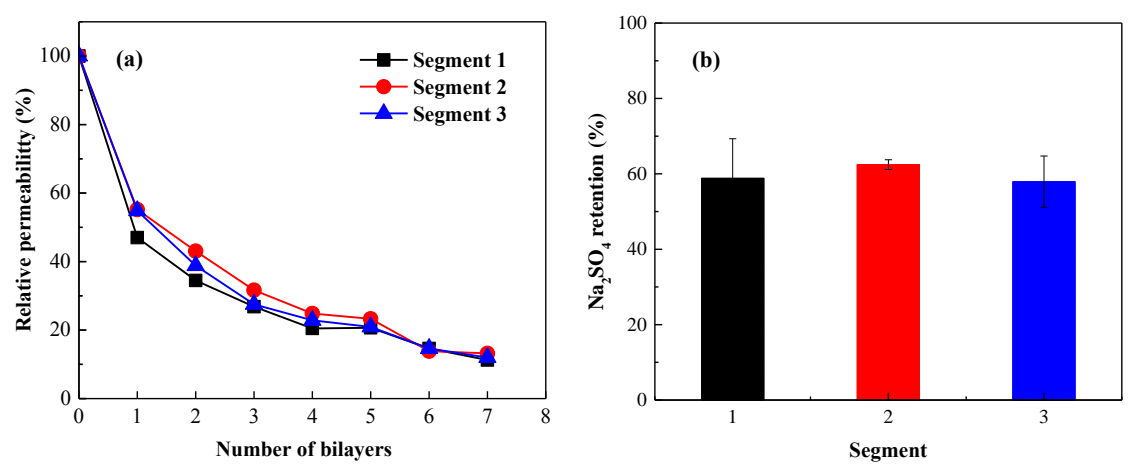

Fig. 5.4: Homogeneity test of dynamic coating (a) Relative permeability of each $10 \mathrm{~cm}$ segments; (b) $\mathrm{Na}_{2} \mathrm{SO}_{4}$ retention of each $10 \mathrm{~cm}$ segment, measured membrane coated with 7 bilayers of PAH/PAA (coating is performed with $0.1 \mathrm{~g} . \mathrm{l}^{-1} \mathrm{PE}$ containing $50 \mathrm{mM}$ salt at $\mathrm{pH}$ 6, under 1 bar pressure and $0.5 \mathrm{~m} \cdot \mathrm{s}^{-1}$ cross flow speed).

\section{Membrane performance as $\mathrm{NF}$}

To check if the created membranes were indeed within the NF performance regime, the retention of different salt ions $\left(\mathrm{NaCl}, \mathrm{Na}_{2} \mathrm{SO}_{4}\right.$ and $\mathrm{MgSO}_{4}$ ) and small organic molecules (Bezafibrate and Naproxen) was investigated. Membranes coated with 7 bilayers of PAH/PAA terminating with the PAA (-) layer with $0.5 \mathrm{~m} \cdot \mathrm{s}^{-1}$ cross flow and 1 bar pressure were used for NF performance test. As can be seen from Fig. 5.5, the prepared membranes are capable of rejecting the divalent anion $\mathrm{Na}_{2} \mathrm{SO}_{4}(60 \%)$ and 
organic solutes $(55-70 \%)$, while monovalent ions $(\mathrm{NaCl})$ and divalent cations $\left(\mathrm{Mg}^{2+}\right)$ are hardly rejected. It is noted that the salt rejection sequence of the PEMs membranes shows the typical performance behavior of a negatively charged NF membrane. Still the high retentions of Bezafibrate and Naproxen must have to do with their size, as they have just a single charge. Based on the results, it is expected that the rejection mechanism is governed mainly by size and charge exclusion although other separation mechanisms also can play a role.

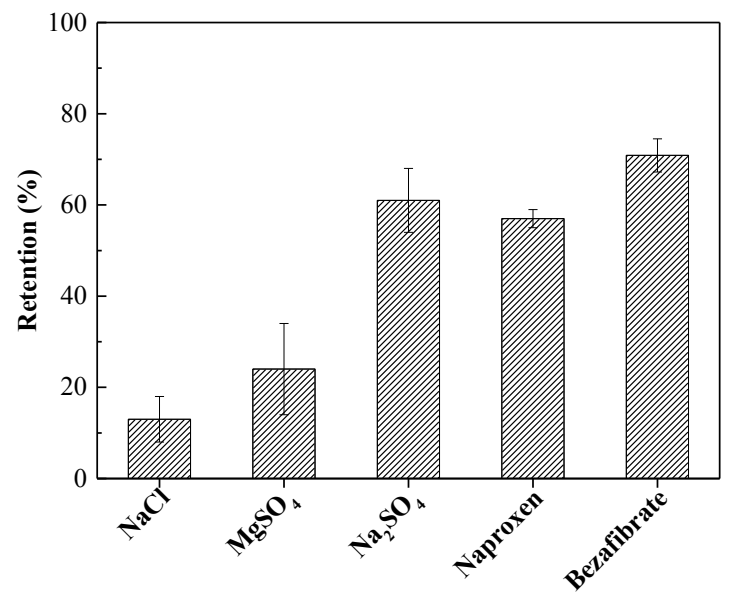

Fig. 5.5: NF membrane performance in terms of retention of mono and divalent salts and organic molecules. The tested membranes were coated with 7 bilayers of PAH/PAA at speed of $0.5 \mathrm{~m} \cdot \mathrm{s}^{-1}$ and 1 bar pressure. Permeability of tested membrane was $6.52 \pm 0.5 \mathrm{l} \cdot \mathrm{m}^{-2} \cdot \mathrm{h}^{-1} \cdot \mathrm{bar} \mathrm{r}^{-1}$.

\section{Upscaling of cross flow dynamic coating approach}

After optimizing the dynamic coating conditions on a single fiber module, we checked the upscaling potential of this dynamic coating approach to coat modules with an effective length of approximately $200 \mathrm{~mm}$ housing 15 fibers in one module yielding a total effective area of $67 \mathrm{~cm}^{2}$. Coating was performed at constant pressure of 1 bar under two cross flow speeds $(0.5$ and $\left.2 \mathrm{~m} \cdot \mathrm{s}^{-1}\right)$. As shown in Fig. 5.6 with every coating step a drop in permeability 
was observed and similar to single fiber module coating the drop is higher for modules coated at low cross flow speed due to accumulation of material. However salt rejection stays constant with coating steps indicating that most of pores are covered with dense thin layers after first bilayer when coating is in pore dominating regime that is why further addition of layer doesn't improve selectivity to greater extent. Membranes coated with PEM's can be either in the pore-dominated regime when layers are thin or layer-dominated regime when the layers are thicker [32]. Moreover dynamic coating approach is equally suitable for coating large modules so could be useful for coating existing UF modules in industrial applications.
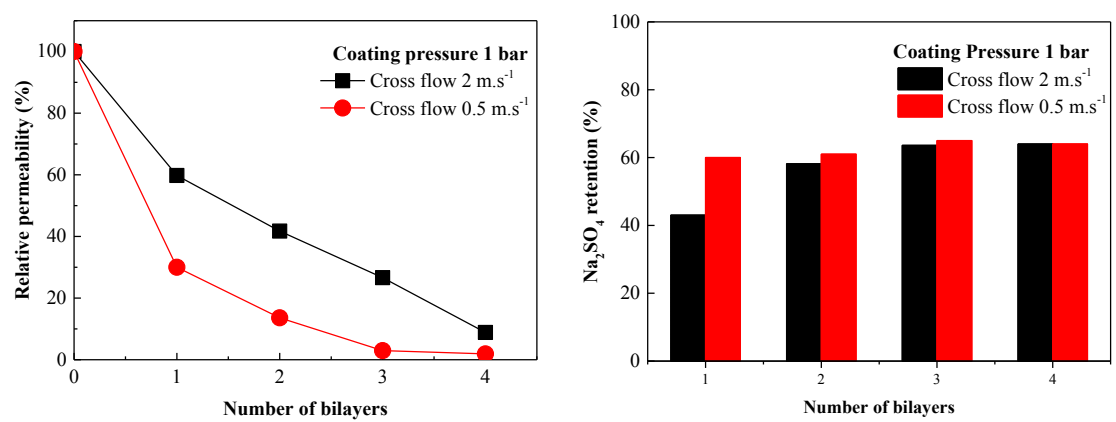

Fig. 5.6: (a) Variations of pure water permeability relative to initial permeability and (b) $\mathrm{Na}_{2} \mathrm{SO}_{4}$ retention of PAH/PAA coated membranes with the number of coated layers.

\subsubsection{Fouling and cleaning studies}

In the second part of this study we test the fouling propensity of PAH/PAA multilayer system and their potential as sacrificial layers for easy membrane cleaning. Fouling and cleaning studies were performed first on model surfaces (silicon wafer) in order to optimize adsorption and release conditions, and were later replicated on LbL coated membranes. 


\section{Reflectometry}

Adsorption, fouling and sacrificial cleaning of PEMs was monitored on silicon wafers using optical fixed angle reflectometry. The adsorption measurements on silicon wafers were started by exposing the surface to a PE solution of PAH (denoted with $+, 0.1 \mathrm{~g} \cdot 1^{-1}, \mathrm{pH} 6,50 \mathrm{mM} \mathrm{NaNO}_{3}$ ), then switching to a PAA (denoted with -, $0.1 \mathrm{~g} \cdot \mathrm{l}^{-1}, \mathrm{pH} 6,50 \mathrm{mM} \mathrm{NaNO}_{3}$ ) solution. Between subsequent adsorption steps, the substrate was rinsed with the background electrolyte solution $(50 \mathrm{mM} \mathrm{NaNO} 3)$ to remove excess PE and avoid the formation of bulk complexes. Continued switching between PAH and PAA exposure leads to a stepwise building of the multilayers. Subsequently, a foulant solution was applied on top of differently terminated multilayers (PAH or PAA as the final layer). To simulate fouling two model foulants were used in this study bovine serum albumin (BSA, $0.1 \mathrm{~g} \cdot \mathrm{l}^{-1}, \mathrm{pH}$ 5.2) and Humic acids (HA, $0.1 \mathrm{~g} \cdot \mathrm{l}^{-1}, \mathrm{pH}$ 7). Both foulants are negatively charged at the $\mathrm{pH}$ conditions used for this study. Similar to the spontaneous self-assembly phenomena observed in PEs, biological materials can adsorb via electrostatic interactions. Many biological foulants are negatively charged therefore negatively charged membranes generally exhibit decreased adsorption in comparison to positively charged membranes. As can be seen in Fig. 5.7, this phenomenon was clearly observed, when the foulants introduced to the PAA (-) terminated layer, the quantity of foulant adsorbed is significantly less at approximately $1 \mathrm{mg} \cdot \mathrm{m}^{-2}$ for BSA and HA. In contrast, for PAH (+) terminated layers the introduction of the foulant leads to a large increase in the quantity of material adsorbed. The factor to which the mass increased for BSA and HA was 5 and 2 respectively. Results of HA fouling of PAH and PAA terminated multilayers are given in Fig. S5.4. Although both foulants adsorbed onto the positive (PAH) layer, they adsorbed to different 
degrees with BSA being adsorbed more. While this behavior is significant, for this particular study, the foulant-polyelectrolyte electrostatic interaction is not the primary focus here. The overall decrease in fouling propensity observed with PAA (-) terminated layers demonstrates that by carefull selection of the final layer of a PEM, a low fouling layer can be achieved. But apart from low fouling surfaces, these multilayers can also be used as sacrificial layers to allow for easy cleaning. When a trigger solution was applied on the fouled PEMs, the adsorbed multilayers along with the fouling agents are desorbed from the silicon wafer surface (Fig. 5.7), again demonstrating the potential of these weak PEMs as sacrificial coatings. When the $\mathrm{pH}$ is low, PAA becomes considerably uncharged and an increase in the ionic strength then further weakens the ionic interactions resulting in disintegration of multilayers, and the removal of all attached foulants.
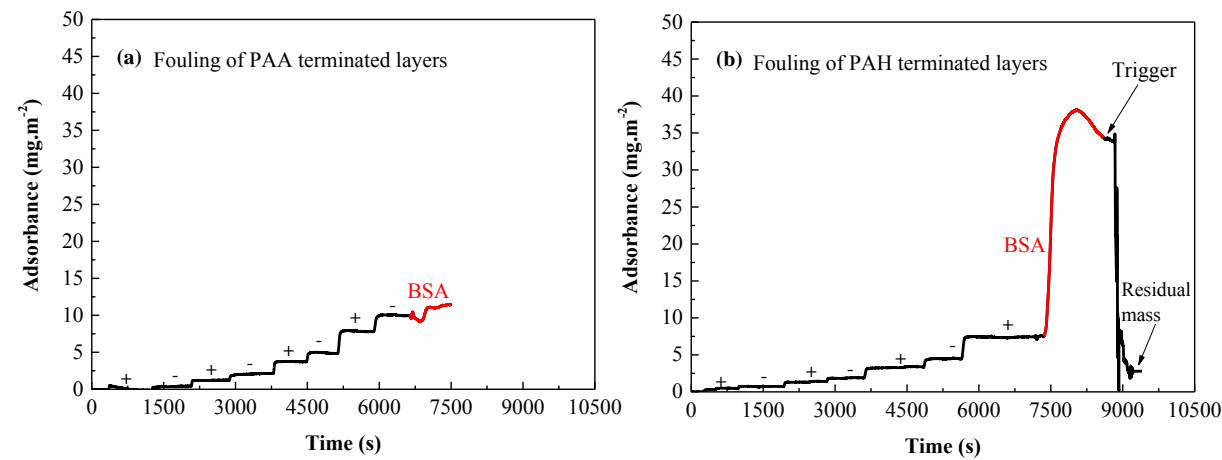

Fig. 5.7: Effect of terminal layer on BSA and HA adsorption and sacrificial layer effect (a) BSA fouling of multilayers terminated with PAA (-) layer; (b) BSA fouling of PAH(+) terminated layers and effect of trigger solution $(\mathrm{pH} 3,3 \mathrm{M})$ on desorption of fouled multilayers. Concentration of BSA $0.1 \mathrm{~g} \cdot \mathrm{l}^{-1}, \mathrm{pH}$ 7. Rinsing solution used after every adsorption step is $50 \mathrm{mM} \mathrm{NaNO}_{3}, \mathrm{pH} 6$. 


\section{Membrane fouling and cleaning}

In this section, we demonstrate that the promising properties of multilayers as observed via reflectometry can also be applied to a membrane system. The interactions between the foulants and the membranes are investigated through cross flow permeation tests using the model foulants BSA and HA. Fouling experiments were conducted under very low cross flow speed $(0.5$ $\mathrm{m} \cdot \mathrm{s}^{-1}$ ) for about $2 \mathrm{~h}$ with $1 \mathrm{~g} \cdot \mathrm{l}^{-1}$ foulant. Initially the Virgin UF support was tested for its performance in terms of pure water permeability. The fouling propensity was measured as the ratio of the permeability at a point in time to the initial permeability. The UF support used contains negative charge and is well developed for retention of silica particles. Hence, the membrane is expected to already have a very low fouling propensity. The negative charge of the virgin membrane surface was expected to result in a strong electrostatic repulsion between the membrane surface and the foulant
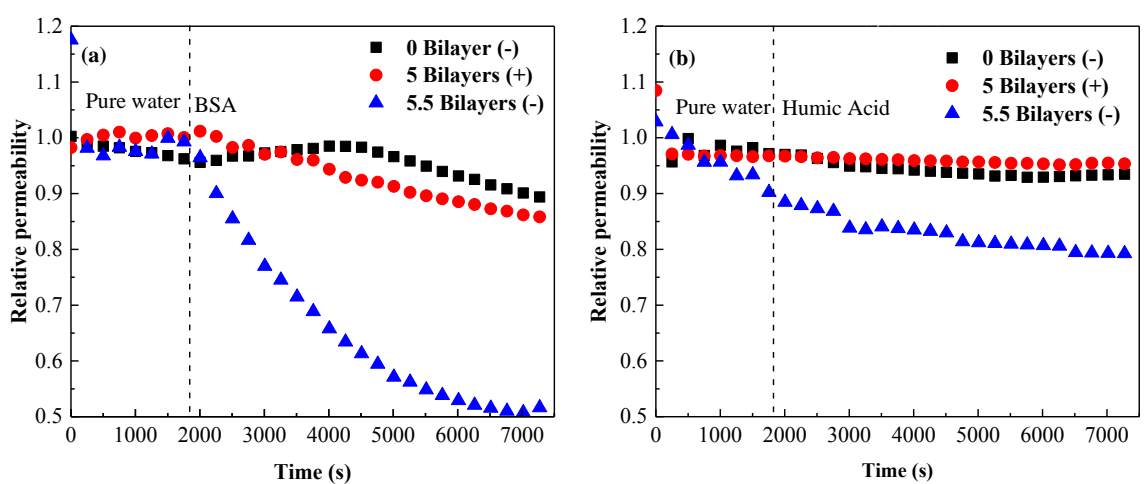

Fig. 5.8: Time dependent permeability of unmodified and modified membranes with $P A H / P A A$ with + and - terminal layers membranes during the filtration of BSA and HA. Fouling experiments were carried out at $25^{\circ} \mathrm{C}$ and 1 bar pressure.

molecules. Additionally, the membrane is known to be hydrophilic such that repulsive hydration forces are expected to repel the hydrophobic foulants. When exposed to the foulants, the support membranes showed an average $8 \%$ decline in permeability (Fig. 5.8). 
This decline in flux is primarily due to the deposition of the foulants on the membrane surface by adsorption and aggregation. When coated membranes (with 5 and 5.5 bilayers of PAH/PAA) were exposed to foulants, it can be observed that BSA exhibited a greater affinity for the membrane surface than HA (Fig. $5.8 \mathrm{a} \& b$ ), which is in line with the results of reflectometry (Fig. 5.7, S5.4). Here we can also see the impact of differently terminated layers (PAA and PAH) on foulant adsorption. A rapid flux decline was observed for PAH terminated membrane during crossflow filtration of $1 \mathrm{~g} \cdot \mathrm{l}^{-1}$ BSA. This behaviour may indeed be explained by the attractive force between the negatively charged BSA molecules and the positively charged PAH membrane. The carboxylic functional groups of the PAA terminated membranes are negative and thus a strong electrostatic repulsion between the negatively charged BSA molecules and the negative membrane surface is expected. While the strong electrostatic repulsion is the most important reason for improved fouling prevention, the ionised carboxylic groups present on the membrane surface also interact with water molecules through Van der Waals forces and hydrogen bonds thereby preventing the deposition of the protein. The overall decrease in fouling of PAA terminated layers relative to PAH terminated layers and the uncoated membrane clearly highlights a viable approach of surface modification while retaining a very low fouling propensity. Antifouling results of PAA terminated layer are comparable to a UF membrane support optimized for fouling control.

\section{Sacrificial membrane cleaning}

In this section, we investigate the use of dynamically coated PEMs as sacrificial layers for cleaning of fouled multilayered NF membranes along with the possibility of regeneration of the PEM membrane. Prior to cleaning the fouled membrane, the use of dynamically assembled PEMs as sacrificial layers was evaluated and for that UF support coated 
with 5 bilayers of PAH/PAA was first rinsed with the trigger

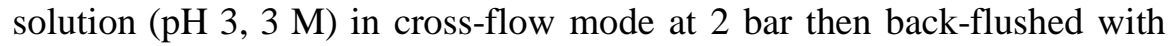
the trigger solution at 2 bar for an hour. It can be seen (Fig. 5.9) that the coating is fully removable with the applied trigger solution bringing the membrane resistance back to the level of uncoated UF support.

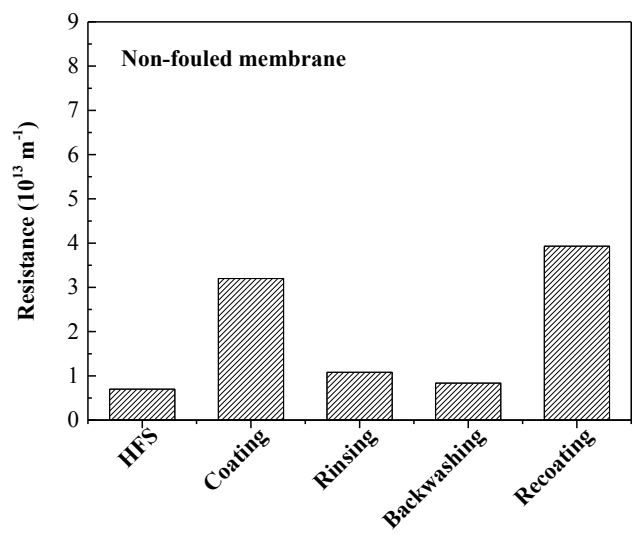

Fig. 5.9: Measured membrane resistance to pure water permeation at different stages of coating and sacrificial cleaning of multilayers. The sequence followed is dynamically coating the HFS membrane with 5.5 bilayers of PAH/PAA, rinsing of multilayers from inside to out for $1 \mathrm{~h}$ with trigger solution ( $\mathrm{pH} 3,3 \mathrm{M})$, backwashing with trigger solution from out to inside of membrane under pressure of 2 bar for $1 \mathrm{~h}$ and recoating of clean membrane with 5.5 bilayers of PAH/PAA.

Subsequently we investigated if the removal of this sacrificial coating could indeed be used to remove BSA foulants from the membrane. For sacrificial cleaning experiments we chose PAH terminated membrane (coated with 5.5 bilayers of PAH/PAA) fouled with BSA because this membrane and foulant showed the highest fouling propensity (Fig. 5.8a). In Fig. 5.10 we show the membrane resistance against pure water permeation for several steps, including dynamic coating with PEMs (coating at $0.5 \mathrm{~m} \cdot \mathrm{s}$ ${ }^{1}$ cross flow and 1 bar pressure), membrane fouling by BSA, membrane cleaning by sacrificing the PEM coating and subsequent re-generation steps. Here we applied the same cleaning protocol for PEM removal as 
used for unfouled membrane, at similar conditions and number of bilayers as the unfouled membrane, the resistance of fouled membrane after cleaning went back close to the resistance of coated membrane suggesting the trigger may not effectively penetrate the foulant layer formed. This proposes that the nature of the foulant greatly impacts the success of the layer removal. Unlike the hard spherical nature of silica particles [34], it is believed that the BSA molecules form a gel like layer on the membrane surface and therefore restricts access of the trigger solution to the PEMs. Consequently, after the cleaning step, the membrane is effectively unchanged and did not return to its pristine state as expected.
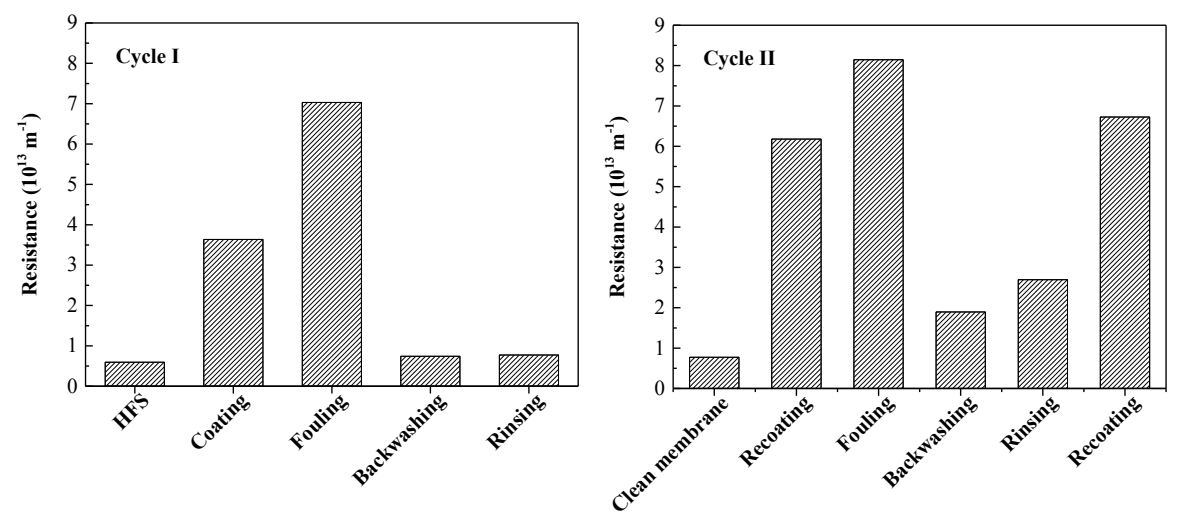

Fig. 5.10: Measured membrane resistance to pure water permeation at different stages of coating, fouling and sacrificial cleaning of fouled multilayers. The sequence followed is dynamically coating the HFS membrane with 5.5 bilayers of PAH/PAA, fouling with $1 \mathrm{~g} \cdot \mathrm{l}^{-1}$ BSA, backwashing with trigger solution from out to inside of membrane under pressure of 4 bar for $8 \mathrm{~h}$ rinsing of multilayers from inside to out for $1 \mathrm{~h}$ with trigger solution ( $\mathrm{pH} 3,3 \mathrm{M})$, and recoating of clean membrane with 5.5 bilayers of PAH/PAA.

In light of these results, the order of cleaning was adjusted to include backflushing as a first step followed by rinsing. During backwash, the permeation is forced in the reverse direction through the membrane so that the polyelectrolyte on the surface can be lifted off and re-suspended 
in a tangential flow. This approach proved to be much more effective than the previous combination as it resulted in an $86 \%$ reduction in the resistance (Fig. S5.5). Rinsing, therefore had no capacity to remove the BSA molecules while backflushing did. This is believed to be due to the fact that the trigger solution now had direct contact with the PEMs through the membrane's structure resulting in immediate removal of the layers and the attached foulants. Complete recovery of the pristine membrane resistance was obtained when modules were backwashed at a bit higher pressure of 4 bars followed by rinsing for an hour. Following up with rinsing resulted in further removal of loosely bound material. The used commercial support can bear upto 5 bar backwash pressure and a $\mathrm{pH}$ as low as 1 so we do not expect any change in membrane performance as a result of the cleaning procedure. This same support was already used by de Grooth et al. [31] successfully in combination with sodium hypochlorite and a backwash pressure of 5 bar without any reported damage to membrane. Two successive sets of BSA fouling, cleaning and regeneration experiments were performed on the same module to evaluate the longevity of the regeneration process. The pure water flux and resistance were re-measured and compared with the initial values. As shown in Fig. 5.10, the membrane maintained a relatively low resistance after a series of runs. After the first regeneration cycle, the resistance returned close to pristine membrane resistance. The second cycle resulted in a further $20 \%$ decrease in the membrane support permeability. While the regeneration results in second cycle are not as impressive as expected based on the reflectometry results, this set of results also illustrates the mechanical strength of the PEM as high shear flow operating conditions and $8 \mathrm{~h}$ rounds of 4 bar backflush pressure with the acidic trigger solution produced no significant change in the membrane resistance relative to the first cycle. It can therefore be concluded that the membranes are 
less prone to fouling if terminated with PAA layer and can be regenerated multiple times with the applied cleaning agent and cleaning protocol. For continuous regeneration some additional cleaning parameters can be taken into account.

\subsection{Conclusions}

In this study sacrificial PEMs based hollow fiber NF membranes were prepared using dynamic LbL coating under constant pressure and in cross flow mode. The effect of different cross flow speeds, pressures and mode of coating was investigated extensively and compared with dip coating method. It is shown that dynamic deposition is a simple way to modify the surface (inside) of existing hollow fiber UF support to make versatile NF membranes with low fouling propensity (if terminated with PAA) and which are easy to clean by sacrificial layer approach. Rejection performance of solutes (salts and organic micropollutants) by dynamically coated membranes fall in typical NF performance range (50-70\% retention). Moreover this coating method with its reproducibility and homogeneity features also shown to have upscaling potential to coat existing UF membrane modules.

\section{Acknowledgments}

S. Ilyas acknowledges the European Commission - Education, Audiovisual and Culture Executive Agency (EACEA), for her PhD scholarship under the program: Erasmus Mundus Doctorate in Membrane Engineering - EUDIME (FPA N ${ }^{\circ}$ 2011-0014, Edition III, http://eudime.unical.it/). We thank Pentair X-Flow, The Netherlands, for kindly supplying the membranes. 


\section{References}

[1] A.W. Mohammad, Y.H. Teow, W.L. Ang, Y.T. Chung, D.L. Oatley-Radcliffe, N. Hilal, Nanofiltration membranes review: Recent advances and future prospects, Desalination, 356 (2015) 226-254.

[2] M. Pontié, H. Dach, J. Leparc, M. Hafsi, A. Lhassani, European Desalination Society and Center for Research and Technology Hellas (CERTH), Sani Resort 22 25 April 2007, Halkidiki, GreeceNovel approach combining physico-chemical characterizations and mass transfer modelling of nanofiltration and low pressure reverse osmosis membranes for brackish water desalination intensification, Desalination, 221 (2008) 174-191.

[3] Membrane filtration technologies tackle water reuse and purification, Membrane Technology, 2007 (2007) 9-11.

[4] W. Guo, H.-H. Ngo, J. Li, A mini-review on membrane fouling, Bioresour. Technol., 122 (2012) 27-34.

[5] A. Al-Amoudi, R.W. Lovitt, Fouling strategies and the cleaning system of NF membranes and factors affecting cleaning efficiency, Journal of Membrane Science, 303 (2007) 4-28.

[6] A. Al-Amoudi, P. Williams, S. Mandale, R.W. Lovitt, Cleaning results of new and fouled nanofiltration membrane characterized by zeta potential and permeability, Separation and Purification Technology, 54 (2007) 234-240.

[7] P. Ahmadiannamini, M.L. Bruening, V.V. Tarabara, Sacrificial polyelectrolyte multilayer coatings as an approach to membrane fouling control: Disassembly and regeneration mechanisms, Journal of Membrane Science, (2015).

[8] G. Pearce, Introduction to membranes: Fouling control, Filtration \& Separation, 44 (2007) 30-32.

[9] A.I. Schäfer, A.G. Fane, T.D. Waite, Nanofiltration: principles and applications, Elsevier, 2005.

[10] L. Liu, D.Y.W. Di, H. Park, M. Son, H.-G. Hur, H. Choi, Improved antifouling performance of polyethersulfone (PES) membrane via surface modification by CNTs bound polyelectrolyte multilayers, RSC Advances, 5 (2015) 7340-7348.

[11] H. Guo, Y. Ma, P. Sun, S. Cui, Z. Qin, Y. Liang, Self-cleaning and antifouling nanofiltration membranes-superhydrophilic multilayered polyelectrolyte/CSH composite films towards rejection of dyes, RSC Advances, 5 (2015) 63429-63438. [12] T. Ishigami, K. Amano, A. Fujii, Y. Ohmukai, E. Kamio, T. Maruyama, H. Matsuyama, Fouling reduction of reverse osmosis membrane by surface modification via layer-by-layer assembly, Separation and Purification Technology, 99 (2012) 1-7.

[13] D. Rana, T. Matsuura, Surface Modifications for Antifouling Membranes, Chemical Reviews, 110 (2010) 2448-2471.

[14] C. Ba, J. Economy, Preparation and characterization of a neutrally charged antifouling nanofiltration membrane by coating a layer of sulfonated poly(ether 
ether ketone) on a positively charged nanofiltration membrane, Journal of Membrane Science, 362 (2010) 192-201.

[15] Y.-L. Ji, Q.-F. An, Q. Zhao, W.-D. Sun, K.-R. Lee, H.-L. Chen, C.-J. Gao, Novel composite nanofiltration membranes containing zwitterions with high permeate flux and improved anti-fouling performance, Journal of Membrane Science, 390-391 (2012) 243-253.

[16] T. Kruk, K. Szczepanowicz, D. Kregiel, L. Szyk-Warszyńska, P. Warszyński, Nanostructured multilayer polyelectrolyte films with silver nanoparticles as antibacterial coatings, Colloids and Surfaces B: Biointerfaces, 137 (2016) 158-166.

[17] L. Setiawan, R. Wang, K. Li, A.G. Fane, Fabrication and characterization of forward osmosis hollow fiber membranes with antifouling NF-like selective layer, Journal of Membrane Science, 394-395 (2012) 80-88.

[18] L. Tang, W. Gu, P. Yi, J.L. Bitter, J.Y. Hong, D.H. Fairbrother, K.L. Chen, Bacterial anti-adhesive properties of polysulfone membranes modified with polyelectrolyte multilayers, Journal of Membrane Science, 446 (2013) 201-211.

[19] L.Y. Ng, A.W. Mohammad, C.Y. Ng, A review on nanofiltration membrane fabrication and modification using polyelectrolytes: Effective ways to develop membrane selective barriers and rejection capability, Advances in Colloid and Interface Science, 197-198 (2013) 85-107.

[20] R. Malaisamy, M.L. Bruening, High-Flux Nanofiltration Membranes Prepared by Adsorption of Multilayer Polyelectrolyte Membranes on Polymeric Supports, Langmuir : the ACS journal of surfaces and colloids, 21 (2005) 10587-10592.

[21] M.D. Miller, M.L. Bruening, Controlling the Nanofiltration Properties of Multilayer Polyelectrolyte Membranes through Variation of Film Composition, Langmuir : the ACS journal of surfaces and colloids, 20 (2004) 11545-11551.

[22] L. Ouyang, R. Malaisamy, M.L. Bruening, Multilayer polyelectrolyte films as nanofiltration membranes for separating monovalent and divalent cations, Journal of Membrane Science, 310 (2008) 76-84.

[23] W. Shan, P. Bacchin, P. Aimar, M.L. Bruening, V.V. Tarabara, Polyelectrolyte multilayer films as backflushable nanofiltration membranes with tunable hydrophilicity and surface charge, Journal of Membrane Science, 349 (2010) 268278.

[24] B.W. Stanton, J.J. Harris, M.D. Miller, M.L. Bruening, Ultrathin, Multilayered Polyelectrolyte Films as Nanofiltration Membranes, Langmuir : the ACS journal of surfaces and colloids, 19 (2003) 7038-7042.

[25] S.U. Hong, M.D. Miller, M.L. Bruening, Removal of Dyes, Sugars, and Amino Acids from $\mathrm{NaCl}$ Solutions Using Multilayer Polyelectrolyte Nanofiltration Membranes, Industrial \& Engineering Chemistry Research, 45 (2006) 6284-6288.

[26] W. Jin, A. Toutianoush, B. Tieke, Use of Polyelectrolyte Layer-by-Layer Assemblies as Nanofiltration and Reverse Osmosis Membranes, Langmuir : the ACS journal of surfaces and colloids, 19 (2003) 2550-2553. 
[27] L. Krasemann, B. Tieke, Selective Ion Transport across Self-Assembled Alternating Multilayers of Cationic and Anionic Polyelectrolytes, Langmuir : the ACS journal of surfaces and colloids, 16 (1999) 287-290.

[28] N. Peng, N. Widjojo, P. Sukitpaneenit, M.M. Teoh, G.G. Lipscomb, T.-S. Chung, J.-Y. Lai, Evolution of polymeric hollow fibers as sustainable technologies: Past, present, and future, Progress in Polymer Science, 37 (2012) 1401-1424.

[29] C.Y. Feng, K.C. Khulbe, T. Matsuura, A.F. Ismail, Recent progresses in polymeric hollow fiber membrane preparation, characterization and applications, Separation and Purification Technology, 111 (2013) 43-71.

[30] J. de Grooth, M. Dong, W.M. de Vos, K. Nijmeijer, Building polyzwitterionbased multilayers for responsive membranes, Langmuir : the ACS journal of surfaces and colloids, 30 (2014) 5152-5161.

[31] J. de Grooth, B. Haakmeester, C. Wever, J. Potreck, W.M. de Vos, K. Nijmeijer, Long term physical and chemical stability of polyelectrolyte multilayer membranes, Journal of Membrane Science, 489 (2015) 153-159.

[32] J. de Grooth, R. Oborný, J. Potreck, K. Nijmeijer, W.M. de Vos, The role of ionic strength and odd-even effects on the properties of polyelectrolyte multilayer nanofiltration membranes, Journal of Membrane Science, 475 (2015) 311-319.

[33] J. de Grooth, D.M. Reurink, J. Ploegmakers, W.M. de Vos, K. Nijmeijer, Charged Micropollutant Removal With Hollow Fiber Nanofiltration Membranes Based On Polycation/Polyzwitterion/Polyanion Multilayers, ACS applied materials \& interfaces, 6 (2014) 17009-17017.

[34] S. Ilyas, J. de Grooth, K. Nijmeijer, W.M. de Vos, Multifunctional polyelectrolyte multilayers as nanofiltration membranes and as sacrificial layers for easy membrane cleaning, Journal of colloid and interface science, 446 (2015) 386393.

[35] B. Su, T. Wang, Z. Wang, X. Gao, C. Gao, Preparation and performance of dynamic layer-by-layer PDADMAC/PSS nanofiltration membrane, Journal of Membrane Science, 423-424 (2012) 324-331.

[36] L. Ouyang, D.M. Dotzauer, S.R. Hogg, J. Macanás, J.-F. Lahitte, M.L. Bruening, Catalytic hollow fiber membranes prepared using layer-by-layer adsorption of polyelectrolytes and metal nanoparticles, Catalysis Today, 156 (2010) 100-106.

[37] C. Liu, L. Shi, R. Wang, Enhanced hollow fiber membrane performance via semi-dynamic layer-by-layer polyelectrolyte inner surface deposition for nanofiltration and forward osmosis applications, Reactive and Functional Polymers, 86 (2015) 154-160.

[38] C. Liu, W. Fang, S. Chou, L. Shi, A.G. Fane, R. Wang, Fabrication of layer-bylayer assembled FO hollow fiber membranes and their performances using low concentration draw solutions, Desalination, 308 (2013) 147-153. 
[39] G. Zhang, X. Song, S. Ji, N. Wang, Z. Liu, Self-assembly of inner skin hollow fiber polyelectrolyte multilayer membranes by a dynamic negative pressure layerby-layer technique, Journal of Membrane Science, 325 (2008) 109-116.

[40] D. Menne, J. Kamp, J. Erik Wong, M. Wessling, Precise tuning of salt retention of backwashable polyelectrolyte multilayer hollow fiber nanofiltration membranes, Journal of Membrane Science, 499 (2016) 396-405.

[41] W.M. de Vos, A. de Keizer, M.A.C. Stuart, J.M. Kleijn, Thin polymer films as sacrificial layers for easier cleaning, Colloids and Surfaces A: Physicochemical and Engineering Aspects, 358 (2010) 6-12.

[42] S.A. Sukhishvili, S. Granick, Layered, Erasable Polymer Multilayers Formed by Hydrogen-Bonded Sequential Self-Assembly, Macromolecules, 35 (2001) 301310.

[43] R. v. Klitzing, Internal structure of polyelectrolyte multilayer assemblies, Physical Chemistry Chemical Physics, 8 (2006) 5012-5033.

[44] S.T. Dubas, J.B. Schlenoff, Polyelectrolyte Multilayers Containing a Weak Polyacid: Construction and Deconstruction, Macromolecules, 34 (2001) 3736-3740. [45] D. Kovacevic, S. van der Burgh, A. de Keizer, M.A. Cohen Stuart, Kinetics of Formation and Dissolution of Weak Polyelectrolyte Multilayers: Role of Salt and Free Polyions, Langmuir : the ACS journal of surfaces and colloids, 18 (2002) 56075612.

[46] J.C. Dijt, M.A.C. Stuart, G.J. Fleer, Reflectometry as a tool for adsorption studies, Advances in Colloid and Interface Science, 50 (1994) 79-101.

[47] J.C. Dijt, M.A.C. Stuart, J.E. Hofman, G.J. Fleer, Kinetics of polymer adsorption in stagnation point flow, Colloids and Surfaces, 51 (1990) 141-158. 


\section{Supplementary Information}

\section{Chapter 5}

\section{Structure of support membrane:}

In Fig. S5.1 SEM images taken by JEOL JSM-6010LA of the PES UF support membrane are given. Membrane has spongy structure with dense separation layer on the lumen side (c) and more open structure towards outer side (d).
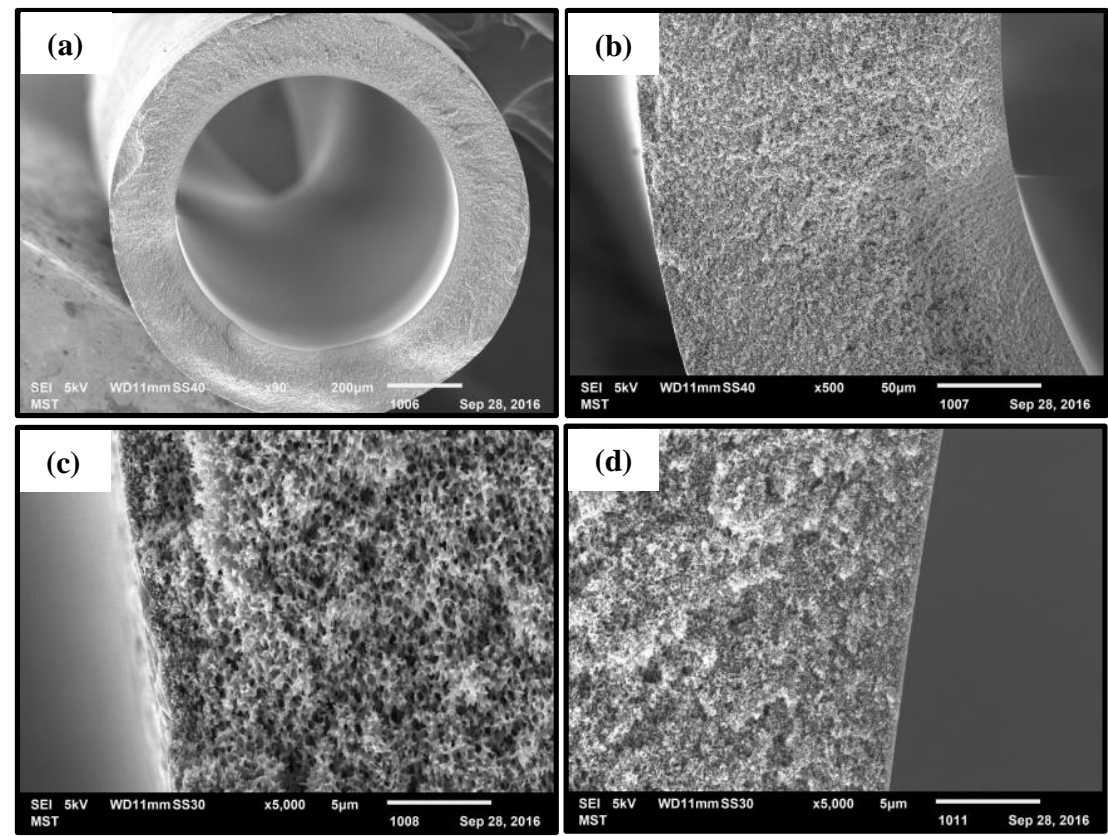

Fig. S5.1: SEM images obtained with JEOL JSM-6010LA of membrane support used for this study. 


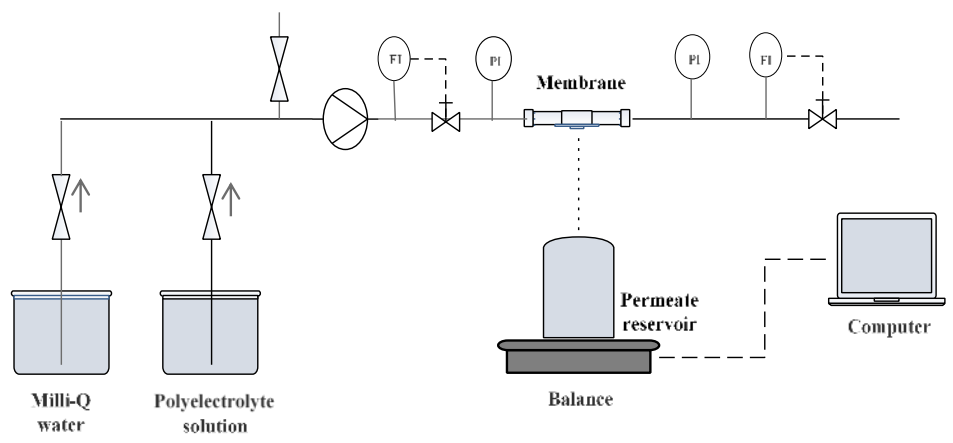

Fig. S5.2: Schematic representation of cross flow setup for coating and filtration experiments.

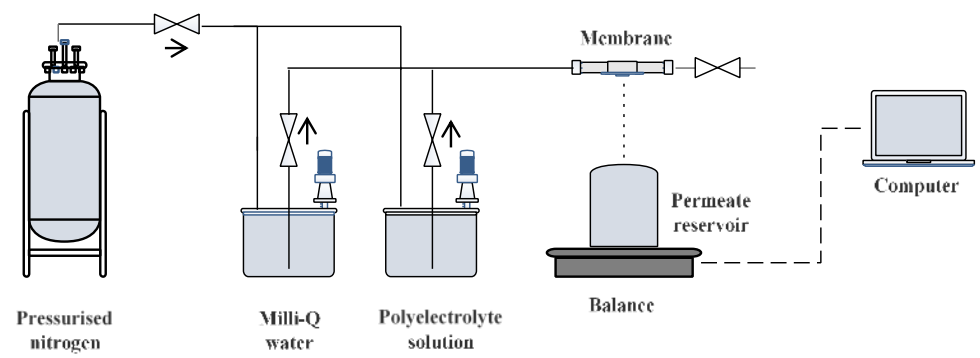

Fig. S5.3: Schematic representation of dead end filtration setup for coating experiments. 

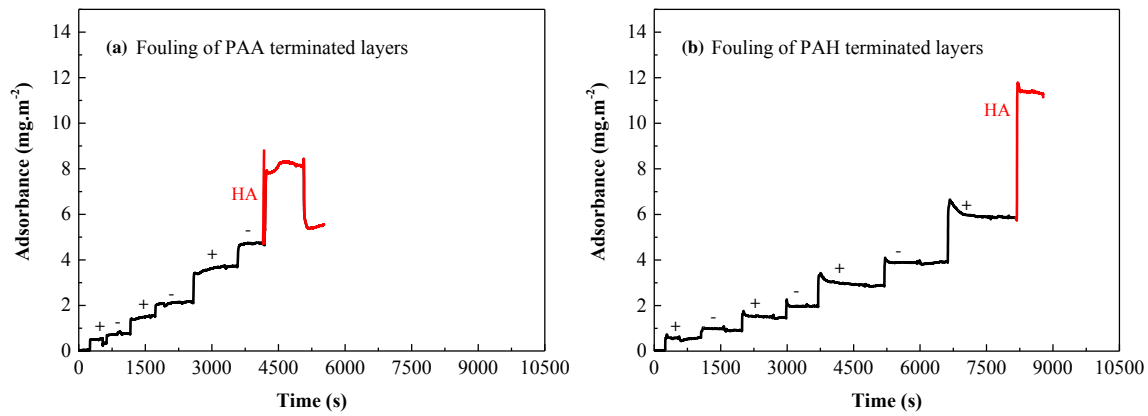

Fig. S5.4: Effect of terminal layer on $H A$ adsorption and sacrificial layer effect (a) $H A$ fouling of multilayers terminated with PAA (-); (b) HA fouling of PAH (+) terminated multilayers and effect of trigger on desorption of fouled multilayers. Concentration of HA 0.1 $g \cdot l^{-1}, p H$ 5.8. Rinsing solution used after every adsorption step is $50 \mathrm{mM} \mathrm{NaNO}, \mathrm{pH} 6$.

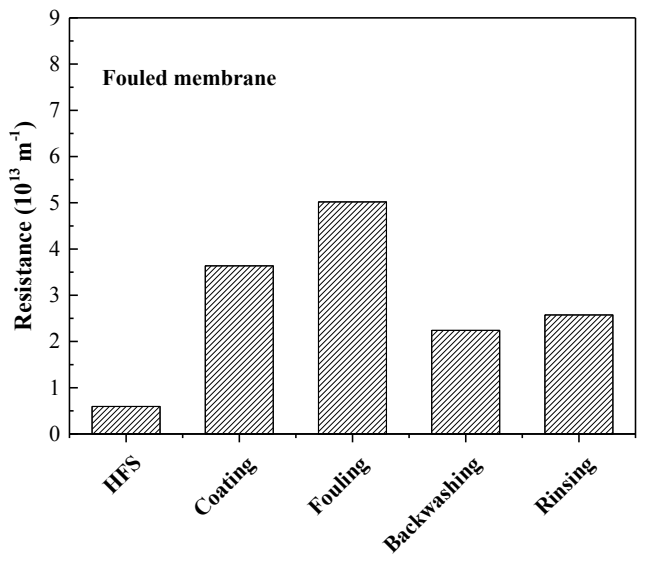

Fig. S5.5: Measured membrane resistance to pure water permeation at different stages of coating, fouling and sacrificial cleaning of fouled multilayers. The sequence followed is dynamically coating the HFS membrane with 5.5 bilayers of PAH/PAA, fouling with 1 $g \cdot l^{-1} B S A$, backwashing with trigger solution from out to inside of membrane under pressure of 2 bar for $8 \mathrm{~h}$ rinsing of multilayers from inside to out for $1 \mathrm{~h}$ with trigger solution ( $p H 3,3 \mathrm{M}$ ), and recoating of clean membrane with 5.5 bilayers of PAH/PAA. 
Conclusions and future perspective 
Polyelectrolyte multilayers (PEM), prepared by layer-by-layer (LbL) selfassembly, are a promising type of coating to modify the surface of a large variety of materials and to create surfaces with desired functionalities. By careful selection of the used polyelectrolytes (PEs) and the used coating conditions ( $\mathrm{pH}$, ionic strength), PEM's can have different properties and therefore different functionalities. In this thesis we present the use of this promising coating approach to create versatile polymeric nanofiltration (NF) and solvent resistant nanofiltration (SRNF) membranes. The current market of NF and SRNF is dominated by polymeric flat sheet membranes because of their low cost and ease of manufacture. However, polymeric membranes suffer from fouling which results in the loss of membrane performance over time and demands the additional effort of cleaning. Moreover, not all polymeric membranes are stable under harsh organic solvents used in industries on a routine basis. This thesis specifically investigates the potential of using a classic $\mathrm{pH}$ responsive, weak polyelectrolyte multilayer system, consisting of poly(allylamine hydrochloride) (PAH) and poly(acrylic acid) (PAA), to prepare antifouling and easy to clean NF membranes and solvent stable SRNF membranes. New membranes were prepared either by dip-coating or active coating on hollow fiber (chapter 2, 3 and 5) or on flat sheet (chapter 4) UF membrane supports. In all chapters, the coating conditions for multilayers were studied and optimized on model surfaces before applying the multilayers to the support membranes. The performance of prepared membranes is explained with the help of results obtained from model surfaces.

In this last chapter of the thesis we present the conclusion of this study and provide suggestions for future work, especially on the multifunctional aspects of PEM membranes. 


\section{Weak PEM's for nanofiltration}

Hollow fiber NF membranes, with a sacrificial PEM as the active separation layer, were prepared in chapter 2, 3 and 5 . In chapter 2, the coating conditions were optimized for adsorption and desorption of the PEM on model surfaces via optical fixed-angle reflectometry. Subsequently hollow fiber UF supports were dip-coated under identical coating conditions as used for the model surfaces, allowing the creation of hollow fiber NF membranes with a PEM separation layer. The resulting membranes were able to reject divalent salt ions and an organic molecule (Bisphenol A) up to 50-70\%. This PEM separation layer was also shown to function as a sacrificial layer when exposed to low $\mathrm{pH}$ and high salt solution ( $\mathrm{pH} 3,3 \mathrm{M}$ ), to allow the easy cleaning of membranes upon fouling with silica-nano particles. Moreover, subsequent recoating of the clean membrane with same PEM system under similar coating conditions resulted in bringing the membrane's resistance to pure water close to the original PEM membrane prepared at first step. In chapter 3, a more detailed investigation of the role of $\mathrm{pH}$ of coating solution of weak polyelectrolytes on NF membrane performance was carried out. It was described that by simple variation in the $\mathrm{pH}$ of the coating solution, hollow fiber NF membranes could be created which selectively remove micropollutants while allowing passage to most of the salt ions from water. In chapter 5, a simplification of the coating method for the sacrificial PEM is presented. Simplification was achieved by employing active coating, which will allow the coating and recoating of new and existing membrane modules. This active coating approach involved flushing the PE solutions through the lumen of the hollow fibre membrane under application of a constant pressure. It was shown that active coating is equally suitable to coat small and long fibers with homogeneous membrane performance. Moreover, PEM membranes terminated with the negative PAA, were found to be less prone to fouling. Applying a low $\mathrm{pH}$ and high salt $(\mathrm{pH} 3,3 \mathrm{M})$ trigger at an appropriate 
backflush pressure, lead to the complete removal of these PEM coatings, including any attached foulants, to obtain a clean membrane support. This clean membrane support was then subsequently recoated with same PE system to regenerate the PEM NF membrane. The rejection mechanism for solutes for hollow fiber PEM NF membranes prepared in chapter 2, 3 and 5 was found to be dominated by size exclusion together with Donon exclusion.

\section{Weak PEM's for solvent resistant nanofiltration}

SRNF offers unique advantages over conventional separation processes (i.e. distillation, extraction, crystallization and chromatography), notably the ability to perform molecular separations in organic solvents at ambient conditions. Furthermore the lack of an energy demanding phase transition and the absence of additives, makes it attractive for the pharmaceutical and chemical industry. In chapter 4 , we presented how the $\mathrm{pH}$ can be used as a tuning parameter for the weak PEM system of PAH/PAA to prepare membranes with tuneable separation for SRNF applications. SRNF membranes were prepared by employing LbL assembly of PEM on a UF hydrolyzed polyacrylonitrile (PAN-H) support, and a detailed investigation of the effect of $\mathrm{pH}$ of coating solution on membrane performance for specific dye molecules from organic media was evaluated. Membrane performance was tested for different organic solvents of industrial importance such as isopropyl alcohol (IPA), acetonitrile (ACN), tetrahydrofuran (THF), and $N, N$ dimethylformamide (DMF), and membranes were found to be stable for these solvents under long term-filtrations. Moreover, membranes with more free acid and amine groups were found to be much more susceptible to dye adsorption, leading to a pronounced film densification, a low permeance, but in some case excellent dye retentions. In this chapter, we presented a simple and versatile approach of using $\mathrm{pH}$ during coating to tune SRNF membrane performance for specific application. 


\section{Multifunctional PEM membranes, a Future perspective}

What stands out in this thesis is the multi-functionality of the involved polyelectrolyte multilayers and the resulting membranes. For example, we presented PEM membranes prepared of weak PEs that function as easy to tune separation layer for both NF (chapter 2, 3 and 5) and SRNF membranes (chapter 4). Moreover, these same layers could be used to provide the membrane with antifouling properties, while also allowing sacrificial cleaning of fouled membranes (chapter 2 and 5). Clearly a single PEM can be used to imbue a membrane with a number of different functionalities. However, in addition to already mentioned functionalities, future research could be broader, and could consider PEM coatings that could imbue even more functionalities to the PEM membranes (see Fig. 6.1) to allow an even greater freedom to create membranes for specific applications. Here we present an overview of possible functionalities.

To provide PEM membranes with additional functionalities, careful selection of the PEs is very important, while one could also introduce other materials into the PEM's during the LbL assembly process. A recent example of this type of modification is the creation of ionic responsive membranes utilizing the polyzwitterion $\operatorname{poly}(N$ (3-sulfopropyl)-N(methacryloxyethyl)- $N, N$-dimethylammonium betaine) (PSBMA) on top of a poly(sodium-4-styrenesulfonate) (PSS), poly(diallyldimethylammonium chloride) (PDADMAC), where a change in water permeability up to $108 \%$ was achieved by varying the ionic strength of feed solution [1]. Such a membranes is an excellent example of ionic responsive NF membranes, while the zwitterion coating also leads to a membrane with a very low fouling potential. Another study reported on the creation of poly(ethyleneimine)/poly(sodium-4-styrenesulfonate) (PEI/PSS)-calcium silicate hydrate (CSH) multilayered membranes with enhanced 
hydrophilicity and self-cleaning properties [2]. Copolymers of poly $(N$ isopropylacrylamide) (PNIPAM) are well known to allow the preparation of thermal responsive PEM's [3, 4]. Although the surface modification of membranes enhances the antifouling properties, the adhesion of microbes is not totally prevented and they may be immobilised due to the drag forces caused during permeate flow. For this reason, the PEM layers could also be provided with antimicrobial/biocidal properties, which can be introduced by the incorporation of silver (Ag) nanoparticles [5-9]. Diagne et al. [10] investigated the incorporation of Ag nanoparticles into the PSS layer of a PEM composed of PSS/PDADMAC for the introduction of biocidal properties. While the Ag nanoparticles did in fact inactivate deposited bacteria, the performance decreased over time as the Ag nanoparticles were leached from the PEM resulting in the need for crosslinking. Recently Zarpelon et al. [11] incorporated silver nanoparticles into PAH/PAA layers and crosslinked with glutaraldehyde to produce bactericidal films for the treatment of industrial wastewater. Incorporation of palladium and gold nanoparticles in PEM's can be used to create catalytic membranes for the removal of organic contaminants such as phenol [20-22] and nitroaromatic compounds [23] through catalytic reduction. Utilization of titanium oxide $\left(\mathrm{TiO}_{2}\right)$ particles can allow one to create antifouling and photocatalytic membranes [12-15]. It is also reported that embedding enzymes such as organophosphorus hydrolase (OPH) in PEM layers not only leads to catalytic membranes, but also prolongs the lifetime of the enzyme [29]. 


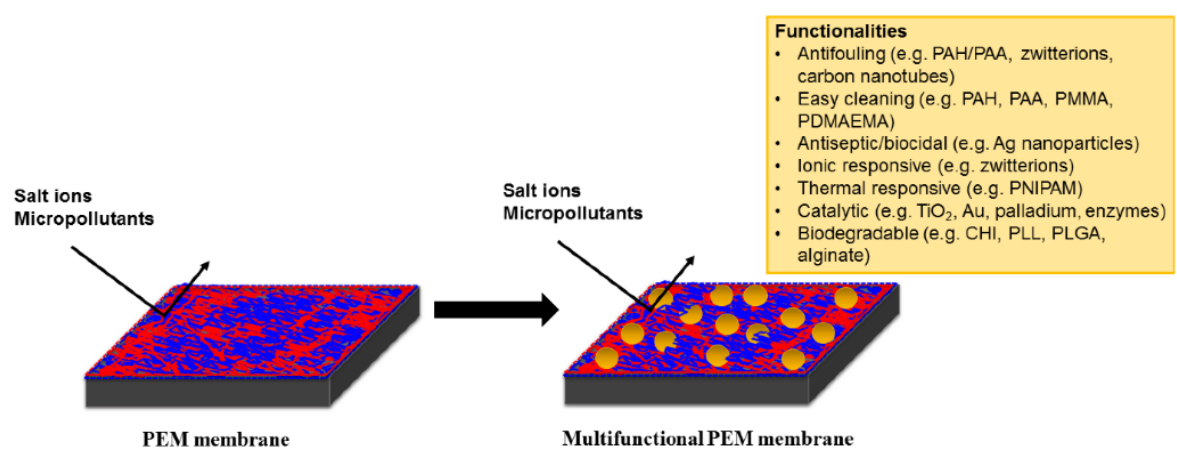

Fig. 6.1: Possible functionalities that can be induced to PEM membranes by incorporating different materials.

Gold nanoparticles can also be utilized to fabricate PEM films with enhanced ionic conductivities [24], which may be especially useful for making ion conductive membranes. Another possible functionality that can be induced in these PEM films is biodegradability which will be useful from an environmental perspective, especially in combination with the sacrificial layer approach. Biodegradable polymers such as of chitosan (CHI), poly(Llysine) (PLL), alginate, poly(lactic acid) and copolymers such as poly(lacticco-glycolic acid) (PLGA) and polylactide (PLA)/polyglycolide can be the polymers of choice for future PEM membranes [25-28].

Multifunctionality could also stem from building PEM membranes in smarter ways. For example to combine the separation mechanism of PEM membranes prepared in this thesis, one could consider utilizing a few bi-layers of strong PE's on top of a weak PEM to have separation in the top layers on the basis of Donnan exclusion and in the bottom layers on the basis of size exclusion. Another possibility could be using a few bi-layers of weak PE's (with antifouling and ease of cleaning) on top of multilayers prepared of strong PEs 
such poly(diallyldimethylammonium chloride) (PDADMAC) and poly(styrenesulfonate) (PSS). In this way instead of sacrificing the whole PEM layer one could only remove just the final fouled layer. Clearly, multifunctionality cannot just come from what we coat, but also from how the membranes are coated. 


\section{References}

[1] J. de Grooth, M. Dong, W.M. de Vos, K. Nijmeijer, Building polyzwitterion-based multilayers for responsive membranes, Langmuir : the ACS journal of surfaces and colloids, 30 (2014) 5152-5161.

[2] H. Guo, Y. Ma, P. Sun, S. Cui, Z. Qin, Y. Liang, Self-cleaning and antifouling nanofiltration membranes-superhydrophilic multilayered polyelectrolyte/CSH composite films towards rejection of dyes, RSC Advances, 5 (2015) 63429-63438.

[3] K. Glinel, C. Déjugnat, M. Prevot, B. Schöler, M. Schönhoff, R.v. Klitzing, Responsive polyelectrolyte multilayers, Colloids and Surfaces A: Physicochemical and Engineering Aspects, 303 (2007) 3-13.

[4] J.A. Jaber, J.B. Schlenoff, Polyelectrolyte Multilayers with Reversible Thermal Responsivity, Macromolecules, 38 (2005) 1300-1306.

[5] J. Kochan, M. Scheidle, J. van Erkel, M. Bikel, J. Büchs, J.E. Wong, T. Melin, M. Wessling, Characterization of antibacterial polyethersulfone membranes using the respiration activity monitoring system (RAMOS), Water research, 46 (2012) 54015409.

[6] T. Kruk, K. Szczepanowicz, D. Kregiel, L. Szyk-Warszyńska, P. Warszyński, Nanostructured multilayer polyelectrolyte films with silver nanoparticles as antibacterial coatings, Colloids and Surfaces B: Biointerfaces, 137 (2016) 158-166.

[7] M.S. Rahaman, H. Therien-Aubin, M. Ben-Sasson, C.K. Ober, M. Nielsen, M. Elimelech, Control of biofouling on reverse osmosis polyamide membranes modified with biocidal nanoparticles and antifouling polymer brushes, Journal of Materials Chemistry B, 2 (2014) 1724-1732.

[8] L. Tang, K.A. Huynh, M.L. Fleming, M. Larronde-Larretche, K.L. Chen, Imparting antimicrobial and anti-adhesive properties to polysulfone membranes through modification with silver nanoparticles and polyelectrolyte multilayers, Journal of colloid and interface science, 451 (2015) 125-133.

[9] X. Zan, Z. Su, Polyelectrolyte multilayer films containing silver as antibacterial coatings, Thin Solid Films, 518 (2010) 5478-5482.

[10] F. Diagne, R. Malaisamy, V. Boddie, R.D. Holbrook, B. Eribo, K.L. Jones, Polyelectrolyte and silver nanoparticle modification of microfiltration membranes to mitigate organic and bacterial fouling, Environmental science \& technology, 46 (2012) 4025-4033.

[11] F. Zarpelon, D. Galiotto, C. Aguzzoli, L.N. Carli, C.A. Figueroa, I.J.R. Baumvol, G. Machado, J.d.S. Crespo, M. Giovanela, Removal of coliform bacteria from industrial wastewaters using polyelectrolytes/silver nanoparticles self-assembled thin films, Journal of Environmental Chemical Engineering, 4 (2016) 137-146.

[12] T.-H. Bae, T.-M. Tak, Preparation of TiO2 self-assembled polymeric nanocomposite membranes and examination of their fouling mitigation effects in a membrane bioreactor system, Journal of Membrane Science, 266 (2005) 1-5. 
[13] R.A. Damodar, S.-J. You, H.-H. Chou, Study the self cleaning, antibacterial and photocatalytic properties of TiO2 entrapped PVDF membranes, Journal of hazardous materials, 172 (2009) 1321-1328.

[14] S.H. Kim, S.-Y. Kwak, B.-H. Sohn, T.H. Park, Design of TiO2 nanoparticle selfassembled aromatic polyamide thin-film-composite (TFC) membrane as an approach to solve biofouling problem, Journal of Membrane Science, 211 (2003) 157-165.

[15] J.-H. Li, Y.-Y. Xu, L.-P. Zhu, J.-H. Wang, C.-H. Du, Fabrication and characterization of a novel $\mathrm{TiO} 2$ nanoparticle self-assembly membrane with improved fouling resistance, Journal of Membrane Science, 326 (2009) 659-666.

[16] E. Celik, H. Park, H. Choi, H. Choi, Carbon nanotube blended polyethersulfone membranes for fouling control in water treatment, Water research, 45 (2011) 274-282. [17] J.-H. Choi, J. Jegal, W.-N. Kim, Fabrication and characterization of multi-walled carbon nanotubes/polymer blend membranes, Journal of Membrane Science, 284 (2006) 406-415.

[18] Y. Mo, X. Zhao, Y.X. Shen, Cation-dependent structural instability of graphene oxide membranes and its effect on membrane separation performance, Desalination, 399 (2016) 40-46.

[19] L. Wang, N. Wang, J. Li, J. Li, W. Bian, S. Ji, Layer-by-layer self-assembly of polycation/GO nanofiltration membrane with enhanced stability and fouling resistance, Separation and Purification Technology, 160 (2016) 123-131.

[20] L. Ouyang, D.M. Dotzauer, S.R. Hogg, J. Macanás, J.-F. Lahitte, M.L. Bruening, Catalytic hollow fiber membranes prepared using layer-by-layer adsorption of polyelectrolytes and metal nanoparticles, Catalysis Today, 156 (2010) 100-106.

[21] C. Chu, Z. Su, Facile Synthesis of AuPt Alloy Nanoparticles in Polyelectrolyte Multilayers with Enhanced Catalytic Activity for Reduction of 4-Nitrophenol, Langmuir : the ACS journal of surfaces and colloids, 30 (2014) 15345-15350.

[22] B. Domènech, M. Muñoz, D.N. Muraviev, J. Macanás, Polymer-stabilized palladium nanoparticles for catalytic membranes: ad hoc polymer fabrication, Nanoscale Research Letters, 6 (2011) 406-406.

[23] D.M. Dotzauer, S. Bhattacharjee, Y. Wen, M.L. Bruening, NanoparticleContaining Membranes for the Catalytic Reduction of Nitroaromatic Compounds, Langmuir : the ACS journal of surfaces and colloids, 25 (2009) 1865-1871.

[24] A. Ostendorf, C. Cramer, G. Decher, M. Schönhoff, Humidity-Tunable Electronic Conductivity of Polyelectrolyte Multilayers Containing Gold Nanoparticles, The Journal of Physical Chemistry C, 119 (2015) 9543-9549.

[25] J.M. Garza, N. Jessel, G. Ladam, V. Dupray, S. Muller, J.-F. Stoltz, P. Schaaf, J.-C. Voegel, P. Lavalle, Polyelectrolyte Multilayers and Degradable Polymer Layers as Multicompartment Films, Langmuir : the ACS journal of surfaces and colloids, 21 (2005) 12372-12377. 
[26] G.E. Luckachan, C.K.S. Pillai, Biodegradable Polymers- A Review on Recent Trends and Emerging Perspectives, Journal of Polymers and the Environment, 19 (2011) 637-676.

[27] A. Schneider, C. Vodouhê, L. Richert, G. Francius, E. Le Guen, P. Schaaf, J.-C. Voegel, B. Frisch, C. Picart, Multifunctional Polyelectrolyte Multilayer Films: Combining Mechanical Resistance, Biodegradability, and Bioactivity, Biomacromolecules, 8 (2007) 139-145.

[28] J.M. Silva, A.R.C. Duarte, S.G. Caridade, C. Picart, R.L. Reis, J.F. Mano, Tailored Freestanding Multilayered Membranes Based on Chitosan and Alginate, Biomacromolecules, 15 (2014) 3817-3826.

[29] Y. Lee, I. Stanish, V. Rastogi, T.-c. Cheng, A. Singh, Sustained Enzyme Activity of Organophosphorus Hydrolase in Polymer Encased Multilayer Assemblies, Langmuir : the ACS journal of surfaces and colloids, 19 (2003) 1330-1336. 


\section{Summary}

Thin polymer coatings in the form of polyelectrolyte multilayers (PEM) are an interesting class of coatings for the surface modification of materials to provide functional interfaces. These layers are prepared by layer-by-layer (LbL) assembly, an attractive technique with control over the thickness and the properties of the multilayer. This LbL technique involves the buildup of PEM's by alternate exposure of a charged substrate to solutions of polycations and polyanions, in combination with a rinsing step between each deposition step to remove weakly associated polymer chains. LbL is a versatile technique where control over multilayer properties such as thickness, charge and density, can be easily achieved simply by the choice of polyelectrolytes, the number of coating steps and the coating conditions ( $\mathrm{pH}$, ionic strength etc.). As the layers are very thin, usually in the order of nanometers, they need to be characterized precisely in detail on model surfaces prior to coating on the desired substrate. LbL is a suitable surface modification technique for any size and shape of the substrate, and if the substrate is porous such as an ultrafiltration (UF) membrane support, then the PEM can act as a membrane separation layer for nanofiltration (NF) or solvent resistant nanofiltration (SRNF) applications. Additionally these multilayers can be useful to alleviate the problem of fouling in membrane technology, as these multilayers can work as antifouling layers and can also make cleaning of fouled membrane easier by sacrificial removal with some trigger (e.g., salt, $\mathrm{pH}$, surfactant etc.). To provide these functionalities to membranes one suitable choice of PEs is a pair of weak polyelectrolytes such as poly(acrylic acid) (PAA) and poly(allylamine hydrochloride) (PAH). Since the charge density is not fixed in these weak polyelectrolytes, control over adsorption, desorption and separation performance of multilayers for membrane applications can be achieved by simple alterations of the $\mathrm{pH}$ of the coating solutions. In this thesis, the focus is to investigate the use of weak PEM's on UF membrane supports to make antifouling and easy to clean hollow fiber NF membranes for micropollutants removal from water and for stable SRNF membranes.

In Chapter 1, we present a general introduction to the topic and introduce the potential of weak polyelectrolyte multilayers to make multifunctional membranes for liquid applications (NF and SRNF), including their respective adjustable parameters. The different aspects of PEM membranes that can be beneficial for membrane technology are highlighted. 
In Chapter 2, we demonstrate that multilayers of weak PEs (PAH/PAA) can be used to provide a dual function to membranes i.e., as a NF separation layer and as a sacrificial coating that allows easy membrane cleaning. In order to optimize the coating and sacrificial removal conditions for the applied PEM, adsorption and desorption studies of these multilayers are performed on a model surface (silica) and monitored via fixed angle optical reflectometry. This allows us to understand the buildup behavior and removal of the multilayers at different conditions, something that cannot be precisely monitored on the membrane itself. Subsequently, tight hollow fiber UF membranes were coated with PEM's under identical conditions via a dip coating method. After each deposited layer, a clear increase in membrane resistance against pure water permeation and a switch of the zeta potential confirms the successful membrane modification. Moreover, these PEM based membranes, show rejection performance of solutes in a range typical for NF membranes i.e., hardly rejecting monovalent ions $(\mathrm{NaCl})(<24 \%)$, while rejecting $>60 \%$ of the divalent ion $\mathrm{SO}_{4}{ }^{2-}$ and of the neutral organic molecule sulfamethoxazole (SMX). Subsequently, the applied PEMs were investigated as sacrificial layers for the cleaning of membranes fouled with silica nanoparticles. A rinse and a low pressure backwash with a suitable trigger solution ( $\mathrm{pH}$ 3, $3 \mathrm{M} \mathrm{NaNO}_{3}$ ) allowed the successful sacrificial cleaning of the fouled membrane, bringing the resistance of the fouled membrane back to that of a pristine membrane. Recoating the clean membrane support with the same PEM system brings the resistance of the coated membrane equal to the resistance of the original polyelectrolyte multilayer membrane, demonstrating the re-usability of this approach.

Chapter 3, focuses on the utilization of these PAH/PAA based weak multilayers to create hollow fiber NF membranes for micropollutant removal from water. The role of the $\mathrm{pH}$ of the coating solution is investigated and coupled to membrane performance in terms of rejection for salt ions and micropollutants. We show the easy preparation of low pressure hollow fiber NF membranes by coating PEMs on a UF support. The newly formed PEM NF membranes allow for the selective removal of micropollutants while allowing passage to most salt ions. It is also shown that variation in the $\mathrm{pH}$ of the coating solutions leads to a large degree of control over the membrane performance. For example denser membranes are formed at $\mathrm{pH}$ [6.0/6.0] of $\mathrm{PAH} / \mathrm{PAA}$ and shows the highest micropollutants retention (60-80\%) while low ion retentions for this membrane indicate that it is not strongly charged. 
The rejection mechanism of the investigated membranes was found to be mainly determined by size exclusion, but influenced by Donnan exclusion. This study shows a simple way of preparing hollow fiber NF membranes for micropollutants removal from water.

In Chapter 4, our weak PEM system is investigated to prepare membranes for solvent resistant nanofiltration (SRNF) applications. SRNF membranes with a PEM separation layer were prepared on a UF hydrolyzed polyacrylonitrile (PAN-H) support by the LbL method while varying the $\mathrm{pH}$ of the coating solutions to tune the charge density and structure of PEs, and thus further control the morphology and performance of the resulting membranes for specific dye molecules from organic media. It is found that membranes with more free acid and amine groups are more susceptible to dye adsorption, leading to a film densification, and a low permeance, but in some case excellent dye retentions. Moreover, the prepared PEM membranes are found to be stable under long term-filtrations in organic solvents including troublesome aprotic solvents of industrial importance such as isopropyl alcohol (IPA), acetonitrile (ACN), tetrahydrofuran (THF), and N,Ndimethylformamide (DMF). Results of this study show a simple and versatile way of using $\mathrm{pH}$ during coating to tune membrane performance for specific SRNF application.

To bring PEM coating and especially the sacrificial cleaning approach into maturity and to coat existing modules we present in Chapter 5, the simplification of the LbL procedure for hollow fibre membranes by employing "dynamic coating" or "active coating”. This involves flushing the PE's solutions through the lumen of the hollow fibre membrane. It is shown that dynamic deposition is a simple way to modify the surface of existing hollow fiber UF support to make versatile NF membranes with low fouling propensity (if terminated with PAA) and easy to clean by utilizing the sacrificial layer approach. Moreover this coating method with its reproducibility and homogeneity, has the potential to coat existing UF membrane modules. Rejection performance of solutes (salts and organic micropollutants) by dynamically coated membranes is found to be in the typical NF performance range (50-70\% retention).

Chapter 6 presents the conclusion and reflections of knowledge obtained from this work. Finally some recommendations and ideas are presented for 
future research to contribute to the continuity of investigations into sacrificial cleaning and the management of fouling in membranes and possible functionalities that can be introduced to PEM membranes. 


\section{Samenvatting}

Dunne polymeercoatings in de vorm van polyelektroliet multilagen (PEM) zijn een interessante coatingsklasse voor oppervlaktemodificatie van materialen om functionele oppervlakken te maken. Deze lagen worden bereid door laag-bij-laag (LbL) assemblage, een aantrekkelijke techniek met controle over de dikte and eigenschappen van de multilaag. Deze LbL techniek is gebaseerd op het opbouwen van PEMs door een geladen substraat om en om aan oplossingen van polykationen en polyanionen bloot te stellen, gecombineerd met een spoelstap tussen elke blootstellingsstap om los gebonden polymeerketens te verwijderen. LbL is een veelzijdige techniek waarin de controle over multilaageigenschappen zoals dikte, lading en dichtheid kan worden bereikt door simpelweg de juiste keuze van polyelektrolieten, aantal coatingsstappen en coatingscondities ( $\mathrm{pH}$, ion sterkte etc.). Gezien deze lagen heel dun zin, vaak in de orde grootte van enkele nanometers, moeten ze nauwkeurig gekarakteriseerd worden op modeloppervlakken voordat ze op echte substraten worden gecoat. LbL is een geschikte oppervlaktemodificatietechniek voor elke grootte en vorm van het substraat en, als het een poreus substraat zoals een ultrafiltratie (UF) membraan betreft, dan kan de PEM als membraanscheidingslaag functioneren voor nanofiltratie (NF) of oplosmiddel-resistente nanofiltratie (SRNF) toepassingen. Bovendien zijn deze multilagen bruikbaar om vervuilingsproblemen van membranen op te lossen, gezien deze multilagen als antivervuilingslagen kunnen werken en tegelijkertijd het schoonmaken van vervuilde membranen simpeler maken door het verwijderen door opoffering door middel van een stimulans (bijv. zout, $\mathrm{pH}$, oppervlakte-actieve stof etc.). Om deze functionaliteiten allemaal aan membranen te geven, is een geschikte keuze van polyelektrolieten om een paar zwakke polyelektrolieten zoals poly(acrylzuur) (PAA) en poly(allylamine hydrochloride) (PAH) te gebruiken. Gezien de ladingsdichtheid niet vaststaat voor zwakke polyelektrolieten, kan er controle over adsorptie, desorptie en scheidingseigenschappen van multilagen in membranen worden bereikt door simpele variaties in de $\mathrm{pH}$ van de coatingsoplossingen. In deze dissertatie is de focus gericht op het gebruik van zwakke polyelektrolieten op UF membraandragers om antivervuilings en simpel schoon te maken holle vezel NF membranen te produceren om microverontreinigingen te verwijderen van water en stabiele SRNF membranen. 
In Hoofdstuk 1 geven we een algemene introductie over het onderwerp en introduceren we de potentie die multilagen van zwakke polyelektrolieten hebben om multifunctionele membranen te maken voor applicaties in vloeistoffen (NF en SRNF), inclusief de aan te passen variabelen. De verschillende aspecten van PEM membranen die gunstig voor membraantechnologie zijn, worden benadrukt.

In Hoofdstuk 2 laten we multilagen van zwakke PEn (PAH/PAA) zien die gebruikt kunnen worden om twee functies te geven aan membranen, bijvoorbeeld als NF scheidingslaag en als opofferingscoating die het schoonmaken van het membraan vergemakkelijkt. Om deze coating en de opofferingsverwijder condities te verbeteren voor PEM, zijn adsorptie en desorptie studies van deze multilagen uitgevoerd op modeloppervlakken (silica) terwijl ze geïnspecteerd werden door optische reflectometrie met vaste hoek. Dit maakte het mogelijk om het opbouw gedrag en verwijdering van de multilaag systeem te begrijpen bij verschillende condities, iets dat niet precies geïnspecteerd kon worden op het membraan zelf. Vervolgens zijn dichte holle vezel UF membranen gecoat met PEM onder identieke omstandigheden door middel van de dip coat methode. Na elke depositielaag, geeft een duidelijke toename in membraan weerstand tegen permeatie van puur water en een wisseling van de zeta potentiaal aan dat de membranen succesvol gemodificeerd zijn. Bovendien laten deze PEM gebaseerde membranen een rejectie van opgeloste stoffen zien die typische zijn voor NF membranen, dat wil zeggen dat er bijna geen monovalente ionen $(\mathrm{NaCl})(<24 \%)$ worden tegengehouden terwijl $>60 \%$ van het divalente ion $\mathrm{SO}_{4}{ }^{2-}$ en het neutrale organische molecuul sulfamethoxazol (SMX) wel worden geblokkeerd. Vervolgens zijn deze PEM onderzocht als opofferingslaag voor het schoonmaken van vervuilde membranen (hier vervuild met silica nanodeeltjes). Een spoelstap en lage druk terugspoel met geschikte stimulansoplossing ( $\mathrm{pH} 3$ en $3 \mathrm{M} \mathrm{NaNO}_{3}$ ) maakte de succesvolle opoffering schoonmaak van een vervuild membraan mogelijk, waardoor de weerstand van de het vervuilde membraan terugkwam naar de waarde van het oorspronkelijke membraan. Opnieuw coating van het schone membraansubstraat met hetzelfde PEM systeem bracht de weerstand van het gecoate membraan gelijk met die van het originele polyelektroliet multilaag membraan, wat de herbruikbaarheid van deze benadering laat zien. 
Hoofdstuk 3 focust op het gebruik van deze PAH/PAA gebaseerde zwakke multilagen om holle vezel NF membranen te maken voor het verwijderen van microverontreinigingen van water. De rol van de $\mathrm{pH}$ van de coatingsoplossing is onderzocht en gekoppeld aan de membraanprestatie van rejectie van zout ionen en microverontreinigingen. We laten de eenvoudige bereiding zien van lage druk holle vezel NF membranen door PEMs te coaten op een UF substraat. Het nieuw gevormde PEM NF membraan maakt het mogelijk om selectief microverontreinigingen te verwijderen terwijl het de meeste zout ionen doorlaat. Het is ook aangetoond dat variatie van de $\mathrm{pH}$ van de coatingsoplossing leidt tot een grote mate van controle over de membraanprestaties. Zo worden bijvoorbeeld dichtere membranen gevormd bij $\mathrm{pH}$ [6.0/6.0] voor PAH/PAA en dat laat een hoge microverontreinigings blokkering zien (60-80\%), terwijl lage ion blokkeringen voor dit membraan aangeven dat het niet erg geladen is. Het blokkeringsmechanisme van de onderzochte membranen blijkt vooral gebaseerd te zijn op grootte exclusie, maar ook beïnvloedt door Donnan exclusie. Deze studie laat een eenvoudige methode zien om holle vezel NF membranen te bereiden om microverontreinigingen van water te verwijderen.

In hoofdstuk 4 zijn onze zwakke PEM systemen onderzocht om membrane te maken voor oplosmiddel-resistente nanofiltratie (SRNF) applicaties. SRNF membranen met PEM scheidingslagen zijn gemaakt op een UF gehydrolyseerd polyacrylonitril (PAN-H) substraat met de LbL methode door de $\mathrm{pH}$ van de coatingsoplossing te variëren om de ladingsdichtheid en structuur van de $\mathrm{PE}$ af te stellen, en daarmee de morfologie en prestatie van de resulterende membranen verder te controleren voor specifieke kleurstof moleculen en organische media. Membranen met meer vrije zuur- en aminegroepen zijn gevoeliger voor kleurstofadsorptie, wat leidt tot filmverdichting en een lage permeatie maar in sommige gevallen uitstekende kleurstofblokkering. Bovendien zijn de gemaakte PEM membranen stabiel tijdens lange termijn filtraties in organische oplosmiddelen inclusief lastige aprotische oplosmiddelen, die relevant zijn voor de industrie, zoals isopropanol (IPA), acetonitril (ACN), tetrahydrofuraan (THF) en $\mathrm{N}, \mathrm{N}$ dimethylformamide (DMF). Resultaten van deze studie laten een eenvoudige en veelzijdige methode zien om $\mathrm{pH}$ gedurende coating te gebruiken om membraanprestraties af te stellen voor specifieke SRNF applicatie. 
Om PEM coating en de benadering van schoonmaken door opoffering volwassen technieken te maken en om bestaande modules te coaten, presenteren we in hoofdstuk 5 de versimpeling van de LbL procedure voor holle vezel membranen door gebruik te maken van "dynamische coating” of "actieve coating” wat inhoudt dat PE oplossingen door de lumen van de holle vezel membranen gespoeld wordt. Er wordt laten zien dat dynamische depositie een eenvoudige methode is om oppervlakken van bestaande holle vezel UF substraten te modificeren om veelzijdige NF membranen met lage neiging tot vervuiling (als deze getermineerd is met PAA) en eenvoudig schoon te maken door gebruik te maken van de opofferingslaag. Bovendien heeft deze coating methode met zijn reproduceerbaarheid en homogeniteit het potentieel om bestaande UF membraan modules te coaten. Rejectie prestaties van opgeloste stoffen (zouten en organische microverontreinigingen) door dynamisch gecoate membranen is in de orde van typische NF prestaties (50$70 \%$ rejectie).

Hoofdstuk 6 laat de conclusies en reflecties van de verkregen kennis van dit werk zien. Aan het einde worden enkele aanbevelingen en ideeën gepresenteerd voor toekomstig onderzoek om bij te dragen aan de continuïteit van het onderzoek naar schoonmaken door opoffering, het managen van vervuiling in membranen en mogelijke functionaliteiten die kunnen worden geïntroduceerd in multilaag membranen. 


\section{Résumé}

Les dépôts minces de polymère sous la forme d'empilements de couches de polyélectrolytes (polyelectrolyte multilayers PEM) sont une classe intéressante de dépôt pour la modification de surface des matériaux afin d'obtenir des interfaces fonctionnelles. Ces couches sont préparées par la méthode d'assemblage couche par couche (LayerByLayer), une technique attrayante permettant le contrôle de l'épaisseur et des propriétés de l'empilement. Cette technique implique l'accumulation de LbL de PEM par une exposition alternée d'un substrat chargé à des solutions de polycations et de polyanions, en combinaison avec une étape de rinçage entre chaque étape de dépôt pour éliminer les chaines polymères faiblement associées. La technique LbL est polyvalente. Le contrôle des propriétés multicouches telles que l'épaisseur, la charge et la densité, peut être facilement obtenu simplement par le choix des polyélectrolytes, le nombre d'étapes de revêtement et des conditions de revêtement ( $\mathrm{pH}$, force ionique, etc.). Étant donné que les couches sont très minces, généralement de l'ordre du nanomètre, elles doivent être caractérisées avec précision sur des surfaces modèles avant le revêtement sur un substrat réel. La méthode LbL est une technique de modification de surface adaptée à toute taille et forme du substrat, et si le substrat est poreux, tel que sur un support membranaire d'ultrafiltration (UF), le PEM peut agir comme une couche de séparation pour les membranes de nanofiltration (NF) éventuellement résistantes aux solvants. En outre, ces empilements peuvent être utiles pour résoudre les problèmes de colmatage des membranes, car ces empilements fonctionnent comme couches anti-colmatantes et permettent également d'effectuer un nettoyage de la membrane encrassée facilitée par l'élimination sacrificielle avec certains stimuli (par exemple, le sel, le $\mathrm{pH}$, un tensioactif, etc.). Pour donner toutes ces propriétés aux membranes un choix approprié est d'utiliser deux polyélectrolytes faibles tels que le poly(acide acrylique) (PAA) et de poly(chlorhydrate d'allylamine) (PAH). Etant donné que la densité de charge est variable pour les polyélectrolytes faibles, le contrôle sur l'adsorption, la désorption et la performance de séparation des empilements dans les membranes peut être obtenu par de simples modifications du $\mathrm{pH}$ des solutions de revêtement. Dans cette thèse, l'objectif est d'étudier l'utilisation des PEM faibles sur membrane soutient d'UF sous forme de fibre creuse pour lui conférer des propriétés anticolmatantes et facile à nettoyer avec comme application l'élimination des micropolluants de l'eau et des membranes résistantes aux solvants de grandes stabilités. 
Dans le chapitre 1, nous présentons une introduction générale sur le sujet et présentons le potentiel de des empilements de polyélectrolytes faibles pour fabriquer des membranes multifonctionnelles pour des applications liquides (NF et FSRR), y compris leurs paramètres ajustables respectifs. Les différents aspects des membranes PEM qui peuvent être bénéfiques pour la technologie de la membrane sont mis en évidence.

Dans le chapitre 2, nous démontrons que des empilements de PEs faibles (HAP / AAP) peuvent être utilisés pour fournir une double fonction aux membranes à savoir, comme couche de séparation NF et comme revêtement sacrificiel qui permet le nettoyage facile des membranes. Afin d'optimiser les conditions de revêtement et d'élimination de la couche sacrificielle de PE, l'étude de l'adsorption et de la désorption de ces empilements est réalisée sur une surface du modèle (silice) et contrôlée par l'intermédiaire de la réflectométrie optique à angle fixe. Cela nous permet de comprendre le comportement de l'accumulation et l'élimination des systèmes multicouches dans des conditions différentes, chose qui ne peut pas être contrôlée avec précision sur la membrane elle-même. Par la suite, les membranes à fibres creuses UF ont été revêtues avec des PEM dans des conditions identiques par la méthode de dépôt par immersion. Après chaque couche déposée, une nette augmentation de la résistance de la membrane contre la perméation de l'eau pure et une inversion du potentiel zêta confirme la modification de la membrane. En outre, ces membranes à base de PEM, montrent des performances de rejet de solutés dans une gamme typique de membranes de $\mathrm{NF}$ c'est à dire, peu de rejet des ions monovalents $(\mathrm{NaCl})(<24 \%)$, tout en rejetant $>60 \%$ de l'ion divalent $\mathrm{SO}_{4}{ }^{2-}$ et de la molécule organique neutre sulfaméthoxazole (SMX). Par la suite, ces PEM ont été étudiées en tant que couches sacrificielles pour le nettoyage des membranes encrassées (ici encrassée avec des nanoparticules de silice). Un rinçage et un lavage à basse pression avec une solution appropriée de déclenchement ( $\mathrm{pH} 3,3 \mathrm{M} \mathrm{NaNO}$ ) permettent un nettoyage sacrificiel d'une membrane encrassée, la résistance d'une membrane encrassée retournant alors à celle de la membrane vierge. Recouvrir une nouvelle fois le support membranaire propre avec le même système PEM apporte une résistance de la membrane revêtue égale à la résistance de la membrane PEM originale, ce qui démontre la possibilité de réutilisation de cette approche. 
Le chapitre 3, met l'accent sur l'utilisation de ces empilements faibles de HAP / PAA pour créer des membranes fibres creuses NF pour l'élimination des micropolluants dans l'eau. Le rôle du $\mathrm{pH}$ de la solution de revêtement est étudié et couplé à la performance de la membrane en termes de rejet des ions de sel et des micropolluants. Nous montrons la préparation facile des membranes de NF fibres creuses basses pression par revêtement PEM sur un support UF. Les membranes NF MEP néoformées permettent l'élimination sélective des micropolluants, tout en permettant le passage de la plupart des ions de sel. Il est également montré que la variation du $\mathrm{pH}$ des solutions de revêtement conduit à un grand degré de contrôle sur les performances de la membrane. Par exemple les membranes plus denses sont formées à pH [6.0 / 6.0] des HAP / PAA et montre une rétention de micropolluant la plus élevée (60-80\%), tandis que les faibles rétentions d'ions pour cette membrane indiquent qu'elle n'est pas fortement chargée.

Nous avons déterminé que le mécanisme de rejet des membranes étudiées est principalement contrôlé par exclusion de taille, mais influencée par l'exclusion Donnan. Cette étude montre une façon simple de préparer des membranes fibres creuses NF pour l'élimination des micropolluants de l'eau.

Dans le chapitre 4, notre système PEM faible est étudié pour préparer des membranes pour la nanofiltration résistantes au solvant (FSRR). Les membranes FSRR avec couches de séparation de PEM sont préparées sur un support UF hydrolysé polyacrylonitrile (PAN-H) par la méthode LbL en faisant varier le $\mathrm{pH}$ des solutions de revêtement pour régler la densité de charge et la structure des PEs, et donc contrôler davantage la morphologie et la performance des membranes résultantes pour des molécules de colorant spécifiques des milieux organiques. Nous avons observé que des membranes avec des groupes acide et amine plus libres sont plus sensibles à l'adsorption du colorant, conduisant à une densification du film, et une faible perméance, mais dans certains cas, d'excellentes rétentions de colorant. En outre, les membranes PEM préparées sont jugées stables durant de longues périodes de filtrations dans des solvants organiques, y compris des solvants aprotiques d'importances industrielle tels que l'alcool isopropylique (IPA), l'acétonitrile (ACN), le tétrahydrofurane (THF), et la N, N-diméthylformamide (DMF). Les résultats de cette étude montrent une méthode simple et polyvalente de 
l'utilisation du $\mathrm{pH}$ pendant le revêtement pour contrôler et choisir les performances des membranes FSRR pour des applications spécifiques.

Pour amener les approches de revêtements PEM et de nettoyage sacrificielle à leur maturité et pour l'appliquer à des modules existants nous présentons au chapitre 5 la simplification de la procédure LbL pour des membranes fibres creuses en utilisant la méthode de «revêtement dynamique» ou «revêtement actif» qui consiste à filtrer les solutions de la PE à travers la membrane fibre creuses. Il est démontré que le dépôt dynamique est un moyen simple de modifier la surface des fibres creuses support UF existantes pour fabriquer des membranes NF polyvalentes avec une faible propension à l'encrassement (si terminé par AAP) et facile à nettoyer en utilisant l'approche de la couche sacrificielle. En outre, ce procédé de revêtement avec sa reproductibilité et son homogénéité, possède le potentiel de modifier par dépôt des modules de membranes d'ultrafiltration existants. Les performances de rejet de solutés (sels et micropolluants organiques) par des membranes revêtues dynamiquement se trouve être dans la gamme de performance NF typique (50$70 \%$ de rétention).

Le chapitre 6 présente les conclusions et les réflexions des connaissances obtenues à partir de ce travail. Enfin, certaines recommandations et idées sont présentées pour la recherche future pour contribuer à la continuité des recherches sur le nettoyage sacrificiel et la gestion de l'encrassement dans les membranes. Nous proposons les fonctionnalités possibles qui peuvent être introduites à des membranes multicouches. 


\section{Acknowledgements}

First of all thanks to Almighty Allah, Most Merciful and Gracious, for blessing me with health, knowledge, courage and patience to complete my $\mathrm{PhD}$.

I started my $\mathrm{PhD}$ on October $1^{\text {st }} 2013$ at University of Twente within the frame-work of Erasmus Mundus Doctorate in Membrane Engineering (EUDIME). When I started my PhD, I didn't know how many challenges were waiting on the way, but I gave a chance to myself to follow this adventurous journey and to explore my abilities. In last three years I have lived and worked in three countries (the Netherlands, Belgium and France), and this was a remarkable journey which taught me life-long lessons about different aspects of personal and professional life. During my $\mathrm{PhD}$, I developed both personally and scientifically at many levels. I learned new scientific skills and learned to work in team with people from different cultural and scientific background. I also learned to adapt to new cultures and environment and take quick decisions. Apart from all, I learned to stay calm and positive in all situations which actually helped me a lot to enjoy my $\mathrm{PhD}$ time. On one side this $\mathrm{PhD}$ was a bit of challenging than the normal Dutch $\mathrm{PhD}$, but on the other side this gave me immense experience of dealing with visa, housing and all bureaucratic stuff. This $\mathrm{PhD}$ gave me an opportunity not only to visit different countries but also to meet many amazing people. I have been very lucky with friends and colleagues who helped making my $\mathrm{PhD}$ journey and stay in Europe an incredible one. I would like to acknowledge all of those who have been involved directly or indirectly in this venture to make it success.

First, I would like to extend my deepest gratitude to my daily supervisor and mentor Dr. Wiebe de Vos. Wiebe thanks for giving me the opportunity to do my $\mathrm{PhD}$ in your supervision. Your trust, patience, continuous encouragement, and efforts during my $\mathrm{PhD}$ are highly appreciated. Thanks for believing in me and supporting me throughout my $\mathrm{PhD}$ and helping me not to lose the track. Without your immense support and scientific input towards this project I would not be able to finish this PhD. Thanks for your scientific and critical remarks. Your positive attitude and encouragement in tough situations during this challenging $\mathrm{PhD}$ increased my hopes and enthusiasm to work harder and overcome all kinds of issues. I learned a lot from you from both scientific and non-scientific point of view. You are one of my role model in the scientific community.

I am also grateful to my promotor Prof. Dr. Erik Roesink for accepting me in his supervision. Erik thanks for your scientific comments on my thesis and 
interesting scientific discussions during Monday morning presentations. I appreciate that you warmly accepted me as your PhD student.

I would like to thank my first exchange promotor Prof. Dr. Ivo Vankelecom (KU Leuven). Ivo I remember you from our first skype meeting during selection for EUDIME and you wanted me to work on membrane bioreactors (MBRs), somehow later we managed to work together. I am thankful to you for giving me the opportunity to join your team. I am thankful to you for your friendly behaviour and your valuable scientific input towards my project. Alexander Volodin thanks for helping me with AFM measurements. I would like to thank Prof. Anthony Szymczyk from Université de Rennes for performing zeta potential measurements for us.

I extend my great appreciation to my second exchange promotor Dr. Pierre Aimar (UPS-France) for accepting me to work at LGC lab. Thanks for your help and hospitality during my mobility. I am very grateful to my daily supervisor at UPS-France Dr. Jean-François Lahitte. Lahitte thank you for your support guidance during my research in France and helping me in the lab. Special thanks for dealing with many document stuffs and French translations till end of $\mathrm{PhD}$. Thanks for introducing me with French culture. I am grateful to European Union and EUDIME consortium for selecting me to be a part of this $\mathrm{PhD}$ programme.

Thanks to my promotion committee for reading my thesis and allowing me to defend it. Thanks to Prof. Dr. Nieck. E. Benes for being part of my supervisory and promotion committee. I am grateful to Dr. Boelo Schuur from Twente for accepting to be part of my promotion committee. Thanks to members from abroad Prof. Dr. Monika Schönhoff, Prof. Dr. Johan Martens for accepting to be part of my promotion committee. Prof. Dr. Merlin L. Bruening thanks for reviewing my thesis. Prof. Dr. J.W.M. Hilgenkamp thank you forchairing my defense.

Audrey special thanks to you for your help in dealing with all bureaucracies and procedures during my $\mathrm{PhD}$ :). Thank you for dealing with defense related matters during my stay in Pakistan. Joris your help and input towards my PhD is highly appreciated. I learned a lot about layer by layer topic from you. Thanks for scientific discussions and always helping me. Özlem and Bob thanks for being my office mates and friends. I enjoyed your presence a lot especially during stress time of my PhD. Bob thank you for your technical support in the lab and for building filtration setup for me. Thanks to Herman, Erik Rolevink and Harmen, for your help with the equipments. Thank you Harmen for telling stories during coffee breaks and explanation of many Dutch words. Antoine thanks for maintaining a pleasant and safe working 
atmosphere in the lab. Your presence during Coffee breaks and Friday borrels always made the atmosphere cheerful. Timon thanks for being my Dutch teacher and always helping me in filling out dutch forms. I wish you good luck with the last bits of your thesis. Özlem, Valentina (Valle ()), Daria and Timon thanks for your friendship and wonderful time, also thanks for convincing me to play football (when it was not allowed from my mom) :p. I would also like to extend my gratitude to my friends from WETSUS Janneke, Terrica, Charu and Jordi. It was always nice to have you people around during group lunches, different group activities and MST bike tour. Dennis thanks for nice chats during coffee breaks. Anne I will miss your delicious cakes and thanks for sharing the recipe. Mehran thanks for collaboration in this project and working together. Namik thank you for your help with ellipsometry measurements. I would also like to thank my other colleagues and friends from cluster of membranes for sharing the nice moments in the group: Rob, Henny, Arian, Walter, Louis, Renaud, Rian, Evelien, Pelin, Fatemeh, Sander, Saim, Jeff, Aura, Dennis, Kristianne, Saim, Marcel, Mehrdad, Jordi, Almohanad, Mandakranta, Joeri, Basma, Mustafa, Patrick, Khalid, Anne, Hani, Mustafa and Pim. My gratitude is also extended to Cindy, Ineke, Frank and Jan.

I would also like to acknowledge some old members of the group: Kitty, Zandrie, Greet, Beata, Krzysztof, Erik, Mette, Kah Peng, Damon, Sinem, Yusuf, Harro, Hammad, Yali and Damon.

Kitty your critical comments towards this project and on articles are highly appreciated. It was nice experience working with you on MST newsletter. Greet, thank you for your help and facilitating me with my initial settlement in the Netherlands. Krzysztof and Beata it was great to have two beautiful and very polite polish people as office mates and friends(-). Beata you will always be remembered thanks for the nice moments and talks we had, though you were a very quiet and shy person and thanks for your pick and drop services $\odot$. Krzysztof thanks a lot for nice office environment and helping with my measurements and for many scientific discussions. Mette Mange tak for your hospitality during my visit to Denmark and thanks for being my tourist guide and telling me a lot about Danish culture. It was always nice to meet you.

Special thanks to my master students Marie-Aline (Ku Leuven), Renee and Zahra (UTwente) for their hard work and enthusiasm to learn. You were all extraordinary students and I wish you great success in your future life.

Valentina, Özlem and Daria thanks for the dinners, parties and cooking time together. Valle thank you for teaching us how to make original Tiramisu. Lionel thank you for checking my thesis on last day of my stay. Thanks to my 
bachelorette party organisers (Valentina, Özlem, Daria, Sinem, Aura, Beata and Pelin). Thanks to TTD members (Valentina, Özlem, Jeff, Aura, Timon, Renaud, Jessica, Lionel, Erik, Sinem) for making my life outside work enjoyable and lively.

I would also like to thank my KU Leuven colleagues and friends. Waqas Bhai, Maarten, Elke, Maxime, Serdar and Yun thanks for the nice time and friendly office environment. Maarten thank you for your technical support with the equipments. Nithya, Veysi, Remigio, Ahmad, Waqas, Lisendra, Parimal, Aylin, Maarten, Elke, Stefan, Jeroen, Yanbo, Satya thank you for making my stay at Leuven enjoyable. Nithya and Lisendra I am thankful to you for the collaboration in the project and for scientific and non-scientific discussions. Remigio and Veysi thanks for your hospitality and cooking delicious Italian and Turkish food for me. Daria and Veysi thanks for being my EUDIME mobility fellows, it is my pleasure to have friends like you.

I also want to thank my colleagues and friends from UPS, Izabella, Lucia, Natalia, Dimitri, Paul, Han, Hugo, Zenamarkos, Ioannis, Meline, Panwana and Marcello Iacono for enjoyable time in Toulouse. I would like to thank Jean-Christophe Rouch for technical helps in laboratory. I would like also to thank Prof. Patrice Bacchin, Prof. Hélène Rouxde Balmann, Remigy, Sandrine Desclaux, Régine Le Goff, Naima Khoujane and all other colleagues.

My Eudime fellows Veysi, Aylin, Ramato, Izabella, Violeta, Joanna, Saim, Salman, Amir, Cheryl, Sushumna, Lakshmeesha, Alessio, Parashuram, Fatemeh, Yahia thanks for nice time during EUDIME meetings and Summer school.

I am also thankful to Pakistani community at UT and KU Leuven for their help. Ammara, Amrozia, Afsheen, Afshan, Urooj, Maham, Mariyam Bhabhi, Hadiya, Sana Saif, Sana Ibrahim, Saira, Amna, Zainab thank you for making my stay in Enschede enjoyable and inviting me for Pakistani food. Nishat (May your soul rest in peace) you were a great person I had many nice moments to remember about you. Saim and Hammad thanks for your help during my stay in Enschede.

Sudeshna my Indian friend thanks for the wonderful time in Twente and teaching me Hindi :). I wish you all the best for your thesis and personal life. 
I would like to extend my gratitude to my mother Shehnaz and my father Muhammad Ilyas for their love, endless support and encouraging me for this $\mathrm{PhD}$. Without your courage and cooperation I would not be able to leave Pakistan and do this PhD. Thanks for your love and prayers. My husband Hassan (Fiancé during my $\mathrm{PhD}$ time), I am lucky to have you in my life. Marrying you was one of the best decisions of my life including my $\mathrm{PhD}$ :). You have been my strength in these years. You always motivated and supported me when things were tough and stressful. Thanks for waiting so long on the other part of the world. Thanks for helping me to successfully complete this journey. I am also thankful to all my relatives and sibling my sister Fozia Adnan, brothers Sohail, Asim and Moin for their love and support. I am also grateful to my parents in law (Shamim Ilyas and Naila Ilyas) for their support and prayers. Anam, Ammara bhabhi, Asad and Mudassar bhai thanks for being part of my new family. Thanks to all of my family members for taking care of all matters of my wedding and arranging a wonderful wedding and giving me time just to focus on my thesis writing. 
UNIVERSITY OF TWENTE.

KU LEUVEN

Université
Paul Sabatier

ISBN: 978-90-365-4281-4 